\title{
Las diatomeas del biofilm fluvial como indicadores ambientales a corto plazo en el seguimiento de la recuperación de la calidad del agua de sistemas acuáticos pampeanos
}

Lic. María Mercedes Nicolosi Gelis

Directores: Dr. Joaquín Cochero y Dra. Nora Gómez

Trabajo de tesis para optar por el título de Doctora en

Ciencias Naturales

Facultad de Ciencias Naturales y Museo Universidad Nacional de La Plata

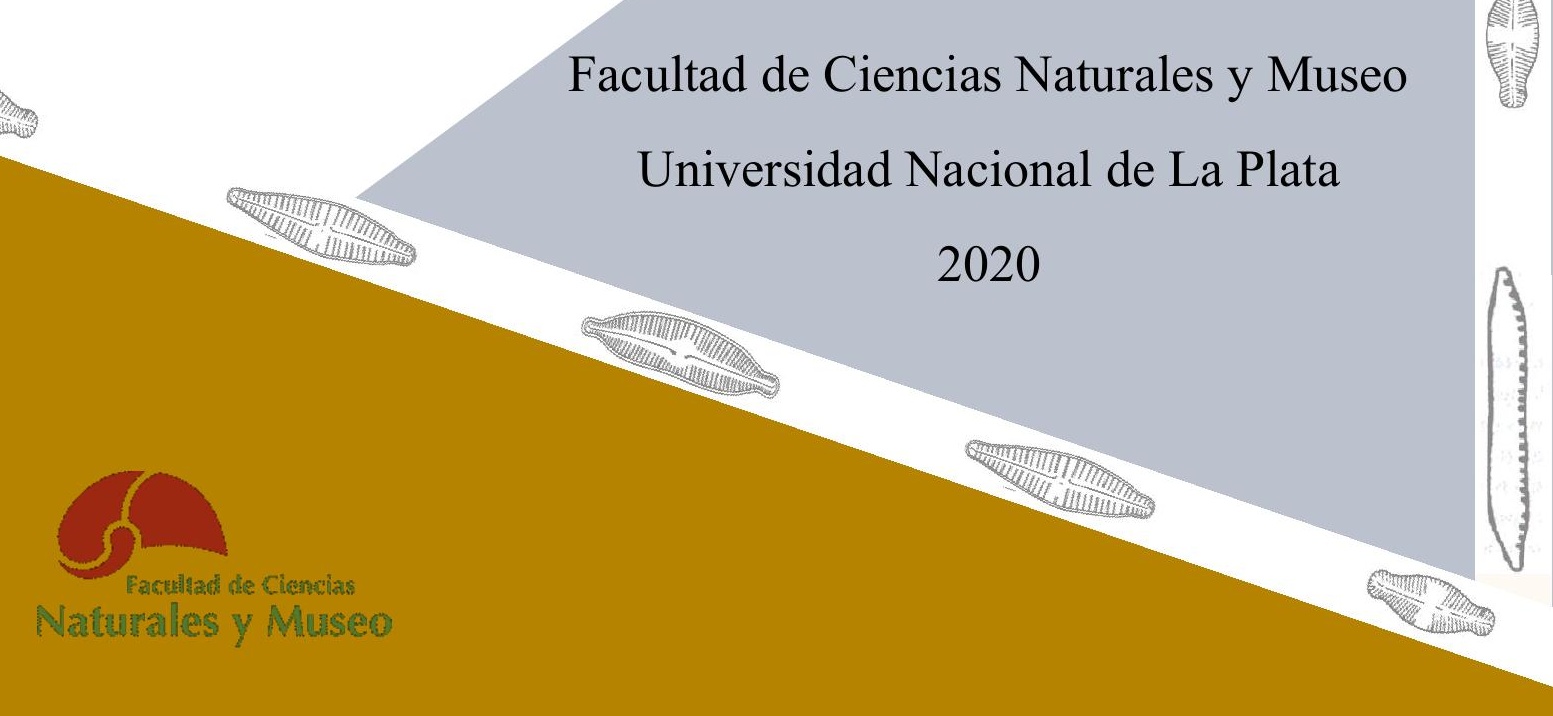


cin...……

miniminiming

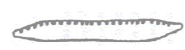




\section{Agradecimientos}

A mis directores Joaquín y Nora por brindarme la oportunidad, enseñarme, incentivarme y acompañarme durante todo el proceso.

A los jurados: Silvia Sala, Irina Izaguirre y Adonis Giorgi por sus aportes, sugerencias y correcciones que enriquecieron este trabajo.

A mi persona favorita en el mundo y mi pequeño bufón: mi hermana. Por ser incondicional, confiar en mí y acompañarme en cualquier decisión. Siempre juntas. Te quiero.

A Mamá y Papá por haberme acompañado y apoyado desde siempre!!!! Los quiero mucho!

A Malve y Tatá, tíos y primos que siempre estuvieron desde el primer acto de jardín.

A mis amigxs y compañerxs de laboratorio: Ro, Santi, Juaco, Pau, Bel, Deli, Mica y Agos por hacer divertidos todos los días de trabajo y respetar las mañanas sagradas de silencio. Pero en especial a Ro y Santi, mis hermanes, porque sin elles no hay tres Maries.

A Male por ser la primera que me recibió en el ILPLA y enseñó acerca de las increíbles diatomeas.

A Palito, Jorge, Hernán, Maxi, Alexandra Elbakyan porque sin su aporte esta tesis no hubiera sido posible

A todos mis compañerxs del ILPLA, y en particular a mis compañerxs del área de extensión y a todxs los Exploracuáticxs.

A las chicas (Pachi y Flor), mis amigas del alma, que siempre estuvieron y en especial en el último tramo, dándome aliento y retándome cuando era muy necesario. Las quiero mucho.

A Sofi, amiga bella que me dio la facu. Con al que compartí este camino y seguiré compartiendo todos los que vengan. Incondicional como no hay. Te adoro ami.

A Lulina, hermana de la vida, feliz de haberte encontrado y compartir la vida con vos.

A los feriado-lovers/ círculo rojo/ plantófilos, porque puede cambiar el nombre pero nunca la amistad. Los adoro.

A Santi y Juli que no sólo me acompañaron en todo este camino, sino que me alegraron los días de tesis cuarentena. Los quiero.

A los que siempre están: Jesi, Mica, Nico, Juan y Nati,

A mis compañerxs de Ecología General, en especial a mis compañeras de comisión Martha, Gabi y Marga.

A Filo por evitar que enloquezca por completo y escribir conmigo gran parte de la tesis. A Berta y Sara.

A la Universidad Nacional de La Plata y a la Facultad de Ciencias Naturales y Museo por mi formación de grado y posgrado, y en especial a Secretaría de Posgrado de FCNyM

A CONICET por haberme otorgado una beca para la realización de este trabajo, y a los organismos de financiamiento de Ciencia y Técnica estatales con cuyos fondos se realizó este trabajo de tesis. 


\section{Contenido}

Resumen

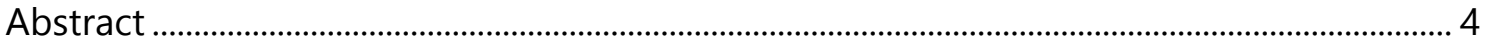

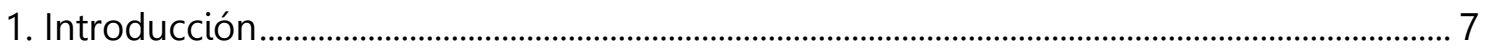

1.1.a Los arroyos pampeanos y los usos del suelo .............................................................. 7

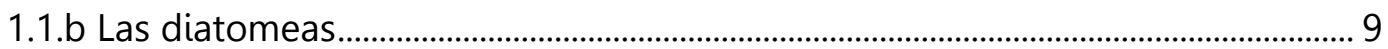

Descriptores de los ensambles de diatomeas para evaluar la calidad del agua.11

Antecedentes de estudios del ensamble de diatomeas en el área de estudio.... 15

1.1.c Estudio de la recuperación de la calidad de agua a través de la evaluación de descriptores del ensamble de diatomeas............................................................................... 16

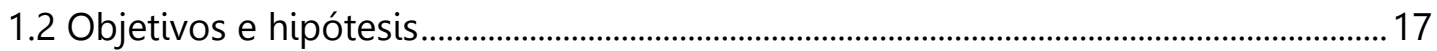

1.2.a Objetivo general ....................................................................................................... 17

1.2.b Objetivos específicos .............................................................................................. 17

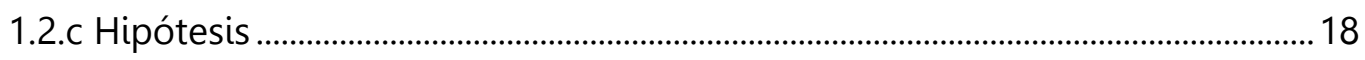

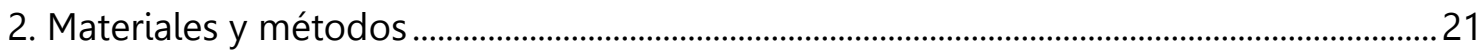

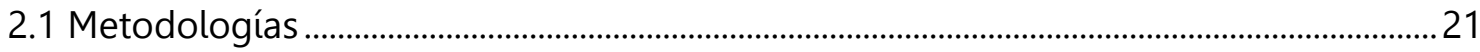

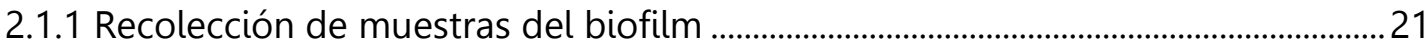

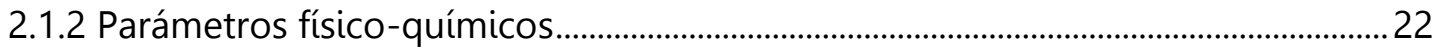

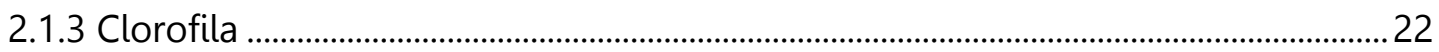

2.1.4 Composición de organismos autotróficos del biofilm (grupos algales)................23

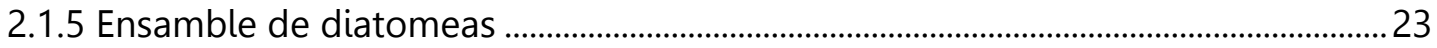

2.1.5.a Identificación del ensamble de diatomeas ..........................................................23

2.1.5.b Parámetros estructurales, IDP y gremios ecológicos..........................................24

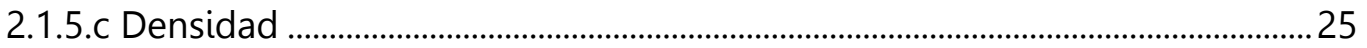

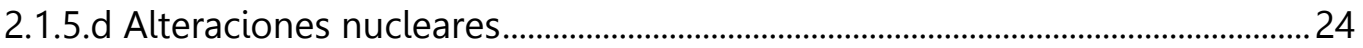

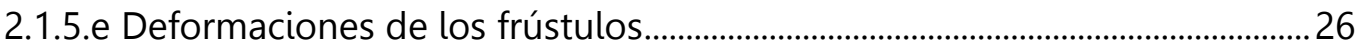

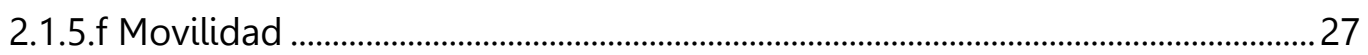

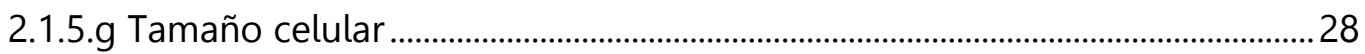


2.1.6 Experiencia de colonización en sustrato artificial duro

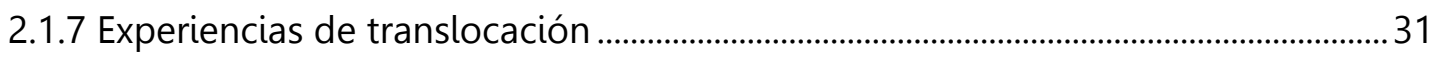

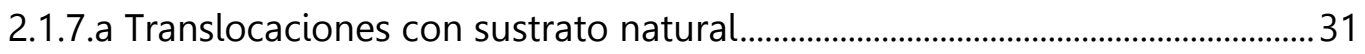

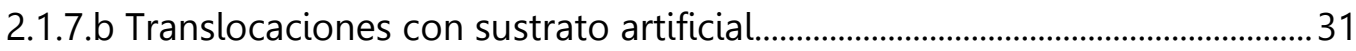

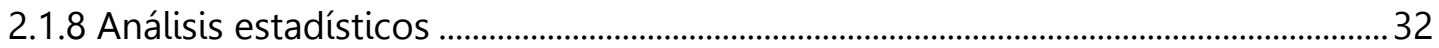

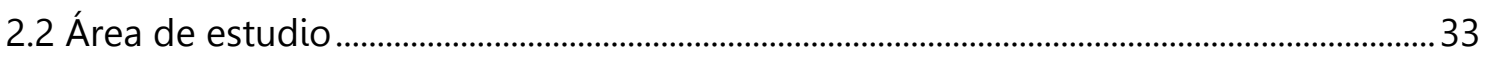

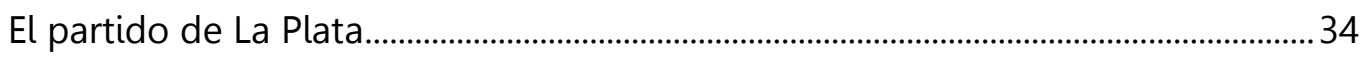

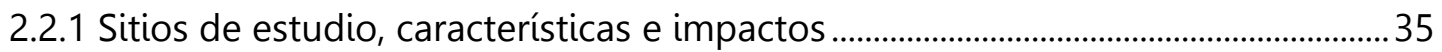

2.2.2 Breve descripción de los arroyos y sitios ..........................................................................

3. Dinámica de la colonización temprana del ensamble de diatomeas bentónicas sobre sustratos duros artificiales en arroyos con diferentes niveles de impacto urbano y

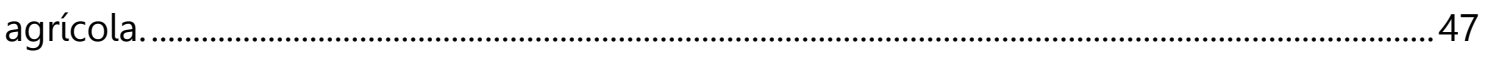

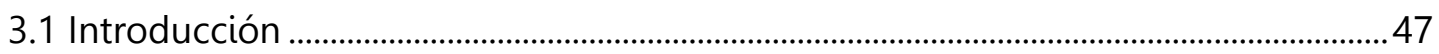

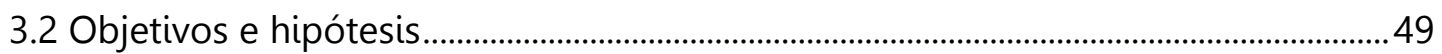

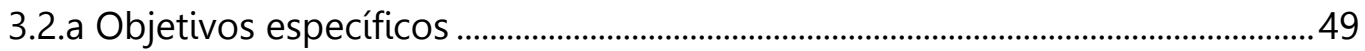

3.2.b Hipótesis y predicciones ........................................................................................ 49

3.3 Materiales y métodos ........................................................................................................ 50

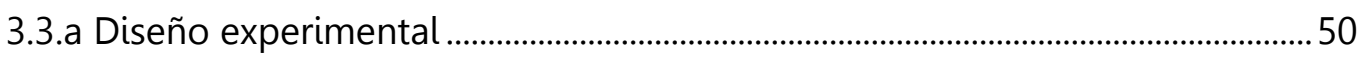

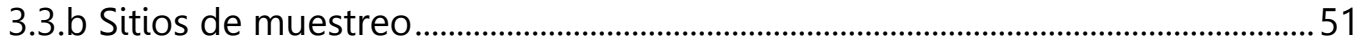

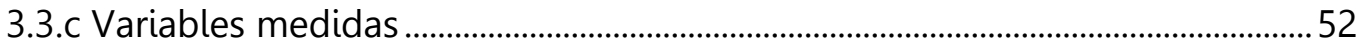

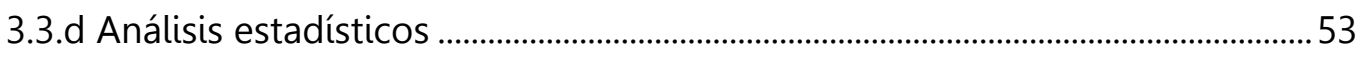

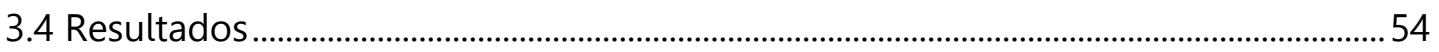

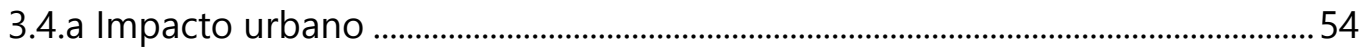

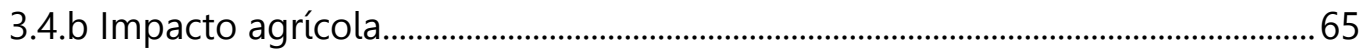

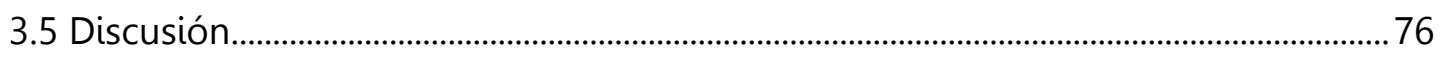

3.5.a Colonización del ensamble de diatomeas en arroyos expuestos a impactos urbanos

Conclusiones: colonización del ensamble de diatomeas en arroyos expuestos a impactos urbanos 
3.5.b Colonización del ensamble de diatomeas en arroyos expuestos a impactos agrícolas

Conclusiones: colonización del ensamble de diatomeas en arroyos expuestos a impactos agrícolas.

3.6 Consideraciones finales del capítulo .84

4. Estudio del ensamble de diatomeas epipélicas en una experiencia de translocación entre sitios con mayor a menor impacto urbano.

4.1 Introducción .86

4.2 Objetivos .87

4.3 Materiales y métodos. .88

4.3.a Diseño experimental. .88

4.3.b Sitios de muestreo .88

4.3.c Variables medidas .88

4.3.d Análisis estadísticos .89

4.4 Resultados .90

4.5 Discusión y conclusiones. 97

5. Estudio del ensamble de diatomeas en sustratos artificiales en una experiencia de translocación entre sitios de mayor a menor impacto agrícola. 102

5.1 Introducción 102

5.2 Objetivos e hipótesis 103

5.3 Materiales y métodos. 104

5.3.a Diseño experimental. 104

5.3.b Sitios de muestreo 104

5.3.c Variables medidas .104

5.3.d Análisis estadísticos 106

5.4 Resultados 106

5.5 Discusión y conclusiones

6. Estudio de la movilidad y alteraciones nucleares de Nitzschia palea frente a la exposición de elutriados del sedimento del arroyo Carnaval 


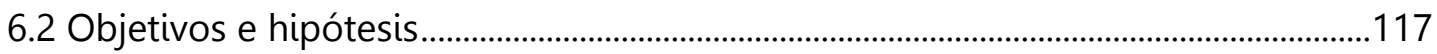

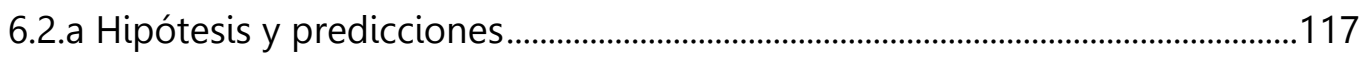

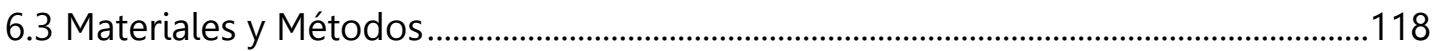

6.3. a Cultivo de N.palea y elutriados................................................................................118

6.3.b Diseño experimental...........................................................................................119

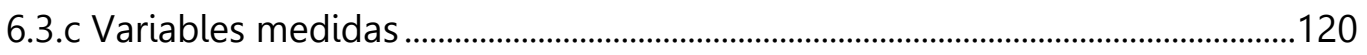

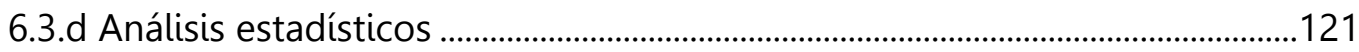

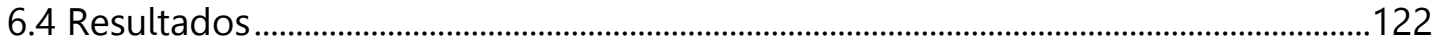

6.5 Discusión y conclusiones ................................................................................................127

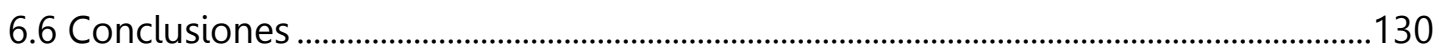

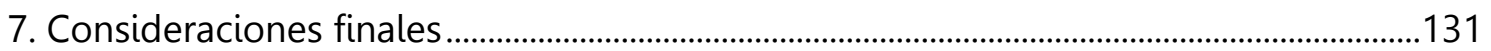

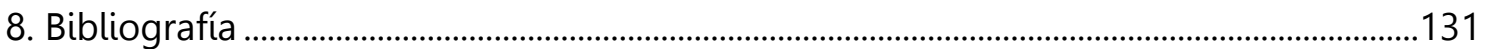

Tablas Anexas 


\section{Resumen}

Los ríos y arroyos que forman parte del paisaje urbano en la Ecoregión Pampeana, han sufrido modificaciones profundas que condujeron a un proceso de simplificación ecológico, a un aumento en la concentración de nutrientes y contaminantes, resultando en arroyos altamente impactados con una gran pérdida de estructura y función. Las diatomeas son usadas comúnmente como indicadores biológicos para evaluar la calidad del agua en ríos y arroyos, debido a que son sensibles a un amplio rango de presiones ambientales. En tal sentido, su uso en las evaluaciones de la calidad del agua se sustenta en las respuestas rápidas tanto a los cambios en las condiciones ambientales debido a un aumento de la contaminación, como al éxito de la restauración del hábitat.

El objetivo general de la presente tesis fue analizar la eficacia de las respuestas estructurales y funcionales del ensamble de diatomeas en diagnosticar la recuperación de la calidad del agua de ambientes fluviales pampeanos. Para esto se realizaron experiencias in situ y ex situ con la finalidad de contrastar hipótesis vinculadas a la respuesta del ensamble de diatomeas frente a diferentes calidades del agua.

En primer lugar se caracterizó el proceso de colonización del biofilm, en particular del ensamble de diatomeas en arroyos expuestos a diferentes niveles de impacto antropogénico, tanto urbano como agrícola. Para tal fin se realizaron dos experiencias (ambas desarrolladas en el capítulo 3) utilizando sustratos artificiales duros en arroyos de la ciudad de La Plata con diferentes niveles y tipos de impacto antropogénico. A través de la realización de estas experiencias de colonización temprana se pudieron identificar las variables que resultaron buenas descriptoras de este proceso en arroyos Entre los principales resultados se destacan que el desarrollo de la biomasa autotrófica del biofilm fue menor y más lento en los arroyos más impactados, independientemente si el impacto era agrícola o urbano. Las diatomeas fueron el grupo algal dominante en arroyos con impacto urbano, mientras que en los arroyos con impacto agrícola estuvieron igual representadas que los otros grupos algales. El análisis de los gremios ecológicos reveló que en las primeras etapas de la colonización el gremio móvil fue el dominante, siendo además el de mayor representación en el ensamble. A su vez se observó que las diatomeas de tallas intermedias a grandes son las que dominan el proceso de colonización de los sustratos artificiales. 
En segundo lugar, se analizaron los cambios estructurales y funcionales del ensamble de diatomeas de sitios estresados por factores agrícolas y urbanos cuando fueron expuestos a mejorías en la calidad del agua. Para esta finalidad se seleccionaron los siguientes descriptores: diversidad, riqueza específica, gremios ecológicos, Índice de Diatomeas Pampeanas (IDP), movilidad celular, tamaño celular, alteraciones nucleares y de las valvas y se realizaron 2 experiencias de translocación La primera experiencia de translocación (capítulo 4) se llevó a cabo con biofilms desarrollados en sustratos naturales (epipelon) en arroyos expuestos a alto impacto urbano a arroyos expuesto a bajo impacto urbano. En tanto, la segunda experiencia de translocación (capítulo 5) se realizó en arroyos con diferentes niveles de impacto agrícola, empleando en este caso el biofilm desarrollado en sustrato artificial (vidrios esmerilados).

Los resultaron de estas experiencias permitieron reconocer que ni la riqueza específica ni el índice de diversidad de Shannon resultaron ser variables indicativas de la mejoría en la calidad del agua, pero sí resultó sensible a los cambios el índice de diatomeas pampeanas (IDP). Las proporciones de los gremios ecológicos (bajo perfil, alto perfil y móvil) fueron variables frente a los cambios en la calidad del agua generados por los distintos tipos de de impacto analizados. El gremio móvil fue el de mayor representación en el ensamble. El gremio de alto perfil respondió en ambos tipos de impacto aumentando su proporción en los ensambles translocados, mientras que el gremio de bajo perfil respondió a las diferencias en la calidad del agua disminuyendo su proporción en los arroyos con impacto agrícola, pero no lo hizo en los arroyos con impacto urbano. El análisis de la proporción de anomalías nucleares, particularmente la proporción de núcleos con ruptura de membrana nuclear fue una variable sensible a la mejoría de la calidad del agua en ambo tipos de impacto. Por lo contrario, la proporción de valvas con deformaciones no resultó ser una variable significativa en manifestar los cambios en la calidad del agua en los arroyos estudiados. En cuanto al análisis de la movilidad de las diatomeas, no respondieron significativamente a los cambios en la calidad del agua.

Por último se analizó la respuesta de la movilidad, de la proporción de anomalías nucleares, la densidad poblacional y el tamaño celular en Nitzschia palea expuesta a elutriados procedentes de sedimentos contaminados por la actividad agrícola, con la finalidad de evaluar su potencialidad en la evaluación de la toxicidad de sedimentos. Para tal fin se realizó un ensayo en laboratorio (desarrollado en el capítulo 6) con elutriados obtenidos a partir de sedimento de un sector del arroyo 
Carnaval expuesto al impacto agrícola. Se expuso un cultivo de Nitzschia palea al elutriado del sedimento, rico en compuestos organoclorados (endosulfán) y metales pesados ( $\mathrm{Cu}$ y $\mathrm{Zn}$ ) y se midieron las variables en cinco muestreos durante una semana. Los resultados demostraron que todas las variables analizadas resultaron afectadas en los tratamientos expuestos a los elutriados de los sedimentos. La movilidad y las alteraciones nucleares evidenciaron los efectos más rápidamente (en 24-48 hs) que la densidad y el tamaño celular (en una semana). Se pudo concluir que las respuestas estudiadas en $N$. palea resultaron eficaces para evaluar la toxicidad del sedimento de los cursos de agua pampeanos.

Los resultados obtenidos en esta tesis, a través de distintos abordajes metodológicos, han permitido reconocer como algunas respuestas del ensamble de diatomeas son capaces de detectar rápidamente los cambios en la calidad del agua, resaltando así su valor como biomonitores en el seguimiento temprano de los procesos de recuperación de los sistemas fluviales de la llanura pampeana. 


\section{Abstract}

The rivers and streams that are part of the urban landscape in the Pampean Ecoregion have undergone profound modifications that led to an ecological simplification process, and an increase in the concentration of nutrients and pollutants resulting in highly impacted streams with a great loss of ecological structure and function. Diatoms are commonly used as biological indicators to assess water quality in rivers and streams, because they are sensitive to a wide range of environmental pressures. Its use in water quality assessments is based on their rapid responses both to changes in environmental conditions due to increased pollution, and to the success of habitat restoration.

The main objective of this thesis was to analyze the efficiency of the structural and functional responses of the diatom assemblage in diagnosing the recovery of water quality in Pampean fluvial environments. For this purpose, in situ and ex situ experiences were carried out in order to contrast hypotheses related to the response of the diatom assemblage to different water qualities.

First of all, the colonization process of the biofilm was characterized; particularly of the diatom assemblage in streams exposed to different levels of anthropogenic impact, both urban and agricultural. For this purpose, two experiments were carried out (both explained in chapter 3) using hard artificial substrates in streams in the city of La Plata with different levels and types of anthropogenic impact. Through these early colonization experiences it was possible to identify the variables that were good descriptors of the colonization process in streams. Among the main results it was measured that the development of the autotrophic biomass of the biofilm was lower and slower in more impacted streams, regardless of whether the impact had an agricultural or urban origin. Diatoms were the dominant algal group in streams with urban impact, while in streams with agricultural impact they were equally represented as the other algal groups. The analysis of the ecological guilds revealed that in the early stages of colonization the mobile guild was the dominant one, being also the one with the greatest representation in the assemblage. In turn, it was observed that diatoms of intermediate to large sizes are those that dominate the colonization process of artificial substrates. 
Secondly, the structural and functional changes of the diatom assemblage from sites stressed by agricultural and urban factors when exposed to improvements in water quality were analyzed. For this purpose, the following descriptors were measured in two translocation experiments: diversity, specific richness, ecological guilds, the Pampean Diatom Index (IDP), cell mobility, cell size, nuclear and valve alterations. The first translocation experiment (Chapter 4) was conducted with biofilms developed in natural substrates (epipelon) in streams exposed to high urban impact to streams exposed to low urban impact. The second translocation experiment (Chapter 5) was conducted in streams with different levels of agricultural impact, using in this case the biofilm developed in artificial substrate (glass).

The results of these experiments allowed us to recognize that neither the specific richness nor the diversity (Shannon index) were variables indicative of the improvement in water quality, but the Pampean diatom index (IDP) was sensitive to changes. The proportions of the different ecological guilds (low profile, high profile and mobile) were variable in relation to the changes in water quality generated by the different types of impacts analyzed. The mobile guild was most represented one in the assemblage. The high-profile guild responded in both types of impacts by increasing its proportion in the translocated assemblages, while the low-profile guild responded to the differences in water quality by decreasing its proportion in streams with agricultural impact, but did not follow this pattern in streams with urban impact. The analysis of the proportion of nuclear anomalies, particularly the proportion of nuclei with nuclear membrane ruptures, was a variable sensitive to the improvement of water quality in both types of impact. On the other hand, the proportion of deformed valves did not turn out to be a significant variable that expresses the changes in water quality in the studied streams. Regarding the analyses of the motility of diatoms, these variables did not respond significantly to changes in water quality.

Lastly, the responses in motility, in the proportion of nuclear anomalies, in population density and cell size in Nitzschia palea exposed to elutriates from sediments from streams polluted by agricultural activity were analyzed, in order to evaluate their potential as indicators of sediment toxicity. For this purpose, a laboratory test (detailed in chapter 6) was carried out with elutriates obtained from stream sediment from a sector of the Carnaval stream, exposed to intense agricultural activity. A culture of Nitzschia palea was exposed to the elutriates of the sediment, rich in organochlorine compounds (endosulfan) and metals ( $\mathrm{Cu}$ and $\mathrm{Zn}$ ), and the variations in the diatom 
population were measured in five sampling times during one week. The results showed that all the variables analyzed were affected by the elutriates treatments. Motility and nuclear alterations showed these effects more quickly (in 24-48 hours) than cell density and cell size (in one week). It was concluded that the responses studied in $N$. palea were effective in responding to the toxicity of the sediment of the Pampean streams.

The results shown in this thesis, through different methodological approaches, have allowed to recognize that some responses of the diatom assemblage are capable of rapidly detecting changes in water quality, thus highlighting their value as biomonitors in the early water quality recovery processes in the fluvial systems of the Pampean plain. 


\section{Introducción}

\section{1.a Los arroyos pampeanos y los usos del suelo}

Los ríos y arroyos constituyen una ínfima porción de la superficie terrestre $(0,01$ 0,1\%), y transportan el 0,0001\% del agua de la Tierra (Wetzel 2001). A pesar de esta baja representación, los sistemas lóticos proveen de recursos vitales para los humanos y constituyen el hábitat de un número extraordinario de especies sensibles y endémicas (Strayer y Dugeon 2010). Además estos sistemas son capaces de brindar información acerca del estado y conservación de la cuenca, ya que que actúan como "sistema nefrítico" de la cuenca hidrográfica que integran, por lo que su geoquímica y su biota reflejan lo que sucede en el conjunto del territorio (Margalef 1997). Actualmente estos ecosistemas son unos de los más amenazados a nivel mundial debido a las crecientes presiones antropógenicas y a los efectos del cambio climático (Maitland et al 2020). Particularmente los arroyos que forman parte del paisaje urbano, han sufrido modificaciones profundas que condujeron en los últimos siglos a un proceso de simplificación ecológico, a un aumento en la concentración de nutrientes y contaminantes, resultando en arroyos altamente impactados con una gran pérdida de estructura y función (Walsh et al. 2005).

En la ecoregión Pampeana, constituida en gran parte por la Provincia de Buenos Aires, se encuentra el Área Metropolitana de Buenos Aires (AMBA) que constituye el mayor conglomerado de Argentina, con más de 13 millones de habitantes (INDEC 2010). En los últimos 60 años, el crecimiento relativamente rápido e incontrolado de su población ha provocado un uso intensivo de la tierra con fuertes consecuencias sobre la calidad ambiental, principalmente en ambientes acuáticos (Öberg et al. 2014).

El aumento de la urbanización en la región ocasionó la ocupación progresiva de tierras para cultivos que anteriormente estaba destinadas a la ganadería. El desplazamiento del ganado a tierras marginales situadas en llanuras aluviales produjo un aumento en la erosión y entrada de material particulado en los arroyos, afectando las propiedades físicas, químicas e hidrológicas de los sistemas lóticos que atraviesan la llanura pampeana (Rodrigues Capítulo et al, 2010). 
Asimismo los cuerpos de agua de la región han sido fuertemente modificados con el fin de evitar inundaciones. Tales modificaciones implican canalizaciones, rectificaciones, desviaciones y entubaciones de los cursos agua resultando en una fuerte simplificación ecológica del hábitat ( $\mathrm{Paz}$ et al., 2018). Además, el gran crecimiento de la población en muchos casos no fue acompañado por inversiones en infraestructura sanitaria, por lo que los ríos y arroyos de la región tienen un alto impacto debido al vuelco de aguas residuales y efluentes domésticos sin tratar (Cirelli y Ojeda 2008), con altos niveles de materia orgánica y contaminación microbiológica (Vilches et al. 2011).

Otro impacto al que se encuentran expuestos los cuerpos de agua de la región es el vinculado al uso del suelo por agricultura. En particular, la ciudad de La Plata, contiene uno de los cinturones verdes hortícolas más relevantes del país que durante los últimos 20 años ha crecido en términos de tamaño y productividad, así como en importancia. El Cinturón Hortícola Platense (CHP) comprende 5000 ha de producción de vegetales, de las cuales 3000 ha son cultivos de invernadero (Mac Loughlin et al. 2020). Uno de los factores que ha facilitado e incluso impulsado esta expansión ha sido la adopción temprana y continua de la tecnología de invernadero con uso intensivo de pesticidas (Mac Loughlin et al. 2017). Según un informe reciente del gobierno (DP, 2015), se aplican hasta 168 ingredientes activos de pesticidas en el CHP. Los estudios ecotoxicológicos realizados en el mismo han detectado la presencia de varios pesticidas, incluidos los herbicidas glifosato y atrazina junto con los insecticidas clorpirifos, cipermetrina y endosulfán en muestras de suelo, agua y sedimentos de arroyos que atraviesan el CHP (Camilión et al., 2003, Ronco et al., 2007, Agostini et al., 2013, Mac Loughlin et al., 2017).

Los diferentes tipos de contaminantes provenientes de las actividades agrícolas, industriales y domésticas ingresan a los cursos de agua de manera continua (produciendo efectos potencialmente crónicos) o en forma de pulsos (causando efectos potencialmente agudos), en función de las características de los episodios de crecida, de la aplicación de pesticidas o de las descargas industriales (Ellis, 2007).

Los biofilms, debido a que actúan como la interfase entre la columna de agua y el sustrato son las primeras comunidades en sufrir las consecuencias de los contaminantes (Sabater et al., 2007). Particularmente los arroyos de la región Pampeana, presentan como sustrato dominante sedimentos finos cubiertos por 
biofilm epipélico, donde las diatomeas bentónicas constituyen el grupo algal dominante (Gómez et al 2010).

\section{1.b Las diatomeas}

Las diatomeas (Bacillariophyceae) son un grupo de algas unicelulares, la mayoría autótrofas y algunas heterótrofas y auxótrofas, caracterizadas por tener una cubierta celular fundamentalmente silícea (Round 2007). Se caracterizan por ser un grupo altamente productivo, que representan apenas el $0.2 \%$ de la biomasa global (Field et al. 1998). Son el grupo de algas con mayor diversidad, con más de 200.000 especies existentes que habitan en una amplia variedad de ambientes acuáticos. Además son un importante componente de la base de la mayoría de las redes tróficas acuáticas y cumplen un rol importante en el ciclado de nutrientes (Field et al 1998; Smetacek 1999; Mann et al 1996).

Las diatomeas son usadas comúnmente como indicadores biológicos para evaluar la calidad del agua en ríos y arroyos, debido a que son sensibles a un amplio rango de presiones ambientales (Van Dam et al., 1994; Kelly, 2003; Morin et al., 2016). Su uso en las evaluaciones de la calidad del agua se sustenta en las respuestas rápidas tanto a los cambios en las condiciones ambientales debido a un aumento de la contaminación, como al éxito de la restauración del hábitat (Stevenson y Pan, 1999). Otras características que benefician su uso son su gran abundancia en la mayoría de los ecosistemas lóticos (Blinn et al., 1980), y los tiempos generacionales cortos (Rott, 1991). Asimismo, han demostrado ser sensibles a sustancias tóxicas orgánicas (ej atrazina, metalocloro, fenoles, PAHs) (Blanco y Bécares 2010) a la materia orgánica, especialmente nutrientes y fosfatos (Stevenson 2014; Licursi et al. 2015; Morin et al. 2016); y a la contaminación inorgánica (metales pesados) (Hirst et al. 2002; De Jonge et al. 2008; Morin et al. 2012; Licursi y Gómez 2013). Una ventaja importante de usar diatomeas en estudios ambientales es que pueden ser utilizadas para evaluar los efectos de la contaminación tóxica en diferentes niveles de organización ecológica (comunidad, población y niveles individuales) (Debenest et al., 2013; Stevenson, 2014).

Tradicionalmente las evaluaciones ambientales o de calidad de agua a través del estudio de las diatomeas se sustentan en la identificación a través de la morfología y cuantificación de las especies. Las variables como el biovolumen y la abundancia relativa proporcionan herramientas sensibles y eficaces para evaluar los cambios en la calidad 
del agua (por ejemplo, Rimet et al., 2009; Morin et al., 2010; Proia et al., 2011; Arini et al., 2012; Corcoll et al., 2012; Morin et al., 2012; Cochero et al., 2015).

El estudio de la calidad del agua a través de las diatomeas es sintetizado mediante la aplicación de índices bióticos. Estos se calculan a partir de análisis cuantitativos (abundancia relativa o densidad) y considerando además la tolerancia a la contaminación de cada especie, o grupos de especies (Lobo et al. 2016). Las diatomeas suelen mostrar diferentes adaptaciones ecológicas según las características morfométricas e hidrológicas de los ríos y según la región geográfica (Kelly et al. 1998), es por eso que existen numerosos índices de calidad de agua que se adaptan a diferentes condiciones ambientales (ejs.: Popatova y Charles 2007; Kelly y Whitton 1995; Lenoir y Coste 1996; Tan et al. 2015; Gómez y Licursi 2001; Lobo et al. 2015).

Stevenson et al. (2010) consideran que las diatomeas se encuentran subutilizadas a nivel mundial como herramientas para la evaluación de riesgos y gestión de los ecosistemas fluviales. Es probable que esto sea debido a los tipos limitados de métricas utilizados en la bioevaluación (Pandey et al. 2017). Existen otros parámetros, que incluyen medidas de comportamiento, fisiológicas y funcionales las cuales tienen ventajas para comprender la dinámica de las comunidades biológicas (Giddings et al., 2002). La combinación de información de variables estructurales y funcionales mejora la sensibilidad y el poder predictivo de los estudios destinados a la evaluación biológica.

En las últimas décadas se han incorporado nuevos parámetros de diatomeas vinculados al campo de la ecotoxicología. Entre éstos se encuentran las anomalías nucleares (Debenest et al., 2008; Licursi y Gómez, 2013); la clasificación de las diatomeas utilizando rasgos ecológicos (Passy et al., 2007; Rimet y Bouchez, 2011; BBéres et al. 2016) y la movilidad (Coquillé et al. 2015; Pandey et al. 2016; Nicolosi Gelis et al. 2020a). Estas variables cuentan con varias ventajas, como ser rápidas, fáciles de aplicar y requieren generalmente menor experiencia en taxonomía (Pandey et al. 2017). 
Descriptores de los ensambles de diatomeas para evaluar la calidad del agua

Diversidad, riqueza e Índice de Diatomeas Pampeanas.

Los índices de diversidad y la riqueza de los ensambles de diatomeas son ampliamente utilizados para evaluar el impacto por contaminantes orgánicos e inorgánicos en los sistemas fluviales. Estos parámetros son particularmente sensibles en los casos de contaminación tóxica ya que la misma afecta singularmente la estructura de la taxocenosis.

El índice de Shannon y Wiener es posiblemente el índice de diversidad más utilizado en ecología de comunidades y constituye una medida del grado medio de "incertidumbre" en la predicción de la especie a la que pertenecerá un individuo escogido al azar de un conjunto de especies e individuos. Esta "incertidumbre" se incrementa a medida que el número de especies aumenta y la distribución de los individuos entre las especies llega a balancearse (Licursi y Gómez 2003). Varios estudios han reportado menores valores de estos parámetros en cuerpos de agua contaminados (ejs.: Gómez 1999; Gold et al. 2002; Morin et al. 2015).

Asimismo se ha estudiado que durante las primeras etapas (horas) de la sucesión del biofilm, el ensamble de diatomeas, se caracteriza por presentar valores bajos de diversidad y riqueza, sin embargo se ha demostrado que con sólo transcurridas 24 hs se pueden encontrar valores de riqueza superiores a 25 y valores de diversidad mayores a 2 bits.ind $^{-1}$ (Ács et al., 2000; Nicolosi Gelis et al., 2020b). Si bien es esperable que la diversidad aumente en las primeras etapas de la sucesión, debido a la llegada de nuevas especies colonizadoras, al transcurrir el tiempo, y en las etapas sucesionales más avanzadas, la competencia entre especies lleva a una disminución de los valores de éste índice (Valiela, 1995).

Dentro de los índices ecológicos indicadores de polución, se encuentra el IDP (Índice de Diatomeas Pampeano, Gómez y Licursi, 2001), que fue diseñado para evaluar la eutrofización y polución orgánica de los ríos y arroyos del área pampeana. Este índice regional fluctúa entre 0 y 4 , donde valores $<0,5$ indican una calidad del agua muy buena $y$ valores $>3$ indican una calidad de agua muy mala.

\section{Gremios ecológicos}

Los gremios ecológicos son grupos de especies que viven en el mismo ambiente y explotan los mismos recursos de forma similar, pero se encuentran adaptados a los 
factores abióticos de diferentes maneras. Existen 3 gremios (alto perfil, bajo perfil y móvil) creados por Passy (2007), basados en la resistencia de las diatomeas al enriquecimiento de nutrientes y a las presiones físicas del cuerpo de agua, tales como la velocidad de la corriente. Rimet y Bouchez (2012) agregaron a la clasificación original un cuarto gremio, el planctónico, que comprende diatomeas que tienen adaptaciones morfológicas para evitar su sedimentación y que por lo tanto están adaptadas a ambientes lénticos.

Comprender el rol de los gremios en el biofilm, permite una mejor comprensión de relaciones e interacciones entre las especies y medio ambiente (Rimet and Bouchez, 2011; Berthon et al., 2001). Varios estudios han demostrado la respuesta de los gremios ecológicos creados por Passy (2007) frente a diferentes tipos de contaminantes. Se ha descripto que el gremio móvil es el que se haya mejor representado cuando los cuerpos de agua están fuertemente impactados, ya sea por contaminantes orgánicos o inorgánicos (Berthon et al. 2001; Licursi et al. 2015; Nicolosi Gelis et al. 2020 a, b). Las formas de bajo perfil suelen encontrarse en baja proporción cuando la carga orgánica y la concentración de nutrientes en los cuerpos de agua son elevadas (Berthon et al. 2001), pero pueden encontrarse en una alta proporción cuando están expuestas a agroquímicos (Rimet y Bouchez 2011; Roubeix et al., 2012). El caso opuesto sucede con las formas de alto perfil. Estas diatomeas son abundantes en cuerpos de agua con concentraciones elevadas de nutrientes y materia orgánica (Passy, 2007; Lange et al. 2001) pero suelen ser sensibles a la contaminación por agroquímicos (Larras et al. 2013). La mayor ventaja de incorporar a los gremios ecológicos en estudios de impacto, es que son sencillos de utilizar, debido a que es una medida que con pocas categorías, informa de la condición del biofilm de forma robusta y sensible a los gradientes de contaminación (Pandey et al. 2017). Estos gremios transforman la información ecológica del nivel especie a un conjunto de datos más claros, con tendencias sólidas e hipótesis más fácilmente comprobables (Potapova y Charles, 2007; Rimet y Bouchez, 2011, 2012).

\section{Clases de tamaño y variación del tamaño del frústulo}

Las diatomeas bentónicas pueden ser clasificadas en clases de tamaño (Berthon et al. 2011), y su distribución y los cambios en la proporción de las clases en el ensamble, pueden utilizarse como indicadores de cambios ambientales tales como la eutrofización, cambio climático, contaminación orgánica, salinización (Snoijes et al. 
2002; Kókai et al. 2015). Se ha demostrado que la proporción de los diferentes tamaños varía según el estado trófico del cuerpo de agua (Cattaneo 1987, Cattaneo et al. 1997, Wunsam et al. 2002, Finkel et al. 2009). Las diatomeas de tamaño grande suelen estar presentes en mayor cantidad en cuerpos de agua enriquecidos por nutrientes, mientras que las diatomeas de tamaños pequeños suelen ser dominantes en aguas pobres en nutrientes (Lavoie et al. 2010).

Los frústulos, a través de cambios fenotípicos, de la reducción del tamaño y de las deformaciones (Kociolek y Stoermer, 2010; Cox et al., 2012; Morin et al., 2012) pueden ser indicadores de alteraciones ambientales y estrés antropogénico. Otro enfoque vinculado al tamaño que resulta de interés para analizar los impactos ambientales, es la reducción del tamaño del frústulo dentro de una especie. Esta característica, además de estar relacionado con la forma de reproducción asexual que presentan las diatomeas, también ha sido reportada como una respuesta a la exposición a tóxicos, tales como metales pesados y pesticidas (Pandey et al., 2018 Winder et al., 2009; Svensson et al., 2014). El estrés conduce a una mayor tasa de división celular, en última instancia esta conduce a tamaños reducidos de los frústulos (Pandey et al. 2017).

\section{Anormalidades nucleares}

Una variable de interés para la utilización en estudios ambientales, pero que no ha sido aún ampliamente estudiada, son las alteraciones en núcleo de las diatomeas. Los efectos de la contaminación tóxica a menudo no se reflejan en los parámetros estructurales de la taxocenosis o en los índices de calidad del agua, sin embargo, la entrada de una sustancia tóxica en la célula puede producir una serie de cambios citológicos que constituyen una señal de advertencia temprana y no taxonómica con el potencial de servir como indicador (Licursi y Gómez 2013).

Existen en la literatura cuatro tipos de anormalidad nucleares en las diatomeas: localización anormal del núcleo, presencia de micronúcleos, ruptura de la membrana nuclear y fragmentación del núcleo (Debenest et al. 2008; Licursi y Gómez 2013). Estas variables ha demostrado ser indicadores sensibles de los efectos de los herbicidas (Debenest et al. 2008), de Cr (VI) (Licursi y Gómez 2013), y de la contaminación urbana (Nicolosi Gelis et al., 2020a)

El estudio de las alteraciones nucleares en diatomeas revela los efectos de los contaminantes (metales y herbicidas) en los microproductores que forman el nivel trófico 
basal de los ecosistemas fluviales, lo que ayuda a comprender los mecanismos de cambio en la composición de especies en los biofilms, la dominancia de las especies de diatomeas más tolerantes, así como factores que pueden conducir a anomalías morfológicas en las frústulos de diatomeas (Pandey et al. 2017).

\section{Alteraciones morfológicas en las valvas}

La variación morfológica en las diatomeas como respuesta a las condiciones ambientales puede ser de carácter adaptativo o no adaptativo. Las formas teratológicas son anomalías fenotípicas no adaptativas que involucran generalmente deformaciones en el contorno de la valva o en el patrón de estriación. Se han observado deformaciones y alteraciones en las valvas de las diatomeas asociadas al envejecimiento de la población, a la baja velocidad de la corriente, a la sequía, a la intensidad de la luz, al pH, al los cultivos a largo plazo, a las concentraciones de nutrientes, y a la presencia de metales pesados y/o agroquímicos (Falasco et al. 2009).

\section{Movilidad}

La movilidad de las diatomeas pennadas con rafe es otra medida que en estos últimos años se ha estado utilizando para evaluar las condiciones ambientales o el estrés generado por un contaminante. Este grupo de diatomeas se mueve a través de la secreción de compuestos mucilaginosos, llamados sustancias poliméricas extracelulares, que salen a través del rafe, colaborando en la adhesión y movimiento a través de un sustrato (Bondoc Disertation). El desplazamiento se caracteriza por ser irregular, con movimientos espasmódicos, con cambios múltiples de dirección, y suelen avanzar y retroceder en un mismo sitio repetidas veces.

La movilidad de las diatomeas, a través del análisis de la velocidad, la distancia y la aceleración responde a cambios en las variables ambientales, tales como intensidad de la luz, pH, temperatura y rayos UV (Cohn, 2001; Cohn et al., 2004, Cohn y Disparti, 1994; Cohn et al., 2003; Gupta y Agrawal, 2007). Las alteraciones en los patrones de movilidad han sido propuestos como una respuesta sensible a la toxicidad del metolacloro (Coquillé et al., 2015); a la exposición a elutriados de sedimentos tóxicos (Cohn y McGuire 2000); y a la concentración de metales pesados (Pandey y Bergey, 2016; Gupta y Agrawal, 2007; Park et al. 2020). 


\section{Biomasa autotrófica}

Una de las formas más utilizadas para medir la biomasa de las algas en el biofilm es la cuantificación de clorofila-a, ya sea utilizando espectrofotometría o cromatografía líquida. Esta medida, además es uno de los parámetros más utilizados para evaluar los efectos sobre el crecimiento de algas del enriquecimiento de nutrientes, del contenido de materia orgánica y de pesticidas en los cuerpos de agua. Varios estudios han demostrado que incrementos de la concentración de nutrientes y materia orgánica se vinculan con mayores valores y tasas de incremento en la biomasa (clorofila-a) de algas (Biggs 2000, Dodds, 2006; Smith y Schindler, 2009; Gudmundsdottir et al., 2011; Sabater et al., 2011). Sin embargo se han reportado disminuciones de los valores de clorofila-a en el biofilm y retrasos en las tasas de incremento de esta variable cuando los biofilms están expuestos a pesticidas (Rohr and Crumrine 2005; Guasch et al. 2007; Tlili et al. 2010; Ricart et al. 2009; López-Doval et al. 2010, Vera et al 2010).

\section{Antecedentes de estudios del ensamble de diatomeas en el área de estudio}

En los sistemas lóticos pampeanos, el empleo de diatomeas como indicadoras de la calidad del agua cuenta con varios antecedentes. Estos estudios, en su mayoría, se centraron en el análisis de la composición específica del ensamble y la utilización de índices de diversidad, la riqueza, la equitabilidad, y el cálculo del Índice de Diatomeas Pampeanas (IDP; Gómez y Licursi, 2001). Se ha estudiado el ensamble de diatomeas que se desarrolla en distinto tipos de sustratos como el biofilm epifítico (Giorgi y Malacalza, 2002; Gómez et al. 2003; Paz et al. 2017), del biofilm episámico (Martínez De Fabricius et al. 2003; Licursi et al. 2006; Gómez et al. 2009; Licursi et al. 2010; Licursi y Gómez 2013) y del biofilm epipélico (Gómez 1998 y 1999; Gómez y Licursi 2003; Gómez et al. 2008; Licursi y Gómez 2002; Tolcach y Gómez, 2002; Licursi y Gómez, 2009; Sierra y Gómez 2010; Cortelezzi et al. 2012; Sierra et al. 2013; Cochero et al. 2015; Licursi et al. 2015).

Algunos de los estudios mencionados previamente se centraron además, en el análisis de otros descriptores del ensamble de diatomeas. Gómez y Licursi (2003), encontraron una gran proporción de valvas anormales de la especie Pinnularia gibba en un arroyo de la región (el Don Carlos), revelando que la mayor proporción de valvas anormales se encontraba en los sitios aguas abajo del efluente de una fábrica textil y una metalúrgica coincidiendo con altas concentraciones de metales pesados (Cu y Zn). Licursi y Gómez 
(2013) analizaron las alteraciones nucleares del ensamble de diatomeas del estuario del Río de la Plata, cuando las expusieron a concentraciones de Cromo hexavalente en el laboratorio reportando la presencia de 3 tipos de alteraciones en las especies Fallacia pygmea y Navicula novaesiberica: ruptura de la membrana nuclear, localización anormal del núcleo y fragmentación del núcleo.

El análisis de algunos rasgos ecológicos (formas de vida; gremios ecológicos) del ensamble de diatomeas se ha estudiado en arroyos con elevadas concentraciones de nutrientes (Licursi et al. 2015) y en una experiencia de laboratorio dónde se evaluó la variación de múltiples estresores tales como velocidad de la corriente, turbidez, concentración de nutrientes y temperatura (Cochero et al. 2015).

Asimismo el análisis del ensamble de diatomeas a través del estudio de las tolerancias de las especies, el cálculo del IDP, el estudio la condición de los cloroplastos y la proporción de valvas con deformaciones son utilizados desde hace ya más de una década en el programa de monitoreo de ACUMAR de la cuenca Matanza-Riachuelo.

1.1.c Estudio de la recuperación de la calidad de agua a través de la evaluación de descriptores del ensamble de diatomeas

La recuperación de un ecosistema alterado depende de la capacidad de retornar a un estado similar al observado previamente al estrés (Dorigo et al. 2010a). Debido a las múltiples presiones antropogénicas a las que se encuentran expuestos los cuerpos de agua de la región Pampeana, es importante estudiar y comprender las trayectorias de recuperación y la resiliencia de las comunidades en estos ambientes acuáticos.

Generalmente, los ambientes acuáticos contaminados son difíciles de remediar y suelen requerir monitoreos a largos plazos para verificar si las medidas de restauración fueron exitosas. En tal sentido, el estudio de las comunidades perifíticas y particularmente el ensamble de diatomeas que las conforman, es una buena herramienta para la evaluación de las consecuencias de la rehabilitación de un sitio (Morin et al., 2010)

Una estrategia utilizada para implementar el monitoreo del seguimiento de la recuperación de los sistemas lóticos contaminados es el uso de técnicas de monitoreo activo como es el caso de las "translocaciones". Esto consiste en trasladar, o "translocar" biofilm de sitios con mayores niveles de contaminación a sitios en mejor 
estado ecológico y viceversa. Es una herramienta valiosa para evaluar in situ los impactos sobre las comunidades microbentónicas, así como también permite evaluar la resiliencia de las comunidades crónicamente expuestas después de la reducción de la presión por contaminación (Ivorra et al., 1999; Tolcach y Gómez, 2002; Morin et al. 2010; Dorigo et al. 2010 a, b; Rotter et al. 2011; Rimet et al. 2005; Corcoll et al. 2012). El tiempo para advertir cambios es variable dependiendo del tipo e intensidad del impacto infringido al ambiente que se desee explorar (Licursi 2005), variando así la escala de tiempo, desde pocas semanas (Tolcach y Gómez 2002) a varias (Dorigo et al. 2010). Por lo tanto esta técnica es una herramienta robusta para analizar los procesos de recuperación de los cuerpos de agua.

Las trayectorias de recuperación del ensamble de diatomeas dependen no sólo de las nuevas condiciones del agua, sino también a la capacidad de inmigración y emigración específica. Sin embargo, en los monitoreos con traslocaciones, resulta prácticamente imposible discriminar entre los efectos de la proliferación de diatomeas viables que se encuentran presentes en el biofilm translocado y la colonización de nuevas especies (Morin et al. 2010). Por ello, conocer el proceso de colonización del ensamble de diatomeas en arroyos con diferentes tipos y niveles de impactos puede ayudar a comprender el proceso de recuperación, a través por ejemplo de la determinación de las especies que actúan como primeros colonizadores.

\subsection{Objetivos e hipótesis}

\section{2.a Objetivo general}

El objetivo general de esta tesis es analizar la eficacia de las respuestas estructurales y funcionales del ensamble de diatomeas en diagnosticar la recuperación de la calidad del agua de ambientes fluviales pampeanos.

\section{2.b Objetivos específicos}

Para analizar cómo el ensamble de diatomeas puede contribuir al análisis de la recuperación de la calidad el agua se plantearon los siguientes objetivos específicos, vinculados a las actividades experimentales realizadas en campo y laboratorio:

1- Caracterizar el proceso de colonización del biofilm, en particular del ensamble de diatomeas en arroyos expuestos a diferentes niveles de impacto antropogénico, tanto urbano como agrícola. 
2- Analizar los cambios estructurales y funcionales del ensamble de diatomeas de sitios estresados por factores agrícolas y urbanos cuando son expuestos a mejorías en la calidad del agua, y seleccionar los descriptores (diversidad, riqueza específica, gremios ecológicos, Índice de Diatomeas Pampeanas, movilidad celular, tamaño celular, alteraciones nucleares y de las valvas) que resulten relevantes para el monitoreo de la rehabilitación de los cursos de agua.

3- Analizar la respuesta de la movilidad, la proporción de anomalías nucleares, la densidad poblacional y el tamaño celular en Nitzschia palea cuando es expuesta a elutriados procedentes de sedimentos contaminados por la actividad agrícola, con la finalidad de evaluar su potencialidad en la evaluación de la toxicidad de sedimentos.

\section{2.c Hipótesis}

La primera hipótesis de esta tesis plantea que la estructura del ensamble de las diatomeas del biofilm bentónico difiere en las etapas tempranas de la colonización en sistemas fluviales de acuerdo a la calidad del agua, relacionada con el tipo e intensidad de la actividad agrícola y urbana. Particularmente se verán afectadas la biomasa, la diversidad y riqueza específica, el índice de diatomeas pampeano, las proporciones de gremios ecológicos y las clases de tamaño.

Las predicciones asociadas a dicha hipótesis son que:

- La biomasa autotrófica (clorofila-a) del biofilm será mayor en el sitio de mayor impacto urbano (mayor concentración de nutrientes), pero menor en el sitio de mayor impacto agrícola (mayor concentración de agrotóxicos).

- Los índices de diversidad y la riqueza de las diatomeas aumentarán con el tiempo de colonización y serán mayores en los sitios de menor impacto. Al final de la experiencia el IDP será mayor en el sitio de mayor impacto.

- La proporción de diatomeas móviles y de alto perfil será mayor y las de bajo perfil será menor en los sitios de mayor impacto urbano. En cambio, la proporción de diatomeas móviles y de bajo perfil serán mayores, mientras que la proporción de alto perfil será menor en los sitios de mayor impacto agrícola. 
- Las diatomeas de tallas grandes serán más abundantes en los sitios de mayor impacto. Los tamaños más pequeños serán los primeros en asentarse, dejando luego lugar a formas más grandes.

La segunda hipótesis de esta tesis es que en un biofilm desarrollado, los descriptores del ensamble de diatomeas (diversidad, riqueza específica, índice de diatomeas pampeanas, proporción de gremios ecológicos, movilidad celular, proporción de alteraciones nucleares y de valvas deformes) responden a la mejoría en la calidad de agua.

Las predicciones asociadas a dicha hipótesis son que frente a la mejoría de la calidad del agua:

- Aumentará la diversidad, la riqueza específica y la movilidad celular.

- Disminuirán el valor del IDP, las proporciones de alteraciones en los núcleos, y las deformaciones en los frústulos del ensamble de diatomeas.

- En los arroyos expuestos a impacto urbano disminuirán la proporción de diatomeas móviles y de alto perfil, mientras que la proporción de diatomeas de bajo perfil aumentará; y en los arroyos expuestos a impacto agrícola disminuirá la proporción de diatomeas móviles y de bajo perfil, y aumentará la proporción de diatomeas de alto perfil.

La tercera hipótesis de esta tesis es que la movilidad, la proporción de anomalías nucleares, la densidad y el tamaño celular de Nitzschia palea responden a la exposición a elutriados provenientes de sedimentos tóxicos, particularmente exhibiendo:

- Disminuciones en la movilidad (velocidad, aceleración, distancia), en la densidad poblacional y en el tamaño celular promedio,

- Y aumentos en la proporción de anomalías nucleares. 


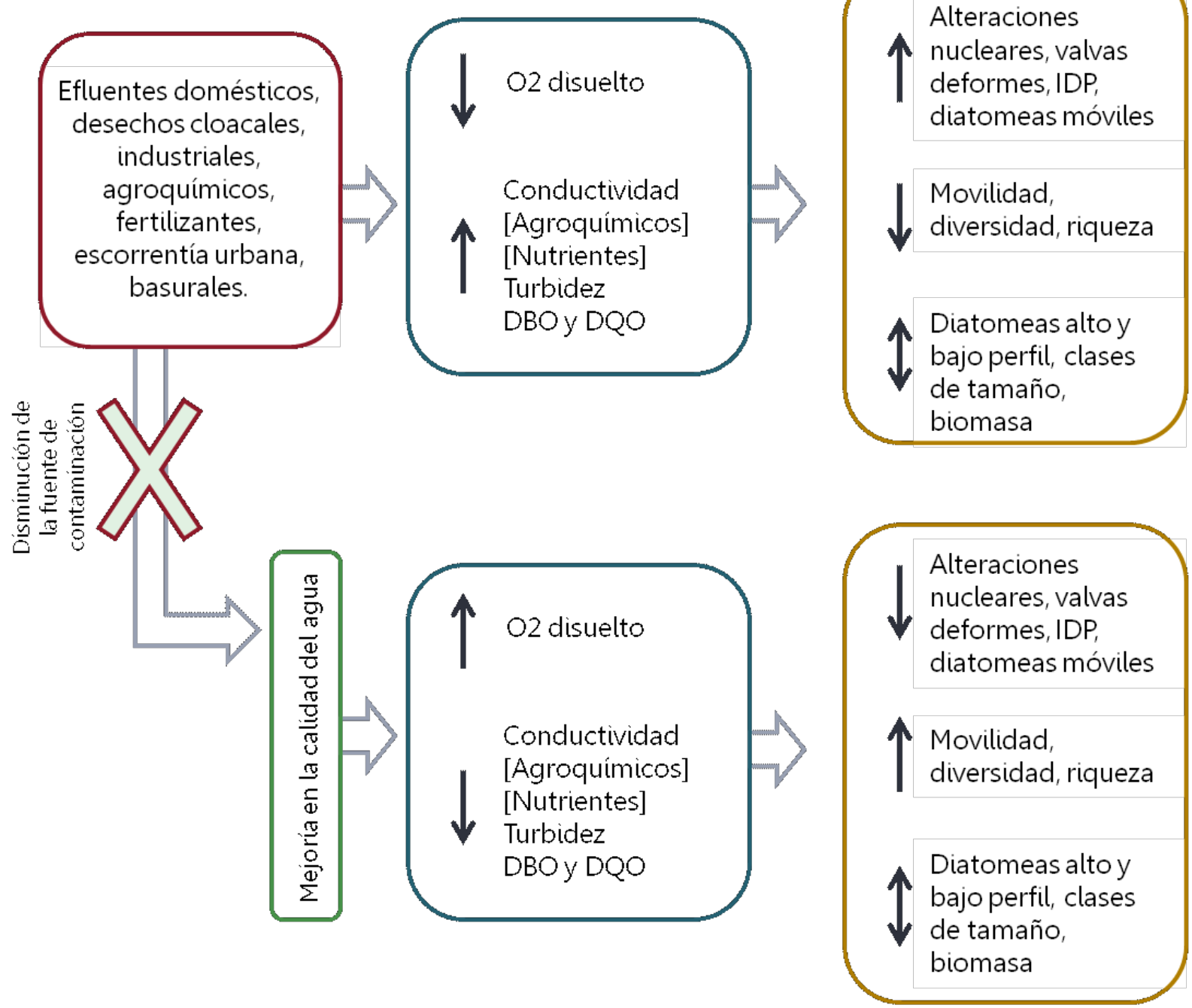

Figura 1.1: Marco conceptual utilizado en la presente tesis 


\section{Materiales y métodos}

\subsection{Metodologías}

\subsubsection{Recolección de muestras del biofilm}

\section{Biofilm epipélico}

Para la recolección de biofilm epipélico se empleó un muestreador que consistió en una pipeta graduada seccionada en un extremo, disponiéndose en el otro una propipeta que permitió aspirar el sedimento superficial (Figura 2.1). Se recolectaron 5 submuestras de los primeros 5-10 $\mathrm{mm}$ de la capa superficial del sedimento a través de la succión de 4 mL de biofilm (Gómez and Licursi, 2001; Licursi and Gómez, 2002; Gómez et al., 2010)

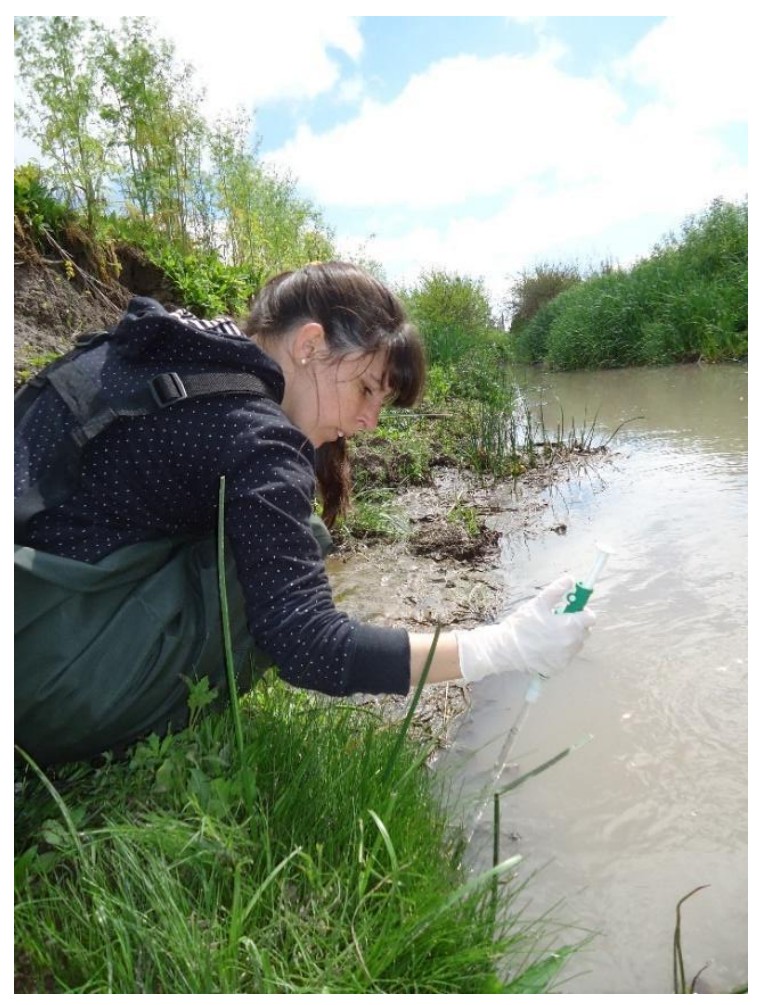

Figura 2.1: Muestreador para colectar el biofilm epipélico 


\subsubsection{Parámetros físico-químicos}

La temperatura $\left({ }^{\circ} \mathrm{C}\right)$, el $\mathrm{pH}$, el oxígeno disuelto $\left(\mathrm{OD}, \mathrm{mgL}^{-1}\right)$, la conductividad ( $\mu \mathrm{S}$ $\mathrm{cm}^{-1}$ ), la turbidez (UNT) y los sólidos suspendidos totales (SST; $\mathrm{mgL}^{-1}$ ) fueron medidos con un sensor multiparamétrico (HORIBA U10). La velocidad de la corriente se midió con un caudalímetro (Schiltknecht MainiAir20).

Los nutrientes fueron analizados por triplicado mediante técnicas estándar (APHA/AWWA/WEF, 2012). Para ello se filtraron $200 \mathrm{ml}$ de agua de los sitios de muestreo en campo por filtros de fibra de vidrio (Whatman GF/C 1,2 micras de apertura de poro) y se congelaron a $-18^{\circ} \mathrm{C}$ hasta su análisis. Además, se extrajeron 250 $\mathrm{ml}$ de agua que fueron refrigeradas hasta su arribo al laboratorio, para el análisis de la demanda biológica de oxígeno y la demanda química del oxígeno.

El fósforo reactivo soluble, nitrito y nitrógeno amoniacal fueron determinados colorimétricamente; el nitrito fue reducido a nitrito antes de realizar las mediciones colorimétricas. El valor de nitrógeno inorgánico disuelto (NID) se obtuvo de la suma de las tres fracciones del nitrógeno analizadas.

La demanda bioquímica de oxígeno $\left(\mathrm{DBO}_{5}\right)$ fue medida luego de una incubación en oscuridad de 5 días a $20{ }^{\circ} \mathrm{C}$, la concentración de oxígeno fue medida con un electrodo de oxígeno YSI-52 y la demanda química de oxígeno (DQO) se determinó por oxidación con dicromato de potasio en medio ácido (APHA/AWWA/WEF, 2012)

\subsubsection{Clorofila}

\section{Clorofila del biofilm}

Para la determinación de la clorofila-a del biofilm epipélico se filtraron $4 \mathrm{ml}$ de epipelon a través de un filtro de fibra de vidrio (Whatman GF/C; Clesceri et al., 1998). Luego se extrajo el exceso de humedad con papel absorbente, y se guardaron en papel de aluminio rotulado dispuesto en frascos con silicagel a $-18^{\circ} \mathrm{C}$ hasta su análisis. La extracción de los pigmentos se realizó con acetona al 90\% [v/v] (APHA/AWWA/WEF, 2012).

Para la determinación de la clorofila-a del biofilm proveniente de sustrato artificial, 3 vidrios fueron extraídos y colocados en tubos de vidrio con $5 \mathrm{ml}$ de acetona $90 \%$ y trasportados en frío y oscuridad hasta el laboratorio. En el laboratorio las muestras se sonicaron en 3 ciclos de 2 minutos de duración cada uno. La suspensión obtenida se utilizó para la determinación de la concentración de clorofila $a$. 
La concentración de clorofila-a fue determinada utilizando un espectrofotómetro Labomed UV-VIS a 665 y 750 nm, y los cálculos fueron realizados de acuerdo con la fórmula propuesta por Lorenzen (1967).

\subsubsection{Composición de organismos autotróficos del biofilm (grupos} algales)

Para el análisis de la composición taxonómica de componente autotrófico del biofilm, se utilizaron muestras de biofilm fijadas en formol al $4 \%$ y conservadas en envases plásticos. Para el recuento e identificación de los principales grupos algales (Cianobacterias, Clorofitas, Euglenofitas, Diatomeas) se usaron cámaras de SedgewickRafter que fueron analizadas en un microscopio Olympus BX 51 A 200X (Stevenson and Bahls, 1999), analizando el contenido completo de 1 cámara $(1 \mathrm{ml})$ por muestra, previa homogeneización de la muestra.

La identificación se llevó a cabo con la ayuda de la siguiente bibliografía, según el grupo taxonómico: Desikachary (1959); Komárek J y Anagnostidis (1999, 2005); Bourrely (1972); Komárek y Praha (1983); Streble y Krauter (1987).

La bibliografía específica para el análisis de diatomeas se lista en la siguiente sección.

\subsubsection{Ensamble de diatomeas}

\subsection{5.a Identificación del ensamble de diatomeas}

Las muestras destinadas a la determinación taxonómica de las diatomeas fueron oxidadas con $\mathrm{H}_{2} \mathrm{O}_{2}$ (100 volúmenes) durante 24 horas en estufa a $60^{\circ} \mathrm{C}$, con el fin de eliminar la materia orgánica, y posteriormente sometidas a tres ciclos sucesivos de centrifugado (3500 rpm) con agua destilada. Las muestras fueron montadas en porta objetos utilizando Naphrax ${ }^{\circledR}$ (Stevenson y Bahls, 1999). Se identificaron un total de 400 valvas por preparado utilizando un microscopio Olympus BX 51 con contraste de fases e interferencial, a una magnificación de 1000X, con el fin de obtener la abundancia relativa de cada taxón (Descy y Coste, 1991).

Sólo en el caso de las muestras de epipelon se realizó un tratamiento previo a la oxidación, utilizando Ludox con el fin de separar las diatomeas del sedimento (de Jonge, 1979). Para ello se centrifugaron partes iguales de muestra y de Ludox-TM $100 \%$, a potencia máxima durante 15 minutos. Posteriormente se recuperó el extracto sobrenadante conteniendo los organismos presentes en el biofilm y se descartó el pellet 
formado principalmente por los sedimentos. La muestra así obtenida fue lavada mediante centrifugación (para eliminar el remanente de Ludox-TM). Luego se con la oxidación, antes descripta.

Para la identificación del ensamble se empleó la siguiente bibliografía:

Patrick y Reimer (1966, 1975); Krammer y Lange-Bertalot (1986, 1988, 1991a, 1991b); Lange-Bertalot (2000); Krammer (1992, 2000); Metzelin y Lange-Bertalot (1998, 2005, 2007); Siver y Hamilton (2011), Morales E.A (2001) y las descripciones e imágenes de https://diatoms.org/.

Las fotografías de las principales diatomeas identificadas en este trabajo de tesis se pueden descargarse de https://github.com/MMnicolosi/Tesis. El listado completo de las especies identificadas para esta tesis se encuentra en la Tabla Anexa 2A.

\subsection{5.b Parámetros estructurales, IDP y gremios ecológicos}

Para cada muestra de diatomeas, se calcularon los siguientes parámetros estructurales: número de especies (Ludwig y Reynolds, 1988), Índice de diversidad de Shannon y Wiener $\left(H^{\prime}\right)$ y Equitabilidad (Shannon y Weaver, 1949).

Asimismo, se calculó el índice de Diatomeas Pampeano (IDP), un índice de calidad de agua regional que considera la tolerancia de las especies a la contaminación orgánica y a la eutrofización (Gómez yLicursi, 2001). El IDP varía entre 0 y 4 , determinando cinco clases de calidad de agua (Tabla 2.1)

Tabla 2.1: Interpretación del IDP, tabla extraída y modificada de Gómez y Licursi 2001

\begin{tabular}{|c|c|c|c|}
\hline $\begin{array}{l}\text { Clase de } \\
\text { calidad de } \\
\text { agua }\end{array}$ & $\begin{array}{l}\text { Valor del } \\
\text { IDP }\end{array}$ & Significado & Características del cuerpo de agua \\
\hline 0 & $0-0,5$ & Muy buena & $\begin{array}{l}\text { Sin contaminación, poco contenido de } \\
\text { nutrientes y materia orgánica }\end{array}$ \\
\hline 1 & $>0,5-1,5$ & Buena & $\begin{array}{l}\text { Levemente contaminado y eutrofizado, poco } \\
\text { contenido de nutrientes y materia orgánica }\end{array}$ \\
\hline II & $>1,5-2$ & Aceptable & $\begin{array}{l}\text { Con contaminación y eutrofización moderadas, } \\
\text { altas concentraciones de nutrientes y materia } \\
\text { orgánica }\end{array}$ \\
\hline III & $>2-3$ & Mala & $\begin{array}{l}\text { Altamente contaminado y eutrofizado, } \\
\text { presencia de materia orgánica parcialmente } \\
\text { degradada, nitritos y amonio }\end{array}$ \\
\hline IV & $>3-4$ & Muy mala & $\begin{array}{l}\text { Fuertemente contaminado, altas } \\
\text { concentraciones de materia orgánica, presencia } \\
\text { de productos industriales. }\end{array}$ \\
\hline
\end{tabular}


Además, las especies fueron clasificadas de acuerdo a su tolerancia a la limitación por nutrientes y a los disturbios físicos, en los gremios ecológicos (bajo perfil, alto perfil y móviles) empleando la clasificación de Passy (2007).

El gremio de "bajo perfil" contiene especies de baja estatura que incluyen diatomeas postradas (adheridas al sustrato con toda la superficie de la valva), adnatas (adheridas apicalmente pero paralelas al sustrato) y erectas (adheridas apicalmente pero perpendiculares al sustrato), centrales solitarias, y especies de baja movilidad. Las especies que cumplen estos criterios son miembros de los géneros Achnanthes, Achnanthidium, Amphora, Cocconeis, Cyclotella, Cymbella, Hannaea, Meridion, Opephora, y Reimeria (Passy 2007). Se caracterizan por ser resistentes a las perturbaciones físicas (turbulencia del agua) y no tienen tolerancia al enriquecimiento de nutrientes.

El gremio de "alto perfil" contiene especies de talla más grande o que tienden a formar grandes colonias. Incluye a las formas erectas, filamentosas, ramificadas, en cadena, tuberiformes, pedunculadas y centrales coloniales. Las especies que cumplen estas características pertenecen a los géneros: Diatoma, Ellerbeckia, Eunotia, Fragilaria, Gomphoneis, Gomphonema, Melosira (Melosira varians), Synedra y Cymbella (las formas que tienen un pedúnculo largo). Las diatomeas que pertenecen a este grupo no resisten altas velocidades de corriente, pero se ven favorecidas por el enriquecimiento de nutrientes. Se caracterizan por explotar los recursos que no están disponibles para las diatomeas de bajo perfil, pero sin embargo se encuentran más expuestas al pastoreo.

El gremio "móvil" contiene especies de rápido movimiento. Estos taxones están adaptados a ambientes turbulentos y a altas concentraciones de nutrientes (Rimet and Bouchez, 2012b). Se incluye dentro de este grupo a las especies de los géneros Navicula, Nitzschia, Sellaphora, y Surirella (Passy 2007).

El gremio "planctónico" creado por Rimet y Bouchez 2012b, no fue considerado en esta tesis ya que el número de diatomeas pertenecientes a este grupo fue muy bajo $(<1 \%)$

\subsection{5.c Densidad}

Para la estimación de la densidad de diatomeas se utilizaron muestras de biofilm fijadas en formol al 4 \% y conservadas en envases plásticos. Para el recuento se utilizó una cámara de Sedgwick-Rafter (APHA, 2012) y un microscopio Olympus BX 50 a una magnificación de 200X. 


\subsection{5.d Alteraciones nucleares}

Para el análisis de las alteraciones nucleares se utilizaron muestras de biofilm fijadas con formol al $4 \%$. Las muestras fueron teñidas con una solución $2 \%(\mathrm{v} / \mathrm{v})$ Hoechst 33342 (CAS No. 23491-52-3, Sigma Chemical Co) e incubadas durante 1.30 hs en estufa a $37^{\circ} \mathrm{C}$. Luego se filtraron por membranas de policarbonato negras lisas de $\varnothing 25 \mathrm{~mm}$, y 0,22 um de apertura de poro específicas para DAPI [4,6- diamidino-2phenylindole] (U-MWU2, Ex. filter, BP 330-385; Em. filter, BA 420). La observación se hizo con un microscopio Olympus BX- 51 con epifluorescencia y una magnificación de 600X. Se contaron un total de 400 diatomeas por muestra para determinar la frecuencia de alteraciones nucleares. Dentro de las alteraciones nucleares identificadas en este trabajo de tesis se encuentran: fragmentación de núcleo en múltiples partes, ruptura de la membrana nuclear, localización anormal del núcleo (Figura 2.2 a, b, c, d) (Debenest et al., 2008; Licursi and Gómez, 2013). Para esta última alteración, se consideraron previamente las diferentes localizaciones del núcleo durante el ciclo celular reportadas por (Round et al., 2007) en orden de establecer si las posiciones observadas eran o no anómalas.

\subsection{5.e Deformaciones de los frústulos}

El porcentaje de alteraciones en la forma y ornamentación de los frústulos fue evaluado a través de la observación de preparados fijos en un microscopio BX51 a una magnificación de 1000x. Las alteraciones fueron: deformaciones en el contorno de la valva; cambios en el patrón de estrías; cambios en la forma, tamaño y posición del área longitudinal y central; modificaciones del rafe y del canal del rafe (Figura 2.2 $e, f, g)$. 


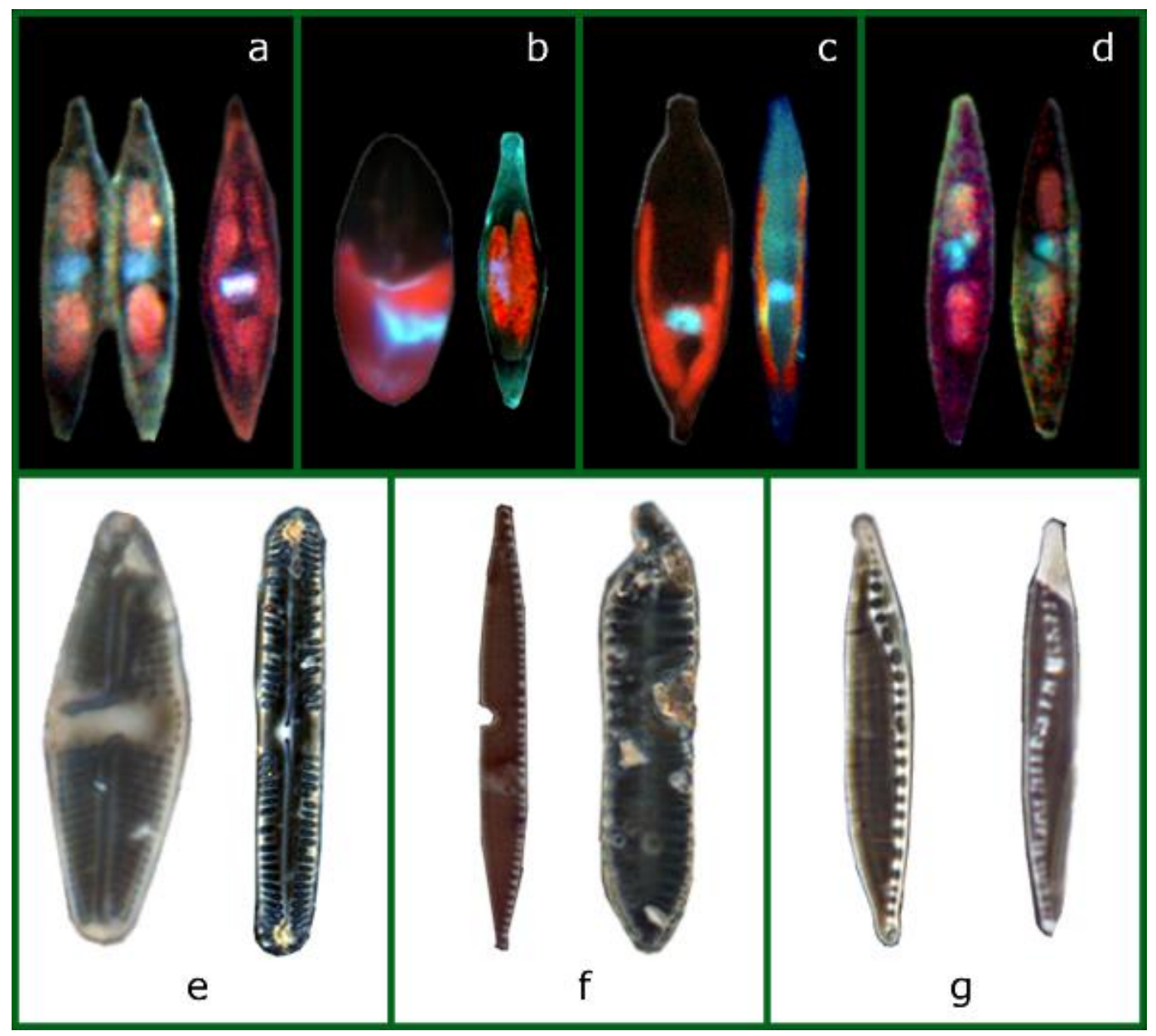

Figura 2.2: Alteraciones nucleares $(a, b, c, d)$ y deformaciones en las valvas $(e, f, g)$ observadas en este trabajo en de tesis. En (a) se observan núcleos de condición normal; en (b) se observan núcleos con ruptura de la membrana nuclear; en (c) se observan núcleos mal localizados y en (d) se muestran núcleos fragmentados. En la figura (e) se muestran valvas con alteraciones en el patrón de estrías y en el área central; en ( $f$ ) se observan anormalidades de contorno; y en ( $\mathrm{g}$ ) modificaciones en el canal del rafe.

\subsection{5.f Movilidad}

Para analizar la movilidad de las diatomeas se adaptaron dos protocolos según si las mismas provenían de muestras crudas de biofilm o si provenían de monocultivos de diatomeas.

\section{Para el análisis de las diatomeas de muestras de biofilm}

Para el análisis de la movilidad de diatomeas se extrajeron muestras de biofilm que fueron colocadas en envases plásticos y conservadas en frío hasta el laboratorio. Se tomó una muestra de $40 \mu \mathrm{l}$ y se diluyó con $100 \mu \mathrm{l}$ de agua filtrada del mismo arroyo, se colocó en un portaobjetos con un cubreobjetos. Se ubicó el preparado en un microscopio BX 50 con cámara Olympus Q Color 5. Se identificaron los individuos a filmar a una magnificación de 400X, y el video se filmó a un aumento de 100x. Con los programas 
Image Pro-Plus y CAM Studio Recorder se filmaron videos de 30 segundos de duración y 5 cuadros por segundo cada uno. Esos videos fueron analizados posteriormente con el plug-in para Image J M-track (Motion tracking and analysis) (Meijering et al., 2012). Las variables medidas fueron: velocidad, longitud del trayecto y velocidad máxima.

\section{Para el análisis de diatomeas proveniente de monocultivos}

Para el análisis de movilidad de diatomeas de un monocultivo, se tomaron muestras de $1 \mathrm{~mL}$ del cultivo, colocándose en una cámara de Sedgwick-Rafter para su análisis. Los videos se filmaron a una magnificación de 200X en un Microscopio BX 50 con una cámara Olympus Q Color 5. Se emplearon los programas Image Pro-Plus y CAM Studio Recorder para filmar videos de 30 segundos de duración y 5 cuadros por segundo cada uno. Para la medición de los parámetros de movilidad (velocidad, distancia y aceleración) se utilizó el software de libre acceso Tracker https://physlets.org/tracker/. Algunos ejemplos de los videos analizados mediante esta técnica pueden ser descargados desde https://github.com/MMnicolosi/Tesis

\subsection{5.g Tamaño celular}

El análisis del tamaño celular se abordó de dos formas:

- Clases de tamaño según biovolumen:

Se clasificó al ensamble de diatomeas en 5 clases de tamaño en función del biovolumen (en $\mu \mathrm{m}^{3}$ ) propuestas por (Rimet and Bouchez, 2012b).Las categorías comprendieron las diatomeas con los siguientes biovolumenes: Clase 1: 0 a $99 \mu^{3}$; Clase 2: $>100-299 \mu \mathrm{m}^{3}$; Clase 3: $>300-599 \mu \mathrm{m}^{3}$; Clase 4: $>600-1499 \mu \mathrm{m}^{3}$; Clase 5: $>1500 \mu \mathrm{m}^{3}$.

\section{- Largo del frústulo:}

Se colocó $1 \mathrm{ml}$ de muestra fijada con formol al 4\% en una cámara de SedgewickRafter y se midió el largo del frústulo de 10 individuos de la misma especie por réplica en un microscopio Olympus BX 51 a una magnificación de 20X utilizando la regla micrométrica (Coquillé et al., 2015). 


\subsubsection{Experiencia de colonización en sustrato artificial duro}

Para la realización de las experiencias de colonización del biofilm en arroyos con diferentes tipos de impactos antropogénicos se utilizaron sustratos artificiales. El uso de sustratos artificiales es ampliamente utilizado y recomendado para el monitoreo de la calidad del agua (Ivorra et al., 2000; Kelly, 1998). Entre los beneficios se encuentran la uniformidad en el tamaño y la superficie, la estandarización del método de muestreo (Dela-Cruz et al., 2006), la exactitud y precisión de las medidas (Sánchez et al., 2017), la disminución de la perturbación del habitat (Dalu et al., 2014) y un desarrollo del biofilm exclusivamente influenciado por la química de la columna del agua (Desrosiers et al., 2013). En estas experiencias se utilizó vidrio como sustrato artificial.

Se utilizaron vidrios esmerilados de $5 \mathrm{~cm}^{2}$. Los mismos fueron esterilizados (Cleason Ficoinox SL-9000) y pegados a segmentos de acrílico que fueron sujetos a ladrillos (Figura 2.3). En cada tramo de los arroyos escogidos se colocaron 3 ladrillos con 100 vidrios. Los ladrillos se fijaron al lecho del arroyo cubiertos al menos por una columna de agua de $10 \mathrm{~cm}$, asegurándose que siempre estuvieran sumergidos y les llegara la luz. En cada muestreo los vidrios fueron retirados utilizando pinzas y colocados en tubos de vidrio que contenían $6 \mathrm{ml}$ de agua destilada con formol al $4 \%$ ० $6 \mathrm{ml}$ de acetona (sólo en el caso de las muestras destinadas a la medición de la clorofila a del biofilm). Para cada variable medida se tomaron 3 réplicas formadas por tres vidrios cada una. Los sustratos que conformaron cada muestra fueron extraídos a la media hora de colocados los ladrillos (T0), a las 3 horas (T1), 6 horas (T2), 24 horas (T3), 48 horas (T4), 168 horas (1 semana, T5) y 336 horas (dos semanas, T6) (Figura 2.4). En el caso de la experiencia de colonización en arroyos de impacto urbano, el muestreo se hizo hasta las 168 hs, debido a que los sustratos se perdieron por causa de una crecida de los arroyos. 


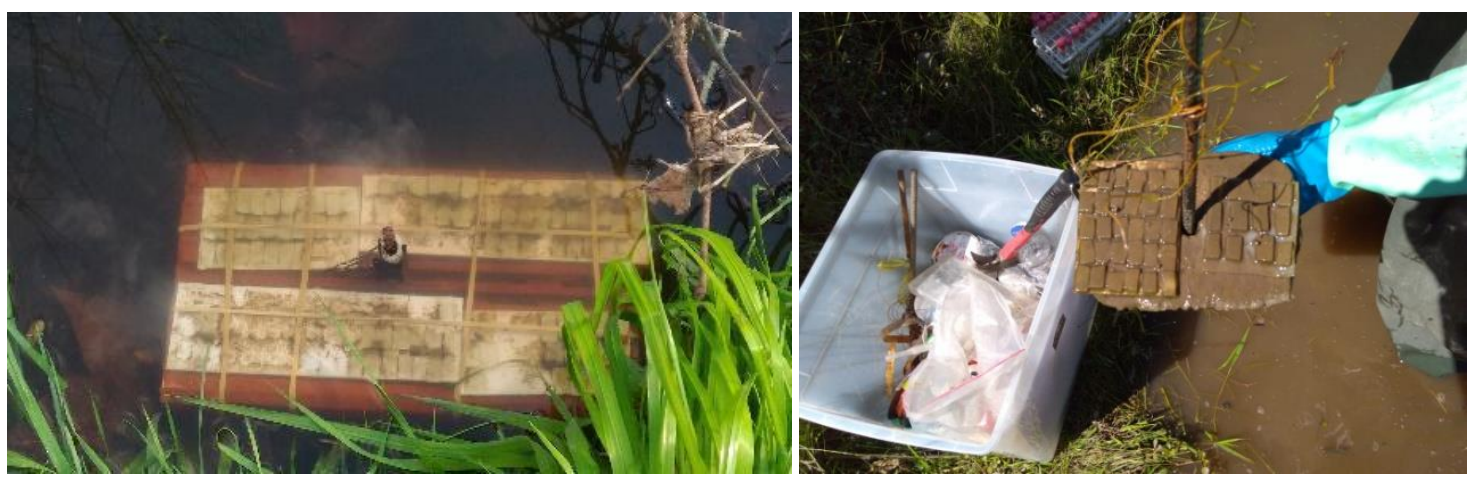

Figura 2.3: detalle de los sustratos artificiales duros (vidrios) adheridos al ladrillo y emplazados en el lecho del arroyo.

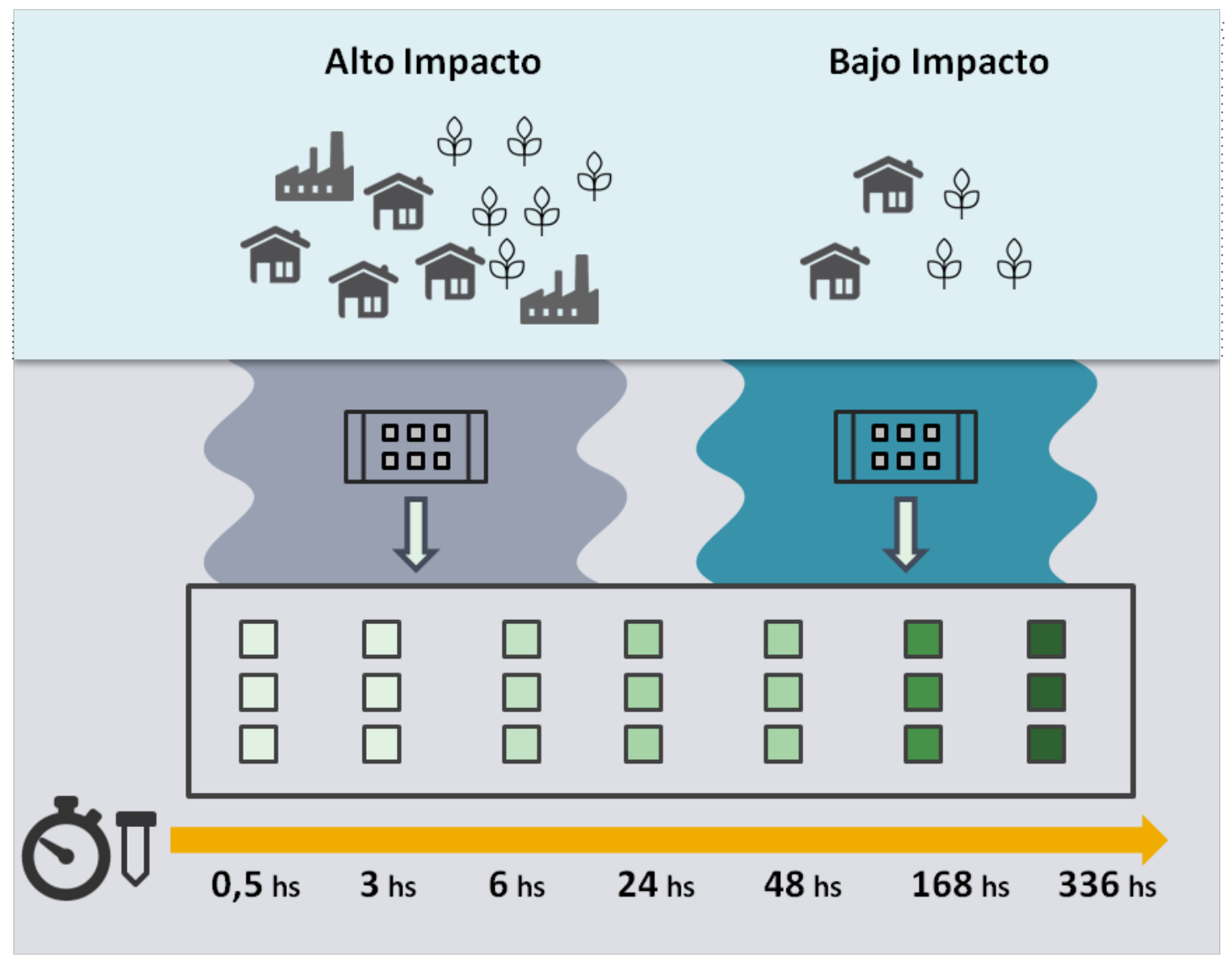

Figura 2.4: Esquema de la experiencia de colonización en arroyos con diferentes tipos de impacto; se indica el tiempo de muestreo (horas). 


\subsubsection{Experiencias de translocación}

\subsection{7.a Translocaciones con sustrato natural}

Para analizar la recuperación del ensamble de diatomeas del biofilm epipélico de sitios estresados por factores urbanos se realizaron translocaciones de biofilm epipélico perteneciente al sitio estresado, a otro sitio del mismo arroyo exento del estrés analizado y considerado como menos impactado (considerando que en el área de estudio no existen sitios de referencia) y situado aguas arriba del sitio disturbado (Figura 2.5).

Se colocaron 6 bandejas de germinación, (cada una con 200 pocillos de 2,5 cm de diámetro y $3 \mathrm{~cm}$ de profundidad) rellenas de sedimento superficial del sitio estresado, que permanecieron durante 3 semanas en el sitio para su estabilización y permitir el desarrollo del biofilm. En los sitios de menor impacto se colocaron 3 bandejas y se procedió de la misma manera. Una vez transcurridas las 3 semanas, se trasladaron 3 de las bandejas de los sitios más impactados a los menos impactados. En todos los casos se dejaron bandejas en los sitios de origen (consideradas control) para realizar las comparaciones y en el lugar de translocación para contar con información del entorno de las bandejas traslocadas. Los muestreos se realizaron en los tiempos 0 (el día de la translocación), a los 15, 30 y 45 días.

\subsection{7.b Translocaciones con sustrato artificial}

Para el estudio de la recuperación del ensamble de diatomeas de arroyos afectados por impacto agrícola se realizaron translocaciones con sustrato artificial. Para este fin se utilizaron vidrios con superficie esmeriladade $5 \mathrm{~cm}^{2}$ de área, previamente esterilizados (Cleason Ficoinox SL-9000). Los vidrios fueron adheridos a piezas de acrílico las cuales fueron sujetadas a ladrillos. Se colocaron un total de 6 ladrillos a una profundidad de 10 $\mathrm{cm}$ en el sitio de mayor impacto agrícola y 3 ladrillos fueron colocados en el sitio de menor impacto. Se dejaron en los sitios durante 30 días para permitir la colonización y el desarrollo de un biofilm maduro (Figura 2.5). Transcurrido ese tiempo 3 ladrillos del sitio más impactado fueron trasladados al de menor impacto. Los muestreos se hicieron en los tiempos 0 (el día de la translocación), a los 15, 30 y 45 días. 


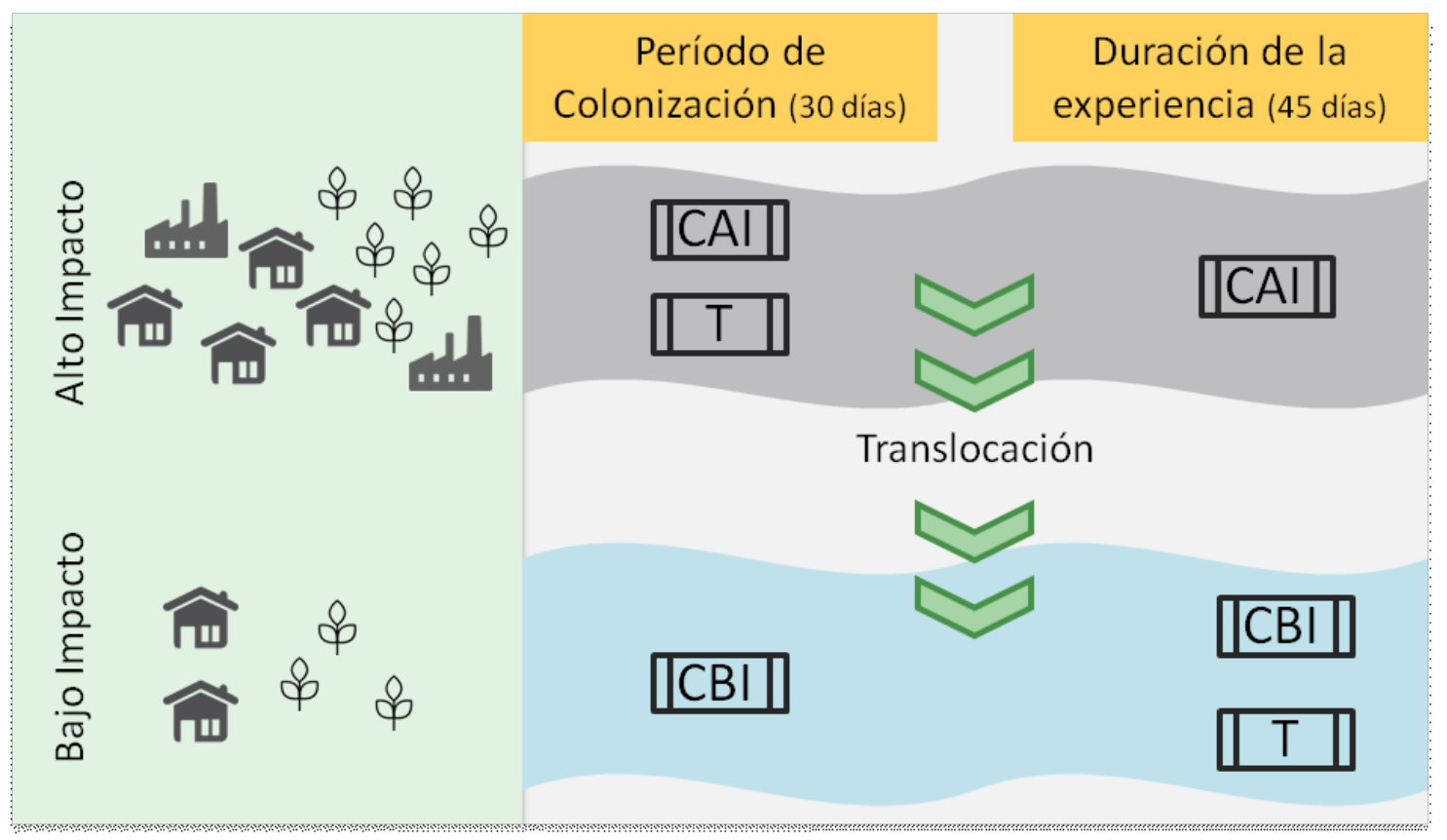

Figura 2.5: esquema de las translocaciones realizadas en entre trabajo de tesis. El sentido de la translocaciones se realizó de arroyos de mayor impacto (urbano o agrícola) a arroyos de menor impacto (se indica con flechas). CAl: sustrato Control de Alto Impacto; CBI: sustrato Control de Bajo Impacto; T: sustrato translocado. Se indican la duración de la colonización del sustrato y de la experiencia.

\subsubsection{Análisis estadísticos}

Para cada diseño experimental empleado se utilizaron análisis estadísticos detallados en los distintos capítulos de la tesis. A modo general y resumido se explican en este apartado los diferentes análisis utilizados.

La abundancia de las especies fue transformada como $\operatorname{Ln}(x+1)$ para aproximarla a una distribución normal, y los datos ambientales fueron estandarizados (ter Braak y Van Tongeren, 1995).

Para examinar las diferencias entre las variables tanto fisicoquímicas como biológicas medidas en este trabajo de tesis, se utilizaron ANOVA (una y dos vías) y MANOVA. En todos los casos se analizaron la homogeneidad de varianzas mediante el test de Cochran (Cochran, 1951) y la normalidad mediante el test de Shapiro-Wilk (Shapiro and Wilk, 1965). En todos los análisis, para establecer las diferencias entre grupos se utilizó el test a posteriori de Student-Newman-Keuls (o SNK) (Cohen, 2013).

Además, se calculó valor Eta-cuadrado $\left(\eta^{2}\right)$, como una medida del tamaño del efecto sobre la comunidad. El mismo indica cuánta variabilidad de la variable 
dependiente puede ser explicada por la variable independiente. El valor de $\eta 2$ se calculó como un cociente de sumas de cuadrados (SS):

$$
\frac{\eta 2=(\text { SSefecto })}{(\text { SS total })}
$$

Para interpretar el valor de $\eta^{2}$ obtenido se siguió la siguiente regla: se consideró un efecto pequeño cuando $\eta^{2} \leq 0,25$; un efecto moderado cuando $0,25>\eta^{2}<0,75$ y un efecto grande cuando $\eta^{2}>0,75$ (Cohen 2013).

\section{2 Área de estudio}

La Ecoregión Pampeana comprende una llanura de aproximadamente medio millón de kilómetros cuadrados con sólo una parte muy reducida ocupada por sierras que apenas superan los $500 \mathrm{~m}$ s.n.m., pertenecientes al sistema serrano de Tandilia, o los 1200 m s.n.m. en el caso del sistema serrano de Ventania (Cabrera y Willink 1980). La temperatura media anual es de $16{ }^{\circ} \mathrm{C}$, comprendiendo valores medios entre los $20-24^{\circ} \mathrm{C}$ en verano y entre $7^{\circ} \mathrm{C}-10^{\circ} \mathrm{C}$ en invierno. La media pluviométrica es de $1100 \mathrm{~mm}$, siendo el otoño la estación más lluviosa, con un gradiente pluviométrico con menores precipitaciones hacia el SO.

El tipo de vegetación natural dominante, resultado de las características climáticas y edáficas, es de tipo estepario o pseudoestepario de gramíneas, entre las cuales crecen numerosas especies herbáceas y algunos arbustos (Cabrera y Willink 1980).

Los arroyos de la llanura pampeana fluyen por áreas deposicionales de sedimentos loéssicos y se caracterizan por tener bajas velocidades de corriente. El lecho de los mismos está constituido por fracciones finas de sedimento (limos y arcillas), lo que provee un sustrato favorable para el desarrollo del biofilm epipélico (Licursi and Gómez, 2002; Cochero et al., 2013). La vegetación de ribera no tiene un gran desarrollo, estando compuesta principalmente por especies herbáceas y con ausencia de estratos arbóreos. (Giorgi et al. 2005, Feijoó y Lombardo 2007). Los niveles de nutrientes en estos arroyos son naturalmente altos aún en sitios expuestos a baja o moderada agricultura y ganadería (Feijoó et al. 1999, Bauer et al. 2002a, b), lo que favorece un desarrollo de densas comunidades de macrófitas (Giorgi 1998, Allan y Castillo 2007). 


\section{El partido de La Plata}

Dentro de la región Pampeana se halla localizada gran parte de la Provincia de Buenos Aires en la que se encuentra el Partido de La Plata donde se realizó este trabajo de tesis. El clima es templado-húmedo, con precipitaciones medias anuales

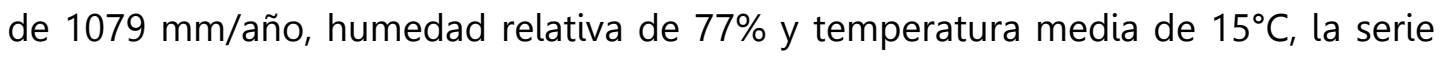
anual de las precipitaciones (1909 - 2011) indica la alternancia de ciclos húmedos y secos (Kruse et al. 2014). El relieve comprende dos zonas bien diferenciadas: la Llanura Alta, desde los 5 a 30 m s.n.m., compuesta por terrenos con suaves ondulaciones conformados por sedimentos loéssicos eólicos de origen continental; y la Llanura Costera, desde los $5 \mathrm{~m}$ s.n.m hasta el nivel del mar, conformada por limos y arcillas estuáricos correspondientes a depósitos marinos del Holoceno (cordón de conchilla) (Hurtado 2006).

Dentro del área se pueden diferenciar 2 vertientes hidrográficas: hacia el Río de la Plata (que abarca algunas de las cuencas seleccionadas en esta tesis) y hacia el Río Samborombón.

Los arroyos de la vertiente del Río de la Plata tienen un rumbo general de escurrimiento SO-NE, desaguando en la Planicie Costera y no en el Río de la Plata. La descarga, en la mayoría de los casos, sólo puede lograrse mediante canalizaciones. Ello se debe a que entre los $5 \mathrm{~m}$ s.n.m. y la costa del estuario se produce un cambio de pendiente regional, la cual se hace mínima (<0,03\%), dando lugar a que los arroyos pierdan energía y sus cursos se hagan divagantes, disipándose y generando bañados (Hurtado et al 2006). Los arroyos, en general, presentan un recorrido recto y en condiciones naturales son de tipo perenne como consecuencia de la descarga del agua freática en el curso. Presentan un índice de escurrimiento del orden del 6\% respecto de la precipitación anual, con caudales medios entre 30 y 70 L. s ${ }^{-1}$ (Kruse et al 2014).

La población total del área de estudio según el censo del 2010 es de 799.523 habitantes, situándose el mayor porcentaje en el casco urbano, seguidos por las localidades de Los Hornos, Villa Elvira y Tolosa. Según afirma Bozzano (2002), sobre el total del territorio municipal de La Plata (94.200 ha), 15\% corresponde a espacios urbanos, $39 \%$ a espacios periurbanos y $46 \%$ al espacio rural.

En esta región se encuentra el cinturón verde de La Plata, que es una franja de territorio de 5 a $12 \mathrm{Km}$ de ancho y 36.580 ha de extensión, que se extiende entre la ciudad y el suburbio, por un lado, y el ámbito rural, por otro. Un tercio de este cinturón 
es de carácter productivo y es considerado el primer productor hortícola de la Argentina, destacándose a nivel nacional en la producción de tomate, alcaucil, apio, lechuga, frutilla y clavel. En la última década, a partir de las transformaciones que se están produciendo en el Partido de La Plata, se observó un notable cambio en la morfología de la ciudad, que afectó fundamentalmente al denominado espacio periurbano (Frediani 2009). La emigración de la población hacia la periferia en busca de nuevas oportunidades laborales y de un nuevo hábitat, se tradujo en un aumento de la ocupación de nuevas superficies en los límites físicos entre los ámbitos urbanos y no urbanos. Con esta expansión, muchas de las tierras que se destinaban a explotaciones primarias intensivas presentan ahora otros usos del suelo, propios de un área urbana (Frediani \& Matti; 2006).

Debido a la gran densidad demográfica, y la concentración de actividades agrícolas y ganaderas, junto con la utilización de agroquímicos, gran parte de los ríos y arroyos de la región son impactados por fuentes puntuales de contaminación provenientes de efluentes domésticos e industriales, como así también por fuentes difusas asociadas a los cultivos.

\subsubsection{Sitios de estudio, características e impactos}

Los sitios fueron elegidos por su exposición a dos tipos de impactos predominantes: impactos urbanos y agrícolas (Figura 2.6). Para establecer los porcentajes del usos de suelo entorno a los sitios de muestreo seleccionados se delimitó un área de $500 \mathrm{~m}$ para cada margen alrededor del sitio, y desde la localización del sitio en el arroyo un tramo de $500 \mathrm{~m}$ aguas arriba (Ding et al. 2016). Se clasificó la cobertura del suelo a partir de imágenes satelitales (Landsat 7+ETM) en los tramos estudiados en: suelo impermeabilizado urbano (ejs. asfalto y edificaciones), suelo vegetado sin cultivos (ejs. pastizal, césped, arboledas), suelo vegetado con cultivos y suelo cubierto por invernaderos.

A partir de la cobertura del suelo en los tramos delimitados, se separaron en tramos con impacto agrícola (suelo mayormente con cultivos o cubierto por invernaderos), e impacto urbano (con suelo impermeabilizado o vegetado sin cultivos o invernaderos). Las capas de SIG con la localización de los sitios de estudio y las coberturas del suelo en los tramos estudiados pueden ser descargadas desde https://github.com/MMnicolosi/Tesis 
Los sitios de impacto urbano, se separaron en aquellos de Bajo Impacto y de Alto Impacto Urbano. Los de bajo impacto se localizaron en zonas periurbanas con un de impermeabilización del suelo y predominio de uso del suelo vegetado sin cultivos, mientras que los de alto impacto se encontraron en zonas urbanas $>50 \%$ de impermeabilización del suelo (Figura 2.7). Esto se reflejó en las características físicoquímicas del agua (Tabla 2.2): los de bajo impacto fueron sitios con promedios más bajos de temperatura, $\mathrm{pH}$, conductividad, $\mathrm{OD}, \mathrm{N}-\mathrm{NO}_{3}{ }^{-}, \mathrm{N}-\mathrm{NH}_{4}{ }^{+}, \mathrm{PRS}, \mathrm{DBO}_{5}$ y DQO. Los sitios de Alto impacto, por otro lado, al estar expuestos a una mayor cantidad de aportes de nutrientes tuvieron por ejemplo valores 2,5 veces más altos de $\mathrm{DBO}_{5}, 1,7$ más altos de DQO, 2,5 veces más concentraciones de PRS y 1,8 veces más concentraciones de nitratos.

En el caso de los sitios con impacto agrícola, los sitios de Bajo Impacto se encontraron en campos con una actividad hortícola leve, con $>50 \%$ de la cobertura del suelo perteneciendo al uso ganadero extensivo o a cañadas naturales, mientras que los de Alto Impacto se encontraban en sitios con un $>50 \%$ de cobertura del suelo por agricultura intensiva o invernaderos (Figura 2.7). En estos últimos sitios se midieron concentraciones de nutrientes mucho más altas que en los sitios de Bajo impacto: 5 veces las concentraciones de nitratos, 2 veces las de NID y 1,5 veces las concentraciones de PRS (Tabla 2.3).

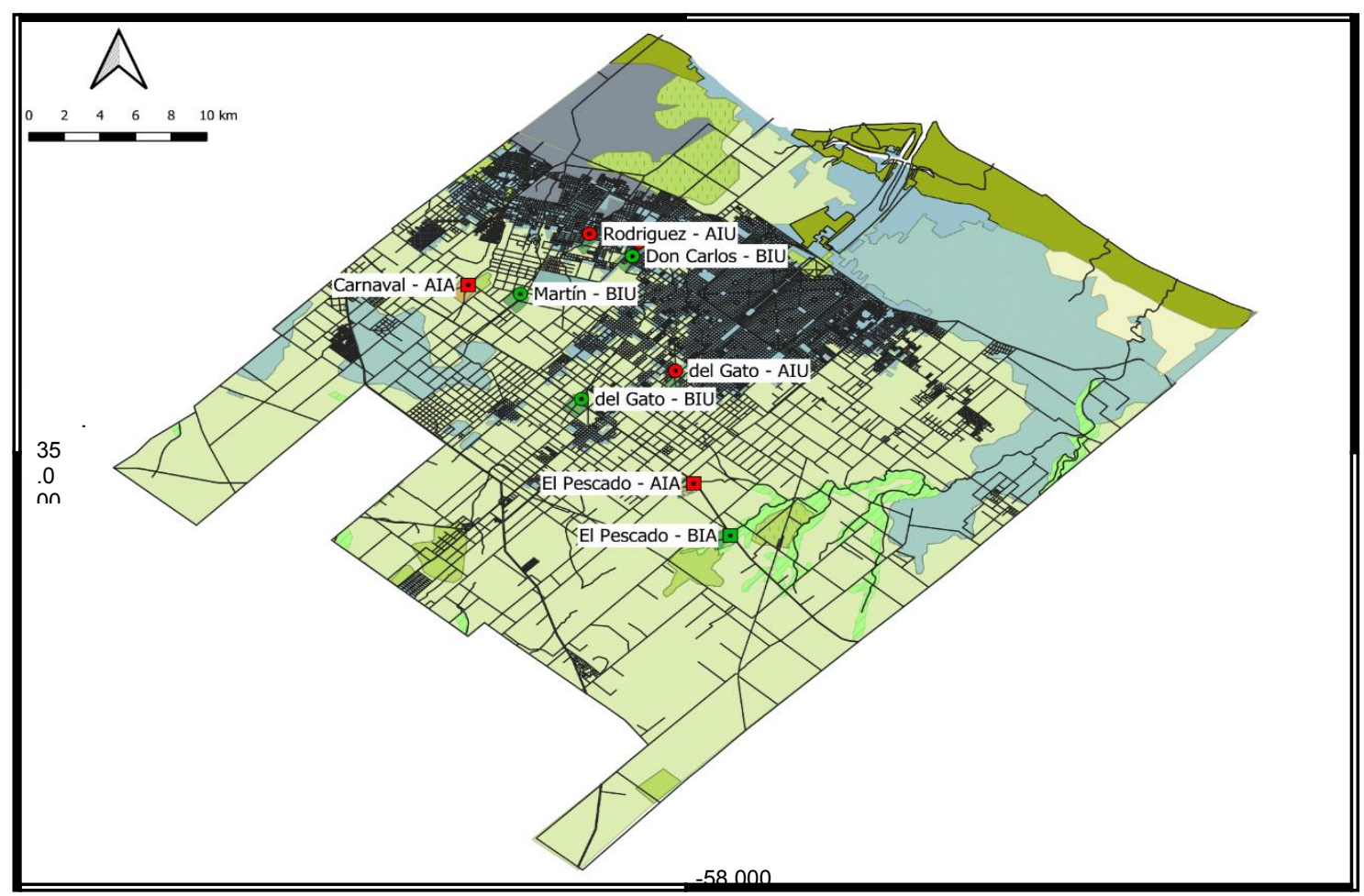

Figura 2.6: mapa de la localización de los sitios de muestreo en el partido de La Plata 


$\begin{array}{lll}\square & \text { Vegetación (sin cultivo) } & \text { Vegetación (con cultivo) } \\ \square & \text { Impermeabilización urbana } & \square\end{array}$

\section{Cobertura del suelo por sitios}
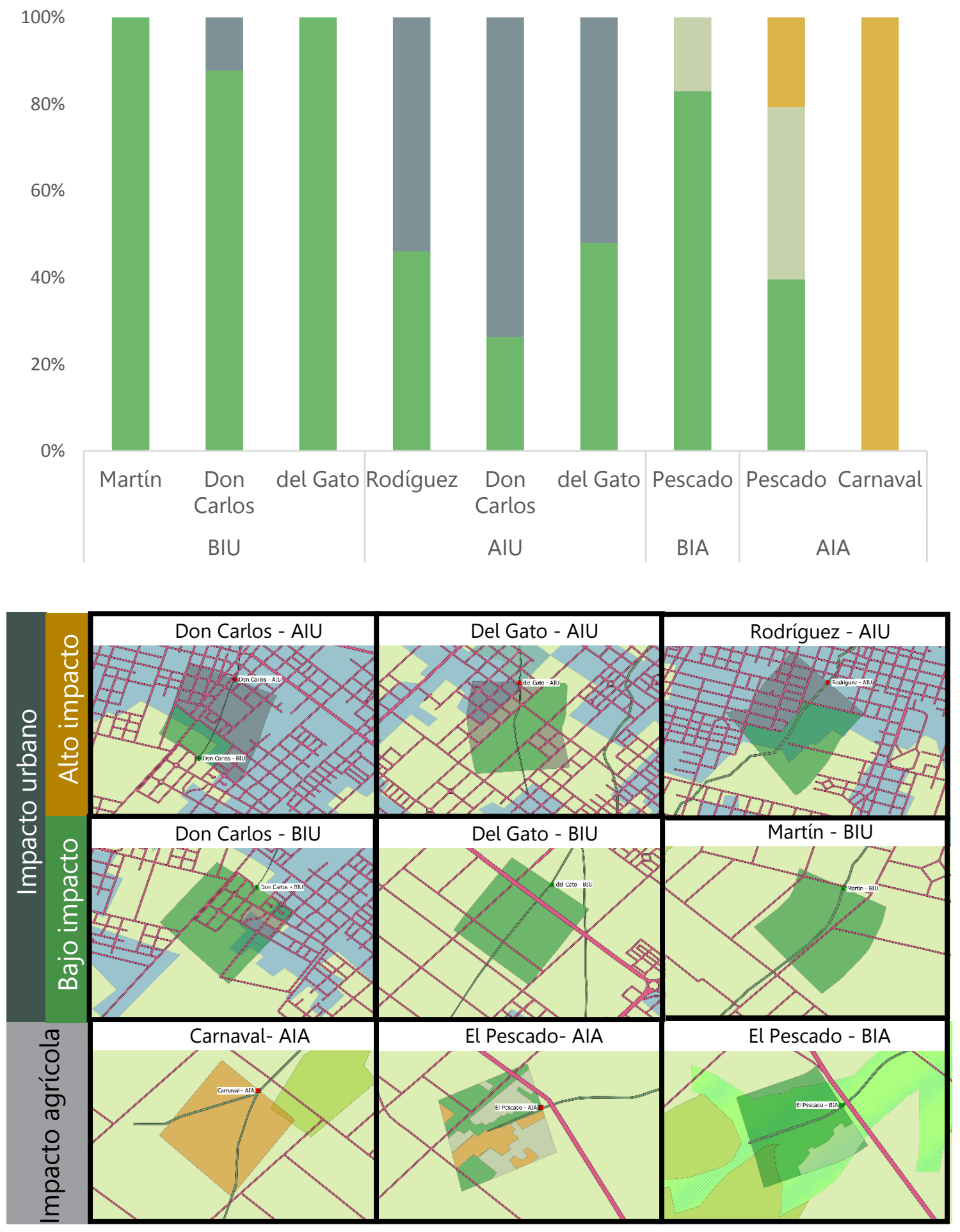

Figura 2.7: Detalle de la cobertura del suelo en las áreas cercanas a los sitios de muestreo. BIU=Bajo impacto urbano; $\mathrm{AIU}=$ Alto impacto urbano; $\mathrm{BI} \mathrm{A}=\mathrm{Bajo}$ impacto agrícola; $\mathrm{AI} A=A$ tto impacto agrícola 


\subsubsection{Breve descripción de los arroyos y sitios}

\section{Impacto urbano}

Los siguientes arroyos y sitios se escogieron para evaluar el efecto del impacto urbano en el ensamble de diatomeas. Los parámetros fisicoquímicos, la ubicación y la experiencia para los que fueron escogidos se detallan en la Tabla 2.2.

\section{Arroyo Martín}

Es un cuerpo de agua de segundo orden, que nace de dos cursos en la localidad de City Bell, cuyas cabeceras se encuentran próximas a los 27,5 msnm. Tiene una longitud de 14,5 km, con un rumbo casi N-S hasta desembocar en la Planicie Costera. Al ingresar en el Parque Ecológico Municipal ha sido rectificado mediante un canal de $1,3 \mathrm{~km}$ de largo.

En este arroyo, se seleccionó un sitio de muestreo caracterizado como Bajo Impacto urbano (Figuras 2.7 y 2.8). En este sitio, el arroyo se encuentra compuesto por sedimentos finos, principalmente limos y arcillas y en menor proporción por gravas. Es angosto y de poco caudal. Presenta vegetación riparia del tipo arbórea compuesta principalmente por Salix humboldtiana Willd. y vegetación acuática representada por las macrófitas Ludwigia peploides (Kunth) P. H. Raven del tipo flotante y Gymnocoronis spilantoides (D. Don ex Hook. \& Arn.) DC. y Polygonum punctatum Elliott del tipo emergente.

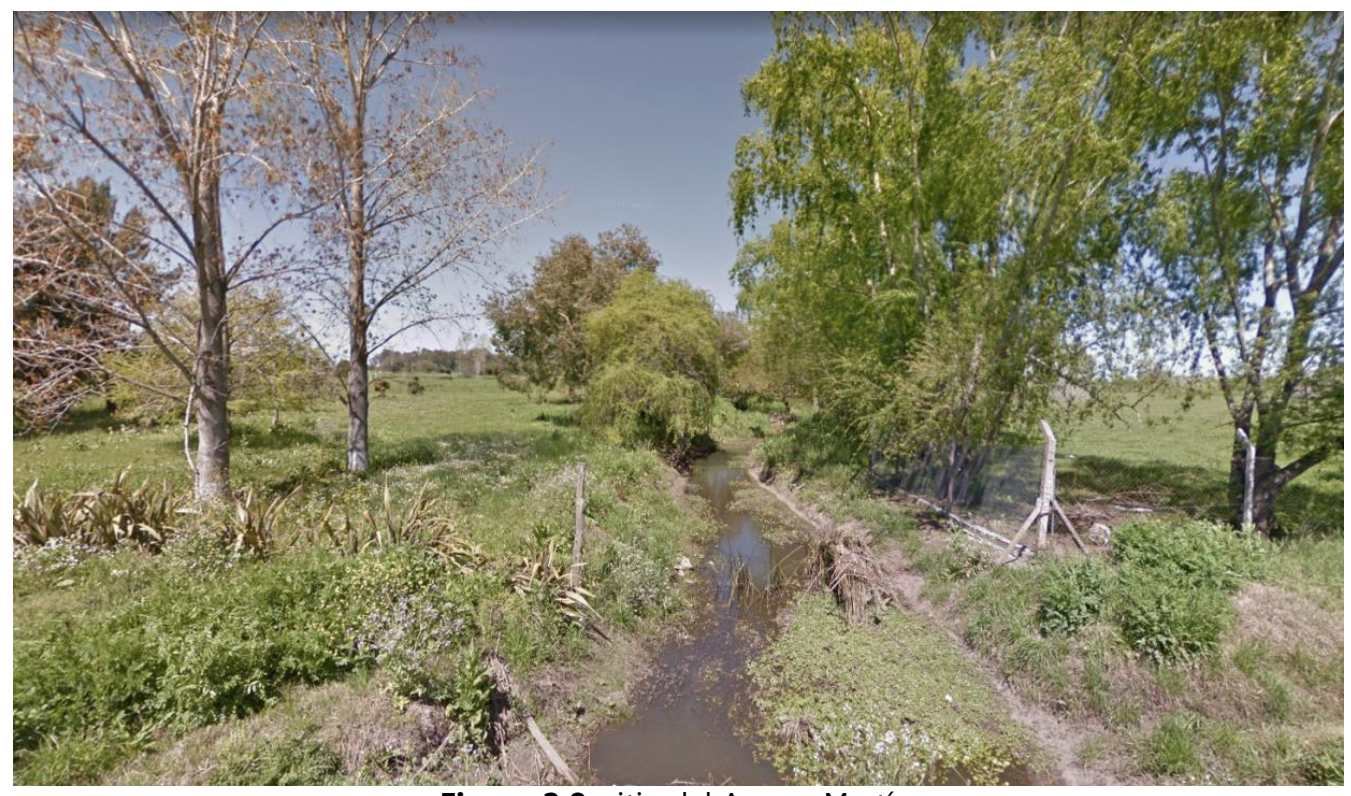

Figura 2.8: sitio del Arroyo Martín 


\section{Arroyo Rodríguez}

El arroyo Rodríguez tiene una longitud de $22 \mathrm{~km}$, la naciente está conformada por la confluencia de tres cursos de carácter transitorio, en cotas cercanas a los 27 y 22,5 msnm, en la localidad de Gorina. Este arroyo, de segundo orden, atraviesa áreas suburbanas hallándose expuesto a diferentes fuentes de contaminación. En las cabeceras se encuentra expuesto mayormente a actividades agrícolas-ganaderas. En la zona media recibe tanto aportes urbanos como de un frigorífico y aguas abajo el impacto es mayormente urbano, causado principalmente por descargas domiciliarias.

En este arroyo se seleccionó un sitio de muestreo definido como sitio de Alto Impacto Urbano. Este sitio se localiza aguas abajo de la descarga de un frigorífico y recibe también efluentes domiciliarios (Figuras 2.7 y 2.10 ).

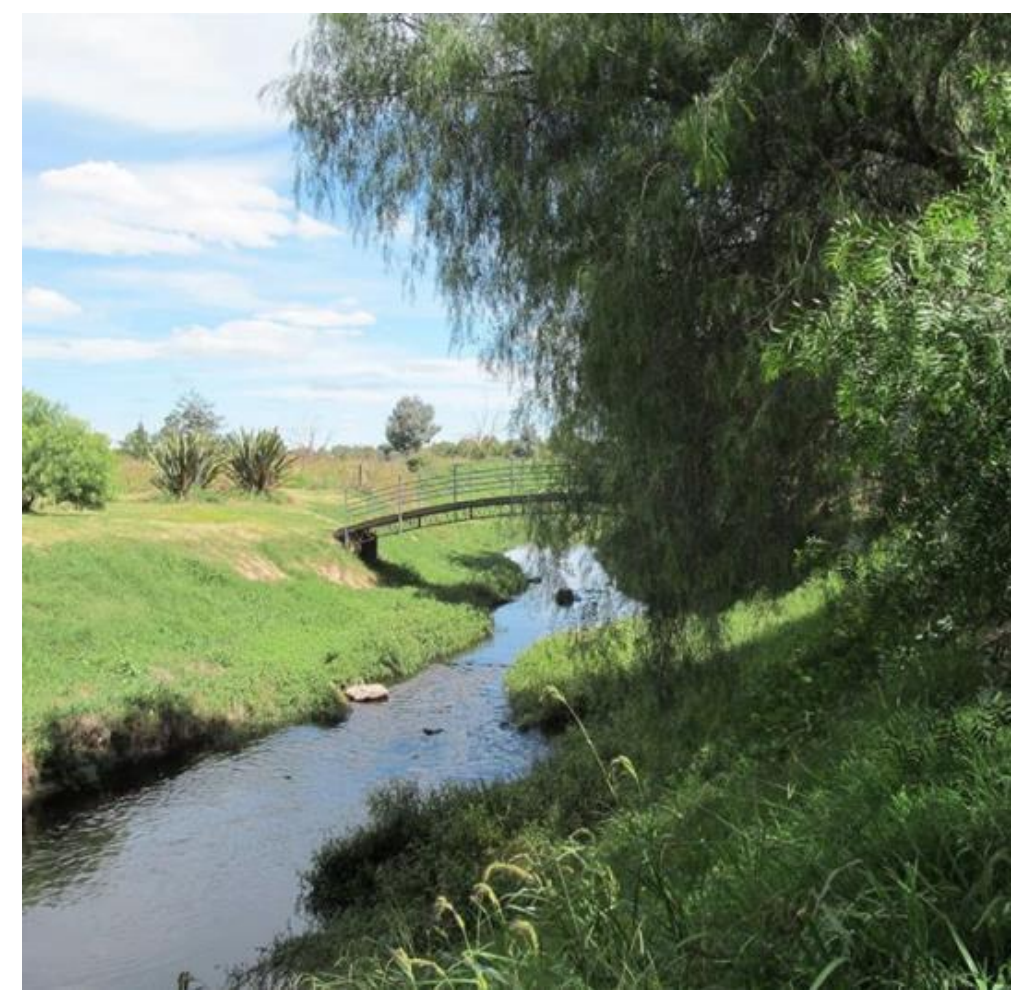

Figura 2.9: sitio del Arroyo Rodriguez

\section{Arroyo Don Carlos}

Tiene una extensión de $4 \mathrm{~km}$ y un rumbo S-N, a partir de la localidad de Gonnet se encuentra parcialmente entubado y luego está canalizado hasta desembocar en el arroyo Rodríguez. A lo largo de su recorrido el arroyo se ve afectado por diferentes impactos antropogénicos tales como actividad agrícola, efluentes domésticos e industriales y obras hidraúlicas. 
En este arroyo se seleccionaron 2 sitios de muestreo uno con un bajo impacto urbano, y el otro con un alto impacto urbano (Figura 2.7).

El sitio con mayor impacto se encuentra expuesto a descargas domiciliarias ya que atraviesa una zona urbanizada. La vegetación riparia arbórea es abundante y las macrófitas son escasas representadas en su mayoría por Sagittaria montevidensis Cham \& Schltdl. ssp montevidensis (Figura 2.10).

El sitio de bajo impacto se encuentra aguas arriba del sitio tratamiento, presenta escasa vegetación riparia arbórea y macrófitas.

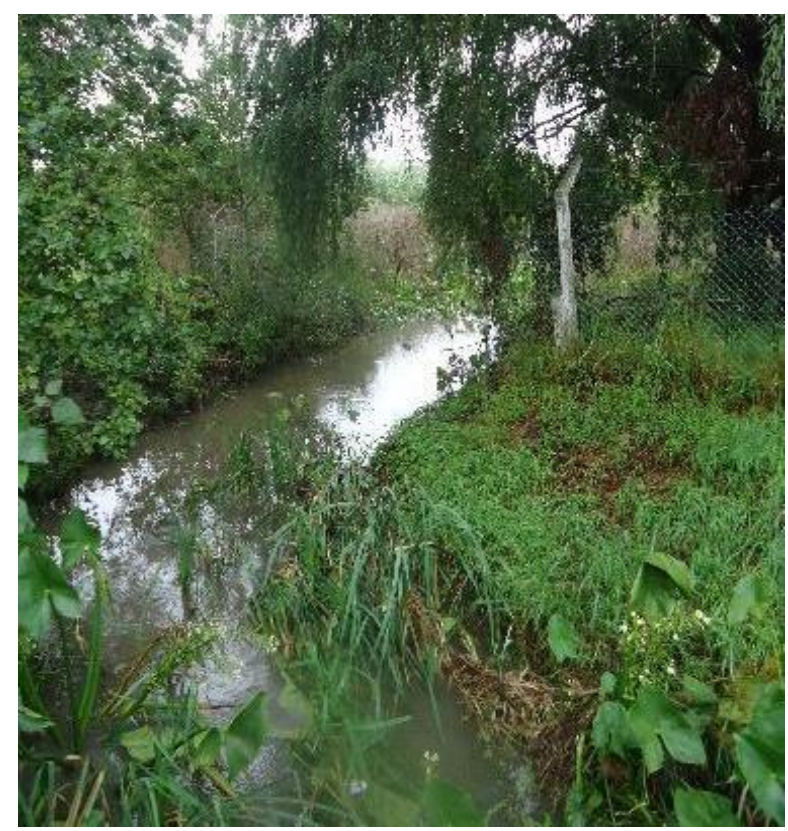

\section{Arroyo del Gato}

Se extiende por una distancia de $15 \mathrm{~km}$. Atraviesa el casco urbano de la ciudad de La Plata por el sector suroeste y desemboca en el estuario del Río de La Plata mediante una canalización que comienza en la localidad de Ringuelet. En el sector superior del arroyo Del Gato se desarrolla un área suburbana, con baja densidad poblacional, donde prevalecen actividades primarias (horticultura y floricultura) e industriales. En el sector medio hay un incremento significativo de la urbanización y de la densidad de población, además de un mayor número de industrias, actividades de servicios y barrios de viviendas precarias instalados próximos al cauce del arroyo. El sector inferior corresponde al tramo canalizado y con escasa población (Bazán et al 2011)

En este arroyo se seleccionó un sitio de muestreo expuesto a un Bajo Impacto Urbano (Figuras 2.7 y 2.11). El sitio corresponde a un área periurbana, con un impacto agrícola moderado, causado por la contaminación difusa proveniente de los 
invernaderos. La vegetación riparia arbórea es escasa, representada por S. humboldtiana Willd. En cuanto a la vegetación acuática, se destaca la presencia de la macrófita sumergida Egeria densa Planch.

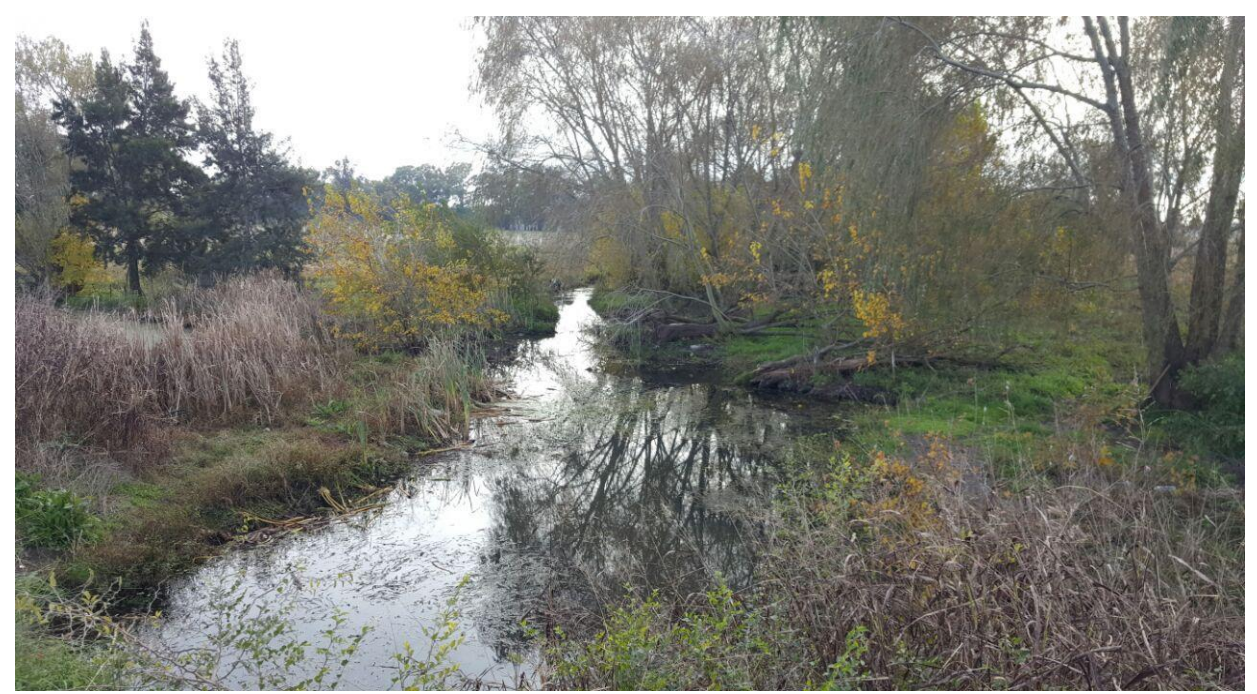

Figura 2.11: sitio del arroyo del Gato

\section{Arroyo Pérez}

Posee una extensión de $12 \mathrm{~km}$, y tiene sus nacientes en la localidad de Abasto (a la altura de la Ruta Provincial $N^{\circ} 10$ ). En su tramo inferior, unos $3 \mathrm{~km}$ antes de su desembocadura en el arroyo del Gato, cambia su rumbo a una dirección SE-NO.

En este arroyo se seleccionó 1 sitio expuesto a un Alto Impacto Urbano (Figuras 2.7 y 2.12). Este sector del arroyo atraviesa un área periurbana (el Barrio El Retiro) y recibe descargas de efluentes domiciliarios. La vegetación riparia está cubierta mayormente por vegetación herbácea y las macrófitas se encuentran representadas mayormente por $L$. peploides (Kunth) P. H. Raven y G. spilantoides (D. Don ex Hook. \& Arn.) DC y por S. montevidensis Cham \& Schltdl. ssp montevidensis.

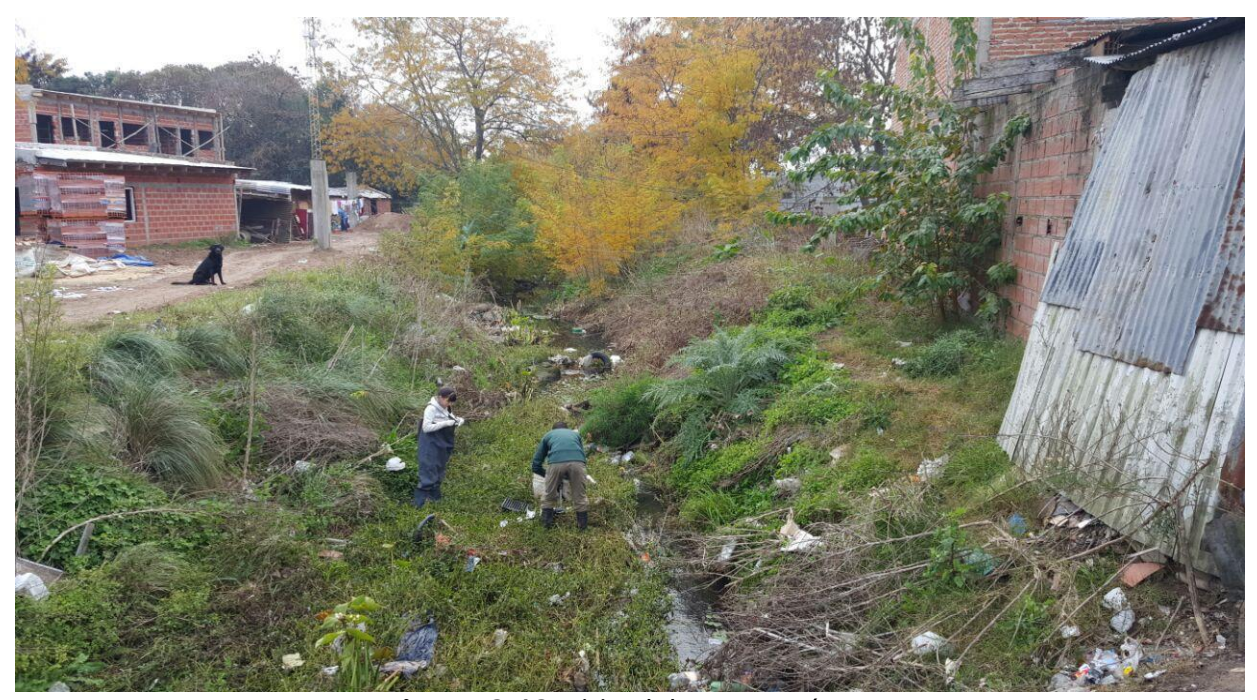

Figura 2.12: sitio del Arroyo Pérez. 
Tabla 2.2: medias ( \pm desvío estándar) de los parámetros físico-químicos y concentraciones de nutrientes medidos en los sitios de muestreo durante las experiencias ( $\mathrm{n}=9$; en el caso de Del Gato y Rodriguez $\mathrm{n}=15$ ). Se indican también la localización y las experiencias en las que se utilizaron los sitios.

\begin{tabular}{|c|c|c|c|c|c|c|}
\hline \multirow[b]{3}{*}{ Arroyos } & \multicolumn{6}{|c|}{ Impacto Urbano } \\
\hline & \multicolumn{3}{|c|}{ Menor Impacto } & \multicolumn{3}{|c|}{ Mayor Impacto } \\
\hline & Don Carlos & Del Gato & Martín & Don Carlos & Perez & Rodriguez \\
\hline Localización sitios & $\begin{array}{l}34^{\circ} 54^{\prime} 8.74^{\prime \prime S} \\
58^{\circ} 1 ' 35.50^{\prime \prime O}\end{array}$ & $\begin{array}{c}34^{\circ} 55^{\prime} 21,93 " \mathrm{~S} \\
58^{\circ} \text { ' } 58,89^{\prime \prime} \mathrm{O}\end{array}$ & $\begin{array}{c}34^{\circ} 55^{\prime} 21.27^{\prime \prime S} \\
58^{\circ} 5^{\prime} 1.98^{\prime \prime O}\end{array}$ & $\begin{array}{l}34^{\circ} 53^{\prime} 40.30^{\prime \prime} \mathrm{S} \\
58^{\circ} 1 ' 22.76^{\prime \prime} \mathrm{O}\end{array}$ & $\begin{array}{l}34^{\circ} 57^{\prime} 52.22^{\prime \prime} \mathrm{S} \\
58^{\circ} 017.07^{\prime \prime O}\end{array}$ & $\begin{array}{l}34^{\circ} 53^{\prime} 24,85 \text { "S } \\
58^{\circ} 2 ' 56,07^{\prime \prime} \mathrm{O}\end{array}$ \\
\hline $\begin{array}{l}\text { Experiencia en la que se } \\
\text { utilizó }\end{array}$ & Translocación & $\begin{array}{l}\text { Translocación y } \\
\text { colonización }\end{array}$ & Translocación & Translocación & Translocación & $\begin{array}{l}\text { Translocación y } \\
\text { colonización }\end{array}$ \\
\hline Temperatura $\left({ }^{\circ} \mathrm{C}\right)$ & $12,48( \pm 0,99)$ & $10,03( \pm 2,24)$ & $13,25( \pm 2,82)$ & $12,03( \pm 0,61)$ & $12,42( \pm 1,09)$ & $14,93( \pm 3,02)$ \\
\hline pH & $8,08( \pm 0,24)$ & $7,60( \pm 0,63)$ & $7,29( \pm 0,44)$ & $7,88( \pm 0,31)$ & $7,70( \pm 0,38)$ & $7,86( \pm 0,34)$ \\
\hline Conductividad ( $\mu \mathrm{S} \mathrm{cm}^{-1}$ ) & $782,92( \pm 70,55)$ & $523,83( \pm 344,13)$ & $306,25( \pm 175,81)$ & $781,33( \pm 66,17)$ & $611,42( \pm 63,08)$ & $1055,28( \pm 328,36)$ \\
\hline OD (mg L-1) & $4,21( \pm 0,71)$ & $7,14( \pm 1,49)$ & $6,03( \pm 2,97)$ & $5,17( \pm 3,03)$ & $7,05( \pm 2,69)$ & $5,43( \pm 1,72)$ \\
\hline OD (\%) & $40,82( \pm 6,76)$ & $66,60( \pm 17,77)$ & $58,22( \pm 26,989$ & $49,78( \pm 29,48)$ & $68,52( \pm 27,34)$ & $54,83( \pm 15,43)$ \\
\hline Turbidez (UNT) & $44,2( \pm 32,42)$ & $128,67( \pm 105,36)$ & $74,89( \pm 96,3)$ & $37,33( \pm 28,27)$ & $61,66( \pm 80,88)$ & $89,24( \pm 48,96)$ \\
\hline SST (mg L-1) & $0,50( \pm 0,04)$ & $0,29( \pm 0,17)$ & $0,20( \pm 0,11)$ & $0,50( \pm 0,04)$ & $0,39( \pm 0,04)$ & $0,62( \pm 0,21)$ \\
\hline $\mathrm{N}-\mathrm{NO}_{3}^{-}\left(\mathrm{mg} \mathrm{L}^{-1}\right)$ & $0,88( \pm 0,14)$ & $0,74( \pm 0,58)$ & $0,29( \pm 0,23)$ & $1,14( \pm 0,32)$ & $1,81( \pm 0,94)$ & $0,41( \pm 0,11)$ \\
\hline $\mathrm{N}-\mathrm{NH}_{4}{ }^{+}\left(\mathrm{mg} \mathrm{L}^{-1}\right)$ & $1,28( \pm 0,74)$ & $0,18( \pm 0,11)$ & $0,07( \pm 0,06)$ & $0,70( \pm 0,80)$ & $0,25( \pm 0,06)$ & $1,00( \pm 0,63)$ \\
\hline PRS (mg L-1) & $0,42( \pm 0,06)$ & $0,39( \pm 0,24)$ & $0,60( \pm 0,08)$ & $0,39( \pm 0,01)$ & $0,62( \pm 0,22)$ & $2,57( \pm 0,96)$ \\
\hline $\mathrm{DBO}_{5}\left(\mathrm{mg} \mathrm{L}^{-1}\right)$ & $7,00( \pm 4,58)$ & $7,40( \pm 5,27)$ & $10,50( \pm 1,29)$ & $11,00( \pm 2,83)$ & $12,00( \pm 4,36)$ & $32,80( \pm 25,65)$ \\
\hline DQO (mg L-1) & $14,33( \pm 2,08)$ & $18,33( \pm 5,05)$ & $24,75( \pm 16,34)$ & $24,00( \pm 2,83)$ & $20,00( \pm 9,17)$ & $54,00( \pm 25,11)$ \\
\hline
\end{tabular}




\section{Impacto agrícola}

Los siguientes arroyos y sitios se escogieron para evaluar el efecto del impacto agrícola en el ensamble de diatomeas. Los parámetros fisicoquímicos, las concentraciones de agroquímicos en sedimentos, la ubicación y el tipo de experiencia para los que fueron escogidos se detallan en la Tabla 2.3.

\section{Arroyo el Pescado}

Es un curso de agua permanente que tiene su naciente en el partido de La Plata, entre las localidades de Olmos y Etcheverry. La cuenca ocupa una superficie aproximada de $625 \mathrm{~km}^{2}$. Tradicionalmente presentaba un uso del suelo ganadero sobre pasturas naturales, tendencia que durante las últimas décadas fue cambiando hacia el reemplazo progresivo por el cultivo de soja (Mugni 2009).

Sitio Bajo Impacto Agrícola: ubicado en la localidad de Poblet, sobre ruta 36. Se encuentra en un área donde se desarrolla agricultura intensiva, sin embargo, en este sitio existe una franja sin cultivar, cubierta por vegetación herbácea, entre el cultivo y las márgenes del arroyo (Figura 2.13). El cauce del arroyo fue rectificado y profundizado. Las macrófitas son escasas, representadas principalmente por L. peploides (Kunth) P. H. Raven del tipo flotante, y P. punctatum Elliott del tipo emergente. En algunas ocasiones de muestreo se observó la presencia de huellas de ganado.

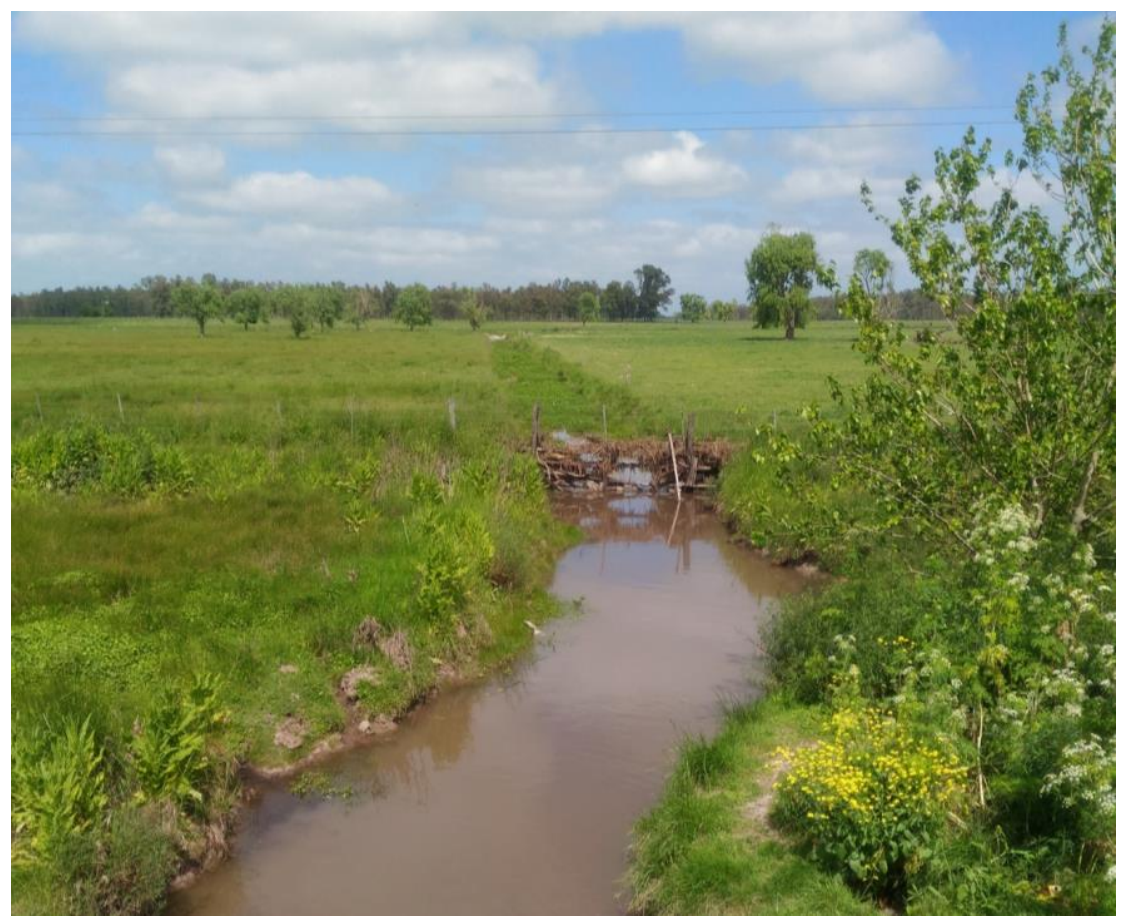

Figura 2.13: sitio de bajo impacto agrícola del arroyo El Pescado 
Sitio Alto Impacto Agrícola: ubicado en la localidad de Olmos, sobre ruta 36, en un área donde se desarrolla agricultura intensiva. En este sitio, el arroyo atraviesa una explotación agrícola de 110 ha, dividida en dos parcelas por el cauce, donde se agricultura con rotación de cultivos (maíz, soja y trigo/soja). Aguas arriba de esta explotación se llevan a cabo cultivos hortícolas (Figura 2.14). Los cultivos se extienden hasta unos pocos metros del arroyo. La vegetación riparia herbácea es abundante y la presencia de macrófitas también. Predominan manchones de L. peploides (Kunth) P., P. punctatum Elliot, G. spilanthoides (D. Don ex Hook. \& Arn.), y S. montevidensis Cham \& Schltdl. ssp montevidensis.

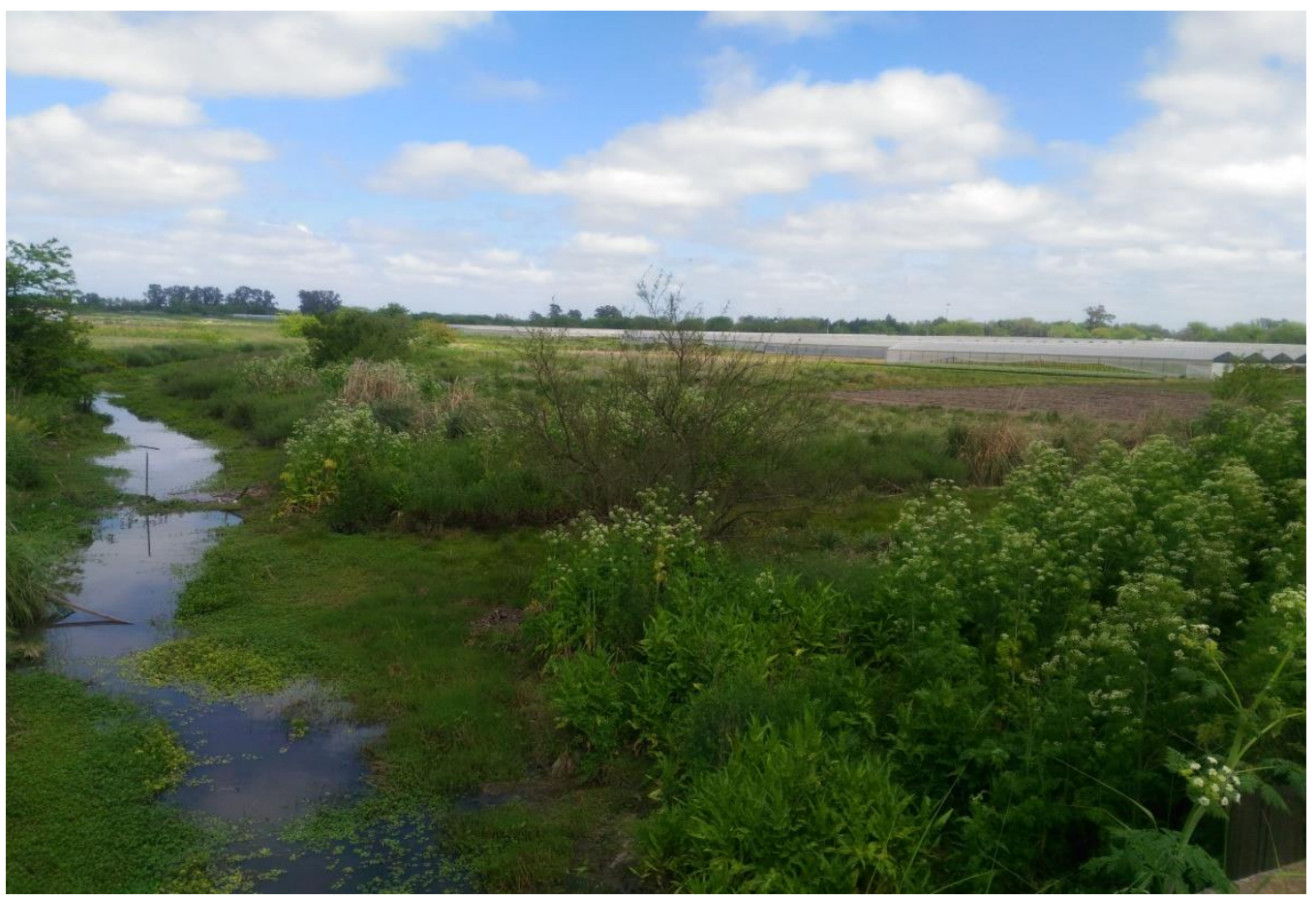

Figura 2.14: sitio de alto impacto agrícola del Arroyo El Pescado 


\section{Arroyo Carnaval}

Este arroyo y sus tributarios pertenecen a una cuenca periurbana de $105 \mathrm{~km}^{2}$ de superficie, cercana a la ciudad de La Plata. El canal principal del arroyo se origina en la laguna García y tiene una longitud de 14,5 km y una dirección de escurrimiento SO-NE. En la cuenca alta y media, los principales usos del suelo son la horticultura, floricultura y cultivos de soja, maíz y trigo (Figura 2.15). La mayor densidad de población junto con algunas industrias se concentra en la cuenca baja.

Se seleccionó un sitio de estudio localizado en la cuenca alta, donde el arroyo atraviesa un campo de soja en el que se emplean agroquímicos periódicamente. El mismo se utilizó para evaluar la toxicidad del sedimento. Los datos de los parámetros físico-químicos, las concentraciones de nutrientes medidas en el agua y la concentración de agroquímicos en sedimento se detallan en la Tabla 2.3.

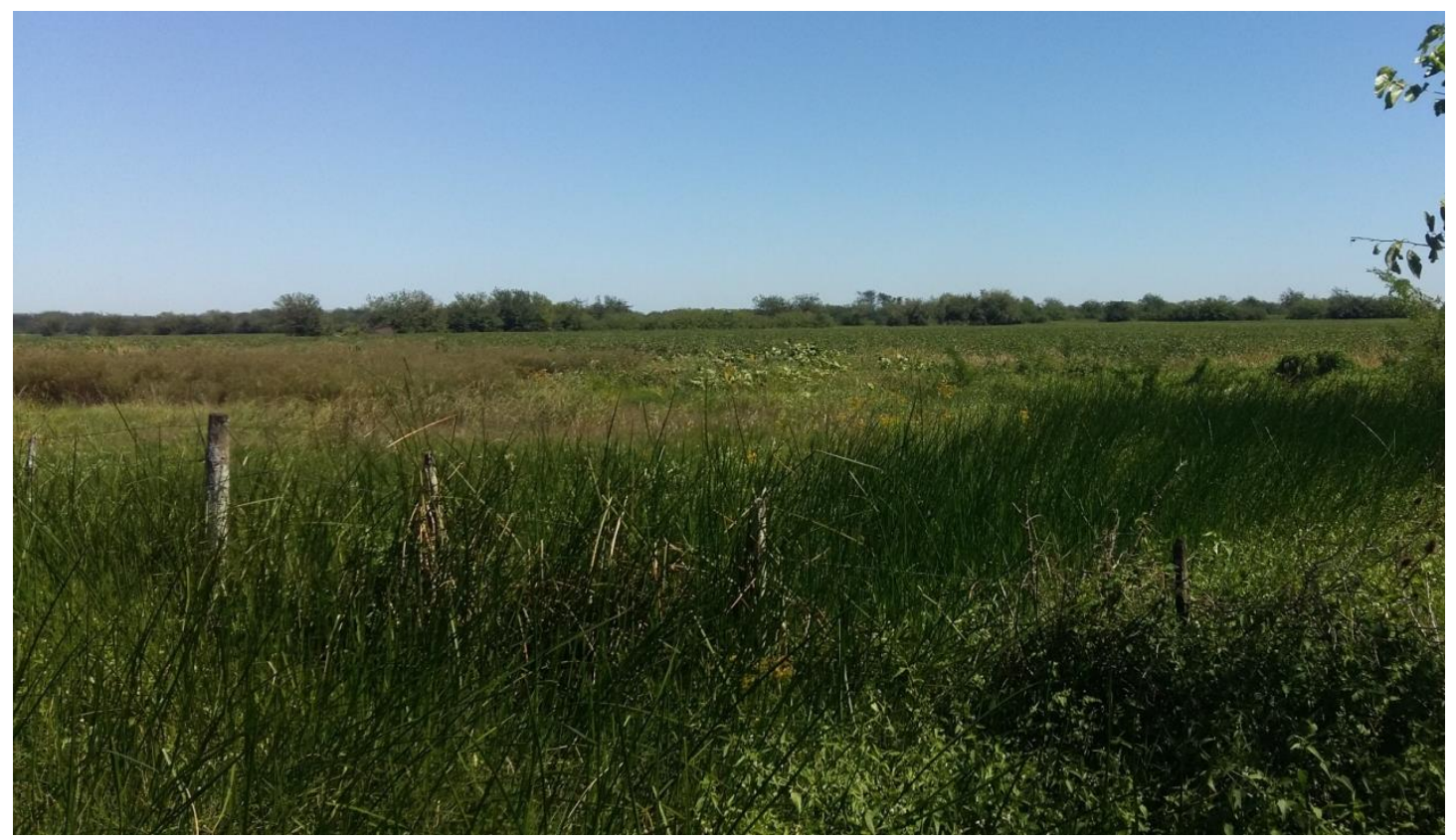

Figura 2.15: sitio de muestreo del Arroyo Carnaval 
Tabla 2.3: valores medios ( \pm desvío estándar) de las concentraciones de agroquímicos medidos en el sedimento $(n=3)$ y de los parámetros físico-químicos y concentraciones de nutrientes medidos en agua de los sitios de muestreo durante las experiencias ( $n . d$. = no detectados) ( $n=14$ los sitios del arroyo Pescado; $\mathrm{n}=3$ en arroyo Carnaval). Se indican también la localización y las experiencias en las que se utilizaron los sitios.

\begin{tabular}{|c|c|c|c|c|}
\hline & \multicolumn{3}{|c|}{ Impacto Agrícola } \\
\hline & & \multirow{2}{*}{$\begin{array}{l}\text { Bajo Impacto } \\
\text { El Pescado }\end{array}$} & \multicolumn{2}{|c|}{ Alto Impacto } \\
\hline & Arroyos & & El Pescado & Carnaval \\
\hline & \multicolumn{4}{|l|}{ Localización } \\
\hline & $\begin{array}{l}\text { Experiencia en la que se } \\
\text { usó }\end{array}$ & $\begin{array}{l}\text { Translocación y } \\
\text { colonización }\end{array}$ & $\begin{array}{l}\text { Translocación y } \\
\text { colonización }\end{array}$ & $\begin{array}{l}\text { Ensayo } \\
\text { elutriados }\end{array}$ \\
\hline \multirow{3}{*}{ 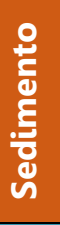 } & Endosulfán I (mg/kg) & $0,03( \pm 0,04)$ & $0,11( \pm 0,02)$ & 0,35 \\
\hline & Endosulfán II (mg/kg) & n.d. & $0,002( \pm 0,003)$ & 0,15 \\
\hline & $\begin{array}{l}\text { Endosulfán sulfato } \\
\text { (mg/kg) }\end{array}$ & n.d. & $0,08( \pm 0,07)$ & 0,1 \\
\hline \multirow{12}{*}{$\frac{\mathbb{8}}{3}$} & Temperatura $\left({ }^{\circ} \mathrm{C}\right)$ & $22,3( \pm 3,96)$ & $20,53( \pm 1,43)$ & $17,08( \pm 0,01)$ \\
\hline & pH & $6,85( \pm 0,26)$ & $6,46( \pm 0,29)$ & $6,37( \pm 0,03)$ \\
\hline & Conductividad ( $\mu \mathrm{S} \mathrm{cm}^{-1}$ ) & $443( \pm 157)$ & $267,4( \pm 7,34)$ & $111,2( \pm 0,00)$ \\
\hline & $O D\left(\mathrm{mg} \mathrm{L}^{-1}\right)$ & $4,64( \pm 1,82)$ & $2,12( \pm 0,96)$ & $8,17( \pm 0,21)$ \\
\hline & OD (\%) & $39,26( \pm 13,13)$ & $20,36( \pm 4,87)$ & $87,37( \pm 2,19)$ \\
\hline & Turbidez (UNT) & $320,4( \pm 103,3)$ & $126,3( \pm 76,1)$ & $\begin{array}{c}134,33( \pm \\
0,57)\end{array}$ \\
\hline & SST (mg L-1) & $0,29( \pm 0,11)$ & $0,17( \pm 0,05)$ & $0,073( \pm 0,00)$ \\
\hline & $\mathrm{N}-\mathrm{NO}_{3}{ }^{-}\left(\mathrm{mg} \mathrm{L}^{-1}\right)$ & $0,03( \pm 0,01)$ & $0,027( \pm 0,01)$ & $0,27( \pm 0,32)$ \\
\hline & $\mathrm{N}-\mathrm{NO}_{2}^{-}\left(\mathrm{mg} \mathrm{L}^{-1}\right)$ & $0,01( \pm 0,005)$ & $0,004( \pm 0,004)$ & $0,02( \pm 0,01)$ \\
\hline & $\mathrm{N}-\mathrm{NH}_{4}{ }^{+}\left(\mathrm{mg} \mathrm{L}^{-1}\right)$ & $0,06( \pm 0,02)$ & $0,03( \pm 0,02)$ & $0,09( \pm 0,04)$ \\
\hline & NID $\left(\mathrm{mg} \mathrm{L}^{-1}\right)$ & $0,11( \pm 0,04)$ & $0,07( \pm 0,02)$ & $0,37( \pm 0,33)$ \\
\hline & PRS (mg L-1) & $0,63( \pm 0,35)$ & $0,77( \pm 0,20)$ & $1,08( \pm 0,35)$ \\
\hline
\end{tabular}



diatomeas bentónicas sobre sustratos duros artificiales en arroyos con diferentes niveles de impacto urbano y agrícola.

\subsection{Introducción}

El proceso de colonización del biofilm, particularmente del ensamble de diatomeas, depende de los múltiples factores ambientales a los que se encuentran expuestas. El desarrollo de estas comunidades está condicionado por la naturaleza del sustrato donde se desarrollan (Potapova y Charles 2005), la velocidad de la corriente (Stevenson, 1993) la concentración de nutrientes (Biggs et al 1998), la temperatura del cuerpo de agua (De Nicola, 1996) y la exposición al pastoreo (Steinman, 1996), entre otros.

El establecimiento inicial de un taxón en un ensamble bentónico está determinado principalmente por su capacidad de colonización (Ács y Kiss, 1993), mientras que el éxito del establecimiento se ve afectado por algunas características morfológicas específicas como pueden ser el tamaño de la célula y su biovolumen (Ács y Kiss, 1993; Snoeijs et al., 2002; Kókai et al., 2015) o por características de adaptación ecológica tales como la demanda de nutrientes o la tolerancia a las perturbaciones físicas (Passy, 2007; Berthon et al., 2011; Rimet y Bouchez, 2012a, b; Stenger-Kovács et al., 2013; B-Béres et al., 2014). Es debido a esto que el proceso de colonización del ensamble de diatomeas puede caracterizarse de forma robusta a través del uso de variables taxonómicas, así como también a través del uso de rasgos funcionales (B-Béres et al 2016, Luckas et al 2018), y conocer la dinámica de su desarrollo puede aportar información sobre los impactos antropogénicos vinculados al cuerpo de agua.

En la llanura pampeana de Argentina los efectos de las altas concentraciones naturales de nutrientes en la biota se intensifican por las fuertes presiones antropogénicas (Giorgi et al., 2005; Gómez et al., 2011; Rodrigues Capítulo et al., 2010). El biofilm epipélico que se desarrolla en estos arroyos se encuentra dominado por diatomeas bentónicas, y su desarrollo está muy influenciado por el enriquecimiento de nutrientes y el contenido de materia orgánica, particularmente en los arroyos de zonas urbanas (Gómez y Licursi 2001; Licursi y Gómez 2002, Licursi et al 2015, Cochero et al 2015), donde los aumentos de nutrientes en el agua se vinculan generalmente con incrementos en la biomasa de algas bentónicas (Biggs 2000, Dodds, 2006; Smith y Schindler, 2009; Sabater et al., 2011). 
Un aumento en la concentración de nutrientes trae como consecuencias diversos efectos en la riqueza, equitabilidad y diversidad de los ensambles de diatomeas (Biggs 2002). Existen algunos estudios que reportan un aumento de estos índices frente a la adición de nutrientes (ej: Pringle 1990, McCormick y Stevenson 1991), otros que no encuentran variación de los mismos en esas circunstancias (Stevenson et al 1991), e incluso estudios que reportan una disminución de los índices (Ndiritu et al., 2006; Ní Chatháin y Harrington, 2008). En los rasgos funcionales de los ensambles, los aumentos de nutrientes generalmente están asociados a un aumento de la proporción de diatomeas móviles (ej: Berthon 2011, Cochero et al 2015, Licursi et al 2015, Nicolosi Gelis et al 2020), y una disminución del gremio de bajo perfil (Berthon et al 2011, Passy 2007, Stenger Kóvacs et al 2013).

A los problemas causados por el aumento de nutrientes y cargas orgánicas, se le suma el ingreso y persistencia de los pesticidas en los ambientes acuáticos que se encuentran en zonas agrícolas (Rimet y Bouchez 2011).Varios estudios han demostrado que el biofilm expuesto a agroquímicos presenta menores valores de clorofila-a (Rohr and Crumrine 2005; Guasch et al. 1997; Tlili et al. 2010; Ricart et al. 2010; Vera et al 2010), que a su vez se ve representado por cambios en la composición de los grupos autotróficos del biofilm (Bérard and Benninghoff 2001; Leboulanger et al. 2001; Seguin et al. 2001). Asimismo, los agroquímicos pueden afectar el crecimiento y la fisiología de las diatomeas bentónicas, así como también su estructura y diversidad (Debenest et al., 2010; DeLorenzo et al., 2001; Morin et al., 2009; Tlili et al 2010), ocasionando muchas veces la pérdida de especies sensibles (Schmitt-Jansen and Altenburger, 2005; Magnusson et al., 2012). Estos cambios en estructura y diversidad vinculados a la contaminación por agroquímicos se pueden evidenciar a través de los rasgos funcionales del ensamble de diatomeas (ej: gremios ecológicos, formas de vida, clases de tamaño) (Rimet et al 2011, Bayona et al 2014, Wood et al 2014; Rémy et al 2013).

El proceso de colonización del biofilm y particularmente la dinámica de colonización de las diatomeas ha sido ampliamente estudiada (Hoagland et al 1982; Eulin and Le Cohu 1998; Acs y Kiss 1993; Morin et al 2007; Plenkovic-Morajt et al 2008), así como también ha sido abordado desde el estudio de los rasgos funcionales del ensamble (B-beres et al 2016, Luckas 2018, Rimet 2011, Morin et al 2007). Sin embargo, hay pocos estudios que vinculen la dinámica de la colonización a diferentes niveles de impactos urbanos (Duong et al. 2007), y no incluye las etapas tempranas de ese desarrollo, relevante para los estudios de recuperación de la comunidad luego de un disturbio. Similarmente, en los 
estudios existentes en arroyos impactados por agroquímicos, las métricas funcionales en el ensamble de diatomeas durante el proceso de colonización sólo fueron contempladas en etapas avanzadas del desarrollo (Rimet y Bouchez 2011). Estudiar las etapas iniciales de colonización bajo distintas condiciones de la calidad del agua es relevante para evaluar las respuestas tempranas de las diatomeas a los cambios en la calidad del agua como consecuencia de los disturbios bajo distintos usos del suelo.

\subsection{Objetivos e hipótesis}

El objetivo general de este capítulo es caracterizar la colonización temprana del ensamble de diatomeas en el biofilm desarrollado sobre sustrato artificial duro, en arroyos con diferentes impactos antropogénicos. Particularmente, en arroyos urbanos con distintas concentraciones de nutrientes (fósforo y nitrógeno) y materia orgánica, y en arroyos de zonas agrícolas con distintas concentraciones de agroquímicos en los sedimentos.

\section{2.a Objetivos específicos}

-Analizar la importancia de las diatomeas dentro del grupo autotrófico en el proceso de colonización temprana sobre sustratos duros en relación a los tipos (urbano/agrícola) y niveles (alto/bajo) de impactos antropogénicos, a través del estudio de la biomasa (clorofilaa), y la densidad y tasas de crecimiento de los principales grupos algales.

- Analizar la dinámica de colonización del ensamble de diatomeas a través del estudio de la riqueza, diversidad de Shannon, Índice de Diatomeas Pampeanas, gremios ecológicos y clases de tamaño; en relación a los tipos (urbano/agrícola) y niveles de impactos (alto/bajo) antropogénicos.

\section{2.b Hipótesis y predicciones}

La hipótesis principal de este estudio es que la estructura del biofilm y de los ensambles de diatomeas que coloniza sustratos artificiales duros bajo distintas condiciones de calidad de agua, sufren cambios en las primeras etapas de colonización vinculadas a los diferentes tipos y niveles de impacto.

Las predicciones para dicha hipótesis son que en los arroyos con impactos urbanos:

- La biomasa (clorofila-a) total del biofilm y la densidad de los grandes grupos algales serán mayores en el sitio con concentraciones de nutrientes y materia orgánica más altas, así como sus tasas de incremento durante el desarrollo temprano del biofilm. 
- Los índices de diversidad y la riqueza del ensamble de diatomeas aumentarán con el tiempo y serán mayores en los sitios de menor impacto. Al final de la experiencia el IDP será mayor en el sitio de mayor impacto.

- La proporción de diatomeas móviles y de alto perfil será mayor en los sitios de mayor impacto. Las diatomeas de bajo perfil representarán la menor proporción del ensamble en todos los sitios; sin embargo, su proporción será aún más baja en los sitios con mayores concentraciones de nutrientes.

- Habrá más diatomeas de tallas grandes en los sitios de mayor impacto. Los tamaños más pequeños serán los primeros en asentarse, dejando luego lugar a formas más grandes.

Mientras que en los arroyos expuestos a impactos agrícolas:

- La biomasa (clorofila-a) del biofilm y la densidad de grupos algales serán menores en el sitio de mayor impacto, así como sus tasas de aumento durante el desarrollo.

- Los índices de diversidad y la riqueza de las diatomeas aumentarán con el tiempo y serán mayores en los sitios de menor impacto. Al final de la experiencia el IDP será mayor en el sitio de mayor impacto.

- La proporción de diatomeas móviles será mayor, mientras que la proporción de alto perfil será menor en los sitios de mayor impacto. Las diatomeas de bajo perfil representarán la menor proporción del ensamble en todos los sitios; sin embargo, su proporción será mayor en los sitios de mayor impacto.

- Habrá más diatomeas de tallas grandes en los sitios de mayor impacto. Los tamaños más pequeños serán los primeros en asentarse, dejando luego lugar a formas más grandes.

\subsection{Materiales y métodos}

\section{3.a Diseño experimental}

Se realizaron dos experiencias de colonización, una en arroyos con impacto urbano y otra en arroyos con impacto agrícola, siguiendo la metodología detallada en el capítulo 2, apartado 2.1.6.

En la experiencia de impacto urbano, las muestras se colectaron a los tiempos $0,5 \mathrm{~h}$ (T0), 3hrs (T1), 6hrs (T2), 24hrs (T3), 48hrs (T4) y 168hrs (una semana, T5) en julio del 2017. 
Mientras que en la experiencia de impacto agrícola, las muestras se colectaron a los tiempos 0,5h (T0), 3hrs (T1), 48hrs (T2), 168 hs (una semana, T3) y 336 hs (dos semanas, T4) en noviembre del 2018.

En el contexto de experiencias de colonización por diatomeas, resulta una ventaja trabajar con sustratos artificiales introducidos en el cuerpo de agua ya que permiten el monitoreo tanto del desarrollo inicial como de la sucesión del biofilm (Nenadović et al 2005), por lo que se utilizó ese sustrato en ambas experiencias. En cada muestreo los sustratos artificiales (vidrios esmerilados) fueron retirados utilizando pinzas y colocados en tubos de vidrio que contenían $6 \mathrm{ml}$ de agua destilada con formol al $4 \%$ o $6 \mathrm{ml}$ de acetona (sólo en el caso de las muestras destinadas a la medición de la clorofila-a del biofilm). Para cada variable medida se colectaron 3 réplicas, cada una de ellas conformada por tres sustratos (submuestras).

\section{3.b Sitios de muestreo}

\section{Impacto urbano}

Se seleccionaron dos sitios de muestreo en arroyos urbanos que atraviesan el partido de La Plata (Mapa y características de los sitios en el Cap. 2.2.1) : un sitio con bajo impacto urbano en el arroyo Del Gato (denominado "BIU", ubicación: 34 58'26,58 "S / 58 3'13,13" O) y un sitio expuesto a un alto impacto urbano localizado en el arroyo Rodríguez (denominado "AlU", ubicación: 34 53'24,85 "S / 58²'56,07" O). El grado de impacto urbano fue definido en base a las concentraciones de nutrientes, oxígeno disuelto y sus demandas $\left(\mathrm{DBO}_{5}\right.$ y $\left.\mathrm{DQO}\right)$, y los usos del suelo (\% de cobertura del suelo impermeabilizado). Para más detalles sobre las características de los sitios, ver capítulo de Materiales y métodos sección 2.2.2.

\section{Impacto agrícola}

Se seleccionaron dos sitios de muestreo en arroyos pertenecientes a la cuenca El Pescado y expuestos a diferentes niveles de impacto agrícola (Mapa y características de los sitios en el Cap. 2.2.1): un sitio de menor impacto agrícola, denominado "Bajo impacto agrícola (BIA) (35 3'14.92"S; $\left.57^{\circ} 58^{\prime} 37.92 " \mathrm{O}\right)$ y un sitio expuesto a un alto impacto agrícola denominado "Alto Impacto agrícola" (AIA) (35 1'32.15"S; 5759'41.18"O). El grado de impacto agrícola fue definido en base a las concentraciones de agroquímicos medidos en el sedimento de los arroyos, y los usos del suelo. Para más detalles sobre las características de los sitios, ver capítulo de Materiales y Métodos sección 2.2.2. 


\section{3.c Variables medidas}

\section{Variables fisicoquímicas}

Se midieron por triplicado, en cada sitio y fecha de muestreo oxígeno disuelto $(O D$, $\left.m g \mathrm{~L}^{-1}\right)$, temperatura $\left({ }^{\circ} \mathrm{C}\right)$, conductividad $\left(\mu \mathrm{S} \mathrm{cm}^{-1}\right), \mathrm{pH}$, sólidos totales suspendidos (STS, $m g \mathrm{~L}^{-1}$ ). Además se tomaron muestras de agua en T0 y T5 para el análisis de nutrientes, la demanda bioquímica de oxígeno (DBO) y la demanda química de oxígeno (DQO). La descripción detallada de las metodologías se encuentra en la sección 2.1.2 de Materiales y Métodos. En la experiencia de impacto agrícola, la caracterización físico-química de los sitios se realizó teniendo en cuenta las mediciones hechas tanto en cada oportunidad de muestreo de la experiencia de colonización como en las experiencias de translocación de sustratos.

\section{Análisis de pesticidas}

Para la caracterización de los sitios de la experiencia agrícola, se tomaron 6 muestras de sedimento, 3 pertenecientes al sitio BIA y 3 pertenecientes al sitio AIA. Las muestras de sedimento se tomaron con palas de acero inoxidable y se colocaron en frascos de vidrio. Las muestras se mantuvieron refrigeradas hasta su llegada al laboratorio. El procesamiento y medición estuvieron a cargo del Laboratorio de Química Ambiental de la UNLP (LAQAB). La medición se hizo siguiendo una modificación del método EPA 525.3 (2012) con cromatografía gaseosa de alta resolución (Agilent 7890N). La cuantificación se realizó mediante cálculo de factores de respuesta para estándares auténticos individuales de pesticidas organoclorados (M-525.2-CP-ASL y M-8140-03, AccuStandard, Inc.).

\section{Clorofila-a}

La recolección y el tratamiento para la extracción del pigmento de las muestras se detallan en el capítulo de materiales y métodos, apartado 2.13. En la experiencia de impacto urbano, la clorofila-a fue medida a través de cromatografía líquida de alta resolución en un equipo Shimadzu CRB - 6A. La separación se realizó con una columna de fase reversa VP-ODS/ C8/Phenyl Shimadzu con un gradiente de elución y con una relación de solventes Bomba A: Metanol/Acetato de NH4 ph: 7,2 80:20; Bomba B: Acetonitrilo/Aguas 90:10; Bomba C: Acetato de Etilo, con un flujo de 1ml/min. Los picos fueron detectados con dos detectores, un arreglo de diodos (DAD) a 430nm y 662nm y un detector de fluorescencia RF-10AXL, 430nm de excitación/600nm de emisión. En la experiencia de impacto agrícola la medición de clorofila-a se realizó mediante 
espectrofotometría, como se detalla en el capítulo de materiales y métodos, apartado 2.1.3.

Análisis de la comunidad autotrófica del biofilm

Para la extracción del biofilm, las muestras se sonicaron en un baño de ultrasonido (Cleanson), durante tres períodos de dos minutos (Romaní and Sabater, 2001). La cuantificación de la densidad de los productores de la comunidad microbentónica (tamaño $<1 \mathrm{~mm}$ ) se estimó utilizando una cámara Sedgwick-Rafter (APHA, 2012) en un microscopio óptico (Olympus BX 50) a 200X. Los taxones identificados se clasificaron en diatomeas, clorofitas, cianobacterias y euglenofitas, la bibliografía utilizada se detalla en el capítulo de Materiales y métodos, sección 2.1.4. En el caso de las diatomeas se contabilizaron por separado las diatomeas con contenido y las vacías. Los valores obtenidos para la densidad de los diferentes grupos se refirieron a superficie de sustrato artificial $\left(\mathrm{cm}^{-2}\right)$ (APHA, 2012).

\section{Ensamble de diatomeas}

Para la identificación del ensamble de diatomeas, se sonicaron las muestras de sustrato artificial para la extracción del biofilm y se prosiguió según metodología detallada en capítulo 2, sección 2.1.5.a.

Se calcularon el índice de diversidad de Shannon-Wiener $\left(\mathrm{H}^{\prime}\right.$, bits.ind-1) (Shannon and Weaver, 1949), y el Índice de Diatomeas Pampeanas (IDP; Gómez y Licursi 2001).

Las especies de diatomeas se clasificaron en los gremios ecológicos: bajo perfil, alto perfil y móvil, según Passy (2007). Los taxones de diatomeas también se asignaron a 5 categorías de tamaño (considerando el biovolumen) según Rimet y Bouchez (2012a). Para más detalle, ver capítulo 2, apartados 2.1.5.b y 2.1.5.g respectivamente.

\section{3.d Análisis estadísticos}

Las diferencias en la calidad del agua entre los dos sitios fueron analizadas mediante un análisis de la varianza (ANOVA). Las variaciones de los descriptores biológicos a lo largo de la experiencia y entre sitios fueron testeadas con un análisis de la varianza con medidas repetidas (RM-ANOVA, Sitio y Tiempo como factores). Los valores primero se transformaron en $\log (x+1)$ para garantizar la normalidad, que fue previamente evaluada por la prueba de Shapiro-Wilk (Shapiro y Wilk, 1965); la homogeneidad de la varianza se probó mediante la prueba de Cochran (Cochran, 1951). Se utilizó la prueba post hoc Student-Newman-Keuls para establecer las diferencias entre grupos, y los valores de $p$ fueron corregidos por falso positivos por la corrección de Benjamini-Hochberg (Benjamini y Yekutieli, 2001). Se calculó eta $^{2}\left(n^{2}\right)$ como una medida de tamaño del efecto y se realizaron comparaciones por pares 
para establecer si cualquier efecto significativo de los tratamientos estuvo presente por fecha (Cohen, 2013).

Las curvas de crecimiento para cada variable biológica también fueron ajustadas por regresión no lineal a uno de los siguientes modelos, en base al mejor ajuste de los datos $\left(R^{2}\right)$ :

a) lineal: $Y=R x+K$

donde $R$. pendiente y $K$ : ordenada al origen.

b) logístico: $\frac{Y=K}{1+e^{-\left(\frac{X-X 50}{b}\right)}}$

donde $Y$ : variable dependiente; $K$ : Ln de la capacidad de carga, $R$ : pendiente,$x$ la variable independiente (tiempo) $X_{50}$ el tiempo para alcanzar el $50 \%$ de la capacidad de carga.

\subsection{Resultados}

\section{4.a Impacto urbano}

\section{Parámetros fisicoquímicos}

El sitio AIU presentó valores significativamente más bajos de $\mathrm{pH}$ y de oxígeno disuelto, y significativamente más altos de conductividad que el sitio BIU ( $p<0,05$, Tabla 3.1). También en el sitio AIU hubo concentraciones promedio significativamente más altas de fósforo reactivo soluble (3: 1), fósforo total $(1,4: 1)$, nitrógeno inorgánico disuelto $(1,6: 1)$, sólidos suspendidos totales (SST; 1,5: 1), demanda bioquímica de oxígeno $(9,5: 1)$ y demanda química del oxígeno (5: 1) que el sitio BIU (ANOVA 1-vía, p <0,05; Tabla 3.1). 
Tabla 3.1: Medias ( \pm desvío estándar) de los parámetros físico-químicos medidos en el agua en los sitios AIU y BIU durante la experiencia, y el valor de significancia ( $p$-valor) obtenido del ANOVA, en negrita se marcan los casos significativos $(p<0,05)$.

\begin{tabular}{|c|c|c|c|c|}
\hline \multirow{2}{*}{\multicolumn{2}{|c|}{$\begin{array}{l}\text { Localización de los sitios de } \\
\text { muestreo }\end{array}$}} & Sitio BIU & \multicolumn{2}{|c|}{ Sitio AIU } \\
\hline & & $\begin{array}{l}34^{\circ} 55^{\prime} 21.93^{\prime \prime S} \\
58^{\circ} \text { '58.89"O }\end{array}$ & \multicolumn{2}{|c|}{$\begin{array}{c}34^{\circ} 577^{\prime} 52.48 " \mathrm{~S} \\
58^{\circ} \cdot 17.29^{\prime \prime O}\end{array}$} \\
\hline \multicolumn{2}{|c|}{ Principal uso del suelo } & Periurbano & \multicolumn{2}{|c|}{ Urbano } \\
\hline \multicolumn{2}{|c|}{$\begin{array}{l}\text { \%Porcentaje de } \\
\text { urbanización }\end{array}$} & $19,8 \%$ & \multicolumn{2}{|l|}{$27,08 \%$} \\
\hline \multirow{16}{*}{$\frac{\pi}{2}$} & Temperatura $\left({ }^{\circ} \mathrm{C}\right)$ & $12,2( \pm 0,5)$ & $13,3( \pm 0, .2)$ & 0,17 \\
\hline & pH & $8,4( \pm 0,1)$ & $7.9( \pm 0.1)$ & 0.01 \\
\hline & Conductividad $\left(\mu \mathrm{S} \mathrm{cm}^{-1}\right)$ & $872,5( \pm 9)$ & $1265( \pm 10)$ & 0,02 \\
\hline & $O D\left(m g ~ L^{-1}\right)$ & $8,2( \pm 0,4)$ & $5,2( \pm 0,2)$ & 0,01 \\
\hline & OD (\%) & $79,7( \pm 4,5)$ & $51,4( \pm 2,5)$ & 0,01 \\
\hline & Turbidez (UNT) & $77( \pm 6,8)$ & $88,3( \pm 12)$ & 0,36 \\
\hline & SST (mg L-1) & $0,4( \pm 0)$ & $0,6( \pm 0)$ & 0,02 \\
\hline & Velocidad (cm s $\left.{ }^{-1}\right)$ & $2,7( \pm 1,1)$ & $2,4( \pm 0,9)$ & 0,74 \\
\hline & PRS (mg L-1) & $0,51( \pm 0,21)$ & $1,51( \pm 0,71)$ & 0,02 \\
\hline & PT (mg L-1) & $0,83( \pm 0,42)$ & $1,15( \pm 0,05)$ & 0,04 \\
\hline & $\mathrm{N}-\mathrm{NO}_{3}^{-}\left(\mathrm{mg} \mathrm{L}^{-1}\right)$ & $0,55( \pm 0,2)$ & $0,47( \pm 0,04)$ & 0,06 \\
\hline & $\mathrm{N}-\mathrm{NO}_{2}^{-}\left(\mathrm{mg} \mathrm{L}^{-1}\right)$ & $0,12( \pm 0,12)$ & $0,12( \pm 0,07)$ & 0,99 \\
\hline & $\mathrm{N}-\mathrm{NH}_{4}{ }^{+}\left(\mathrm{mg} \mathrm{L}^{-1}\right)$ & $0,17( \pm 0,24)$ & $0,79( \pm 0,77)$ & 0,39 \\
\hline & NID (mg L-1) & $0,84( \pm 0,17)$ & $1,38( \pm 0,73)$ & 0,01 \\
\hline & $\mathrm{DBO}_{5}\left(\mathrm{mg} \mathrm{L}^{-1}\right)$ & $8,0( \pm 1,0)$ & $78,0( \pm 2,5)$ & 0,04 \\
\hline & DQO (mg L-1) & $17( \pm 0)$ & $84,5( \pm 6,36)$ & 0,04 \\
\hline
\end{tabular}

\section{Variables biológicas}

\section{Clorofila-a}

En el sitio BIU en TO se registraron valores medios de clorofila-a de 3,54 $\pm 2,98 \mu \mathrm{g} \cdot \mathrm{cm}^{-2}$, mientras que en el sitio AIU, los valores de clorofila-a en T0 fueron prácticamente cero (Figura 3.1). Desde T0 a T4, la concentración de clorofila-a fue significativamente más alta en el sitio BIU que en AIU (RM - ANOVA $p<0,05$; Figura 3.1).

Los valores medios de clorofila-a en el sitio BIU aumentaron de T0 a T2, permanecieron similares a través de T3 y T4 y disminuyeron en T5. En el sitio de AIU, la clorofila-a permaneció baja hasta T3 para luego aumentar en T4 y T5 (Tabla 3.3).

La tasa de incremento de la concentración de clorofila-a se ajustó significativamente a la curva logística $(p<0,01)$ en ambos sitios (Tabla 3.2), siendo el valor de $X_{50}$ menor en el sitio BIU (1,4 hs) en comparación con el sitio AIU (18,6 h). 


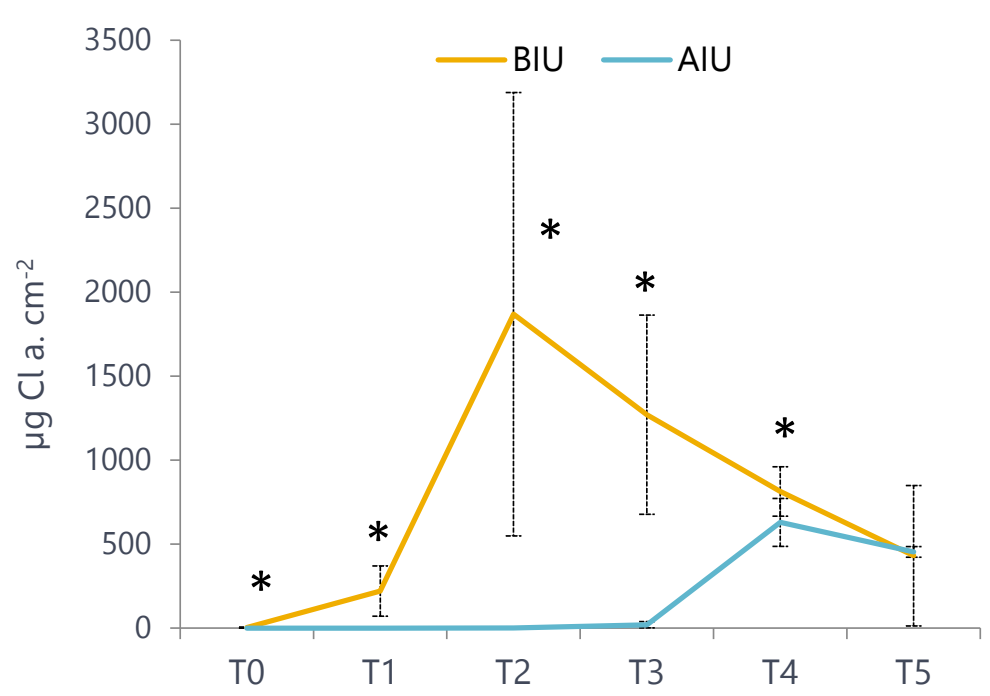

Figura 3.1: variación de los valores medios de la clorofila-a a lo largo de la experiencia en ambos sitios (BIU= bajo impacto urbano; AIU = alto impacto urbano) Las barras indican los desvío estándar y los asteriscos $\left(^{*}\right)$ indican diferencias significativas entre sitios en cada tiempo de muestreo ( $p$-valor $<0,05)$.

\section{Composición algal}

La densidad total de algas fue significativamente mayor en el sitio BIU que en el sitio AIU en el tiempo T2 (Tabla 3.3); la densidad máxima en el sitio BIU fue en T2 (480399 cél.cm $\left.{ }^{-2}\right)$, mientras que en el sitio AIU, la densidad máxima se registró en T4 (92081 cél.cm², Figura 3.2).

El grupo taxonómico dominante en ambos sitios fueron las diatomeas (Figura 3.2), representando del 21\% al 75\% (10686 - 108843 cél.cm²) de la composición general en el sitio BIU y del 7\% al 75\% en el sitio AIU (1985-69581 cél.cm²).Las primeras diatomeas se hallaron a los 30 minutos de exposición del sustrato en ambos sitios. El porcentaje de frústulos vacíos en T0 superó el 68\%, pero a partir de T3 el porcentaje fue prácticamente nulo (Figura 3.2).

La densidad de diatomeas fue significativamente mayor en el sitio de menor impacto $(<0,001$; Tabla 3.3). Asimismo la denisdad de este grupo fue significativamente mayor en T4 independientemente del sitio analizado. El aumento de la densidad de diatomeas durante la experiencia en ambos sitios se ajusta a una función logística, siendo los valores de la tasa de incremento mayor en el sitio de BIU (Tabla 3.2, p <0,05).

La densidad de clorofitas se mantuvo invariable en el sitio BIU, mientras que en AIU aumentó durante los tiempos T3 y T4 para luego disminuir en T5 (Tabla 3.3). Al comparar los dos sitios, la densidad de este grupo algal fue significativamente mayor en el control solamente durante el T3. 
Con respecto a las cianobacterias, en el sitio BIU la densidad aumento gradualmente de T1 a T5 hasta un 22\% de abundancia relativa máxima (32400 cél.cm², Figura 3.2), siendo significativamente mayor la densidad en T5 (Tabla 3.3). Mientras que en el sitio AIU las cianobacterias estuvieron presentes durante todo el experimento registrándose el mayor valor de abundancia relativa máxima (22\%) en T5 (Figura 3.2), sin embargo no se registraron diferencias significativas entre los tiempos (Tabla 3.3). Al comparar los sitios, la densidad de cianobacterias fue significativamente mayor en BIU solamente durante T5.

En el sitio BIU, la abundancia de euglenofitas alcanzó un máximo del 61\% en T1 (54181 cél. $\mathrm{cm}^{-2}$ ), mientras que en el sitio AIU, las euglenofitas alcanzaron el mayor valor de abundancia relativa en T2 (13739 cél. $\left.\mathrm{cm}^{-2}, 25 \%\right)$. La densidad de este grupo fue significativamente mayor en BIU que en AIU independientemente del tiempo analizado (Tabla 3.3)

Tabla 3.2: parámetros del modelo logístico para las variables autotróficas del biofilm en cada sitio (BIU = Bajo Impacto Urbano; $\mathrm{AIU}=$ Alto Impacto Urbano). $\mathrm{K}=\mathrm{Ln}$ de la capacidad de carga; $\mathrm{r}=$ tasa de crecimiento; $\mathrm{X}_{50}=$ tiempo (h) en que la variable alcanza el $50 \%$ de la capacidad de carga. En negrita se muestran los casos significativos ( $p$-valor $<0,05$ )

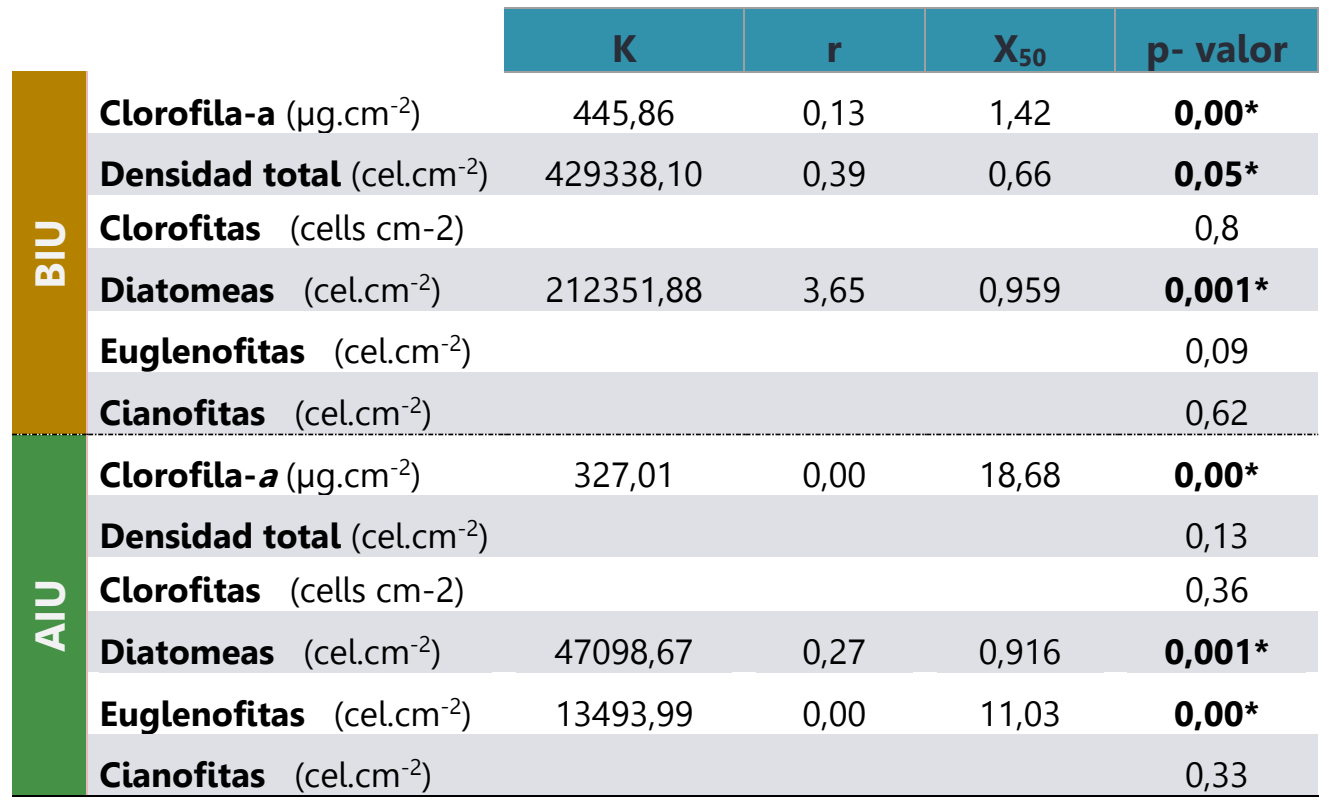



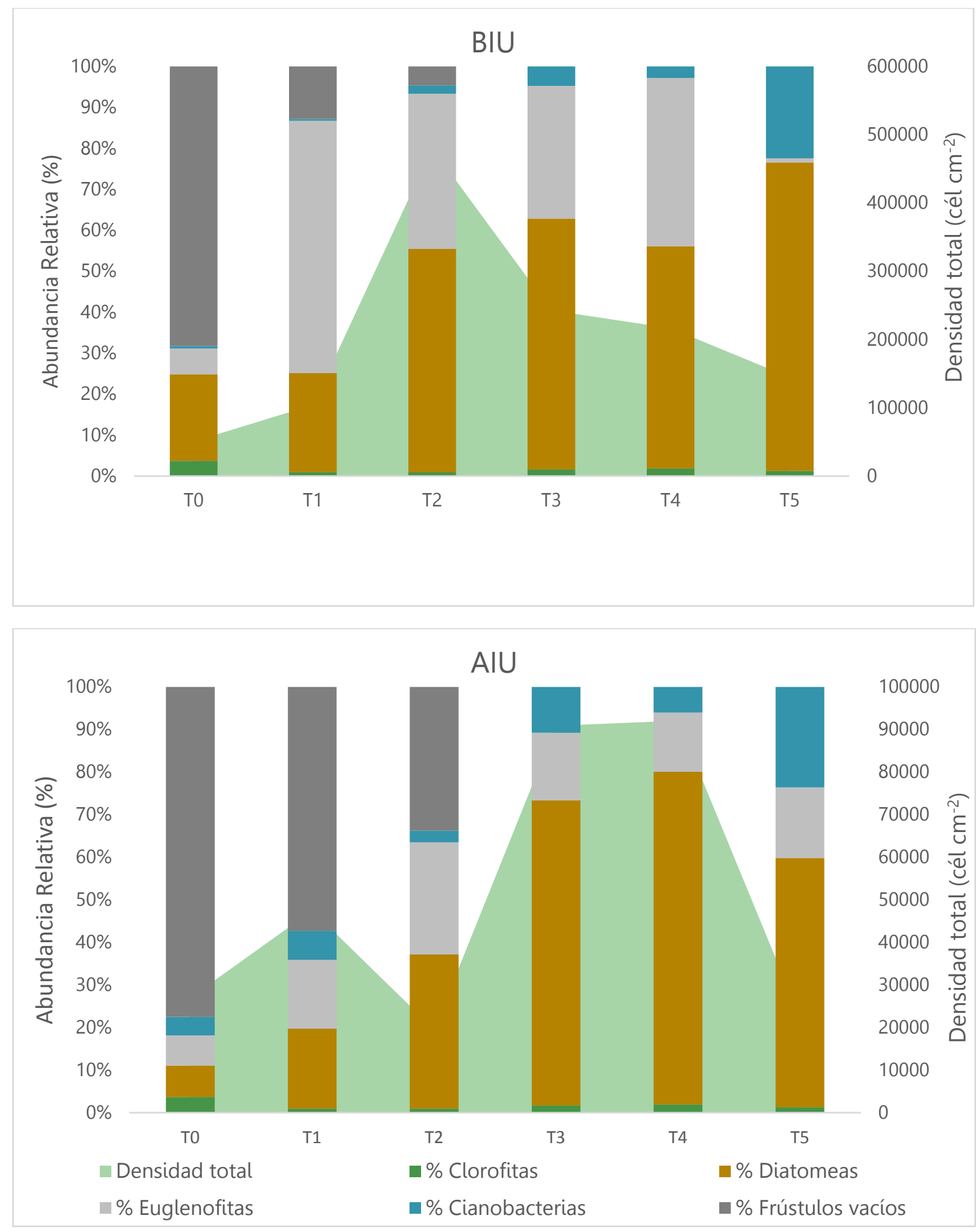

Figura 3.2: Abundancia relativa (eje izquierdo) y densidad total de algas (eje derecho, área sombreada) de los principales grupos algales del biofilm que colonizó el sustrato artificial en el sitio de bajo impacto urbano (BIU) y en el sitio de alto impacto urbano (AIU), durante los tiempos de muestreo (T0=0,5 hs, T1= $3 \mathrm{hs}, \mathrm{T} 2=6 \mathrm{hs}, \mathrm{T} 3=$ 24 hs, T4= 48 hs, T5= 168 hs). 
Tabla 3.3: Resultados de los RM-ANOVA a dos vías (Factores: Tiempo, Sitio, Tiempo*Sitio) para las variables autotróficas del biofilm. Las diferencias significativas se muestran en negrita $(p<0,05)$; se muestran los resultados de los test a posteriori Holm-Sidack para el factor tiempo y sitio, y el tamaño del efecto biológico n2.

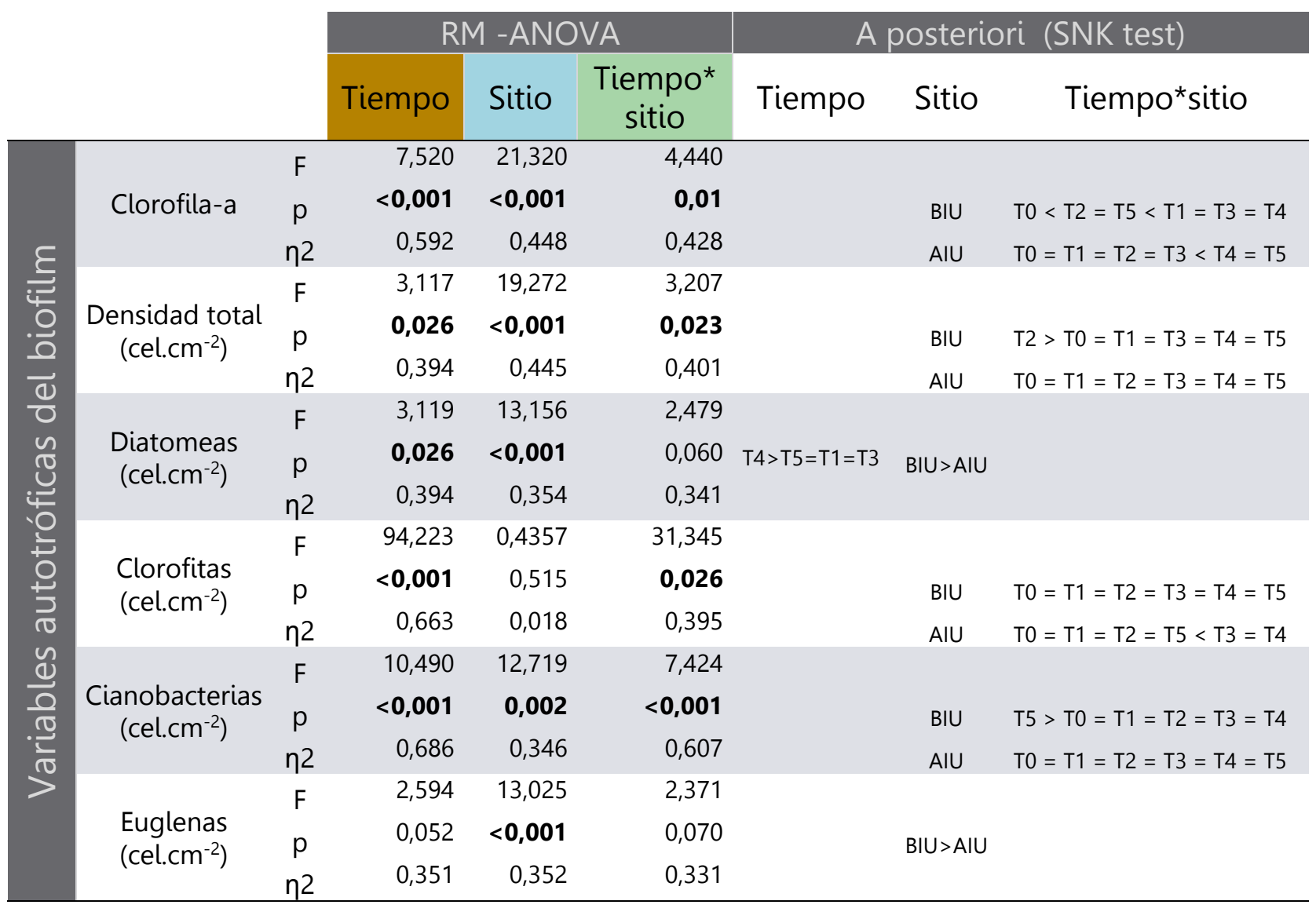




\section{Ensamble de diatomeas}

Se identificaron un total de 72 especies en el sitio BIU y 54 en el sitio de AIU, y los taxa más abundantes se muestran en la Tabla 3.4. La riqueza y la diversidad registraron valores medios de $20 \pm 4$ y 2,23 $\pm 0,28$ bits.ind-1 respectivamente en el sitio BIU; mientras que en el sitio AIU el valor medio de la riqueza fue de 18 \pm 3 y el de la diversidad fue de 2,09 $\pm 0,48$ bits.ind ${ }^{-1}$ (Figura 3.3). Estas variables no fueron diferentes entre los sitios (Tabla 3.5).

El Índice de Diatomeas Pampeano (IDP) fue significativamente mayor en el sitio BIU ( $p<0,05$, eta2 $=0,248$ ), teniendo un valor promedio de 3,29 $\pm 0,29$ ("muy mala" calidad del agua) en el sitio Bl y de 2,93 \pm 0,31 en el sitio de AIU ("mala" calidad de agua) (Tabla 3.5, Figura 3.3).

Tabla 3.4. Porcentaje de abundancia de las especies más representadas en los sitios BIU y AIU, el gremio ecológico al que pertenecen y su clase de tamaño.

\begin{tabular}{lcccc}
\multicolumn{1}{c}{ Especies } & BIU & AIU & Gremio & $\begin{array}{c}\text { Clase de } \\
\text { tamaño }\end{array}$ \\
\hline $\begin{array}{l}\text { Planothidium lanceolatum (Brebisson ex Kützing) Lange- } \\
\text { Bertalot }\end{array}$ & 2,70 & 1,62 & BP & 2 \\
$\begin{array}{l}\text { Diadesmis confervacea Kützing } \\
\text { Eolimna subminuscula (Manguin) Moser Lange-Bertalot \& }\end{array}$ & 2,52 & 1,18 & AP & 2 \\
Metzeltin & 0,16 & 6,98 & M & 1 \\
Gomphonema parvulum (Kützing) Kützing & 3,48 & 28,71 & AP & 3 \\
Nitzschia amphibia Grunow & 19,04 & 39,26 & M & 3 \\
Nitzschia palea (Kutzing) W.Smith & 26,42 & 9,44 & M & 3 \\
Nitzschia umbonata (Ehrenberg)Lange-Bertalot & 35,44 & 2,27 & M & 5 \\
\hline
\end{tabular}


$\mathrm{BIU}=\mathrm{AIU}$

Riqueza
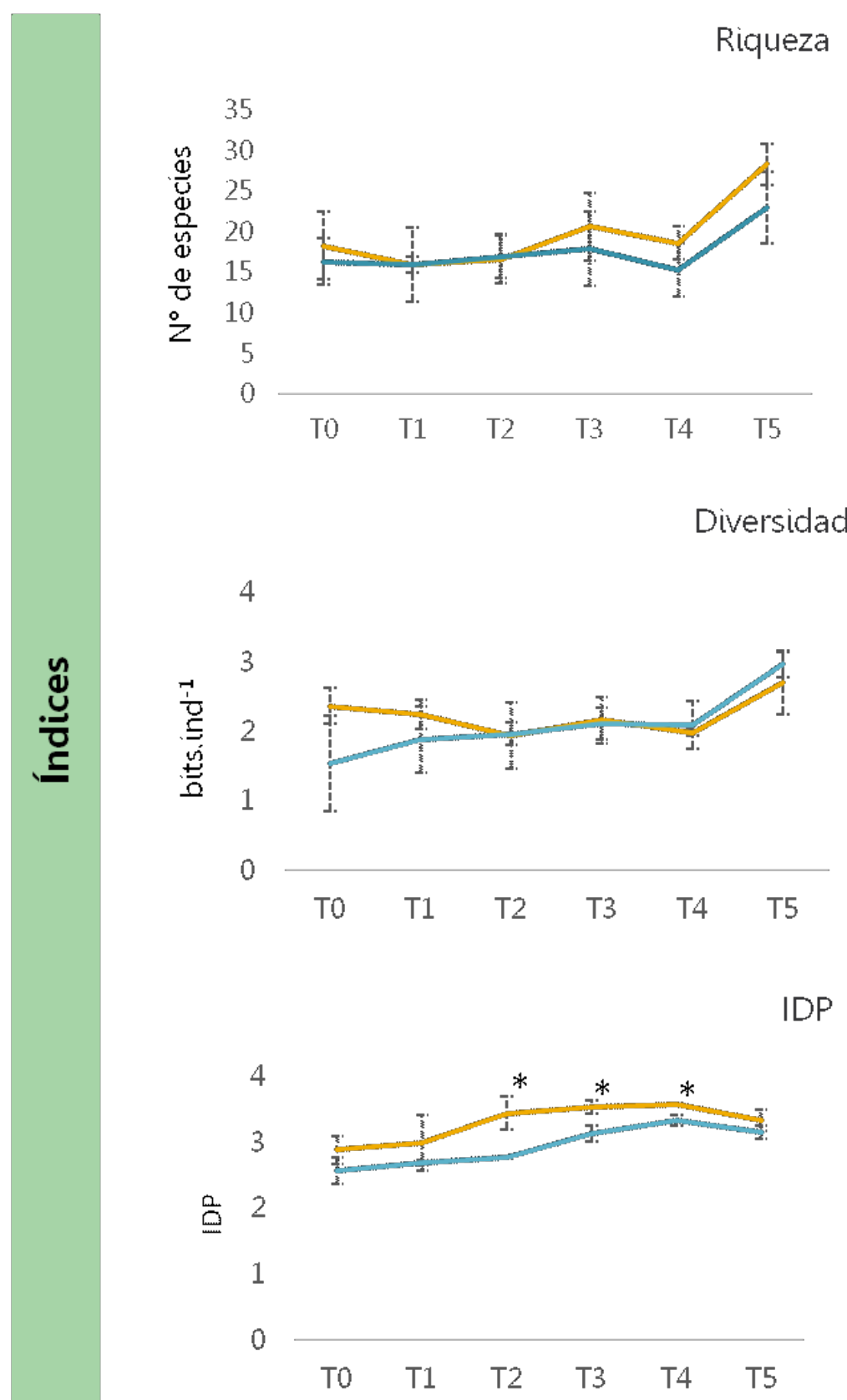

Tiempo

Figura 3.3: variación de los valores medios de la riqueza específica, diversidad de Shannon e Índice de Diatomeas Pampeanas (IDP) del ensamble de diatomeas a lo largo de la experiencia en ambos sitios (BIU= bajo impacto urbano; AIU = alto impacto urbano) Las barras indican los desvío estándar y los asteriscos $\left(^{*}\right)$ indican diferencias significativas ( $p$-valor $<0,05)$. 


\section{Gremios ecológicos}

El gremio de bajo perfil fue el menos representado en ambos sitios, con una media de $4,89 \pm 2,54 \%$ en el sitio BIU y un valor medio de $2,41 \pm 2,15 \%$ en el sitio de AIU. se observaron diferencias significativas en ninguno de los dos factores considerados y Sitio; Tabla 3.5; Figura 3.4).

Los taxones de alto perfil se mantuvieron similares durante todo el experimento en el sitio BIU, mientras que en el sitio AIU hubo un aumento significativo de la proporción de estos taxones a partir de T3 (Tabla 3.5, $\mathrm{p}<0.05$ ) (Figura 3.4). Al comparar los dos sitios, a partir del tiempo T2 la proporción de diatomeas de alto perfil fue significativamente mayor en AIU. (Tabla 3.4; $p<0,05)$.

Con respecto a las diatomeas del gremio móvil, estas fueron las de mayor representatividad en el ensamble encontrado en ambos sitios. Sin embargo, fueron significativamente mayores en BIU ( $p<0,05$; eta $^{2}=0,91$; Tabla 3.5), con un valor medio de $88,2 \pm 7,4 \%$; mientras que en AIU el valor medio fue de $66,6 \pm 19,6 \%$.

\section{Clases de tamaño}

La clase de tamaño 1 fue significativamente mayor en el sitio AIU con respecto al sitio BIU independientemente del tiempo analizado $\left(p=0,001\right.$; eta $^{2}=0,998$; Tabla 3.5, Figura 3.4).

La abundancia de la clase de tamaño 2 fue significativamente mayor en el sitio AIU durante T4 y T5 con un valor medio de $22,3 \pm 9,08 \%$, mientras que en esas fechas la abundancia relativa de esta clase en BIU fue de 4,9 $\pm 29 \%$ (Tabla 3.5, Figura 3.4). En el sitio BIU la abundancia de esta clase no varió en el tiempo mientras que en AIU la abundancia fue significativamente mayor en T5.

La abundancia de la clase de tamaño 3 fue significativamente mayor en el sitio AIU donde alcanzó valores medios de $81,2 \pm 13 \%$, mientras que los valores medios en BIU fueron de 56,6 $\pm 15,5 \%\left(p<0,05\right.$; eta ${ }^{2}=0,99$; Tabla 3.5) independientemente del tiempo analizado.

La abundancia de las diatomeas de la clase de tamaño 4 fue significativamente mayor en el sitio AIU (5,88 $\pm 1,75 \%)$ con respecto al sitio BIU $(1,26 \pm 1,02 \%)$ en los tiempos T4 y T5. Además en el sitio AIU, la abundancia de esta clase de tamaño fue significativamente mayor en los últimos tiempos de muestro respecto a los iniciales (Tabla 3.5, Figura 3.4). 
La clase de tamaño 5 fue significativamente mayor en BIU con respecto a AlU durante todo el experimento ( $p<0,05$; eta ${ }^{2}=0,97$; Figura 3.4). Las especies mas representativas de cada rasgo ecológico (gremios ecológicos y clases de tamaño) en ambos sitios expuestos a impacto urbano se muestran en las Tablas Anexas $\underline{3 \mathrm{~A}}$ y $\underline{3 \mathrm{~B}}$.

Tabla 3.5: Resultados de los RM-ANOVA a dos vías (Factores: Tiempo, Sitio, Tiempo*Sitio) para las variables del ensamble de diatomeas. Las diferencias significativas se muestran en negrita $(p<0,05)$; se muestran los resultados de los test a posteriori Holm-Sidack para el factor tiempo y sitio, y el tamaño del efecto biológico $\eta 2$.

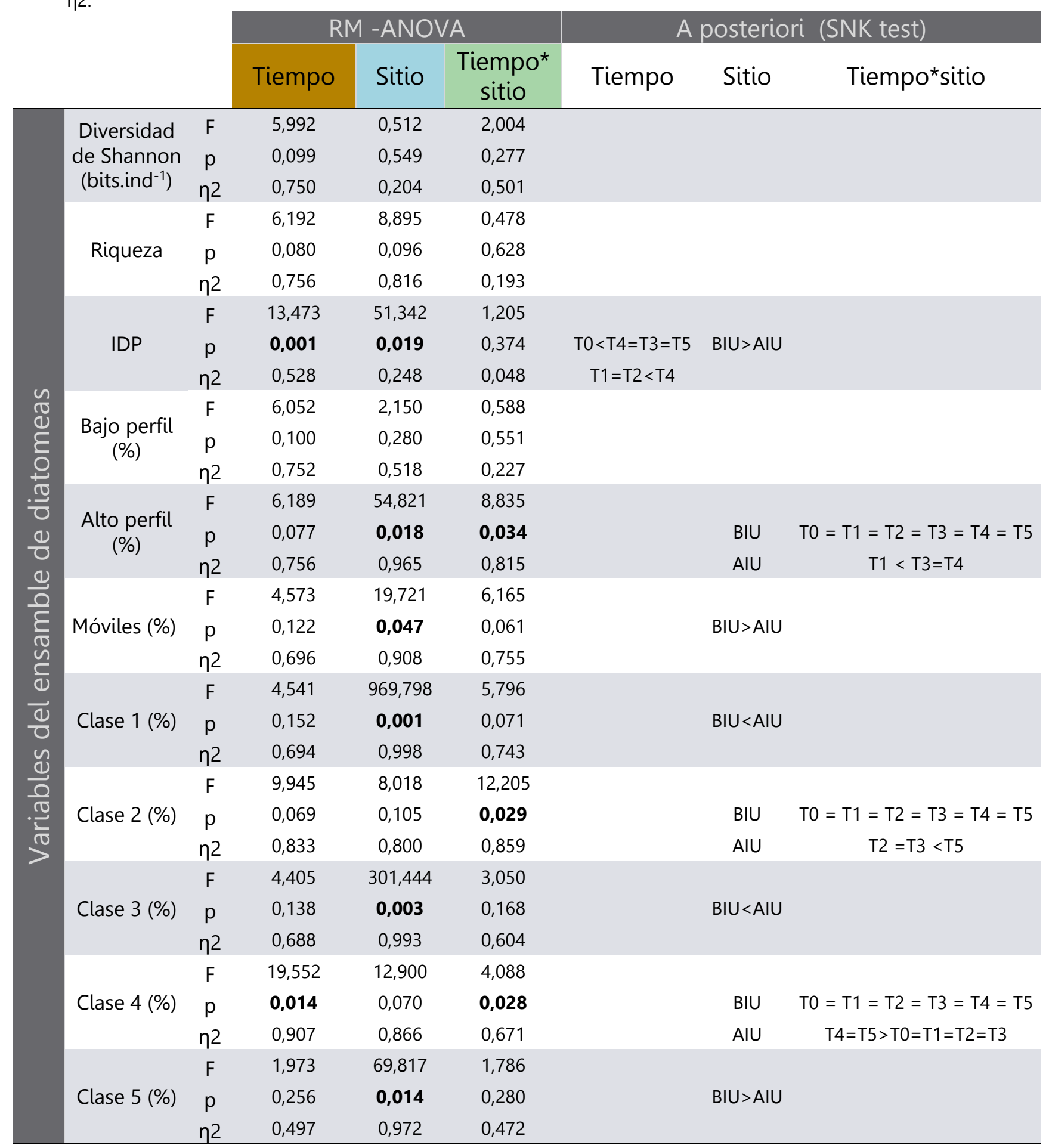



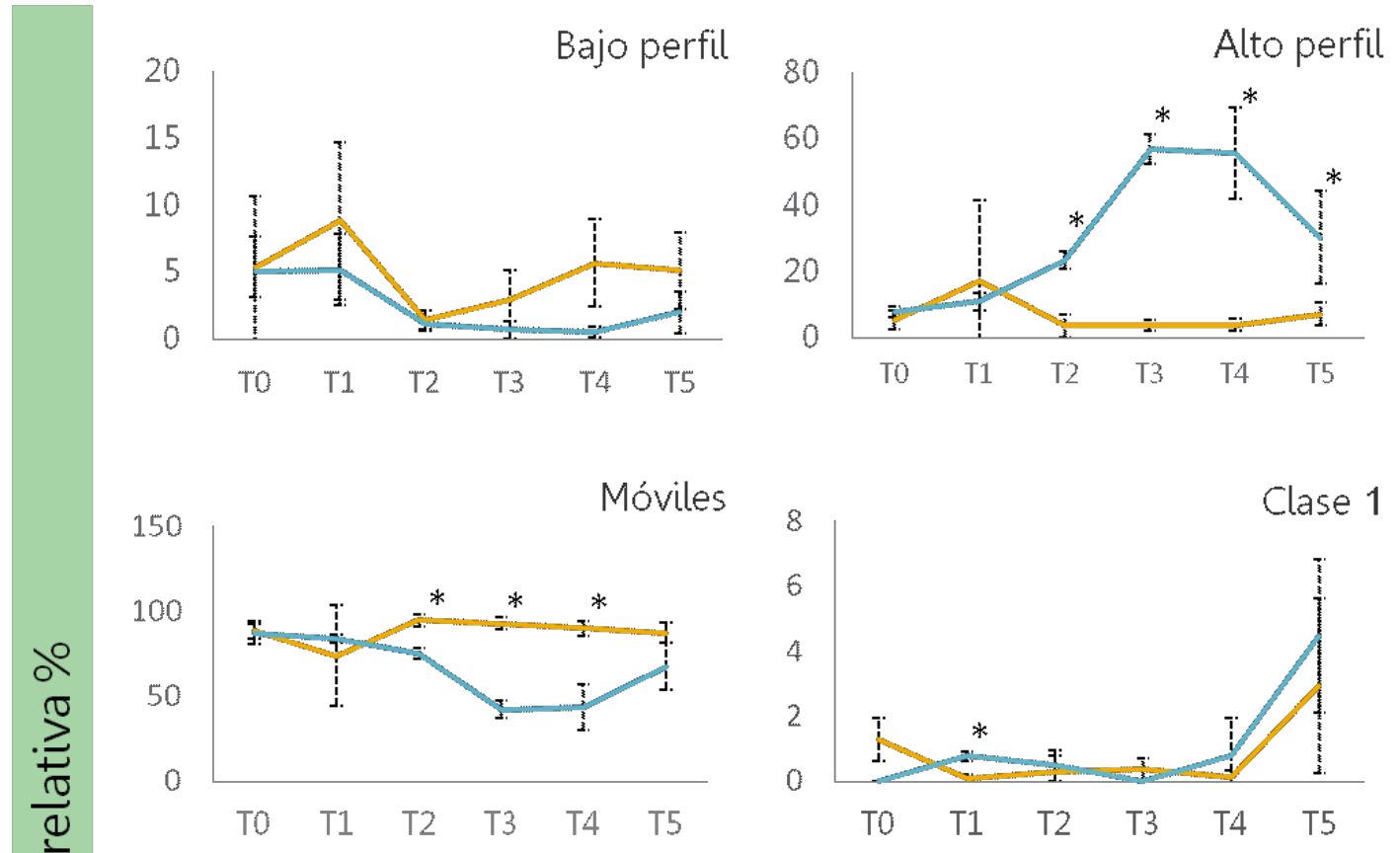

Clase 2

Clase 3
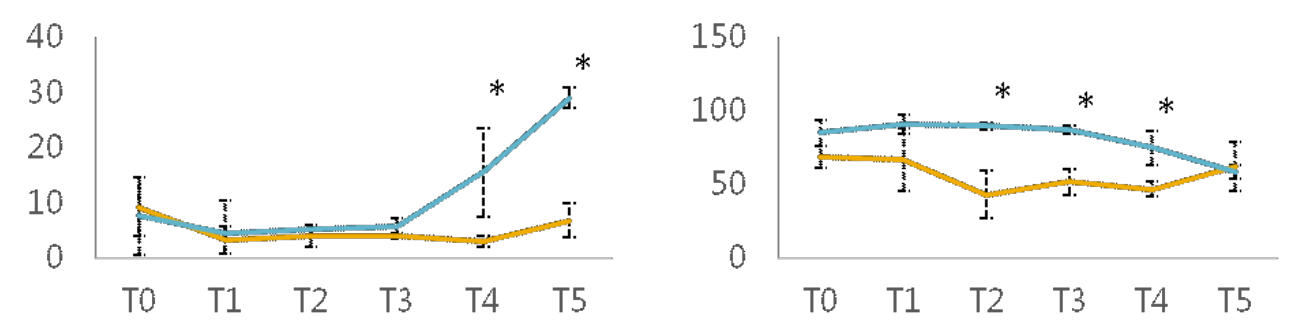

Clase 4
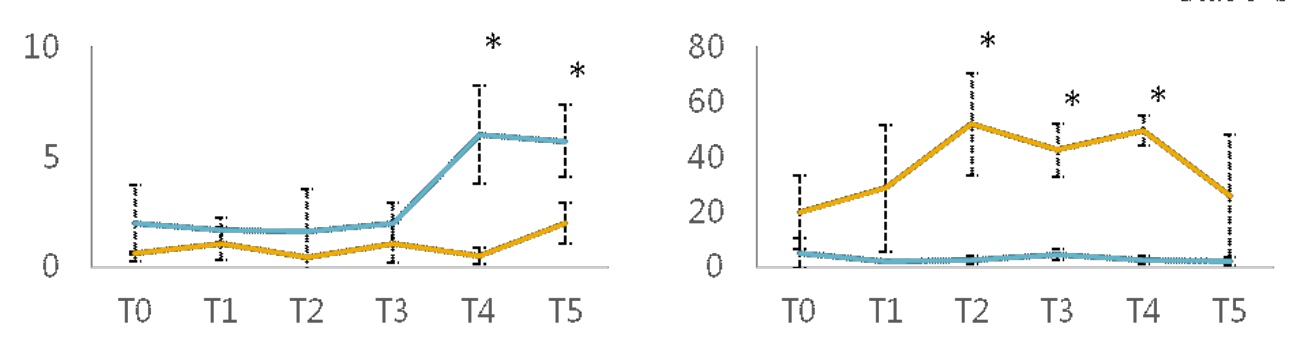

\section{Tiempo}

Figura 3.4: variación de los valores medios de los gremios ecológicos (Bajo perfil, alto perfil, móvil) y las clases de tamaño $(1,2,3,4,5)$ del ensamble de diatomeas a lo largo de la experiencia en ambos sitios (BIU= bajo impacto urbano; AIU = alto impacto urbano) Las barras indican los desvío estándar y los asteriscos (*) indican diferencias significativas ( $p$-valor $<0,05$ ). 


\section{4.b Impacto agrícola}

Parámetros fisicoquímicos

La temperatura media registrada en el sitio BIA fue de $22,3 \pm 3,96^{\circ} \mathrm{C}$ y el valor medio de $\mathrm{pH}$ fue de $6,85 \pm 0,26$, mientras que en el sitio AIA los valores medios de temperatura y $\mathrm{pH}$ fueron de $20,53 \pm 1,43{ }^{\circ} \mathrm{C}$ y $6,46 \pm 0,29$ respectivamente, sin diferencias significativas entre los sitios. El oxígeno disuelto $\left(\mathrm{mg} \mathrm{O}_{2} \mathrm{~L}^{-1}\right)$, la conductividad $\left(\mu \mathrm{Scm}^{-1}\right)$, la turbidez (NTU) y los sólidos disueltos totales $\left(\mathrm{mgL}^{-1}\right)$ fueron significativamente mayores en el sitio de BIA (Tabla 3.5). En cuanto a los nutrientes, sólo los nitritos $\left(\mathrm{mgL}^{-1}\right)$ y el DIN fueron significativamente mayores en el sitio BIA (Tabla 3.6).

Las mediciones de pesticidas en sedimento, arrojaron valores detectables tanto de los isómeros $\alpha$ y $\beta$ de endosulfán y de endosulfán sulfato en todas la muestras del sitio AIA, mientras que en el sitio BIA sólo se detectó el isómero a (en una proporción menor a la detectada en AIA) en una única muestra (Tabla 3.6).

Tabla 3.6: Medias ( \pm desvío estándar) de los parámetros físico-químicos medidos en agua y valores de pesticidas del sedimento en los sitios AIA (Alto impacto agrícola) y BIA (Bajo impacto agrícola) durante la experiencia, y el valor de significancia ( $p$-valor) obtenido del ANOVA. En negrita se marcan los casos significativos $(p<0,05)$, n.d. = no detectado.

\begin{tabular}{|c|c|c|c|c|}
\hline \multirow{2}{*}{\multicolumn{2}{|c|}{ Localización de los sitios de muestreo }} & \multirow{2}{*}{$\begin{array}{c}\text { Sitio BIA } \\
35^{\circ} 3^{\prime} 14.95^{\prime \prime S} \\
57^{\circ} 58^{\prime} 37.92^{\prime \prime O}\end{array}$} & \multicolumn{2}{|c|}{ Sitio AIA } \\
\hline & & & \multicolumn{2}{|c|}{$\begin{array}{c}35^{\circ} 11^{\prime 32.10 " S ~} \\
57^{\circ} 59^{\prime} 41.30^{\prime \prime O}\end{array}$} \\
\hline & Endosulfán I (ng/g de peso seco) & $26( \pm 45,03)$ & $111,3( \pm 16,5)$ & 0,037 \\
\hline & Endosulfán II (ng/g de peso seco & n.d. & $1,66( \pm 2,88)$ & 0,374 \\
\hline & Endosulfán Sulfato ( $\mathrm{ng} / \mathrm{g}$ de peso seco) & n.d. & $83( \pm 73,3)$ & 0,121 \\
\hline & Temperatura $\left({ }^{\circ} \mathrm{C}\right)$ & $22,3( \pm 3,96)$ & $20,53( \pm 1,43)$ & 0,281 \\
\hline & pH & $6,85( \pm 0.26)$ & $6,46( \pm 0.29)$ & 0,539 \\
\hline & Conductividad $\left(\mu \mathrm{S} \mathrm{cm}^{-1}\right)$ & $443( \pm 157)$ & $267,4( \pm 7,34)$ & $<0,001$ \\
\hline & $O D\left(\mathrm{mg} \mathrm{L}^{-1}\right)$ & $4,64( \pm 1,82)$ & $2,12( \pm 0.96)$ & $<0,001$ \\
\hline & SST $\left(\mathrm{mg} \mathrm{L}^{-1}\right)$ & $0,29( \pm 0,11)$ & $0,17( \pm 0,05)$ & $<0,001$ \\
\hline & Turbidez (UNT) & $320,4( \pm 103,3)$ & $126,3( \pm 76,1)$ & $<0,001$ \\
\hline & PRS (mg L-1) & $0,630( \pm 0,355)$ & $0,772( \pm 0.199)$ & 0,358 \\
\hline & $\mathrm{N}-\mathrm{NO}_{3}{ }^{-}\left(\mathrm{mg} \mathrm{L}^{-1}\right)$ & $0,033( \pm 0,009)$ & $0,027( \pm 0,009)$ & 0,278 \\
\hline & $\mathrm{N}-\mathrm{NO}_{2}^{-}\left(\mathrm{mg} \mathrm{L}^{-1}\right)$ & $0.011( \pm 0.005)$ & $0.004( \pm 0.004)$ & 0,008 \\
\hline & $\mathrm{N}-\mathrm{NH}_{4}{ }^{+}\left(\mathrm{mg} \mathrm{L}^{-1}\right)$ & $0,065( \pm 0.025)$ & $0,033( \pm 0,02)$ & 0,081 \\
\hline & NID $\left(\mathrm{mg} \mathrm{L}^{-1}\right)$ & $0.111( \pm 0.042)$ & $0,070( \pm 0.02)$ & 0,035 \\
\hline
\end{tabular}




\section{Variables biológicas}

\section{Clorofila-a}

En el sitio BIA los valores de clorofila-a permanecieron bajos de T0 a T2 $(0,46 \pm 0,3$ $\mathrm{mg} . \mathrm{cm}^{-2}$ ) y aumentaron significativamente a partir de T3 llegando a un valor medio de $2,97 \pm 1,2 \mathrm{mg} \mathrm{cm}^{-2}$ en T4. Mientras que en el sitio AIA, los valores de clorofila-a fueron de $0,52 \pm 0.39 \mathrm{mg} \cdot \mathrm{cm}^{-2}$ de T0 a T3 aumentando significativamente a $1,71 \pm 0,55 \mathrm{mg} \cdot \mathrm{cm}^{-2}$ en T4 (Figura 3.5).

Los valores de clorofila-a en el biofilm del sitio BIA fueron más altos en el sitio de BIA a partir de T3 al compararlos con el sitio AIA (RM - ANOVA $p<0,05$; Tabla 3.8). El tamaño del efecto de la interacción entre factores fue intermedia ( $\left(\operatorname{eta}^{2}=0,232\right.$ ).

La tasa de incremento de la concentración de clorofila-a se ajustó significativamente a una curva logística $(p<0,05)$ en ambos sitios (Tabla 3.7), siendo la tasa de crecimiento mayor y el valor de $X_{50}$ menor en BIA ( $r=2,42 ; X 50=5,60$ h) en comparación con el sitio AIA $(r=2,02 ; X 50=1,98)$.

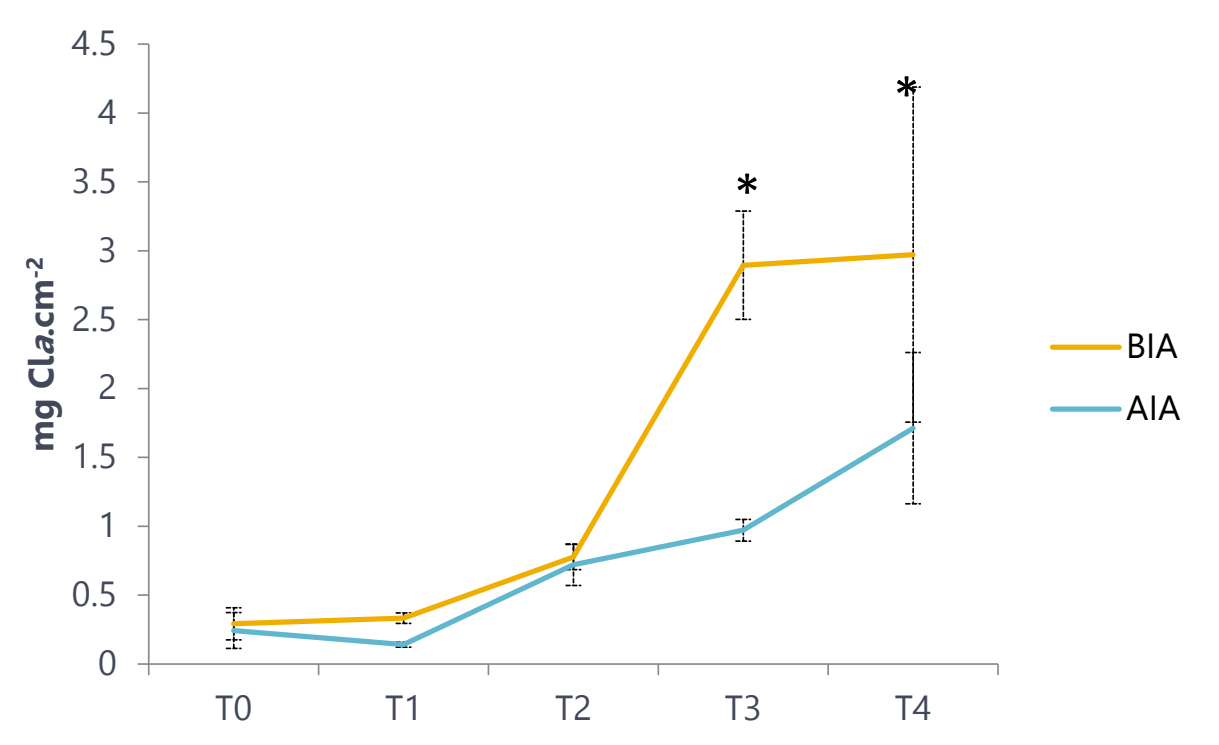

Figura 3.5: variación de los valores medios de la clorofila-a a lo largo de la experiencia en ambos sitios (BIA= bajo impacto agrícola; $\mathrm{AIA}=$ alto impacto agrícola) Las barras indican los desvío estándar y los asteriscos $\left({ }^{*}\right)$ indican diferencias significativas entre sitios en cada tiempo de muestreo ( $p$-valor $<0,05)$. 


\section{Composición algal}

La densidad total de algas varió de 4950, 19 ( \pm 7821,4) cel.cm-2 a 79984,9 \pm 48376 cel.cmcel.cm-2 durante la experiencia en el sitio BIA, siendo significativamente mayor transcurridas transcurridas las 2 semanas (T4). En el sitio AIA se registraron valores iniciales de 384,5 $( \pm 72,6)$ cel.cm-2 en T0 llegando a 3497,7 $( \pm 3373,3)$ cel.cm-2 en T4, sin diferencias significativas. A partir de la semana de colonización (T3) la densidad de organismos autótrofos fue significativamente mayor en el sitio BIA con respecto al sitio AIA. El tamaño del efecto de la interacción entre factores fue intermedia (Tabla 3.8, eta ${ }^{2}=0,249$ )

Los grupos taxonómicos dominantes en el sitio BIA fueron las diatomeas representando del $10 \%$ al $41 \%$ ) y las cianobacterias representando $88 \%$ al $57 \%$; mientras que en el sitio AIA fueron las diatomeas representando del $95 \%$ al $5 \%$ junto a las clorofitas representando del $2 \%$ al $12 \%$ (Figura 3.6).

La densidad de diatomeas en el sitio BIA, aumentó en el transcurso de la colonización, siendo este aumento significativo en T3 y T4 en comparación de los demás tiempos. Al comparar los sitios la densidad de diatomeas y la tasa de incremento fueron mayores en BIA a partir de la semana de colonización (Tablas 3.7, 3.8; Figura 3.6).

La densidad de cianobacterias en el sitio BIA aumentó gradualmente y fue mayor al final de la colonización, mientras que en AIA no mostró diferencias significativas. Al comparar los dos sitios se observó que transcurridas las 2 semanas de colonización la densidad de este grupo fue mayor en BIA que en AIA (Tabla 3.8).

Con respecto a las clorofitas, la densidad en el sitio BIA se mantuvo en valores bajos excepto en T3, donde alcanzó su valor máximo $\left(4057 \pm 2245\right.$ cel.cm $\left.{ }^{-2}\right)$. En el sitio AIA, también alcanzó su valor máximo en T3, pero no fue significativo. Al comparar los sitios sólo hubo diferencias significativas en T3, siendo mayor la densidad en BIA.

El tamaño del efecto de las interacciones entre factores para estos tres grupos algales fue intermedia (eta ${ }^{2}=0,232-0,271$, Tabla 3.8).

Las euglenofitas fueron el grupo con menor representación en ambos sitios, siendo significativamente mayores en BIA. El tamaño del efecto de esta variable fue bajo (eta ${ }^{2}=$ $0,1)$. 
Tabla 3.7: parámetros del modelo lineal y logístico (sigmoideo) para las variables autotróficas del biofilm en cada sitio (BIA= bajo impacto agrícola; $\mathrm{AIA}=$ alto impacto agrícola). Para el modelo lineal: $\mathrm{K}=$ ordenada al origen; $r$ = pendiente. Para el modelo sigmoideo: $\mathrm{K}=$ la capacidad de carga; $r=$ tasa de crecimiento; $\mathrm{X}_{50}=$ tiempo (h) en que la variable alcanza el $50 \%$ de la capacidad de carga. En negrita se muestran los casos significativos ( $p$-valor $<0,05)$.

\begin{tabular}{|c|c|c|c|c|c|c|}
\hline & \multirow[b]{2}{*}{$\begin{array}{l}\text { Modelo de } \\
\text { mejor ajuste }\end{array}$} & & & & \\
\hline & & & $\mathbf{K}$ & $\mathbf{r}$ & $X_{50}$ & $\begin{array}{c}\mathrm{p}- \\
\text { valor }\end{array}$ \\
\hline \multirow{5}{*}{$\overleftarrow{\omega}$} & Clorofila-a $\left(\mathrm{mg}^{-1} \mathrm{~cm}^{2}\right)$ & Sigmoideo & 0,31 & 2,45 & 5,60 & 0,01 \\
\hline & Cianofitas (cel.cm²) & Linear & $-482,27$ & 122,23 & & 0,01 \\
\hline & Clorofitas (cel. $\mathrm{cm}^{-2}$ ) & & & & & 0,07 \\
\hline & Diatomeas $\left(\mathrm{cel} . \mathrm{cm}^{-2}\right)$ & Linear & 531,02 & 93,52 & & 0,00 \\
\hline & Densidad total $\left(\mathrm{cel} . \mathrm{cm}^{-2}\right)$ & Linear & 754,06 & 221,31 & & 0,00 \\
\hline \multirow{5}{*}{$\frac{\pi}{<}$} & Clorofila-a $\left(\mathrm{mg}^{-1} \mathrm{~cm}^{2}\right)$ & Sigmoideo & $-0,34$ & 2,02 & 1,98 & 0,03 \\
\hline & Cianofitas (cel.cm²) & & & & & 0,11 \\
\hline & Clorofitas (cel.cm²) & Sigmoideo & 316,38 & 0,18 & 28,31 & 0,00 \\
\hline & Diatomeas $\left(\mathrm{cel} . \mathrm{cm}^{-2}\right)$ & & & & & 0,38 \\
\hline & Densidad total (cel. $\left.\mathrm{cm}^{-2}\right)$ & Linear & 285,03 & 8,74 & & 0,01 \\
\hline
\end{tabular}

Tabla 3.8: Resultados de los RM-ANOVA a dos vías (Factores: Tiempo, Sitio, Tiempo*Sitio) para las variables autotróficas del biofilm. Las diferencias significativas se muestran en negrita $(p<0,05)$; se muestran los resultados de los test a posteriori Holm-Sidack para el factor tiempo y sitio, y el tamaño del efecto biológico $\eta^{2}$.

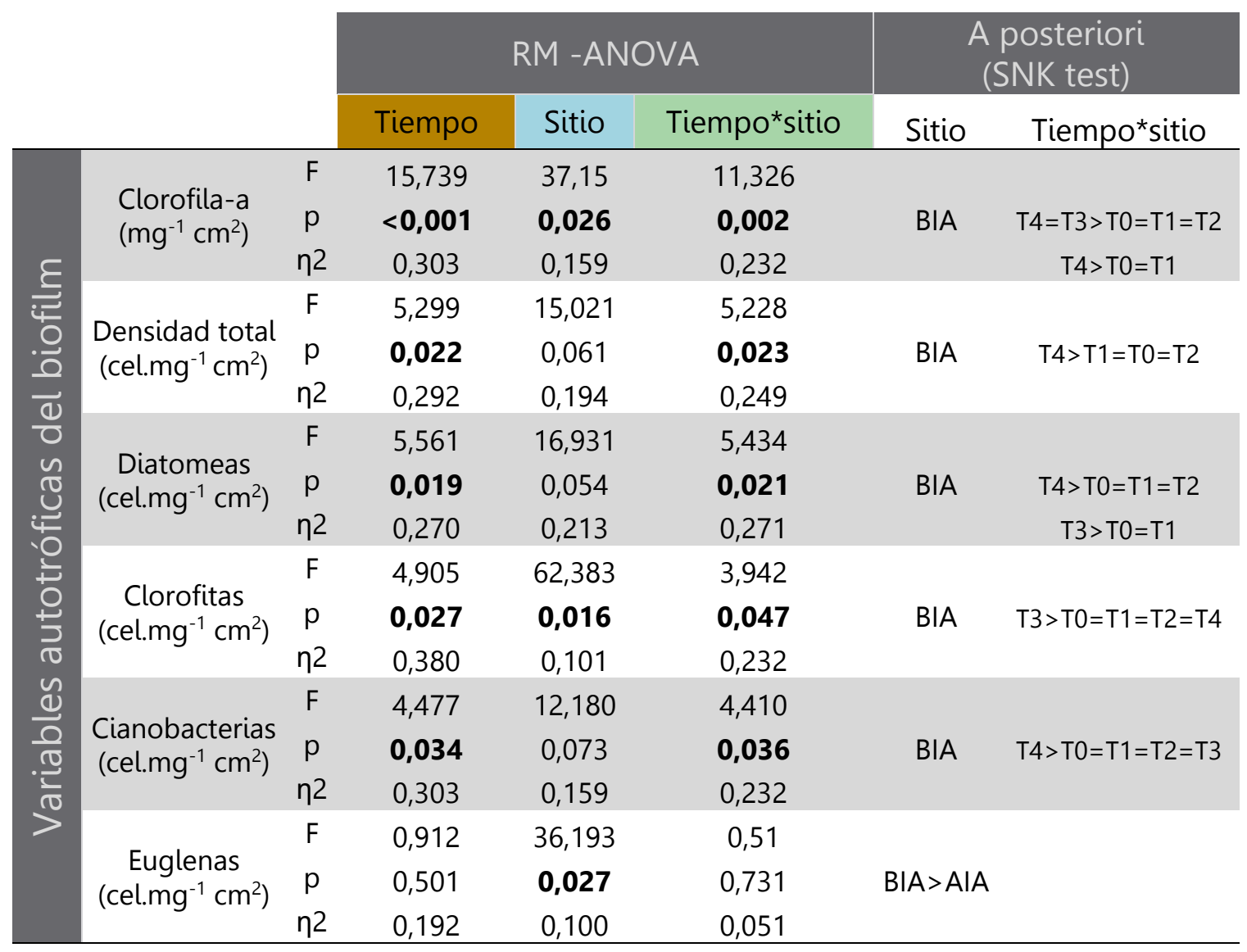



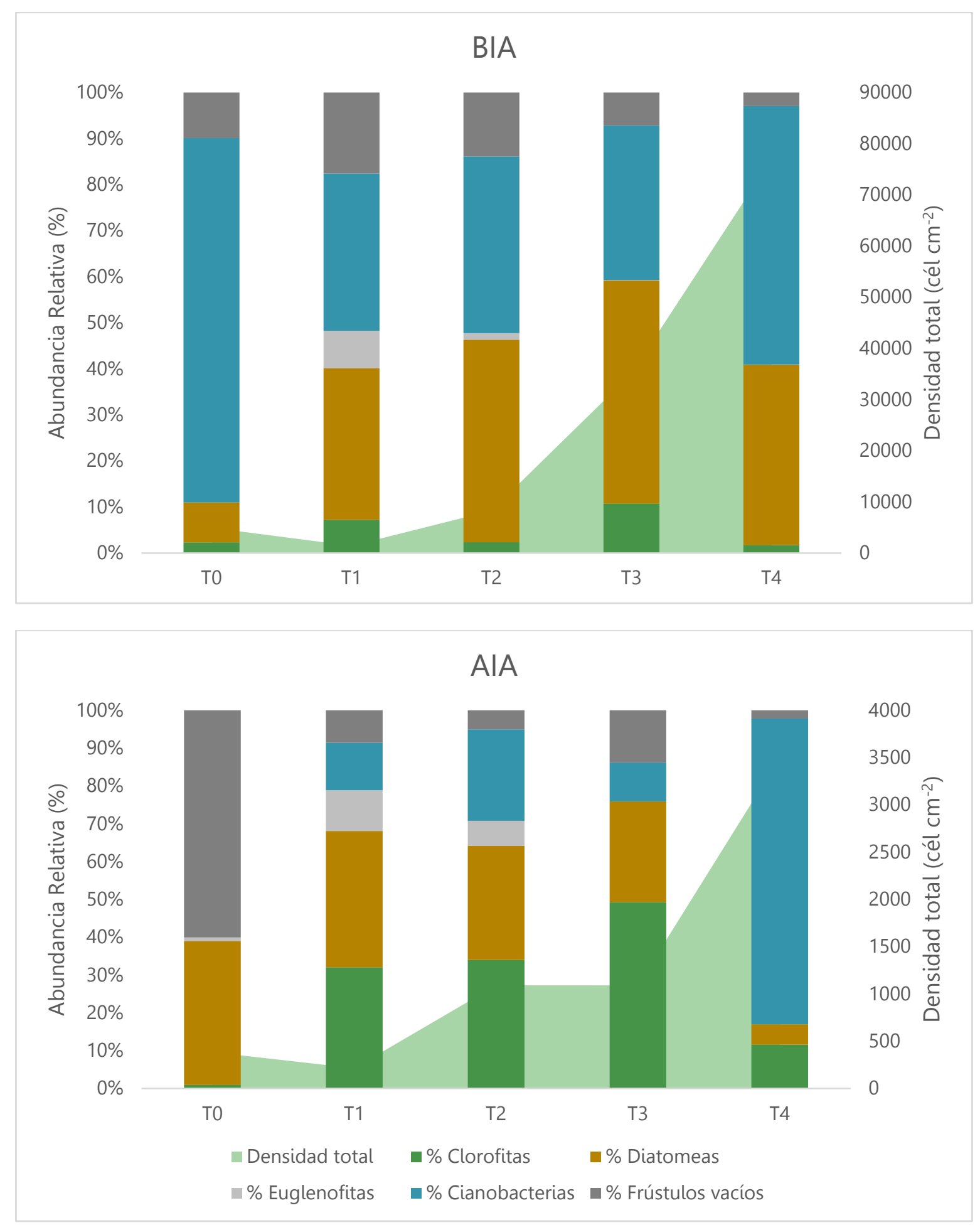

Figura 3.6: Abundancia relativa (eje izquierdo) y densidad total (eje derecho, área sombreada) de los principales grupos algales del biofilm que colonizó el sustrato artificial en el sitio de bajo impacto agrícola (BIA) y en el sitio de alto impacto agrícola (AIA), durante los tiempos de muestreo (T0=0,5 hs, T1= $3 \mathrm{hs}, \mathrm{T} 2=24 \mathrm{hs}$, $\mathrm{T} 3=48 \mathrm{hs}, \mathrm{T} 4=168 \mathrm{hs})$. 


\section{Ensamble de diatomeas}

Se identificaron un total de 124 especies de diatomeas en el sitio BIA y 131 en el sitio AIA, las especies más abundantes se muestran en la Tabla 3.9. La riqueza y la diversidad registraron valores medios de 51,7 5 5,7 y 4,1 $\pm 0,44$ bits.ind $^{-1}$ respectivamente en el sitio $\mathrm{BIA}$; mientras que en el sitio AIA el valor medio de la riqueza fue de 53,9 4,15 y el de diversidad fue de $3,73 \pm 0,422$ bits.ind $^{-1}$ (Figura 3.7). La riqueza fue significativamente mayor en el sitio AIA sólo en T0 ( $p<0,05$; eta ${ }^{2}=0,230$, Tabla 3.10, Figura 3.7), mientras que la diversidad fue significativamente mayor en el T0 con respecto a T4, independientemente del sitio (Tabla 3.10), con un tamaño del efecto intermedio (eta ${ }^{2}=$ $0,454)$.

El Índice de Diatomeas Pampeano (IDP) calculado para el sitio BIA arrojó un valor medio de 2,96 $\pm 0,1$ y en el sitio de AIA fue de 3,2 $\pm 0,1$ (Figura 3.7). Se encontraron diferencias significativas sólo en el factor tiempo, siendo el tiempo inicial el que registró los menores valores del índice (Tabla 3.10), y con un tamaño del efecto pequeño (eta ${ }^{2}=$ $0,18)$.

Tabla 3.9. Porcentaje de abundancia de las especies más representadas en los sitios BIA y AIA, el gremio ecológico al que pertenecen y su clase de tamaño

\begin{tabular}{lcccc}
\multicolumn{1}{c}{ Especies } & BIA & AIA & Gremio & $\begin{array}{c}\text { Clase de } \\
\text { tamaño }\end{array}$ \\
\hline Nitzschia palea (Kutzing) W.Smith & 25,88 & 44,12 & M & 3 \\
Nitzschia filiformis (W.M.Smith) Van Heurck var. filiformis & 12,88 & 1,62 & M & 4 \\
Nitzschia amphibia Grunow & 6,08 & 7,42 & M & 3 \\
Pseudostaurosira trainorii Morales & 1,65 & 0,05 & AP & 1 \\
Diadesmis confervacea Kützing & 3,54 & 1,35 & AP & 3 \\
Nitzschia frustulum(Kützing)Grunow & 4,00 & 0,43 & M & 2 \\
Gomphonema parvulum (Kützing) Kützing & 2,59 & 4,38 & AP & 3
\end{tabular}



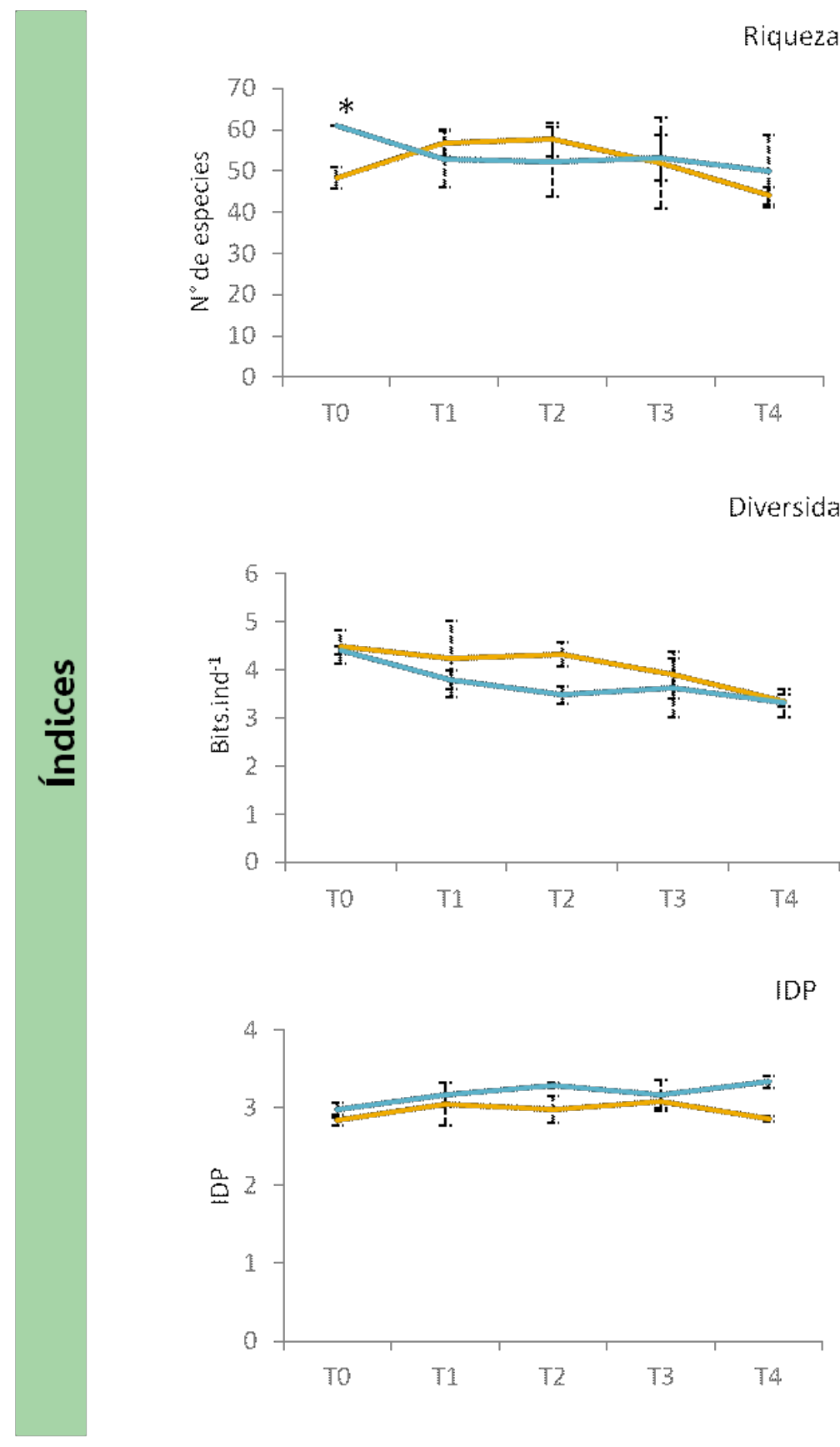

Diversidad

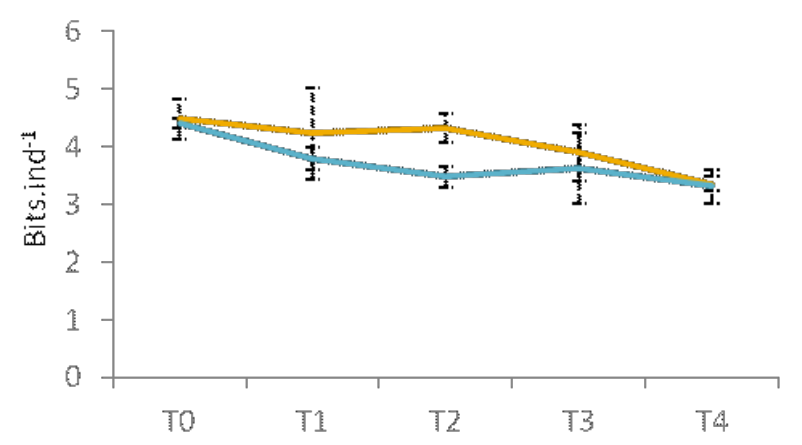

IDP

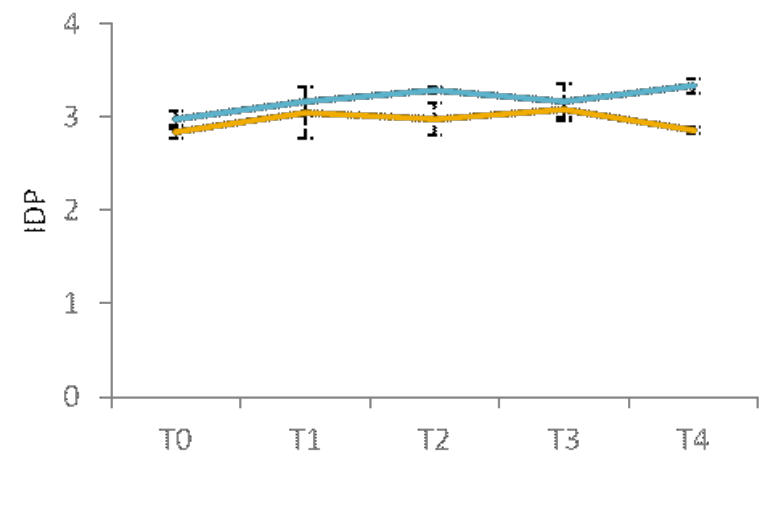

\section{Tiempo}

Figura 3.7: variación de los valores medios de la riqueza específica, diversidad de Shannon e índice de diatomeas pampeanas del ensamble de diatomeas a lo largo de la experiencia en ambos sitios $(\mathrm{BIA}=$ bajo impacto agrícola; $\mathrm{AIA}=$ alto impacto agrícola) Las barras indican los desvío estándar y los asteriscos $\left(^{*}\right)$ indican diferencias significativas ( $p$-valor $<0,05$ ). 


\section{Gremios ecológicos}

El gremio de bajo perfil fue el menos representado en ambos sitios, con una abundancia media de 3,57 $\pm 3,9 \%$ en el sitio BIA y un valor medio de $4,5 \pm 0,9 \%$ en el sitio de AIA (Figura 3.8). No se observaron diferencias significativas en ninguno de los dos factores considerados (Tiempo y Sitio; Tabla 3.10).

El gremio de alto perfil presentó un valor medio de abundancia relativa de 12,6 $\pm 2,1$ \% en el sitio BIA y un valor medio de 13, $9 \pm 3,4 \%$ en el sitio de AIA (Figura 3.8). El factor tiempo presentó diferencias significativas $\left(p<0,05\right.$; eta ${ }^{2}=0,20$, Tabla 3.10), siendo mayor el valor de abundancia en T3 que en T4 independientemente de los sitios.

Con respecto a las diatomeas del gremio móvil, estas fueron las de mayor representatividad en el ensamble encontrado en ambos sitios, presentando valores medios de $83,2 \pm 5,5 \%$ en el sitio BIA y $81,4 \pm 3,5 \%$ en el sitio AIA (Figura 3.8). Sin embargo no se registraron diferencias significativas en las abundancias de este gremio durante la experiencia (Tabla 3.10).

\section{Clases de tamaño}

La abundancia media de la clase de tamaño 1 varió de $15,01 \pm 16 \%$ en T0 a 1,7 \pm 0 , $51 \%$ en el sitio BIA; mientras que en el sitio de AIA varió de $7,6 \pm 1,8$ a $4,8 \pm 2,1$, aunque no se registraron diferencias en esta clase de tamaño durante la experiencia (Figura 3.8, Tabla

3.10). En ambos las mayores abundancias de esta clase de tamañose registraron en T0 y $T 1$, aunque no fue significativo.

La abundancia de la clase de tamaño 2 fue significativamente mayor en el sitio BIA, donde alcanzó valores medios de 20,7 \pm 6 , 3\% mientras que los valores medios en el sitio AlA fueron de 13,1 $\pm 2,1 \%$ (Figura 3.8). Además, se observaron diferencias significativas en el tiempo, siendo mayores los valores de abundancias en los tiempos iniciales con respecto a los finales (Tabla 3.8) en ambos sitios.

La proporción de diatomeas de la clase de tamaño 3 fue significativamente mayor en el sitio AIA ( $p<0,05 ;$ eta $^{2}=0,47$, Tabla 3.10), teniendo un valor promedio de $62,1 \pm 5,9 \%$, mientras que el valor en BIA fue de $43,4 \pm 8,9 \%$.

En el sitio BIA, la clase de tamaño 4 varió desde $13,3 \pm 5,6 \%$ en T0 a $48,2 \pm 2,2 \%$ en T4; mientras que en el sitio AIA varió desde $17,5 \pm 7 \%$ en T0 a 11, $3 \pm 2,7$ en T4. Se 
observaron valores significativamente mayores de abundancias en BIA con respecto a AIA sólo en T2 y T4 (Figura 3.8). Además en el sitio BIA se observó una proporción significativamente mayor esta clase de tamaño en el tiempo T4 (Tabla 3.10, Figura 3.8).

Con respecto al último tamaño de clase, la abundancia de las diatomeas de clase de tamaño 5 fue mayor en T2 con respecto a T0, independientemente de los sitios (Tabla 3.10, Figura 3.8). La proporción tuvo valores medios de 5,5 $\pm 3 \%$ en el sitio BIA y de 5,9 $\pm 1,6 \%$ en el sitio AIA.

Las especies mas representativas de cada rasgo ecológico (gremios ecológicos y clases de tamaño) en ambos sitios expuestos a impacto agrícola se muestran en las Tablas Anexas $\underline{3 C}$ y $\underline{3 D}$. 
Tabla 3.10: Resultados de los RM-ANOVA a dos vías (Factores: Tiempo, Sitio, Tiempo*Sitio) para las variables del ensamble de diatomeas. Las diferencias significativas se muestran en negrita $(p<0,05)$; se muestran los resultados de los test a posteriori Holm-Sidack para el factor tiempo y sitio, y el tamaño del efecto biológico $\eta^{2}$.

\begin{tabular}{|c|c|c|c|c|c|c|c|}
\hline & \multicolumn{3}{|c|}{ RM -ANOVA } & \multicolumn{3}{|c|}{ A posteriori (SNK test) } \\
\hline & & Tiempo & Sitio & $\begin{array}{l}\text { Tiempo* } \\
\text { sitio }\end{array}$ & Tiempo & Sitio & Tiempo*sitio \\
\hline \multirow{3}{*}{$\begin{array}{l}\text { Diversidad } \\
\text { de Shannon } \\
\text { (bits.ind }^{-1} \text { ) }\end{array}$} & $\mathrm{F}$ & 4,515 & 8,174 & 0,997 & & & \\
\hline & $\mathrm{p}$ & 0,034 & 0,104 & 0,462 & T0 $>$ T4 & & \\
\hline & $\eta 2$ & 0,454 & 0,096 & 0,073 & & & \\
\hline \multirow{3}{*}{ Riqueza } & $\mathrm{F}$ & 1,158 & 1,402 & 4,332 & & & \\
\hline & $\mathrm{p}$ & 0,397 & 0,358 & 0,037 & & & \\
\hline & $\eta 2$ & 0,196 & 0,026 & 0,230 & & & \\
\hline \multirow{3}{*}{ IDP } & $\mathrm{F}$ & 5,49 & 18,362 & 1,468 & & & \\
\hline & $\mathrm{p}$ & 0,02 & 0,05 & 0,298 & $\mathrm{~T} 2=\mathrm{T} 3>\mathrm{T} 0$ & & \\
\hline & $\eta 2$ & 0,181 & 0,338 & 0,137 & & & \\
\hline \multirow{3}{*}{$\begin{array}{c}\text { Bajo perfil } \\
\text { (\%) }\end{array}$} & $\mathrm{F}$ & 1,465 & 0,264 & 1,331 & & & \\
\hline & $p$ & 0,299 & 0,659 & 0,338 & & & \\
\hline & $\eta 2$ & 0,113 & 0,011 & 0,195 & & & \\
\hline \multirow{3}{*}{$\begin{array}{c}\text { Alto perfil } \\
(\%)\end{array}$} & $\mathrm{F}$ & 3,896 & 0,566 & 0,224 & & & \\
\hline & $\mathrm{p}$ & 0,048 & 0,53 & 0,918 & $\mathrm{~T} 3>\mathrm{T} 4$ & & \\
\hline & $\eta 2$ & 0,204 & 0,014 & 0,048 & & & \\
\hline \multirow{3}{*}{ Móviles (\%) } & $\mathrm{F}$ & 2,217 & 0,261 & 0,253 & & & \\
\hline & $\mathrm{p}$ & 0,157 & 0,66 & 0,900 & & & \\
\hline & $\eta 2$ & 0,154 & 0,010 & 0,050 & & & \\
\hline \multirow{3}{*}{ Clase 1 (\%) } & $\mathrm{F}$ & 2,364 & 0,4 & 0,705 & & & \\
\hline & $p$ & 0,14 & 0,592 & 0,611 & & & \\
\hline & $\eta 2$ & 0,299 & 0,011 & 0,093 & & & \\
\hline \multirow{3}{*}{ Clase 2 (\%) } & $\mathrm{F}$ & 10,38 & 33,388 & 2,018 & $\mathrm{~T} 0>\mathrm{T} 4$ & & \\
\hline & $\mathrm{p}$ & 0,003 & 0,029 & 0,185 & $\mathrm{~T} 0>\mathrm{T} 2$ & $\mathrm{BI} A>\mathrm{AIA}$ & \\
\hline & $\eta 2$ & 0,249 & 0,314 & 0,139 & $\mathrm{~T} 1>\mathrm{T} 4$ & & \\
\hline \multirow{3}{*}{ Clase 3 (\%) } & $\mathrm{F}$ & 3,499 & 36,066 & 1,777 & & & \\
\hline & $p$ & 0,062 & 0,027 & 0,227 & & $\mathrm{AI} A>\mathrm{BIA}$ & \\
\hline & $\eta 2$ & 0,174 & 0,479 & 0,078 & & & \\
\hline \multirow{3}{*}{ Clase 4 (\%) } & $\mathrm{F}$ & 7,077 & 107,109 & 17,626 & & & \\
\hline & $p$ & 0,01 & 0,009 & $<0,001$ & & $\mathrm{BIA}$ & $\mathrm{T} 4>\mathrm{T} 0=\mathrm{T} 1=\mathrm{T} 2=\mathrm{T} 3$ \\
\hline & $\eta 2$ & 0,279 & 0,181 & 0,401 & & & \\
\hline \multirow{3}{*}{ Clase 5 (\%) } & $\mathrm{F}$ & 4,358 & 0,928 & 2,423 & & & \\
\hline & $p$ & 0,037 & 0,437 & 0,133 & $\mathrm{~T} 2>\mathrm{T} 0$ & & \\
\hline & $\eta 2$ & 0,234 & 0,005 & 0,274 & & & \\
\hline
\end{tabular}



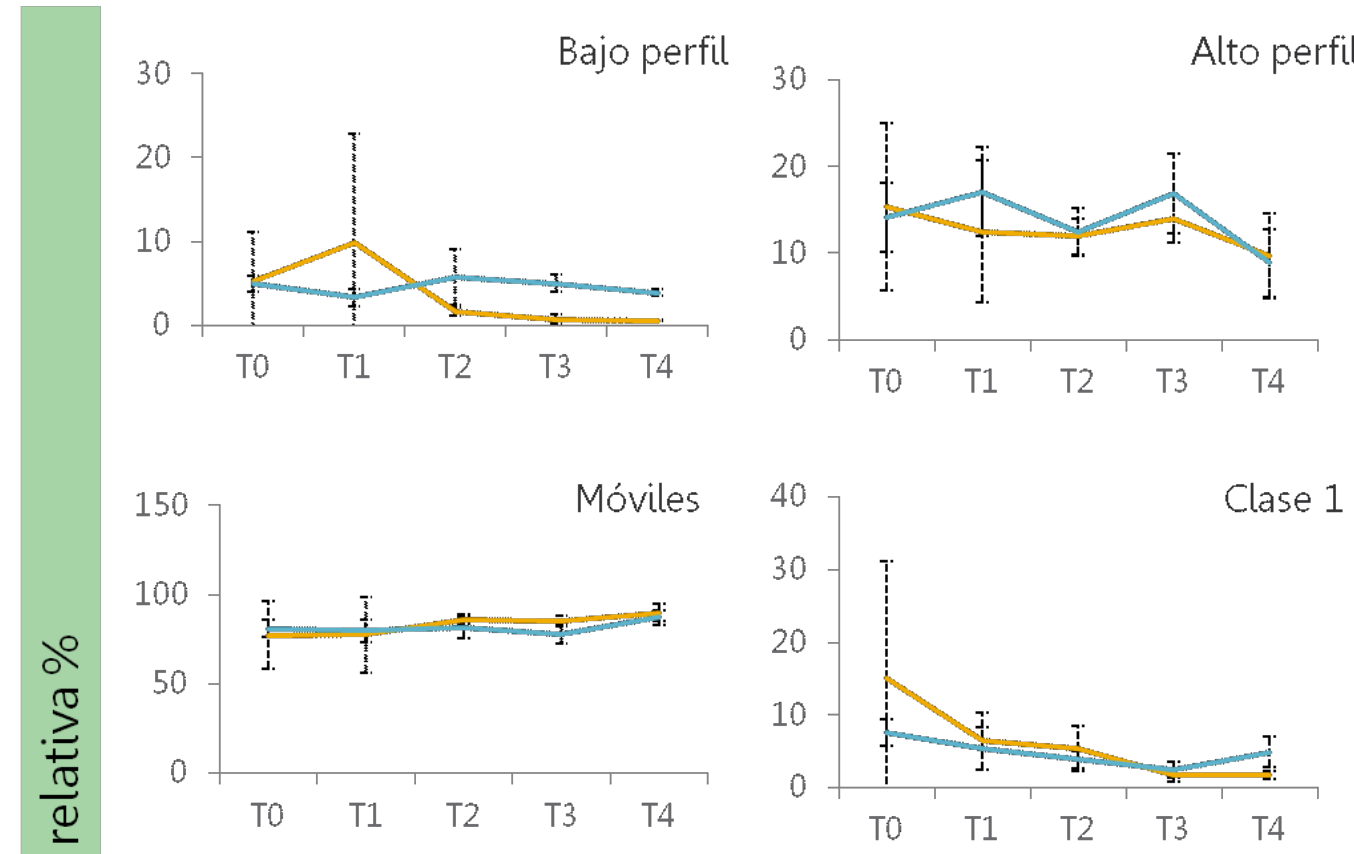

Clase 2
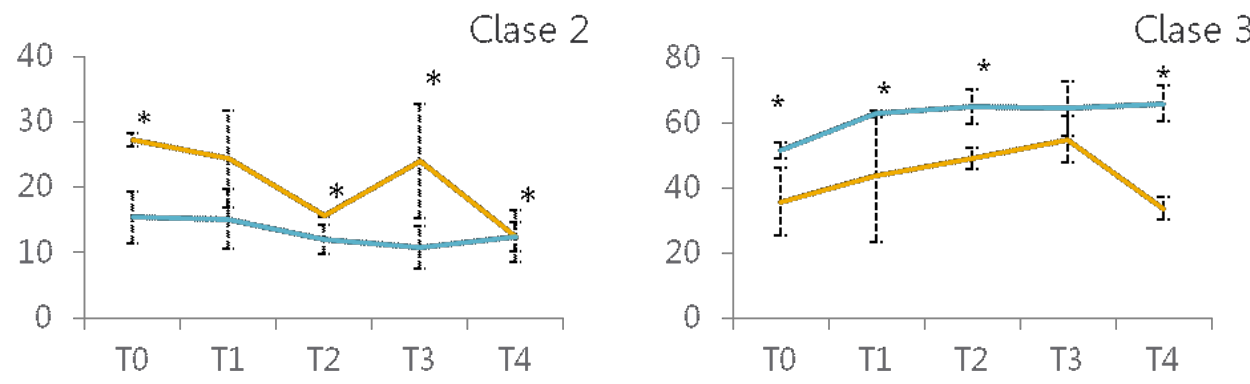

Clase 4 Clase 5
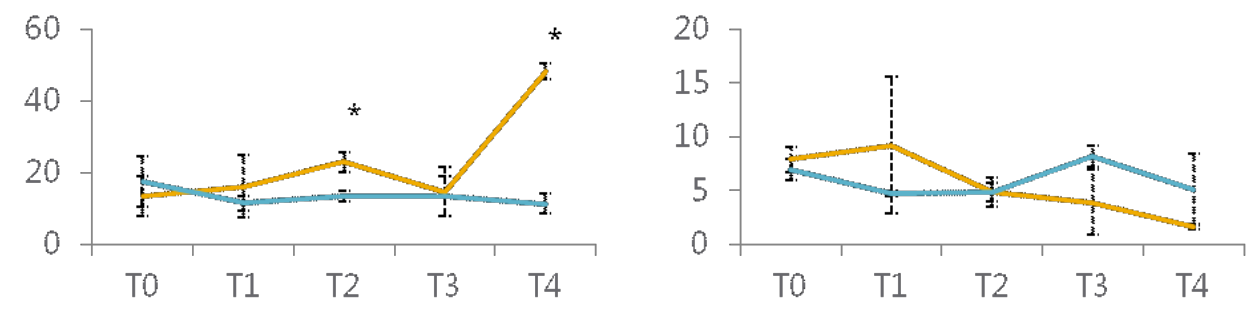

\section{Tiempo}

Figura 3.8: variación de los valores medios de los gremios ecológicos (Bajo perfil, alto perfil, móvil) y las clases de tamaño $(1,2,3,4,5)$ del ensamble de diatomeas a lo largo de la experiencia en ambos sitios $(B I A=$ bajo impacto agrícola; AIA = alto impacto agrícola) Las barras indican los desvío estándar y los asteriscos $\left(^{*}\right)$ indican diferencias significativas ( $p$-valor $<0.05)$ 


\subsection{Discusión}

En este capítulo se caracterizó la dinámica de colonización del biofilm en sustratos artificiales duros, en arroyos expuestos a diferentes niveles de impacto urbano y agrícola, a través de las variaciones de la estructura del ensamble de diatomeas (índice de diversidad de Shannon, riqueza, el Índice de diatomeas pampeanas, gremios ecológicos y clases de tamaño), la clorofila-a, y la densidad de los grupos algales. Las respuestas de las diatomeas fueron evaluadas en arroyos expuestos a dos tipos de impactos antropogénicos (urbano y agrícola) y a su vez bajo dos niveles de intensidad de impacto (alto y bajo), obteniendo distintas respuestas en algunos parámetros del ensamble a la variedad de condiciones ambientales:

\section{5.a Colonización del ensamble de diatomeas en arroyos expuestos a impactos urbanos}

Transcurridas unas pocas horas, el desarrollo del biofilm fue detectable en ambos sitios. En el arroyo con una mejor calidad del agua (menor concentración de nutrientes y materia orgánica y mayor oxígeno disuelto), el aumento de la biomasa de algas fue más rápido y la concentración de clorofila-a fue medible después de transcurridos sólo 30 minutos. Si bien, esta rápida colonización inicial en arroyos con una mejor calidad del agua coincide con los resultados encontrados en investigaciones previas realizadas en un arroyo oligotrófico (Pohlon, Marxsen y Küsel, 2010), donde se registró una densidad de algas inicial de $10 \mathrm{cel.cm}^{-2}$ dentro de la primera hora del proceso de colonización; los resultados fueron contrarios a lo esperado. La hipótesis planteada en este capítulo fue que tanto el valor de biomasa y su tasa de incremento serían mayores en el sitio con mayor concentración de nutrientes y materia orgánica, en coincidencia con lo medido en estudios previos (Borchardt, 1996; Stevenson, 1996; Wyatt et al., 2010). Si bien la contaminación urbana en los arroyos está asociada principalmente a un aumento de la concentración de nutrientes y materia orgánica, existen otros contaminantes tóxicos (ej: metales pesados) que intervienen en este tipo de contaminación, formando parte de lo que se conoce como el "Síndrome del arroyo urbano" (Walsh et al 2005). A pesar de que la principal diferencia entre los arroyos estudiados es el contenido de nutrientes y materia orgánica, no se puede dejar de lado, que estudios previos en el sitio de mayor impacto han registrado la presencia de metales pesados (Armendáriz et al., 2017; Cochero et al., 2017; López van Oosterom et al., 2015; Ronco et al., 2001; Sierra et al., 2013), lo que podría explicar el hecho de que la biomasa y su tasa de incremento fueron menores en el sitio de mayor impacto. 
Las primeras algas se encontraron a los 30 minutos de exposición de los sustratos, siendo las dominantes las diatomeas, representadas principalmente por Nitzschia amphibia, Nitzschia umbonata y Nitzschia palea en ambos sitios. Dentro de las primeras 24 hs del proceso de colonización de sustrato artificial es esperable encontrar una gran proporción de frústulos vacíos (Stevenson, 1983, 1984), probablemente causado por el proceso de sedimentación. En coincidencia, los resultados de este estudio mostraron que dentro de ese período (T0-T3) la proporción de frústulos vacíos fue grande, pero a partir de las 24hs disminuyó notablemente en ambos sitios.

La densidad de diatomeas en este estudio resultó ser mayor en el sitio de menor impacto contrariamente a los reportado por otros estudios donde mayores densidades de diatomeas fueron reportadas en sitios con mayor concentración de nutrientes (Duong et al., 2007; Licursi et al 2015). Esto pone en evidencia que otros factores además de las concentraciones de nutrientes, como por ejemplo mayor disponibilidad de luz debido a la menor concentración de sólidos suspendidos totales, podrían estar influenciando en la densidad total del ensamble tal como fue observado por Licursi y Gómez 2009.

En este estudio, no se observaron diferencias entre los índices de diversidad, ni la riqueza, como era esperado para ambientes ricos en nutrientes donde se ha comproabado que la diversidad del microalgas bentónicas puede verse afectada, a través de una reducción en la equitabilidad, debido al incremento de especies dominantes en el ensamble (Hillebrand and Sommer 2000). Sin embargo, los resultados hallados coinciden con los reportados por Duong et al. (2007), quienes no encontraron variaciones significativas de estos índices durante la colonización del ensamble de diatomeas en arroyos con diferentes niveles de impacto urbano.

Los ensambles de diatomeas responden al enriquecimiento de nutrientes del cuerpo de agua a través del cambio en la proporción de especies tolerantes a la eutrofización, la proporción de especies heterotróficas y la proporción de formas móviles (Fore y Grafe, 2002). El ensamble de diatomeas que se desarrolló en el sustrato artificial en este estudio, es característico de ambientes eutróficos con contaminación orgánica de moderada a alta según lo reportado por Gómez y Licursi (2001). La colonización desde etapas tempranas estuvo dominada en ambos sitios por taxones muy tolerantes a la contaminación, tales como Nitzschia palea, Nitzschia umbonata, Nitzschia amphibia y Gomphonema parvulum, los cuales son comunes y abundantes en arroyos pampeanos afectados por el uso de suelo urbano y/o agrícola como consecuencia de los altos niveles de materia orgánica y nutrientes (Gómez y Licursi, 2001; Licursi y Gómez, 2002; Sierra et al., 2013). Los valores del IDP hallados 
reflejan las características del ensamble encontrado en ambos sitios. Sin embargo, los valores del IDP resultaron mayores en el sitio de bajo impacto en las primeras fechas, siendo iguales en la última fecha en ambos sitios, posiblemente debido a que el índice fue creado para evaluar la calidad del agua a través del estudio del ensamble de diatomeas de un biofilm completamente desarrollado (Gómez y Licursi 2001), en vez de uno en formación.

La abundancia de diatomeas del gremio de bajo perfil en este estudio se caracterizó por ser muy baja en los dos arroyos estudiados. A pesar de que las especies que componen este gremio son en su mayoría especies pioneras en el proceso de colonización, su abundancia en los cuerpos de agua en los cuerpos de agua con altos niveles de de nutrientes y materia orgánica es muy baja (Passy 2007, Berthon et al., 2011, Stenger-Kóvacs et al., 2013), razón que puede explicar los bajos valores de este gremio.

Con repecto al gremio de alto perfil, a partir de las 48 hs, la proporción fue mayor en el sitio con mayor concentración de nutrientes. Estos resultados concuerdan con el hecho de que, este gremio, suele ser abundante en cuerpos de agua ricos en nutrientes (Lange et al., 2011; Passy, 2007; B-Béres et al., 2016; Stenger-Kovács et al., 2013). Esta respuesta fue causada principalmente por el aumento de la proporción de G. parvulum. Esta especie ha sido descripta como un taxón abundante en ambientes que reciben efluentes de aguas residuales urbanas (Vis et al., 1998). Además está adaptada a la competencia por el espacio (Hoagland et al., 1982), y está fuertemente asociada con ambientes ricos en materia orgánica (Kelly and Whitton, 1995; Medley y Clements, 1998; Van de Vijver y Beyens, 1998).

El gremio móvil fue el más abundante en ambos sitios, siendo su proporción significativamente mayor en el sitio de bajo impacto a partir de las 48 hs. Su gran abundancia en ambientes con altos contenidos de nutrientes puede explicarse debido a que este gremio comprende principalmente especies eutróficas y tolerantes a la contaminación que pueden evitar físicamente el estrés, al pasar a microhábitats ricos en recursos (Johnson et al., 1997). Asimismo, las representantes de este gremio pueden buscar refugio dentro del biofilm (Larras et al., 2013) y regular el balance entre el acceso a los recursos ambientales (luz, nutrientes) y la exposición al estrés (Fore y Grafe, 2002; Laviale et al., 2009), lo que explica su máximo en niveles altos de nutrientes

Con respecto a las clases de tamaño, los resultados de este capítulo confirman que las clases de tamaño pequeño (clase 1 y 2 ) son poco abundantes en cuerpos de agua ricos 
en nutrientes y materia orgánica, en concordancia con lo reportado por Berthon et al (2011) y Lavoie et al (2010). Asiminsmo, a pesar de su baja proporción en ambos sitios, la abundancia de las clases pequeñas fue mayor en el sitio más impactado, en coincidencia con Morin et al (2006), quienes han reportado un aumento de la proporción de tallas pequeñas frente a la exposición a compuestos tóxico.

Asimismo, se ha demostrado que las especies pertenecientes a las clases de tamaño más grandes también pueden ser pioneras debido a su rápida capacidad de asentamiento en varios sustratos (Ács y Kiss, 1993; Ács et al., 2000), como resulta el caso de Nitzschia palea (Duong et al., 2007). En este estudio la clase de tamaño 3 fue la más abundante en ambos sitios, en todos los tiempos de colonización, siendo significativamente mayor en los sitios más impactados. Esta clase de tamaño está dominada por especies tolerantes a la eutrofización y a la materia orgánica, tales como Nitzschia palea, Gomphonema parvulum, Nitszchia amphibia que coincidentemente fueron las especies más abundantes en ambos ensambles. La abundancia de la clase de tamaño 4 aumentó, como era esperado, sólo en el sitio de mayor impacto. Mientras que la clase de tamaño 5 fue mayor en el sitio de menor impacto, debido a la gran abundancia de Nitzschia umbonata.

Los resultados no indicaron un patrón claro de colonización temprana con respecto a los tamaños. Es probable que la proporción de las diferentes clases de tamaño durante el desarrollo inicial del biofilm en estos arroyos ricos en nutrientes sea más dependiente de la composición del ensamble del medio que a las habilidades de colonización de las diferentes clases de tamaño.

Conclusiones: colonización del ensamble de diatomeas en arroyos expuestos a impactos urbanos

En función de las predicciones planteadas para esta experiencia se advirtió que las mismas se cumplieron parcialmente. En tal sentido, el estudio de colonización del ensamble de diatomeas en el biofilm de sustratos artificiales en arroyos con diferentes niveles de impacto urbano reveló que el desarrollo de la biomasa del biofilm en el arroyo más impactado fue menor y más lento.

Los resultados mostraron que los gremios ecológicos de las diatomeas no muestran patrones lo suficientemente claros como descriptores de colonización temprana en arroyos con concentraciones elevadas de nutrientes. La pequeña proporción de gremios de bajo perfil que se halló en los sustratos fue consistente con el hecho de que este gremio se encuentra poco representado en ambientes con altos niveles de nutrientes. La gran 
abundancia del gremio de alto perfil en el sitio de alto impacto y la abundancia de grupos móviles en ambos sitios confirmó el hecho de que estos gremios son dominantes en ricos en nutrientes. Las clases de tamaño permitieron diferenciar entre sitios, y mostraron una variación temporal principalmente en el sitio de mayor impacto. Asimismo se observó que la clase de tamaño intermedia fue la más abundante independientemente del grado de impacto, liderando el proceso de colonización

\section{5.b Colonización del ensamble de diatomeas en arroyos expuestos a impactos agrícolas}

La dinámica de colonización y la evolución del biofilm tienen un impacto directo en la respuesta de las algas frente a la exposición a compuestos tóxicos como los pesticidas (Guasch et al. 1997), ya que el desarrollo de la matriz del biofilm actúa como una capa protectora frente a estos compuestos permitiendo la evolución de las microalgas (Peres et al. 1996).

Los resultados de esta experiencia evidenciaron menores valores de clorofila-a en el sitio con mayor concentración de agroquímicos. Esto concuerda con el hecho de que la concentración de clorofila-a del biofilm, como medida general de la biomasa autotrófica, puede verse afectada por la presencia de agrotóxicos, encontrándose bajos valores del pigmento frente a la exposición a compuestos como la atrazina, el diuron, el glifosato, el endosulfán y otros compuesto orgánicos persistentes (ej: Vera et al., 2010; Guasch et al. 2007; López-Doval et al. 2010; Ebenezer et al 2014; Downing et al 2004). Sin embargo, los valores registrados en el sitio de mayor impacto en este estudio, fueron mayores a los reportados en biofilms expuestos a glifosato en experiencias de mesocosmos $(0,2$ a 1,71 $\mu \mathrm{g} . \mathrm{cm}^{-2}$; Vera et al 2009), y a los valores registrados en comunidades expuestas a atrazina en arroyos mediterráneos ( $<1 \mu \mathrm{g} \cdot \mathrm{cm}^{-2}$; Guasch et al 1997).

El proceso de colonización de los grupos algales demostró ser más lento en el arroyo de mayor impacto con respecto al del menor, en coincidencia con lo demostrado por Vera et al., (2009). Sin embargo durante las primeras 3 horas, el proceso de colonización por algas ya había comenzado en ambos arroyos. En ninguno de los sitios las diatomeas fueron el grupo algal dominante, en el sitio de BIA la colonización fue dominada por cianofitas y diatomeas; mientras que en el sitio de AIA dominaron las clorofitas y las diatomeas. Al final de la experiencia, las densidades de los grandes grupos algales fueron mayores en el sitio menos impactado, evidenciando un mayor desarrollo de la porción autotrófica del biofilm. La densidad de microalgas puede verse afectada por la presencia 
de pesticidas (Pesce et al 2011) y en particular por el endosulfán, probablemente debido a daños ocasionados en el aparato fotosintético (Ebenezer et al 2014; Downing et al 2004). Varias especies de cianobacterias filamentosas y cocoides, junto a especies del género Melosira y Oscillatoria desaparecen frente a concentraciones elevadas de este compuesto organoclorado (10 $\left.\mathrm{gg}^{\mathrm{L}} \mathrm{L}^{-1}\right)$ (DeLorenzo et al., 1999). Estas respuestas coinciden con los resultados expuestos, donde estos grupos taxonómicos estuvieron mejor representados en el sitio menos impactado.

Los ensamble de diatomeas de los arroyos estudiados en este capítulo están dominados por especies tolerantes a la eutrofización y contaminación por materia orgánica, tal como lo indican los valores de IDP calculados (Sitio Bajo impacto: 2,96 \pm 0,1 y Sitio de Alto impacto: $3,2 \pm 0,1)$. Independientemente del sitio analizado, se observó que la diversidad resultó ser significativamente menor en el tiempo final del estudio (2 semanas). Si bien es esperable que la diversidad aumente en las primeras etapas de la sucesión, debido a la llegada de nuevas especies colonizadoras, al transcurrir el tiempo, y en las etapas sucesionales más avanzadas, la competencia entre especies lleva a una disminución de los valores de éste índice (Valiela, 1995). Esta dinámica coincide con los resultados expuestos en este capítulo, y los reportados por Ács et al 2000, los cuales coinciden en hallar una disminución del valor de la diversidad 2 semanas luego de comenzada la colonización, con respecto a los valores encontrados en las primeras horas.

Con respecto a los gremios ecológicos, los resultados de este capítulo muestran que el gremio de bajo perfil no refleja un patrón definido durante la colonización ni se ve afectado por los aspectos de la calidad de agua abordados en los arroyos estudiados. Debido a sus características, las especies de este gremio tienden a disminuir su proporción cuando aumente la carga orgánica y la concentración de nutrientes (Berthon et la 2011), razón que puede explicar su baja representatividad en los arroyos estudiados.

El gremio de alto perfil no se vió significativamente afectado por los diferentes niveles de impacto que tienen los arroyos estudiados en esta experiencia. Estos resultados no se corresponden con lo reportado por otros estudios donde este gremio resultó ser el más afectado frente a la exposición a agrotóxicos tanto en experiencias en mesocosmos (Rimet et al 2012), como en campo (Bouchez et al 2012). Asimismo ha sido reportado como el único gremio que se correlacionó negativamente con aumentos en los niveles de atrazina medidos en campo, y mostró la misma tendencia con las concentraciones de diuron e isoproturon (Rémy et al 2013). Sin embargo cabe destacar que la especie más representativa de este 
gremio en el sitio de mayor impacto fue Gomphonema parvulum, catalogada como tolerante a los pesticidas (Peres et al 1996; Pesce et al 2011, Roubeix et al 2010).

En los resultados expuestos en este capítulo, más del $70 \%$ de las especies que se encontraron en el biofilm desarrollado en el sustrato artificial pertenecen al gremio móvil. La abundancia de este gremio no tuvo diferencias entre los sitios, a pesar que la bilbiografía muestra respuestas bastantes congruentes de este gremio frente a la exposición a agroquímicos. La abundancia relativa de este gremio aumentó en arroyos artificiales tratados con diuron y azoxystrobin (Rimet et al 2011), en mesocomos tratados con thiram (Bayona et al 2012) y en ríos contaminados por diuron (Morin et al 2009). Cabe destacar, que en ambos sitios la especie más representativa fue Nitzschia palea (>40\% en el sitio Más impactado, > 20\% en el sitio Menos impactado). Esta especie es catalogada como tolerante a la contaminación por nutrientes y materia orgánica, es considerada tolerante a los agroquímicos (Debenest et al 2010), y cumple el criterio de especie colonizadora debido a su fuerte capacidad de colonizar un nuevo sustrato formando una primera capa viva que puede albergar nuevas especies (Duong et al 2007).

Las clases de tamaño son otros de los rasgos de las diatomeas que se han estudiado como indicadores de diferentes tipos de contaminantes. En esta experiencia la abundancia de las clases de tamaño pequeñas (particularmente la clase 2) fue mayor en las primeras horas de colonización que al trascurridas las 2 semanas. Esto puede deberse al hecho de que las especies de tamaño pequeño tienen una alta tasa de crecimiento, lo que les permite colonizar sustratos y otras superficies naturales antes que otras especies, incluso en condiciones desfavorables, como la presencia de contaminación tóxica (Goldsborough y Robinson 1986; Peres et al.1996). Por otro lado, diversos estudios han demostrado que en arroyos con elevada concentración de nutrientes, las especies de menor tamaño son minoría (Berton 2011, Lovoie et al 2010), resultados que coinciden con los hallados en este capítulo, en los que las clase 1 y 2 representan un porcentaje muy bajo en el ensamble de diatomeas.

La clase de tamaño intermedia (clase 3), no mostró variaciones a través del tiempo de colonización, pero si resultó ser más abundantes en el sitio de mayor impacto, debido principalmente a la abundancia de Nitzschia palea. Asimismo, dentro de esta clase se incluyen especies tolerantes a la eutrofización, a la materia orgánica, y a los agroquímicos tales como Nitzschia palea, Gomphonema parvulum, Nitzschia amphibia, entre otras.

Con respecto a las clases de tamaño más grandes (clases 4 y 5), los resultados en este estudio evidenciaron que estas clases no mostraron diferencias significativas entre sitios 
con diferentes niveles de impacto agrícola. Asimismo según lo reportado en la bibliografía, se esperaba que las clases de tamaño más grandes fueran más abundantes en sitios ricos en nutrientes, debido a que la competencia no es fuerte donde los nutrientes están disponible (Lovoie et al 2010), sin embargo esto no se vió reflejado en los ensambles estudiados en este capítulo. Cabe destacar que como se hipotetizó, sí se encontró un aumento en el tiempo de la clase de tamaño 4 en el sitio con menor impacto.

Conclusiones: colonización del ensamble de diatomeas en arroyos expuestos a impactos agrícolas

En función de las predicciones planteadas para esta experiencia se advirtió que las mismas se cumplieron parcialmente. En tal sentido, el estudio de colonización del biofilm y su ensamble de diatomeas en sustratos artificiales, en arroyos con diferentes niveles de impacto agrícola, reveló que el desarrollo de la biomasa del biofilm en el arroyo más impactado fue menor y más lento.

En cuanto a las variables del ensamble de diatomeas, la riqueza y los índices (Shannon, IDP) no evidenciaron variaciones en los cortos tiempos evaluados. El análisis de los rasgos del ensamble de diatomeas mostró que, el uso de los gremios ecológicos no resultó ser una herramienta sólida para describir las diferencias en la dinámica de colonización temprana en los arroyos con distinto impacto. En tanto, las variaciones en las proporciones de las clases de tamaño de las diatomeas, sí permitieron diferenciar los sitios, y resultaron útiles para la caracterización del proceso de colonización temprana. 


\subsection{Consideraciones finales del capítulo}

En ambas experiencias presentadas en este capítulo, la biomasa autotrófica del biofilm, analizada a través de la clorofila-a, demostró ser una variable que respondió a los niveles de impactos estudiados. Su concentración en el biofilm fue menor en los sitios más impactados, y sus tasas de incremento durante el desarrollo de la comunidad fueron menores. Con respecto a las densidades de los grandes grupos de algas, los resultados fueron más variables. En los arroyos urbanos, las diatomeas dominaron el biofilm en comparación con los otros grupos estudiados. Asimismo, en el caso de los arroyos que atraviesan zonas agrícolas, las diatomeas no fueron dominantes en biofilm, sino que otros grupos como las cianofitas y las clorofitas estuvieron representados en mayor o igual medida. Al comparar los valores de las tasas de incremento de los grupos algales entre los tipos de impacto, se encontró que fueron mayores en los arroyos de impacto agrícola.

El ensamble de diatomeas en ambos casos de impactos antropogénicos, a través de lo reflejado por los valores de IDP, demostró que las especies que colonizan los sustratos artificiales son tolerantes a la contaminación orgánica y a la eutrofización, reflejan la condición ambiental bajo la cual se desarrollaron, y la mayor proporción de especies pertenece al género Nitzschia.

Los índices de diatomeas (índice de diversidad de Shannon, índice de diatomeas pampeano) y la riqueza no resultaron ser buenos descriptores del proceso de colonización temprana en los diferentes tipos de impacto considerados. Muy probablemente sean medidas que requieran de mayor tiempo para evidenciar diferencias.

En cuanto al análisis de los gremios ecológicos se pudo confirmar en ambas experiencias que el gremio de bajo perfil es el de menor representación en los ensambles que colonizan sustratos artificiales en arroyos con estos tipos de impacto. Los gremios de alto perfil y móvil fueron los de mayor representación, confirmando su preferencia por ambientes ricos en nutrientes. La variación de la abundancia de estos gremios mostró algunas tendencias solamente en la experiencia de impacto urbano, aunque su representación en el ensamble no varió lo suficiente como para ser considerado un indicador de la colonización temprana en ese tipo de impacto.

Con el análisis de las clases de tamaño se pudo establecer que en cuerpos de agua con impactos antropogénicos, analizados en este estudio, las células de tallas intermedias a grandes son las primeras colonizadoras de los sustratos artificiales. Particularmente la 
clase de tamaño 3 resultó ser la más abundante en los sitios de mayor impacto en ambas experiencias.

Tabla resumen: principales diferencias entre las experiencias de caracterización del proceso de colonización temprana del biofilm y del ensamble de diatomeas. Resumen de los resultados del RM ANOVA de las variables estudiadas y su potencial como indicadoras de colonización temprana. Referencias: $\leftrightarrow=$ diferencias entre sitios sólo en algunos tiempos; $\Delta=$ diferencias entre sitios; $T=$ diferencias en los tiempos; $\phi=$ sin diferencias significativas. Los colores de los símbolos indican el tamaño del efecto de la variable según el valor de $\eta^{2}$ (verde: $\eta^{2} \geq 0,75$, efecto grande; amarillo: 0,25> $\eta^{2}<0,75$ efecto moderado; rojo: $\eta^{2} \leq 0,25$, efecto pequeño). Para una mejor comparación se muestran los resultados hasta las 168 hs.

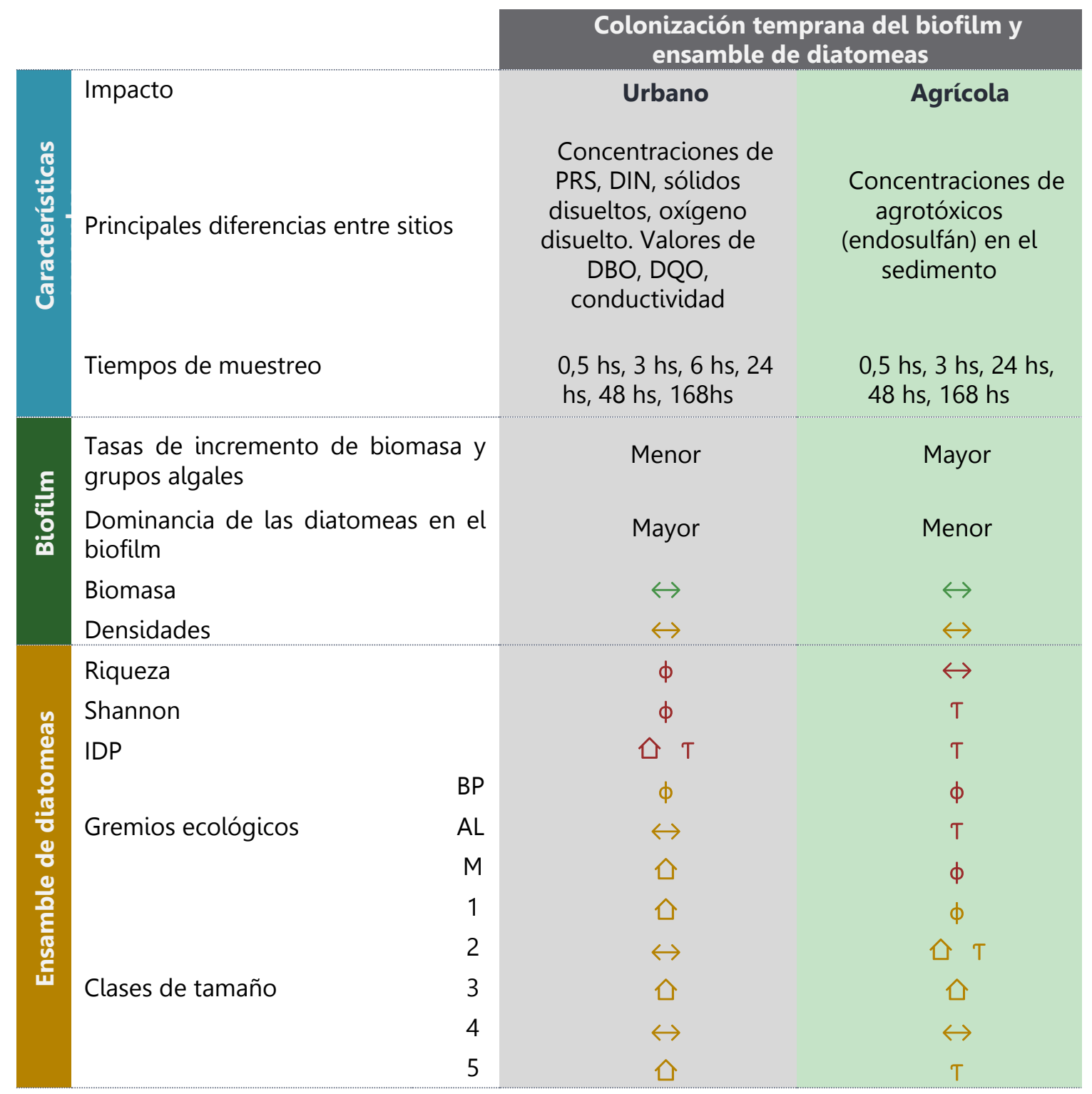


Estudio del ensamble de diatomeas epipélicas en una experiencia de translocación entre sitios con mayor a menor impacto urbano.

\subsection{Introducción}

Varios estudios han demostrado que existe una relación entre los aumentos en las concentraciones de nitrógeno y fósforo en los cuerpos de agua y el aumento en la biomasa de algas bentónicas del biofilm (Dodds, 2006; Smith y Schindler, 2009; Sabater et al., 2011), así como también ocasiona cambios en la composición de especies (ej: Stevenson, 1996; Wyatt et al., 2010). Frente al enriquecimiento de nutrientes debido a los impactos antropogénicos el ensamble de diatomeas responde con cambios en la proporción de especies tolerantes a la eutrofización, en la proporción de especies heterotróficas y en la proporción de las formas móviles (Fore y Grafe 2002). En los cuerpos de agua de la región de estudio, se ha encontrado que un aumento en la concentración de nutrientes produce una disminución de las taxa sensibles (Cochero et al 2015, Gómez et al., 2008; Licursi and Gómez, 2009).

Por otro lado se ha visto que los rasgos funcionales del ensamble de diatomeas, tales como la clasificación de las diatomeas en gremios ecológicos (Passy 2007), pueden proporcionar descriptores sensibles para evaluar cambios de la calidad de agua debido al enriquecimiento de nutrientes (Berthon et al 2011, Rimet et al 2009). En tal sentido se ha observado que los gremios de alto perfil y móvil se ven beneficiados frente a un aumento de la concentración de nutrientes, mientras que las de bajo perfil se ven perjudicadas (Berthon et al 2011; Stenger-Kóvacs et al 2013; Lange et al 2011).

Asimismo, el análisis de la movilidad de las diatomeas se ha sugerido como una herramienta útil para el biomonitoreo de cuerpos de agua contaminados con metales pesados (Pandey y Bergey, 2016). También se ha analizado en relación con la intensidad de la luz (Cohn, 2001; Cohn et al., 2004), frente a la toxicidad del metolacloro (Coquillé et al., 2005), a la toxicidad en los elutriados de sedimentos tóxicos (Cohn y McGuire, 2000), y frente a distintitos factores físico químicos, por ejemplo: $\mathrm{pH}$, exposición a rayos UV, metales y pesticidas (Gupta y Agrawal 2007). Por otro lado, el estudio de las anomalías nucleares (ubicación anormal del núcleo, presencia de micronúcleos, o alteración de la membrana nuclear), constituyen otra 
medida no taxonómica, que ha resultado sensible a la exposición de herbicidas (Debenest et al., 2008) y de Cr (IV) (Licursi y Gómez, 2013).

En el biofilm epipélico de los arroyos de la región de estudio se han explorado formas teratológicas, cambios en la composición de las especies y en la tolerancia de las especies a la contaminación para evaluar la calidad del agua (Gómez y Licursi 2001; Tolcach y Gómez, 2002; Gómez y Licursi, 2003; Gómez et al., 2009; Cochero et al., 2013; Licursi et al., 2016) pero la movilidad, las anomalías nucleares y la proporción de gremios ecológicos son parámetros que no han sido explorados como posibles indicadores de calidad del agua en estos cursos de agua. Por lo tanto la finalidad de este estudio es explorar estas características (movilidad, anormalidades nucleares, gremios ecológicos) conjuntamente con otros descriptores del ensambles de diatomeas (riqueza, diversidad, Índice de Diatomeas Pampenas ) a través de una experiencia de translocación desde arroyos con un alto nivel de impacto urbano a otros de menor impacto.

\subsection{Objetivos}

El objetivo de este capítulo es analizar los cambios estructurales y funcionales del ensamble de diatomeas en arroyos de zonas urbanas, particularmente en relación a concentraciones altas de nutrientes (fósforo y nitrógeno) y materia orgánica, cuando son expuestos a mejoras en la calidad del agua.

La hipótesis de este estudio es que los ensambles de diatomeas en el biofilm epipélico responderán modificando su estructura cuando la calidad del agua mejora:

- Aumentará la movilidad celular, la riqueza y la diversidad del ensamble de diatomeas.

- Disminuirán las proporciones de alteraciones nucleares de los taxa que conforman el ensamble de diatomeas, el índice de diatomeas pampeanas, la proporción de valvas deformadas; estas modificaciones irán acompañadas por una disminución de clorofila-a del biofilm.

- Disminuirán la proporción de diatomeas móviles y de alto perfil; mientras que la proporción de diatomeas de bajo perfil aumentará. 


\subsection{Materiales y métodos}

\section{3.a Diseño experimental}

Para el análisis de la recuperación del ensamble de diatomeas, se realizó una experiencia de translocación de sustrato natural detallada en la sección 2.1.7.a del capítulo de Materiales y Métodos. Las bandejas translocadas se denominaron TU, las bandejas control de los sitios de bajo impacto CBIU, y las bandejas control de los sitios de alto impacto CAIU. Los sitios y las bandejas fueron muestreadas durante julio-agosto del 2016 con los siguientes intervalos de tiempo: Día 0, Día 15, Día 30 y Día 45.

\section{3.b Sitios de muestreo}

Se seleccionaron 6 sitios en el partido de La Plata con características similares de profundidad, caudal, y cauces compuestos principalmente de arcilla con una baja proporción de grava y arena. Los sitios se seleccionaron considerando los usos del suelo urbano y su grado de impacto fue definido en base a las concentraciones de nutrientes (fósforo y nitrógeno) y materia orgánica medidos en el agua. Para más detalles sobre las características de los sitios, ver capítulo de Materiales y Métodos sección 2.2.2. Tres sitios fueron caracterizados como de bajo de impacto urbano (BIU) (34 5 58'47.66 "S / $58^{\circ} 33^{\prime} 7.81^{\prime \prime}$ O; $34^{\circ} 53^{\prime} 40.52$ "S / $58^{\circ}$ 1'22.69" O; $34^{\circ} 55^{\prime} 22.12$ "S / $58^{\circ} 4^{\prime} 58.91^{\prime \prime}$ )), y otros tres sitios, ubicados aguas abajo de los sitios BIU fueron referidos como sitios de alto impacto urbano (AIU) (34 57'52.37 "S / $58^{\circ}$ 0'16.96" O;

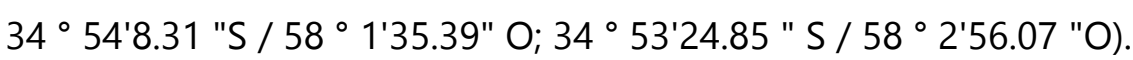

\section{3.c Variables medidas}

\section{Variables fisicoquímicas}

Se midieron por triplicado, en cada sitio y fecha de muestreo oxígeno disuelto $(O D$, $\left.\mathrm{mg} \mathrm{L}{ }^{-1}\right)$, temperatura $\left({ }^{\circ} \mathrm{C}\right)$, conductividad $\left(\mu \mathrm{S} \mathrm{cm}{ }^{-1}\right), \mathrm{pH}$, sólidos totales suspendidos (SST, mg L ${ }^{-1}$ ). Además se extrajeron muestras de agua para el análisis de nutrientes, la demanda bioquímica de oxígeno (DBO) y la demanda química de oxígeno (DQO). Para mayor detalle ver sección 2.1.2 de Materiales y Métodos. 


\section{Clorofila -a}

La recolección y el tratamiento para la extracción y medición del pigmento de las muestras de biofilm epipélico se detallan en el capítulo de materiales y métodos, apartado 2.1.3.

\section{Variables del ensamble de diatomeas}

Para análisis del ensamble de diatomeas se extrajeron 3 submuestras colectadas de cada bandeja por pipeteo (5-10 mm; 3 pocillos por bandeja) y fijadas en $4 \%$ de formaldehído (Stevenson, 1984; Lowe y Laliberte, 1996). Para la identificación y cuantificación del ensamble de diatomeas, se prosiguió según metodología detallada en capítulo 2, sección 2.1.5.a.

A partir del análisis del porcentaje de las valvas de diatomeas, se calcularon el índice de diversidad de Shannon-Weaver ( $H^{\prime}$ ', bits.ind-1) (Shannon and Weaver, 1949), y el índice de diatomeas pampeanas (IDP; Gómez y Licursi 2001).

Las especies de diatomeas se clasificaron en los gremios ecológicos: bajo perfil, alto perfil y móvil, según Passy (2007). Para más detalle, ver capítulo 2, apartados 2.1.5.b.

Para el análisis de movilidad, se siguió el protocolo detallado en la sección 2.1.5.f del capítulo de materiales y métodos. Solo se consideraron individuos del género Nitzschia. Se filmaron diez individuos por muestra.

Para el análisis de las alteraciones nucleares si siguió la metodología detallada en el capítulo de materiales y métodos sección 2.1.5.d.

Asimismo se contabilizó el porcentaje de valvas con alteraciones (cambios en el patrón de estrías; deformación del contorno de la valva; cambios en la forma, tamaño y posición del área longitudinal y central; modificaciones del rafe y del canal del rafe), (ver sección 2.1.5.e de Materiales y Métodos).

\section{3.d Análisis estadísticos}

Las diferencias entre las variables fisicoquímicas en los sitios se analizaron mediante un análisis de varianza multivariado de dos factores (MANOVA; Tiempo: Día 0, Día 15, Día 30, Día 45; Sitio: AIU, BIU), siguiendo el modelo $[X=\mu+$ Sitio + Tiempo + Tiempo * Sitio + Residuos] (Dytham, 2011). 
Para comparar las variables biológicas en las bandejas a lo largo de la experiencia y entre tratamientos se utilizó un análisis de la varianza de dos vías (ANOVA) (Dytham, 2011), los análisis siguieron el modelo $[X=\mu+$ Tratamiento + Tiempo + Tiempo * Tratamiento + error], con el factor de Tratamiento compuesto por tres niveles (CBIU = Bandejas control de los sitios BIU; CAIU = Bandejas control de los sitios AIU; TU = Bandejas translocadas desde los sitios AIU hasta los sitios BIU), y el factor Tiempo compuesto de cuatro niveles (Día 0, Día 15, Día 30 y Día 45).

La normalidad se evaluó previamente mediante la prueba de Shapiro-Wilk (Shapiro y Wilk, 1965) y la homogeneidad de varianzas mediante la prueba $C$ de Cochran (Cochran, 1951). Se calculó el Eta ${ }^{2}\left(\eta^{2}\right)$ como una medida del tamaño del efecto, y la prueba de Holm-Sidak (Holm, 1979) se utilizó como prueba post-hoc para los ANOVAS (Cohen, 2013).

\subsection{Resultados}

\section{Variables fisicoquímicas}

Los resultados de los análisis multivariados muestran diferencias significativas entre los sitios BIU y AIU (Factor de sitio: $F=6.40, p<0.05$ ), con un tamaño de efecto grande $\left(\eta^{2}\right.$ Parcial $\left.=0.84\right)$, independientemente del tiempo de muestreo (Factor de tiempo: $F=1.8, p=0.09 ; \eta^{2}$ Parcial $\left.=0.60\right)$. Los análisis univariados muestran que las diferencias entre los sitios se deben a mayores valores de nitratos, nitritos, $\mathrm{PRS}, \mathrm{DBO}_{5}$ conductividad, pH, temperatura y SST en los sitios AIU que en los BIU (Tabla 4.1). 
Tabla 4.1: Valores medios ( \pm desvío estándar) de las variables fisicoquímicas medidas en los sitios $\mathrm{BI}$ y $\mathrm{Al}$ durante el experimento, junto con los valores de significación de los análisis univariados del MANOVA (tiempo, sitio, tiempo * sitio), comparaciones post-hoc para esos factores y $\eta^{2}$ como medida del tamaño del efecto.

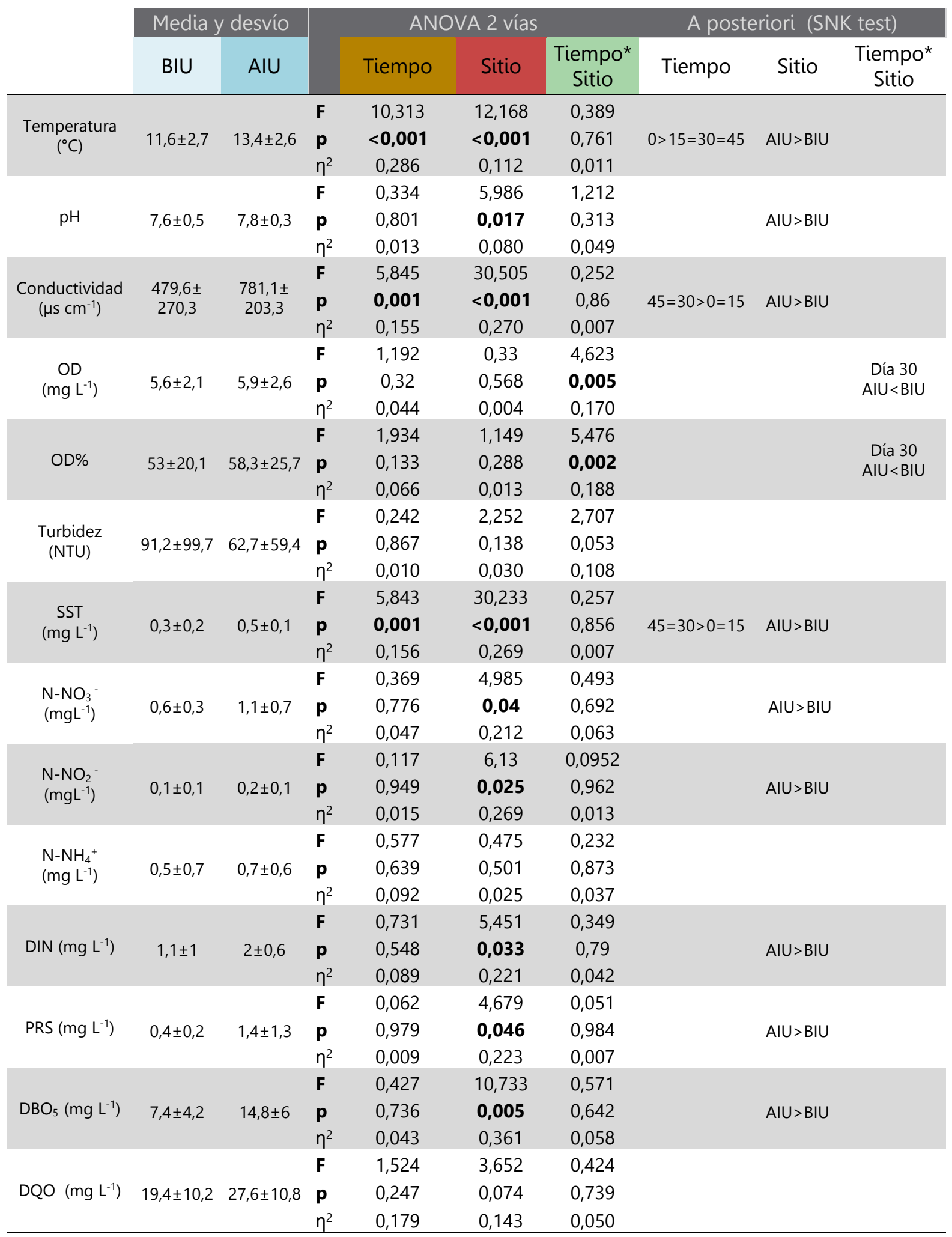




\section{Variables biológicas}

Los resultados del Anova 2-vías para la clorofila-a del biofilm epipélico muestra que no hubo diferencias significativas entre las bandejas a lo largo de la experiencia ni entre los tiempos de muestreo (Tabla 4.3).

\section{Variables del ensamble de diatomeas}

Se identificaron 160 especies de diatomeas en el epipelon durante la experiencia. Los taxa más representados en todos los sitios se muestran en la Tabla 4.2.

Tabla 4.2. Porcentaje de abundancia de las especies más representadas en los tratamientos CBIU, CAIU y T, y el gremio ecológico al que pertenecen.

\begin{tabular}{lccccc}
\multicolumn{1}{c}{ Especie } & CBIU & CAIU & T & Gremio \\
\hline Nitzschia palea (Kützing) W.Smith & 36 & 37,3 & 42,6 & M \\
Pseudofallacia monoculata (Hustedt) DGMann & 15,2 & 20,3 & 14,5 & M \\
Gomphonema parvulum (Kützing) Kützing & 4,01 & 6,5 & 5,4 & AP \\
Melosira varians Agardh & 8,8 & 0,72 & 3,5 & AP \\
Nitzschia umbonata (Ehrenberg) Lange-Bertalot & 0,5 & 6,4 & 4,9 & M \\
Sellaphora pupula (Kützing) Mereschkowksy & 2,5 & 4,9 & 4,1 & M \\
Navicula schroeteri Meister & 2,8 & 2,35 & 1,3 & M \\
\hline
\end{tabular}

La riqueza varió entre $21 \pm 5,9$ y $32 \pm 9,38$ en CBIU, entre $28 \pm 9,64$ y $29 \pm 9,04$ en CAIU y entre $23 \pm 8,35$ y $34 \pm 6,54$ en TU. El índice de diversidad de Shannon varió entre 1,85 $\pm 0,44$ y 3,01 $\pm 0,93$ bits.ind $^{-1}$ en CBIU, entre 2,58 $\pm 0,66$ y 2,93 $\pm 0,71$ bits.ind $^{-1}$ entre CAIU y 2,54 $\pm 0,79$ a 3,09 $\pm 0,42$ bits.ind $^{-1}$ en TU. La riqueza no fue significativamente distinta entre los tratamientos a lo largo de la experiencia, mientras que el índice de diversidad de Shannon fue sólo significativamente menor en el día 0 en todos los tratamientos en comparación con los siguientes tiempos de muestreo (Tabla 4.3, Fig. 4.1). El índice de Diatomeas Pampeanas, fue significativamente menor en CBIU $(3,15 \pm 0,17)$ con respecto a los valores hallados en CAIU $(3,35 \pm 0,11)$ y en TU $(3,32 \pm 0,2)$. Sin embargo el tamaño del efecto fue muy pequeño $(0,071)$. Los valores en todos los casos indican una muy mala calidad del agua (Figura 4.1).

El porcentaje de valvas con deformaciones (deformaciones en el contorno de la valva; cambios en el patrón de estrías; cambios en la forma, tamaño y posición del área longitudinal y central; modificaciones del rafe y del canal del rafe) no mostró diferencias entre los tratamientos, pero si en los tiempos de muestreo (Tabla 4.3). Esta 
variable alcanzó valores promedios de $0,18 \pm 0,14 \%$ en CBIU, 0,22 $\pm 0,06 \%$ en CAIU; T $0,15 \pm 0,14 \%$ en TU.

El análisis de las proporciones de los gremios ecológicos de los ensambles de diatomeas reveló que la proporción de diatomeas de alto perfil fue significativamente mayor en CBIU con valores medios de 14,89 15,45\%; mientras que en CAIU alcanzó valores de 7,99 $\pm 8,45 \%$ y en el ensamble translocado presentó valores de 10,04 $\pm 13,31 \%$. Sin embargo el tamaño del efecto fue pequeño ( $\eta^{2}$ Parcial $<0,25$; Tabla 4.3). Las especies mas representativas de cada gremio ecológicos en cada tratamiento se muestran en la Tabla Anexa 4A.

Las diatomeas de bajo perfil exhibieron una menor abundancia relativa en todos los tratamientos y no mostraron diferencias significativas. Los valores medios en CBIU fueron de 1,11 $\pm 1,61 \%$, en TU fueron de 1,54 $\pm 1,26 \%$; y en CAIU 1,31 $\pm 1,52 \%$.

El gremio móvil fue significativamente mayor en CAIU (Tabla 4.3, $p=0,012$ ), pero presentó un tamaño del efecto pequeño $\left(\eta^{2}\right.$ Parcial $\left.<0,25\right)$. Además se produjo una disminución significativa de las diatomeas móviles en los sustratos translocados (Figura 4.1). Sin embargo, este gremio fue el de mayor representación en todos los tratamientos presentando valores medios de 82,22 \pm 15,68\% en CBIU; $87,81 \pm 13,69 \%$ en TU; y 90,62 $\pm 8,27 \%$ en CAIU.

En cuanto a las medidas de las variables de movilidad, ninguna presentó diferencias significativas entre tratamientos durante la experiencia (Tabla 4.3). La distancia varió de 74,5 a 159,2 $\mu \mathrm{m}$, la velocidad media de 0,61 a 1,34 $\mu \mathrm{m} \mathrm{seg}^{-1}$ y la velocidad máxima de 16,25 a $32,08 \mu \mathrm{m} \mathrm{seg}^{-1}$.

La distancia y la velocidad máxima mostraron diferencias significativas solo en el día 15 donde los controles de bajo impacto (CBIU) presentaron valores más bajos que los controles de alto impacto (CAIU) y los sustratos translocados (TU) (Figura 4.2).

La cantidad de núcleos mal localizados fue significativamente mayor en las bandejas control de los sitios expuestos a alto impacto urbano (Tabla 4.3, Figura 4.2, $p<0,05$ ) en comparación con los sitios de bajo impacto, aunque el tamaño del efecto fue pequeño $\left(\eta^{2}\right.$ Parcial $\left.=0,075\right)$. La proporción de diatomeas con ruptura de la membrana nuclear fue significativamente menor en las bandejas CBIU que en las bandejas CAIU y las bandejas TU. Como se muestra en la Figura 4.2, en el día 45 la proporción de membranas nucleares 
rotas fue significativamente mayor en los controles de AIU en comparación con las bandejas translocadas y las bandejas controles de los sitios BIU

Tabla 4.3: Resultados del ANOVA 2 vías (Factores: Tiempo, Tratamiento y Tiempo * Tratamiento) para la clorofila $a$, la riqueza, la diversidad de Shannon, el índice de diatomeas pampeanas (IDP), la distancia ( $\mu \mathrm{m})$, velocidad $\left(\mu \mathrm{m} . \mathrm{seg}^{-1}\right)$, velocidad máxima $\left(\mu \mathrm{m} . \mathrm{seg}^{-1}\right)$, la proporción de diatomeas con localización anormal del núcleo y con ruptura de membrana nuclear, la proporción de gremios ecológicos (bajo perfil, alto perfil, móvil) y la proporción de valvas deformes. Las diferencias significativas se destacan en negrita. Los resultados de la prueba post-hoc también se muestran mediante la prueba de Holm-Sidak y $\eta^{2}$ como una medida del tamaño del efecto.

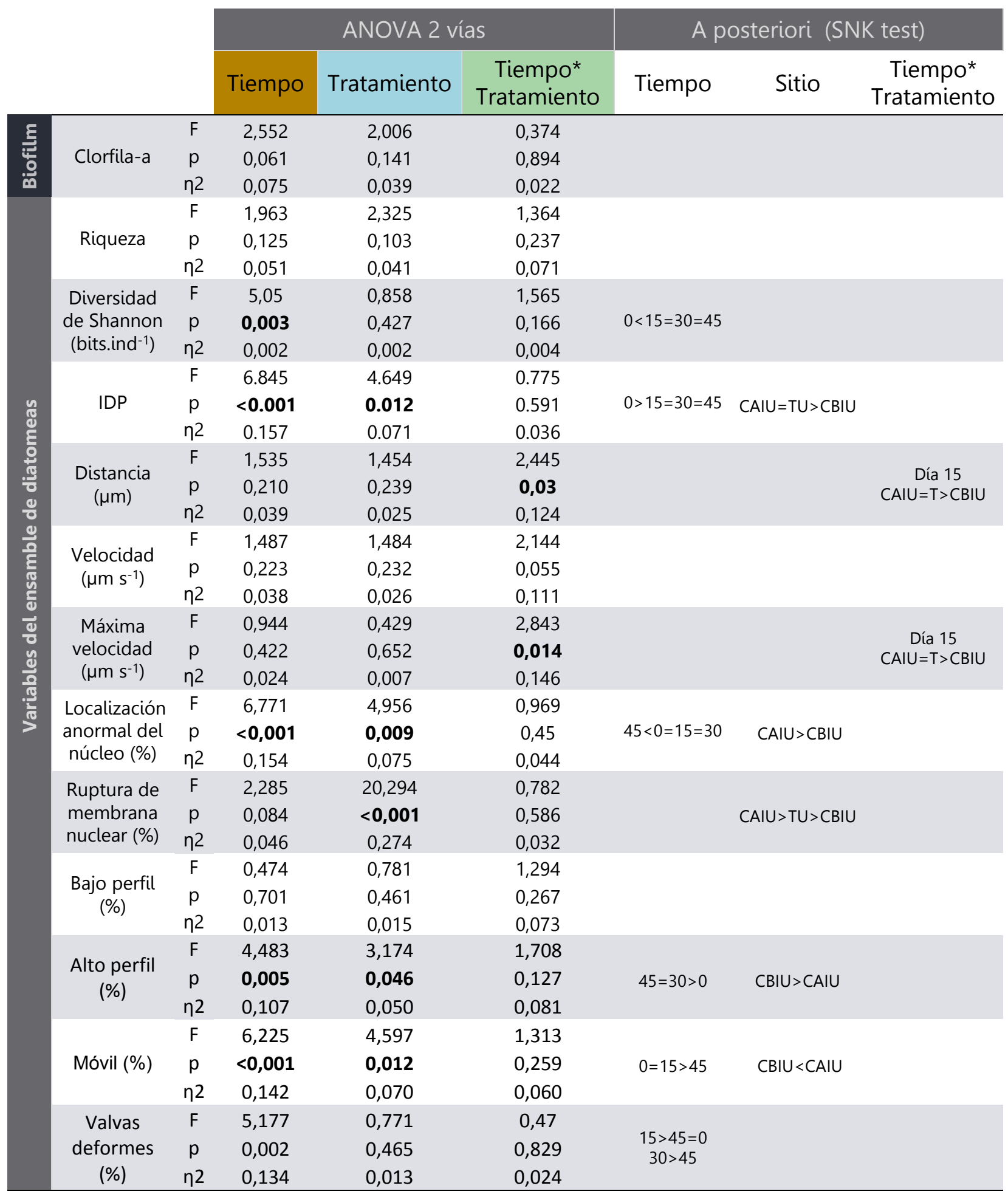




\section{$\mathrm{CBIU} \quad \mathrm{TU}=\mathrm{CAIU}$}

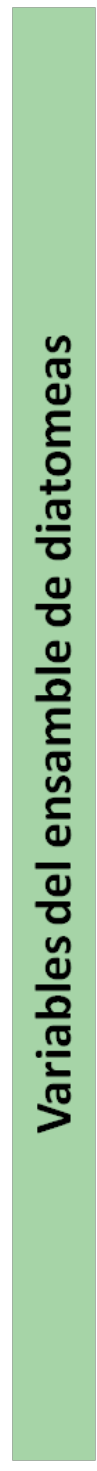

Riqueza

Diversidad de Shannon
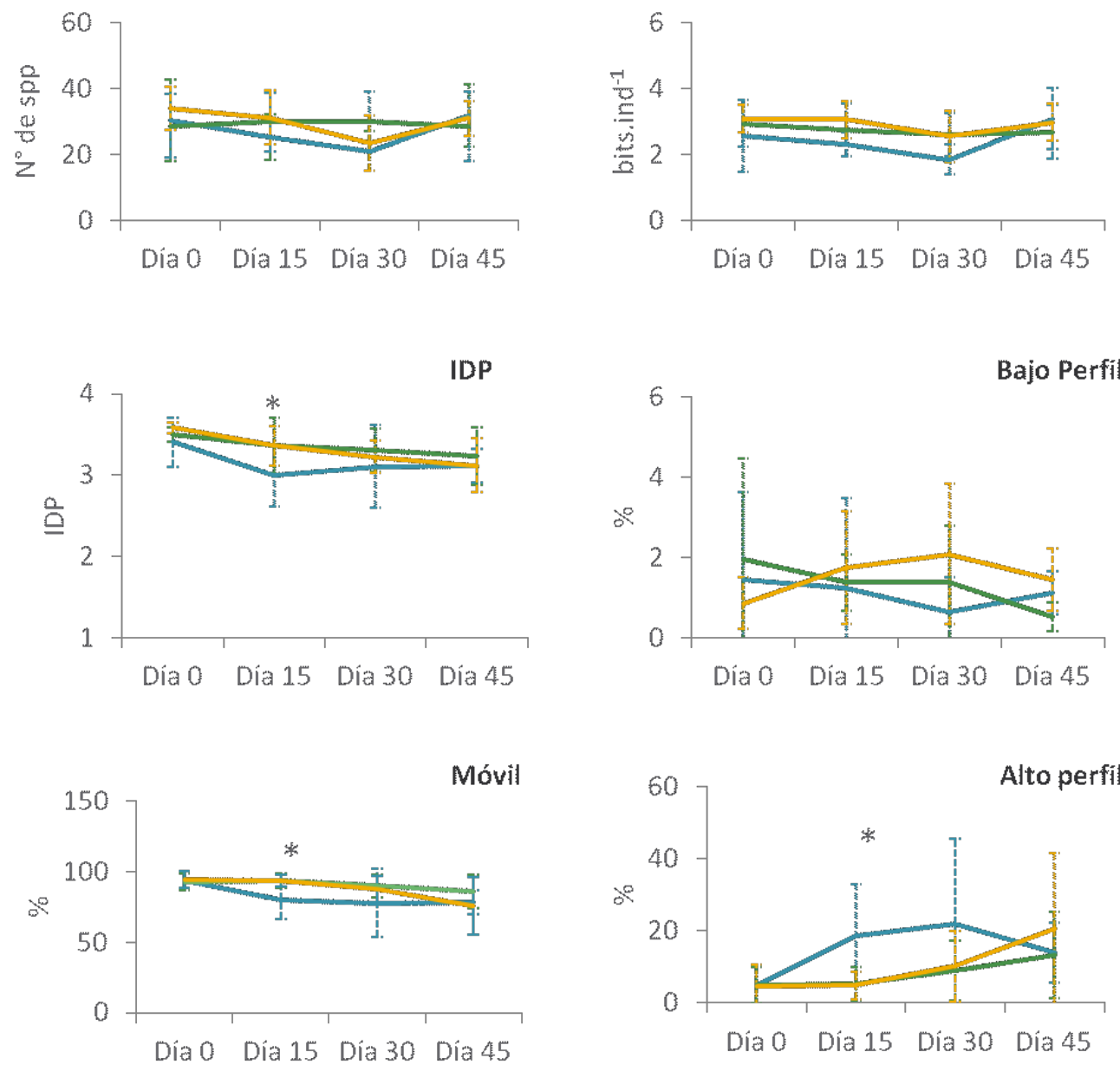

\section{Tiempo}

Figura 4.1: promedio y desvío estándar de la riqueza, diversidad de Shannon; Índice de Diatomeas Pampeanas (IDP); y los gremios ecológicos (Bajo perfil, alto perfil, móvil) del ensamble de diatomeas a lo largo de la experiencia en los tres tratamientos (CBIU = bandejas control de bajo impacto urbano; TU= bandejas translocadas; CAIU = bandejas control de alto impacto urbano en los tiempos de muestreo. Las barras indican los desvío estándar y los asteriscos $\left(^{*}\right)$ indican diferencias significativas $(p$-valor $<0,05)$. 
$\mathrm{CBIU}$

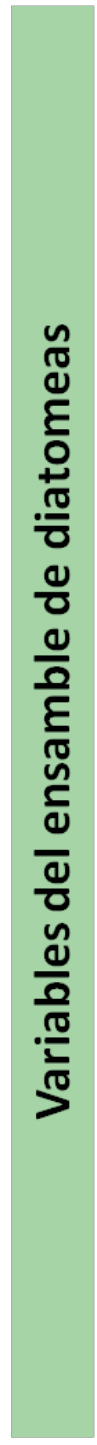

TU

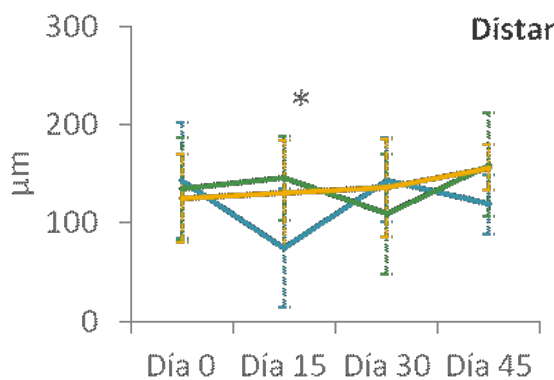

Máxima velocidad
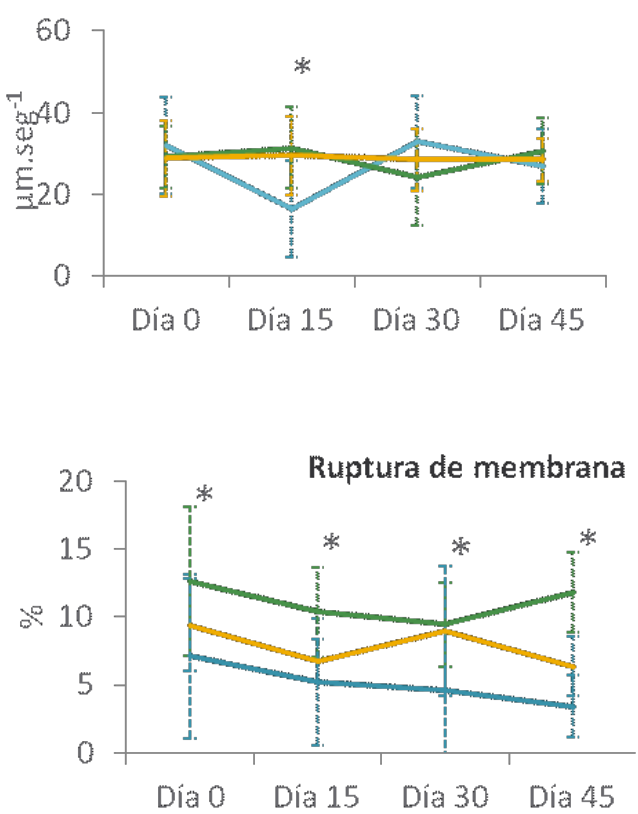

CAIU

Velocidad

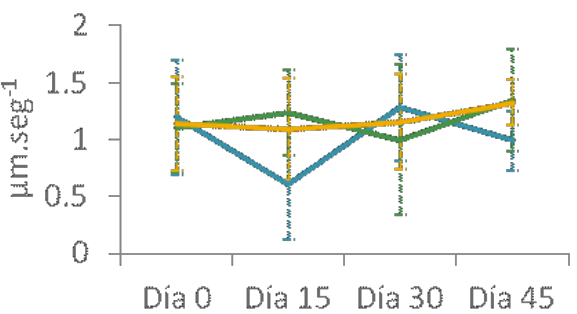

Valvas deformes

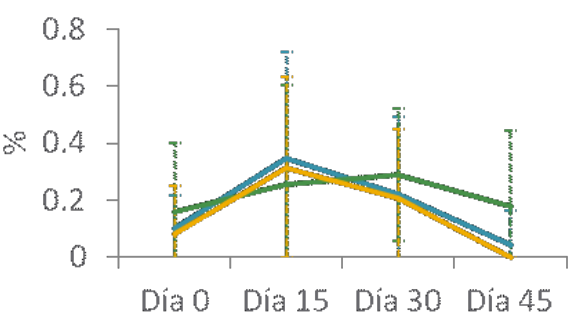

Mal localizados

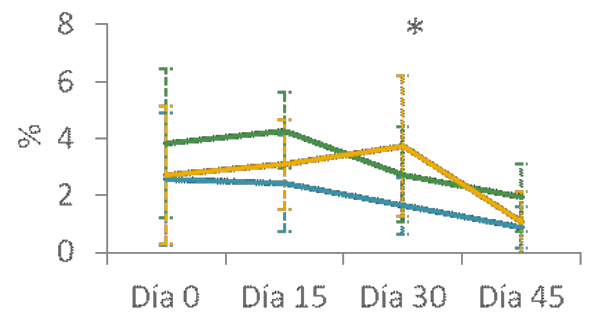

\section{Tiempo}

Figura 4.2: Promedio de las medidas de movilidad (distancia $(\mu \mathrm{m})$; velocidad máxima $\left(\mu \mathrm{m} \mathrm{seg}{ }^{-1}\right)$, velocidad $\left(\mu \mathrm{m} \mathrm{seg}{ }^{-1}\right.$ ); de la proporción de valvas deformes y de las variables del estado de los núcleos (ruptura de la membrana nuclear, ubicación anormal del núcleo) del ensamble de diatomeas a lo largo de la experiencia en los tres tratamientos (CBIU = bandejas control de bajo impacto urbano; $\mathrm{TU}=$ bandejas translocadas; $\mathrm{CAIU}=$ bandejas control de alto impacto urbano en los tiempos de muestreo. Las barras indican los desvío estándar y los asteriscos $\left(^{*}\right)$ indican diferencias significativas ( $p$-valor $\left.<0,05\right)$. 


\subsection{Discusión y conclusiones}

Los resultados de la experiencia mostraron que la proporción de los gremios ecológicos del ensamble de diatomeas cambió cuando el sedimento fue translocado a sitios con menor impacto urbano, afectando particularmente el gremio de alto perfil y móvil. Además, se observó una mayor proporción de núcleos mal localizados y con ruptura de la membrana nuclear de las diatomeas en los sitios de mayor impacto urbano. Por otro lado, no hubo diferencias significativas en las variables asociadas a la movilidad (velocidad, máxima velocidad, distancia) que puedan atribuirse a los cambios en la calidad del agua.

La biomasa de algas bentónicas en el biofilm está vinculada con la concentración de nutrientes. Se han reportado aumentos de esta variable con los incrementos en la concentraciones de nutrientes (ej: Smith y Schindler, 2009), por lo que en este estudio se esperaba una disminución de este parámetro debido la disminución en los mismos. Sin embargo en esta experiencia la biomasa, medida a través de la clorofila-a no resultó ser una medida sensible de este aspecto de la calidad de agua.

Los ensambles de diatomeas de los sitios se corresponden con los encontrados en ambientes eutróficos con contaminación orgánica de moderada a alta (Licursi 2005), lo que explica también los valores obtenidos en el Índice de Diatomeas Pampeanas. $N$. palea fue el taxón dominante en todos los sitios de muestreo. P. monoculata y $G$. parvulum fueron las siguientes especies más abundantes en todos los sitios, ambas consideradas altamente tolerantes a la contaminación orgánica y la eutrofización (Lobo et al., 2010). La moderada mejoría de la calidad del agua aumentó la abundancia de $M$. varians después de 45 días de exposición. A pesar de que $M$. varians se ha considerado tolerante a la eutrofización (Debenest el al., 2009), investigaciones previas en arroyos pampeanos han demostrado que altos niveles de contaminación pueden afectar su densidad (Gómez y Licursi, 2001). La respuesta opuesta se observó en N. umbonata, que disminuyó en el sustrato translocado; esto coincide con investigaciones previas que concluyen que esta especie se encuentra generalmente en sitios fuertemente contaminados con altas concentraciones de materia orgánica y en presencia de descargas industriales y urbanas (Gómez 1998, 1999; Licursi y Gómez, 2002; Duong et al., 2007). A pesar de estos cambios registrados en las abundancias de las especies, la riqueza y el índice de diversidad de Shannon no respondieron a la mejora de la calidad de agua como era esperado. Varios autores han reportado un menor índice de diversidad de Shannon y riqueza en sitios más contaminados (Gold et al 2002, Verb and 
Vis 2005, Morin et al 2015). Sin embargo, estos parámetros de biodiversidad que son utilizados regularmente a veces no proporcionan información consistente sobre el deterioro de los cuerpos de agua (Blanco et al., 2012). Hirst et al. (2002) mostraron que la riqueza, la equitabilidad y la diversidad de las especies no estaban significativamente relacionadas con las características químicas del agua de arroyos contaminados por actividades mineras. Asimismo, Duong et al. (2008) no encontraron diferencias en los índices de diversidad de las comunidades de diatomeas perifíticas examinadas en los sitios de referencia y sitios contaminados del río Riou-Mort, en el suroeste de Francia. Sin embargo tanto los índices de diversidad como la riqueza, responden a los cambios en la calidad del agua en situaciones de contaminación muy fuertes y contrastantes (Gómez, 1999). En situaciones intermedias de contaminación, la coexistencia de especies muy tolerantes junto con especies tolerantes incrementa el valor de estos descriptores bióticos no guardando correspondencia con la calidad del agua (Licursi 2005).

El análisis de los gremios ecológicos reveló que las diatomeas de alto perfil fueron más abundantes en los sitios menos impactados y aumentaron su proporción con la mejora de la calidad del agua, principalmente debido al aumento de la abundancia de $M$. varians, mientras que las formas de gremios móviles alcanzaron mayores proporciones en los sitios altamente impactados, siendo la especie dominante $N$. palea. Las diatomeas pertenecientes a los gremios de alto perfil y móviles son frecuentes en ambientes eutróficos, estas últimas además tienen la ventaja de poseer movilidad que les permite el desplazamiento físico a través de microhábitats, evitando así las condiciones adversas que genera una peor calidad del agua (Johnson et al., 1997; Passy 2007). Estas diatomeas pueden buscar refugio dentro del biofilm (Larras et al, 2012) y regular el equilibrio entre el acceso a los recursos ambientales (luz, nutrientes) y la exposición al estrés (Fore y Grafe, 2002; Laviale et al., 2009), lo que explica sus densidades máximas a altos niveles de nutrientes. De esta manera, las especies móviles son abundantes en los cuerpos de agua receptores de aguas residuales, mientras que las especies con forma de vida erecta y pedunculadas (pertenecientes al gremio de alto perfil) disminuyen su proporción (Smucker y Vis, 2010).

Las diatomeas de bajo perfil se caracterizan por ser poco abundantes en el epipelon debido a la inestabilidad y el movimiento de los sustratos blandos (Passy 2007), condición que se vió bien reflejada en los ensambles de esta experiencia. 
Asimismo, este gremio se ve favorecido en ambientes con elevadas velocidades de corriente y bajas concentraciones de nutrientes. En los arroyos estudiados, las bajas velocidades de corriente $\left(0,07 \pm 0,04 \mathrm{~ms}^{-1}\right)$ junto con las altas concentraciones de nutrientes podrían explicar el hecho de que este gremio fue muy poco abundante y similar entre todos los tratamientos.

Las medidas de movilidad analizadas en este capítulo no respondieron, como era esperado, a los cambios en la calidad del agua. Estudios previos han demostrado que una variedad de perturbaciones ambientales naturales (Cohn y Disparti, 1994) y antropogénicas (Svensson et al., 2014; Coquille et al., 2015) pueden alterar la velocidad y los patrones de movimiento de las diatomeas, sin embargo ninguno de los parámetros analizados en este estudio (distanacia, velocidad, velocidad máxima) evidenciaron diferencias significativas entre los sitios con diferentes niveles de impacto. Esta falta de respuestas significativas coinicide con Pandey y Bergey (2016) quienes evaluaron la movildad en arroyos con diferentes niveles de contaminación crónica, y reportaron valores medios de velociad menores en sitios mas impactados pero no fueron significativamente diferentes.

Asimismo los valores de los parámetros de movilidad de Nitzschia medidos resultaron más bajos que los informados para otros experimentos (Cohn y Disiparti, 1994; Cohn y Weitzell, 1996; Pandey y Bergey, 2016), lo que sugiere que este parámetro es muy variable incluso dentro del mismo género taxonómico. En particular, el género Nitzschia es un grupo heterogéneo que requiere revisión, y que incluso puede incluir numerosos géneros diferentes. Pandey y Bergey (2016) registraron diferentes valores de velocidad, que van desde $10 \pm 3$ y $9 \pm 3 \mu \mathrm{m} \mathrm{s}^{-1}$ para Nitzschia sigmoidea y $12 \pm 2$ y $9 \pm 4 \mu \mathrm{m} \mathrm{s}^{-1}$ para Nitzschia linearis en sitios altamente contaminados y no contaminados, respectivamente. Considerando esto, el uso de medidas de movilidad de las diatomeas como herramienta para la evaluación de los impactos urbanos debe explorarse también a nivel de especie.

Los resultados del análisis de las anormalidades nucleares revelaron que aunque, la proporción de células con localización anormal del núcleo fue mayor en los sitios más impactados, esta variable no cambió con el tiempo en las bandejas translocadas como se esperaba, por lo que su uso como indicador de la recuperación del ensamble es incierto. Por otro lado, la proporción de núcleos con ruptura de membrana nuclear disminuyó con el tiempo en el ensamble translocado, lo que indica que esta variable podría proporcionar un indicador sensible de mejora de la calidad del agua. La presencia 
de anormalidades nucleares podría explicarse debido a que en los arroyos expuestos a aguas residuales urbanas del área de estudio, es frecuente que además de nutrientes y materia orgánica, contengan compuestos tóxicos como metales pesados, compuestos orgánicos, entre otros (Gómez et al., 2008; Sierra y Gómez 2010; Solis et al., 2017; Rimoldi et al., 2018). Estas condiciones conducen a la localización anormal del núcleo y ruptura de la membrana nuclear (Licursi y Gómez 2013), así como también puede ocasionar la aparición de micronúcleos y la fragmentación del núcleo (Debenest et al., 2008).

El análisis del porcentaje de alteraciones en las valvas en este estudio no resultó ser una variable sensible a los cambios en la calidad del agua. Asimiso, los porcentajes de valvas deformes hallados, se corresponden con valores promedio más bajos que los reportados por Tornés et al (2018); quienes también evaluaron la contaminación urbana vinculada a elevadas concentraciones de nutrientes y materia orgánica. Sin embargo, ellos registraron también altas concentraciones de productos farmacéuticos, condición que pudo potenciar la presencia de malformaciones en los sitios de mayor impacto. Cabe destacar que esta medida ha recibido críticas vinculadas a que el conteo de las valvas deformadas se realiza en preparados fijos, lo que impide evaluar todas las vistas del frústulo de las diatomeas (Pandey et al 2017). 


\section{Conclusiones}

En función de las predicciones planteadas para este capítulo se advirtió que las mismas se cumplieron parcialmente. En tal sentido, el ensamble de diatomeas desarrollado en sustrato natural (epipelon), translocado de sitios de mayor a menor impacto urbano reveló que entre los descriptores analizados la proporción de anormalidades nucleares y los gremios ecológicos demostraron ser los más sensibles, ya que respondieron significativamente al exponerlo a una mejor calidad del agua.

Las medidas de movilidad de las diatomeas, por otro lado, fueron muy variables durante la experiencia de translocación. Sin embargo, no se descarta su potencial utilidad frente a factores estresantes específicos y a nivel de especie. Por otro lado, la riqueza y el índice de diversidad de Shannon no resultaron ser sensibles. Estos resultados también fueron acompañados por resultados no significativos de la clorofila-a del biofilm.

Los resultados alcanzados permiten distinguir el empleo de los indicadores que resultaron más sensibles en el seguimiento temprano de los procesos de recuperación de los cursos de agua que atraviesan zonas urbanizadas. 
Estudio del ensamble de diatomeas en sustratos artificiales en una experiencia de translocación entre sitios de mayor a menor impacto agrícola.

\subsection{Introducción}

Varios estudios han demostrado que el desarrollo del biofilm se ve afectado negativamente ante la presencia de pesticidas, incluso a bajas concentraciones, disminuyendo su biomasa autotrófica (Debenest et al., 2007; Debenest et al., 2009 capitulo; Pesce et al., 2011).

Particularmente en el ensamble de diatomeas, en el biofilm bentónico, los herbicidas, fungicidas y pesticidas pueden alterar la estructura y el funcionamiento del ensamble (Guasch et al., 2003; Dorigo et al., 2007), a través de cambios en la abundancia relativa de la especies (Ricart et al., 2010), que modifican su diversidad y riqueza (Debenest et al., 2010). Esto también tiene repercusiones en las proporciones de los distintos gremios de diatomeas (Rimet and Bouchez, 2011). Las formas pioneras y pequeñas, en su mayoría pertenecientes al gremio de bajo perfil, han sido reportadas como buenas indicadoras de la contaminación por agroquímicos (Rimet et al. 2012, Rimet and Bouchez, 2011). Asimismo las diatomeas de alto perfil, que se caracterizan por tener la capacidad de usar nutrientes disueltos en el agua (Passy 2007), resultan más sensibles a la exposición a pesticidas disueltos, mientras que las especies del gremio móvil son las dominantes en estas condiciones (Rimet and Bouchez, 2011, Bouchez et al., 2012).

Otra medida de interés para evaluar el impacto de los agroquímicos sobre el ensamble de diatomeas es el análisis de las alteraciones nucleares (localización anormal del núcleo, ruptura de la membrana nuclear, fragmentación del núcleo, micronúcleos). Debenest et al (2008), estudiaron el efecto de un herbicida exponiendo en un ensayo de laboratorio a un ensamble de diatomeas, a 3 concentraciones de hidrazida maleica. La proporción de anomalías nucleares resultó ser significatiavmente mayor en las mayores dosis. El análisis de esta variables podría ayudar a entender los mecanismos de cambio en la composición de los ensambles del biofilm, especialmente en la dominancia de las especies más tolerantes así como también los factores que dan lugar a las deformaciones de los frústulos (Debenest et al., 2008; Licursi and Gómez, 2013). Coincidentemente, en arroyos con alto nivel de 
impacto por fertilizantes y pesticidas, la abundancia de diatomeas con frústulos anormales es elevada (Denbenest el al., 2008), así como también lo prueban los ensayos ensayos de laboratorio frente a la exposición a isoproturon, maleica hidrazida y colchicina (Schmitt-Jansen and Altenburger 2005; Debenest et al. 2008; Van Den Hoek et al. 1995).

Una vez afectado el biofilm por agrotóxicos, su recuperación se ha estudiado tanto en experiencias de campo (Dorigo et al., 2010 a, b; Morin et al., 2010; Rimet et al., 2005) como de laboratorio (Proia et al., 2011; Wood et al., 2017; Gustavson et al., 2003). Así, se ha observado que la biomasa autotrófica (clorofila-a) aumenta frente a la mejora de la calidad del agua (Dorigo et al 2010 a) y tiene unas tasas de recuperación rápidas (Morin et al 2010), incluso pudiendo alcanzar valores similares a los medidos previo al impacto por herbicidas una semana después de la exposición al tóxico (Proia et al 2011). Por otra parte, el estudio de las consecuencias de la rehabilitación de sitios con impacto agrícola a través del uso de comunidades perifíticas podría servir como un método alternativo y rápido en sitios contaminados que requieren un monitoreo a largo plazo (Morin et al 2010).

Sin embargo, hasta el presente no se cuenta con antecedentes sobre la recuperación del ensamble de diatomeas en arroyos pampeanos expuestos a la actividad agrícola. En este capítulo se explorará la recuperación del ensamble de diatomeas del biofilm de arroyos expuestos a la actividad agrícola, a través de los cambios en la riqueza y diversidad del ensamble, la proporción de los distintos gremios ecológicos de diatomeas, la proporción de anomalías nucleares y de frústulos deformados y la clorofilaa hallada en el biofilm

\subsection{Objetivos e hipótesis}

El objetivo de este capítulo es analizar los cambios estructurales y funcionales del ensamble de diatomeas en arroyos de zonas agrícolas, en relación a las concentraciones de agroquímicos en los sedimentos de los arroyos, cuando son expuestos a mejoras en la calidad del agua.

La hipótesis de este estudio es que los ensambles de diatomeas en el biofilm responden modificando su estructura frente a cambios favorables en la calidad del agua, particularmente: 
- Aumentarán la clorofila-a del biofilm, la riqueza y la diversidad del ensamble de diatomeas, y disminuirá el Índice de diatomeas pampeanas.

- Disminuirán las proporciones de alteraciones en el núcleo, y la proporción de valvas deformadas en el ensamble de diatomeas.

- Aumentará la proporción de diatomeas de alto perfil y disminuirán las proporciones de diatomeas de bajo perfil y móviles.

\subsection{Materiales y métodos}

\section{3.a Diseño experimental}

Para el análisis de la recuperación del ensamble de diatomeas, se realizó una experiencia de translocación con sustrato artificial, detallada en la sección 2.1.7.b del capítulo de Materiales y Métodos. Los sustratos control del sitio de bajo impacto agrícola serán denominados $\mathrm{CBIA}$, los sustratos control de los sitios de alto impacto agrícola serán llamados CAIA, mientras que los sustratos Translocados se denominarán TA. Los muestreos se hicieron en marzo y abril del 2019 en cuatro tiempos (Día 0, Día 15, Día 30 y Día 45).

\section{3.b Sitios de muestreo}

Se seleccionaron dos sitios de muestreo en arroyos pertenecientes a la cuenca El Pescado y expuestos a diferentes niveles de impacto agrícola (Mapa y características de los sitios en el Capítulo 2 sección 2.2.1 y 2.2.2): un sitio de menor impacto agrícola, denominado "Bajo impacto agrícola (BIA) (35 3'14.95"S 5758'37.92"O) y un sitio expuesto a un alto impacto agrícola denominado "Alto Impacto agrícola" (AIA) (35 1'32.10"S $57^{\circ} 59^{\prime} 41.30^{\prime O}$ ). El grado de impacto agrícola fue definido en base a las concentraciones de agroquímicos medidos en el sedimento de los arroyos, y los usos del suelo.

\section{3.c Variables medidas}

Se midieron por triplicado, en cada sitio y fecha de muestreo los parámetros físicoquímicos, detallados en la sección 2.1.2 de materiales y métodos. En cada muestreo, se tomaron muestras de agua para la medición de nutrientes, para más detalles de la metodología individual ver capítulo 2, sección 2.1.2. La caracterización físico-química de los sitios se realizó teniendo en cuenta las mediciones hechas en cada oportunidad de muestreo de la experiencia de colonización y de translocación de sustratos. 


\section{Medición de pesticidas}

Se tomaron 6 muestras de sedimento, 3 pertenecientes al sitio BIA y 3 pertenecientes al sitio AIA. Las muestras de sedimento se extrajeron con una pala de acero inoxidable y se colocaron en envases de vidrio. Las muestras se mantuvieron refrigeradas hasta su llegada al laboratorio. El procesamiento y medición estuvieron a cargo del Laboratorio de Química Ambiental de la UNLP (LAQAB). La medición de los compuestos organoclorados (Endosulfán I, Endosulfán II, Endosulfán Sulfato) se hizo siguiendo una modificación del método EPA 525.3 (2012) con cromatografía gaseosa de alta resolución (Agilent 7890N). La cuantificación se realizó mediante cálculo de factores de respuesta para estándares auténticos individuales de pesticidas organoclorados (M-525.2-CP-ASL y M-8140-03, AccuStandard, Inc.).

Se realizó la medición de este compuesto organoclorado, ya que es uno de los agroquímicos reportados con mayor frecuencia y en mayor concentración en los sedimentos de los arroyos de la región de estudio (ej: Hunt et al., 2016). Las mediciones se llevaron sólo a cabo en muestras de sedimento del arroyo y no el agua debido a que la vida media del compuesto en agua es de 4 días (SHRA, 2004; Barry et al., 1998), y estudios previos en el área de estudio no lo dectectaron en muestras de agua, pero sí en sedimento (Solís 2016).

\section{Clorofila-a}

La recolección y el tratamiento para la extracción y medición del pigmento de las muestras se detallan en el capítulo de materiales y métodos, apartado 2.1.3.

\section{Ensamble de diatomeas}

Para la identificación del ensamble de diatomeas, se sonicaron las muestras de sustrato artificial para la extracción del biofilm y se prosiguió según metodología detallada en capítulo 2, sección 2.1.5.a.

A partir del análisis del ensamble de diatomeas, se calcularon el índice de diversidad de Shannon-Weaver (H', bits.ind-1) (Shannon y Weaver, 1949), y el índice de diatomeas pampeanas (IDP; Gómez y Licursi 2001).

Las especies de diatomeas se clasificaron en los gremios ecológicos: bajo perfil, alto perfil y móvil, según Passy (2007): El gremio planctónico (B-Béres et al., 2017; Rimet and Bouchez, 2012a) no se consideró en este estudio debido a que el número total de taxones planctónicos fue relativamente bajo $(<1 \%)$. Para más detalle, ver capítulo 2 , apartados 2.1.5.b. 
Para el análisis de las alteraciones nucleares se siguió la metodología detallada en el capítulo de materiales y métodos sección 2.1.5.d.

Asimismo, se contabilizó el porcentaje de valvas con deformaciones (cambios en el patrón de estrías; deformación del contorno de la valva; cambios en la forma, tamaño y posición del área longitudinal y central; modificaciones del rafe y del canal del rafe.) (ver sección 2.1.5.e de Materiales y Métodos).

\section{3.d Análisis estadísticos}

Las diferencias en la calidad del agua entre los sitios fueron analizadas mediante un análisis de la varianza a 1 vía (ANOVA).

Para comparar las variables biológicas en los sustratos a lo largo de la experiencia y entre tratamientos se utilizó un análisis de la varianza de dos vías (ANOVA) (Dytham, 2011), los análisis siguieron el modelo $[X=\mu+$ Tratamiento + Tiempo + Tiempo * Tratamiento + error], con el factor de Tratamiento compuesto por tres niveles (CBIA = Sustratos control del sitio de Bajo Impacto Agrícola ; CAIA = Sustratos control del sitio de Alto Impacto Agrícola; T = Bandejas translocadas desde el sitio AIA hasta el sitio BIA), y el factor Tiempo compuesto de cuatro niveles (Día 0, Día 15, Día 30 y Día 45).

La normalidad se evaluó previamente mediante la prueba de Shapiro-Wilk (Shapiro y Wilk, 1965) y la homogeneidad de varianzas mediante la prueba de Cochran (Cochran, 1951). Se calculó el Eta ${ }^{2}\left(\eta^{2}\right)$ como una medida del tamaño del efecto, y la prueba de Holm-Sidak (Holm, 1979) se utilizó como prueba post-hoc para los ANOVAS (Cohen, 2013).

\subsection{Resultados}

La temperatura media registrada en el sitio BIA fue de $22,3 \pm 3,96{ }^{\circ} \mathrm{C}$ y el valor medio de $\mathrm{pH}$ fue de $6,85 \pm 0,26$, mientras que en el sitio AIA los valores medios de temperatura y $\mathrm{pH}$ fueron de $20,53 \pm 1,43^{\circ} \mathrm{C}$ y $6,46 \pm 0,29$ respectivamente, sin mostrar diferencias significativas entre los sitios. $\mathrm{El}$ oxígeno disuelto ( $\mathrm{mg} \mathrm{O}_{2} \mathrm{~L}^{-1}$ ), la conductividad $\left(\mu \mathrm{Scm}^{-1}\right)$, la turbidez (NTU) y los sólidos disueltos totales $\left(\mathrm{mgL}^{-1}\right)$ fueron significativamente mayores en el sitio de BIA (Tabla 5.1). En cuanto a los nutrientes, 
sólo los nitritos $\left(\mathrm{mgL}^{-1}\right)$ y el DIN fueron significativamente mayores en el sitio BIA (Tabla 5.1).

Tabla 5.1: Medias ( \pm desvío estándar) de los parámetros físico-químicos medidos en agua y valores de pesticidas del sedimento en los sitios AIA (Alto impacto agrícola) y BIA (Bajo impacto agrícola) durante la experiencia, y el valor de significancia ( $p$-valor) obtenido del ANOVA. En negrita se marcan los casos significativos $(p<0,05)$, y n.d. = no detectado.

\begin{tabular}{lccc} 
& Sitio BIA & Sitio AIA \\
\hline Localización de los sitios de muestreo & $35^{\circ} 3^{\prime} 14.95 " \mathrm{~S}$ & $35^{\circ} 11^{\prime} 32.10^{\prime \prime} \mathrm{S}$ \\
& $57^{\circ} 58^{\prime} 37.92^{\prime \prime O}$ & $57^{\circ} 59^{\prime} 41.30 " \mathrm{O}$ \\
\hline Endosulfán I (ng/g de peso seco) & $26( \pm 45,03)$ & $111,3( \pm 16,5)$ & $\mathbf{0 , 0 3 7}$ \\
\hline Endosulfán II (ng/g de peso seco & n.d. & $1,66( \pm 2,88)$ & 0,374 \\
\hline Endosulfán Sulfato (ng/g de peso seco) & n.d. & $83( \pm 73,3)$ & 0,121 \\
\hline Temperatura ('C) & $22,3( \pm 3,96)$ & $20,53( \pm 1,43)$ & 0,281 \\
pH & $6,85( \pm 0.26)$ & $6,46( \pm 0.29)$ & 0,539 \\
Conductividad $(\boldsymbol{\mu S} \mathbf{~ c m - 1 )}$ & $443( \pm 157)$ & $267,4( \pm 7,34)$ & $<\mathbf{0 , 0 0 1}$ \\
OD (mg L-1) & $4,64( \pm 1,82)$ & $2,12( \pm 0.96)$ & $<\mathbf{0 , 0 0 1}$ \\
\hline SST (mg L-1) & $0,29( \pm 0,11)$ & $0,17( \pm 0,05)$ & $<\mathbf{0 , 0 0 1}$ \\
\hline Turbidez (UNT) & $320,4( \pm 103,3)$ & $126,3( \pm 76,1)$ & $<\mathbf{0 , 0 0 1}$ \\
PRS (mg L-1) & $0,630( \pm 0,355)$ & $0,772( \pm 0.199)$ & 0,358 \\
N-NO3- (mg L-1) & $0,033( \pm 0,009)$ & $0,027( \pm 0,009)$ & 0,278 \\
N-NO2- (mg L-1) & $0.011( \pm 0.005)$ & $0.004( \pm 0.004)$ & $\mathbf{0 , 0 0 8}$ \\
N-NH4+ (mg L-1) & $0,065( \pm 0.025)$ & $0,033( \pm 0,02)$ & 0,081 \\
NID (mg L-1) & $0.111( \pm 0.042)$ & $0,070( \pm 0.02)$ & $\mathbf{0 , 0 3 5}$ \\
\hline
\end{tabular}

Las mediciones de pesticidas en sedimento, arrojaron valores detectables tanto de los isómeros $\alpha$ y $\beta$ de endosulfán y de endosulfán sulfato en todas la muestras de el sitio AIA, mientras que en el sitio BIA sólo se detectó el isómero a (en una proporción menor a la detectada en AIA) en una única muestra (Tabla 5.1).

\section{Variables biológicas}

\section{Clorofila a}

Los resultados del Anova 2-vías para la clorofila-a del biofilm desarrollado en el sustrato artificial indican que no hubo diferencias significativas entre los tratamientos a lo largo de la experiencia, pero si hubo diferencias significativas entre los tiempos de muestreo (Figura 5.1; Tabla 5.3). 


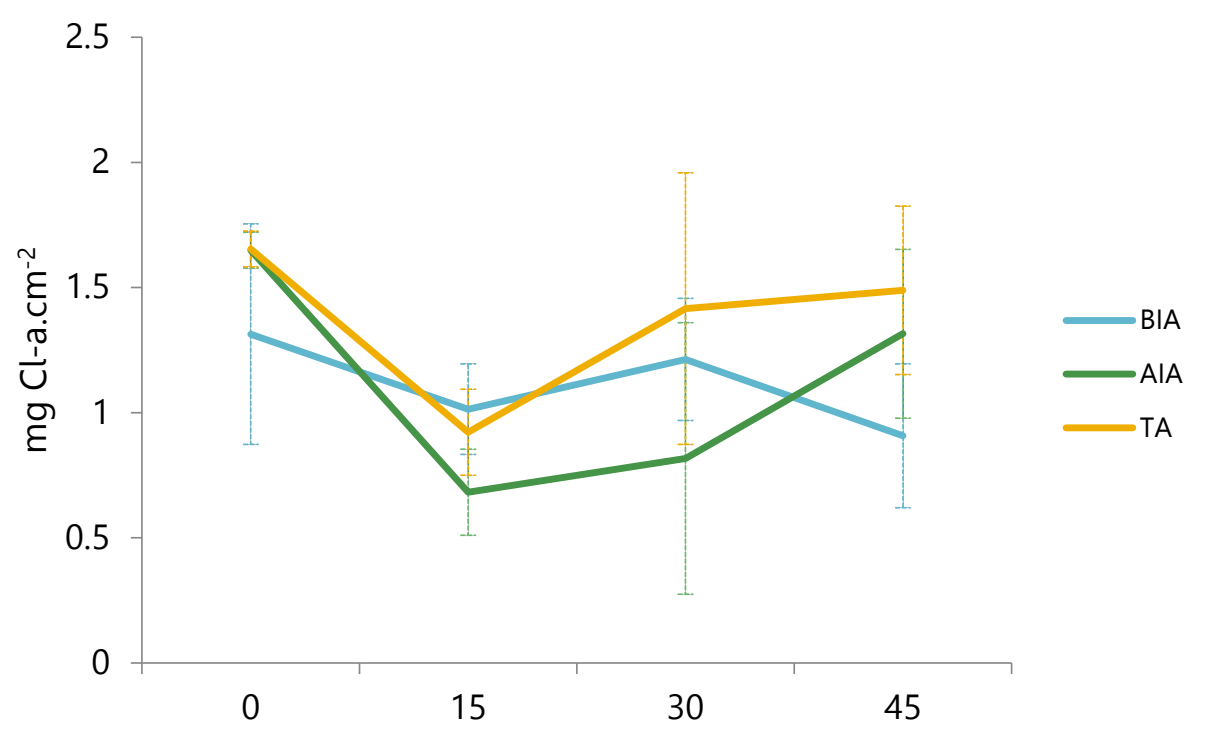

Figura 5.1: variación de los valores medios de la clorofila-a a lo largo de la experiencia entre los tratamientos $(\mathrm{CBIA}=$ sustratos control de bajo impacto agrícola; $\mathrm{TA}=$ sustratos translocados; $\mathrm{CAIA}=$ sustratos control de alto impacto agrícola) en los tiempos de muestreo. Las barras indican los desvíos estándar.

\section{Ensamble de diatomeas}

Se encontraron un total de 124 especies de diatomeas en el ensamble desarrollado en los sustratos artificiales durante la experiencia. Las especies con mayor abundancia relativa en los sustratos en los diferentes sitios se muestran en la Tabla 5.2.

Tabla 5.2. Porcentaje de abundancia de las especies más representadas en los tratamientos CBIA, CAIA y TA, y el gremio ecológico al que pertenecen.

\begin{tabular}{lcccc} 
Especies & CBIA & CAIA & TA & Gremio \\
\hline Nitzschia palea (Kützing) W.Smith & 22,41 & 25,13 & 20,45 & $\mathrm{M}$ \\
Nitzschia amphibia Grunow & 29,59 & 11,27 & 19,17 & $\mathrm{M}$ \\
Nitzschia frustulum (Kützing)Grunow & 9,83 & 0,08 & 2,50 & $\mathrm{M}$ \\
Diadesmis confervacea Kützing & 7,19 & 0,77 & 5,79 & $\mathrm{AP}$ \\
Planothidium frequentissimum (Lange-Bertalot) Lange- & & & & \\
Bertalot & 0,31 & 20,99 & 11,79 & $\mathrm{BP}$ \\
Eolimna minima (Grunow) Lange-Bertalot & 0,54 & 9,88 & 2,73 & $\mathrm{M}$ \\
Nitzschia clausii Hantzsch & 4,58 & 0,37 & 10,03 & $\mathrm{M}$ \\
\hline
\end{tabular}

La riqueza tuvo valores medios de 36,1 $\pm 3,01$ en CBIA, 34,6 $\pm 2,8$ en CAIA y 40,5 $\pm 3,9$ en TA. En cuanto a los valores medios del índice de diversidad de Shannon, en CBIA fueron de 3,26 $\pm 0,15$ bits.ind $^{-1} ; 3,34 \pm 0,13$ bits.ind $^{-1}$ en CAIA y 3,62 $\pm 0,17$ bits.ind ${ }^{-1}$ en TA. Ni la riqueza ni el índice de diversidad de Shannon mostraron 
diferencias significativas (Tabla 5.3, Figura 5.2). En cuanto al Índice de Diatomeas Pampeanas, el valor del índice fue significativamente mayor en CAIA $(3,18 \pm 0,2)$ que en en CBAIA $(2,76 \pm 0,01)$ y TA $(2,73 \pm 0,36)$, sin embargo el tamaño del efecto de esta variable fue pequeño ( $\eta^{2}=0,2 ;$ Tabla 5.3, Figura 5.2). Los valores del IDP indican una "muy mala" calidad del agua en el sitio de mayor impacto; mientras que el ensamble del sitio de menor impacto y de los sustratos translocados indican una "mala" calidad del agua.

La proporción de los distintos gremios ecológicos mostró diferencias significativas entre los tratamientos. Las diatomeas de bajo perfil fueron significativamente diferentes entre los tratamientos, siendo mayor la proporción en CAIA $(21,54 \pm 5,37)$, seguida por TA $(12,30 \pm 3,24)$ y por último CBIA $(0,75 \pm 0,74)$, con un tamaño del efecto moderado $\left(\eta^{2}=0,67\right.$; Tabla 5.3). Las especies mas representativas de cada gremio ecológicos en cada tratamiento se muestran en la Tabla Anexa 5A.

En cuanto a las diatomeas de alto perfil, fueron significativamente menores en CAIA, con un valor medio de 5,25 $\pm 1,12$; mientras que en CBIA alcanzó un valor de 11, $6 \pm 1,87$ y en los sustratos translocados alcanzó un valor de 10, $15 \pm 4,30$; el tamaño del efecto en este caso fue bajo $\eta^{2}=0,33$ (Tabla 5.3, Figura 5.2).

Las diatomeas del gremio móvil, constituyeron el gremio mejor representado en todos los tratamientos con una proporción mayor al 70\%. Su proporción fue significativamente mayor en los sustratos de CBIA $(87,35 \pm 3,39)$ en comparación con los sustratos TA $(77,33 \pm 1,82 \%)$ y CAIA $(73,15 \pm 5,08 \%)$ (Tabla 5.3, $\eta^{2}=0,480$; Figura 5.2)

La proporción de valvas con deformaciones (deformaciones en el contorno de la valva; cambios en el patrón de estrías; cambios en la forma, tamaño y posición del área longitudinal y central; modificaciones del rafe y del canal del rafe) no mostró diferencias

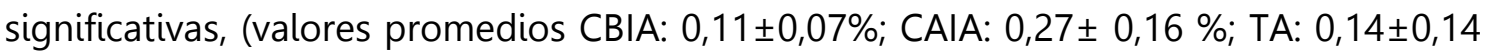
$\%)$, sin embargo el análisis de las anomalías nuclearles mostró diferencias significativas en la proporción de núcleos con ruptura de membrana. La proporción de esta anomalía mostró diferencias significativas entre tratamientos, siendo la mayor proporción encontrada en CAIA $(34,42 \pm 6,26)$, seguida por los valores medios hallados en TA $(24,82 \pm 3,85)$ y por último los valores encontrados en CBIA $(11,08 \pm 0,72)$. El tamaño del efecto fue moderado $\eta^{2}=0,689$ (Tabla 5.3, Figura 5.2). 
Tabla 5.3 Resultados del ANOVA 2 vías (Factores: Tiempo, Tratamiento y Tiempo * Tratamiento) para la clorofila $a_{1}$ la riqueza, la diversidad de Shannon, el índice de diatomeas pampeano (IDP); la proporción de gremios ecológicos( bajo perfil, alto perfil, móvil) la proporción de diatomeas con localización anormal del núcleo y ruptura de membrana nuclear y la proporción de valvas deformes. Las diferencias significativas se destacan en negrita. Los resultados de la prueba post-hoc también se muestran mediante la prueba de Holm-Sidak y $\eta^{2}$ como una medida del tamaño del efecto.

\begin{tabular}{|c|c|c|c|c|c|c|c|}
\hline & & & \multicolumn{3}{|c|}{ ANOVA 2 vías } & \multicolumn{2}{|c|}{$\begin{array}{c}\text { A posteriori } \\
\text { (SNK test) }\end{array}$} \\
\hline & & & Tiempo & Tratamiento & $\begin{array}{c}\text { Tiempo* } \\
\text { Tratamiento }\end{array}$ & Tiempo & Tratamiento \\
\hline \multirow{3}{*}{ ह } & \multirow{3}{*}{ Clorofila-a } & $\mathrm{F}$ & 7,016 & 2,721 & 1,673 & \multirow{3}{*}{ T0> T15 } & \\
\hline & & $p$ & 0,002 & 0,086 & 0,171 & & \\
\hline & & $\eta 2$ & 0,348 & 0,090 & 0,166 & & \\
\hline & \multirow{3}{*}{$\begin{array}{l}\text { Diversidad } \\
\text { de Shannon } \\
\text { (bits.ind }^{-1} \text { ) }\end{array}$} & $\mathrm{F}$ & 0,75 & 2,662 & 0,318 & & \\
\hline & & $\mathrm{p}$ & 0,533 & 0,09 & 0,921 & & \\
\hline & & $\eta 2$ & 0,067 & 0,159 & 0,057 & & \\
\hline & \multirow{3}{*}{ Riqueza } & $\mathrm{F}$ & 1,246 & 1,646 & 0,0861 & & \\
\hline & & $p$ & 0,315 & 0,214 & 0,997 & & \\
\hline (ָ) & & $\eta 2$ & 0,119 & 0,104 & 0,016 & & \\
\hline$\varepsilon$ & \multirow{3}{*}{ IDP } & $\mathrm{F}$ & 0,502 & 4,189 & 1,083 & & \multirow{3}{*}{$\mathrm{CAIA}>\mathrm{CBIA}=\mathrm{T}$} \\
\hline$\stackrel{0}{+}$ & & $\mathrm{p}$ & 0,684 & 0,028 & 0,4 & & \\
\hline 西 & & $\eta 2$ & 0,037 & 0,207 & 0,161 & & \\
\hline 0 & \multirow{3}{*}{$\begin{array}{l}\text { Bajo perfil } \\
(\%)\end{array}$} & $\mathrm{F}$ & 0,118 & 34,952 & 1,549 & & \multirow{3}{*}{$\mathrm{CAIA}>\mathrm{T}>\mathrm{CBIA}$} \\
\hline$\frac{\pi}{0}$ & & $\mathrm{p}$ & 0,949 & $<0,001$ & 0,205 & & \\
\hline (1) & & $\eta 2$ & 0,003 & 0,675 & 0,090 & & \\
\hline 을 & \multirow{3}{*}{$\begin{array}{l}\text { Alto perfil } \\
(\%)\end{array}$} & $\mathrm{F}$ & 0,884 & 9,539 & 2,058 & & \multirow{3}{*}{$\mathrm{CBIA}=\mathrm{T}>\mathrm{CAIA}$} \\
\hline$\frac{\varepsilon}{\pi}$ & & $p$ & 0,463 & $<0,001$ & 0,097 & & \\
\hline$\underline{n}$ & & $\eta 2$ & 0,046 & 0,328 & 0,213 & & \\
\hline (1) & \multirow{3}{*}{ Móviles (\%) } & $\mathrm{F}$ & 0,753 & 14,33 & 0,794 & & \multirow{3}{*}{$\mathrm{CBI} A \mathrm{~A}=\mathrm{T}=\mathrm{CAIA}$} \\
\hline$\widetilde{0}$ & & $p$ & 0,531 & $<0,001$ & 0,584 & & \\
\hline 0 & & $\eta 2$ & 0,038 & 0,480 & 0,080 & & \\
\hline $\mathfrak{u}$ & \multirow{3}{*}{$\begin{array}{l}\text { Núcleos con } \\
\text { membrana } \\
\text { estallada (\%) }\end{array}$} & $\mathrm{F}$ & 0,877 & 39,651 & 1,528 & & \multirow{3}{*}{$\mathrm{CAIA}>\mathrm{T}>\mathrm{CBIA}$} \\
\hline 을 & & $\mathrm{p}$ & 0,467 & $<0,001$ & 0,212 & & \\
\hline 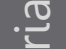 & & $\eta 2$ & 0,023 & 0,689 & 0,080 & & \\
\hline$\stackrel{\sigma}{>}$ & \multirow{3}{*}{$\begin{array}{c}\text { Núcleos mal } \\
\text { localizados } \\
(\%)\end{array}$} & $\mathrm{F}$ & 0,58 & 2,746 & 0,593 & & \\
\hline & & $p$ & 0,634 & 0,084 & 0,733 & & \\
\hline & & $\eta 2$ & 0,050 & 0,158 & 0,102 & & \\
\hline & \multirow{3}{*}{$\begin{array}{c}\text { Valvas } \\
\text { deformes (\%) }\end{array}$} & $\mathrm{F}$ & 1,742 & 1,239 & 0,301 & & \\
\hline & & $p$ & 0,185 & 0,307 & 0,93 & & \\
\hline & & $\eta 2$ & 0,156 & 0,074 & 0,054 & & \\
\hline
\end{tabular}


CBIA
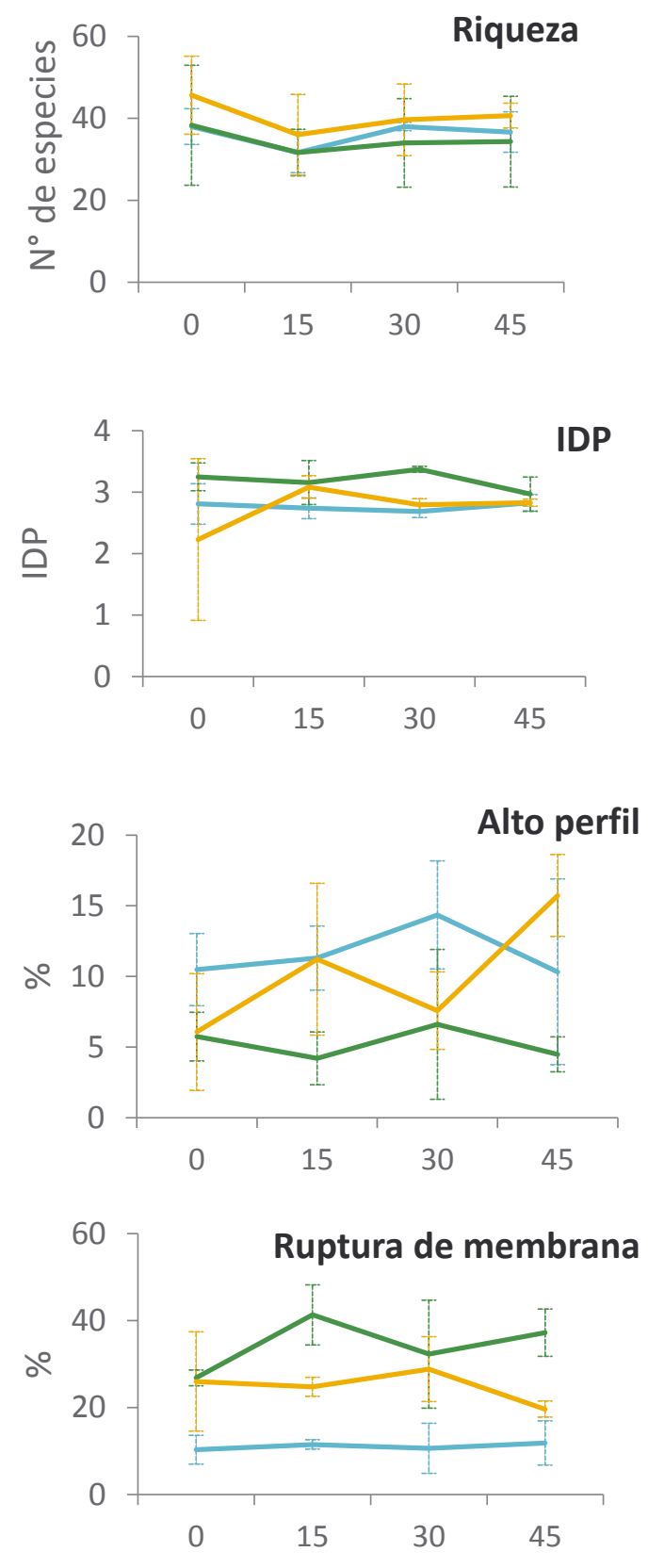

CAIA
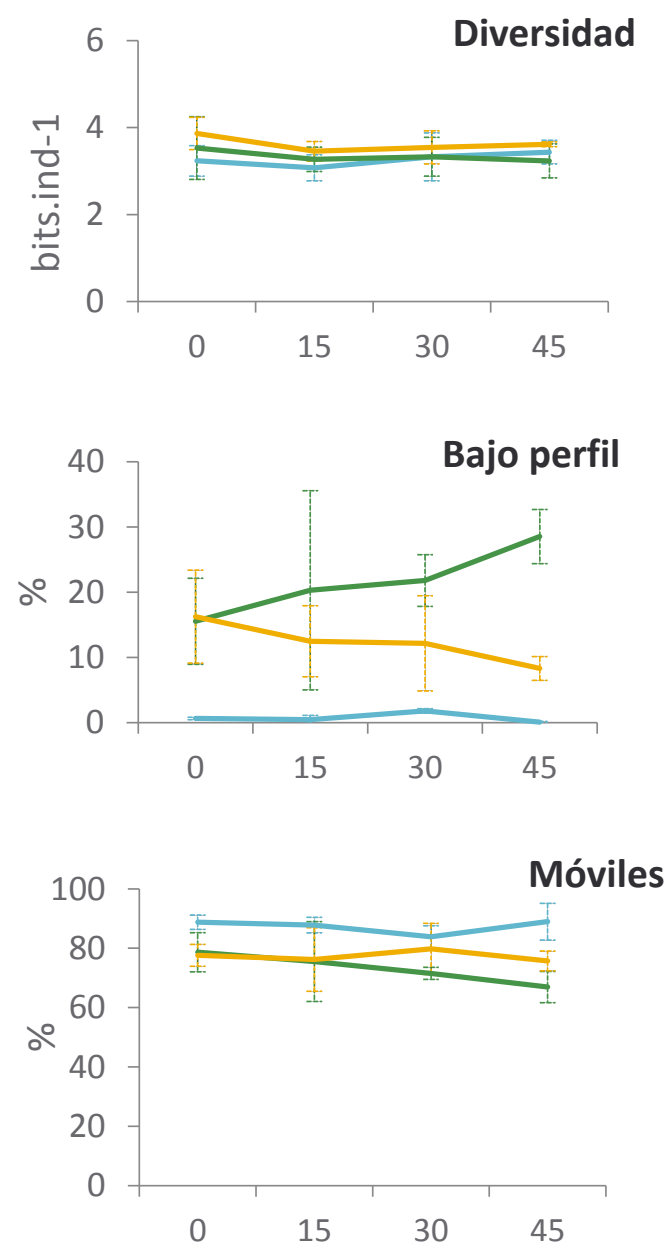

Mal localizados

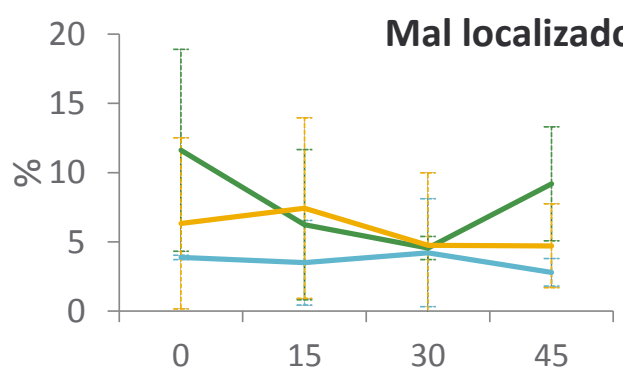

\section{Tiempo}

Figura 5.2: Promedio y desvío estándar de la riqueza, diversidad de Shannon; Índice de Diatomeas Pampeanas (IDP); y los gremios ecológicos (Bajo perfil, alto perfil, móvil); de la proporción de valvas deformes y de las variables del estado de los núcleos (ruptura de la membrana nuclear, ubicación anormal del núcleo) del ensamble de diatomeas a lo largo de la experiencia en los tres tratamientos (CBIA= sustratos control de bajo impacto agrícola; $\mathrm{TA}=$ sustratos translocados; $\mathrm{CAIA}=$ sustratos control de alto impacto agrícola en los tiempos de muestreo. Las barras indican los desvío estándar y los asteriscos $\left(^{*}\right)$ indican diferencias significativas ( $p$-valor $<0,05)$. 


\subsection{Discusión y conclusiones}

En esta experiencia se estudiaron los cambios en el ensamble de diatomeas desarrollado sobre sustratos artificiales cuando son expuestos a mejorías en la calidad del agua en relación a arroyos expuestos a impactos agrícolas.

La biomasa de algas bentónicas, a través de la medición de la clorofila-a es uno de los parámetros más usados para medir los efectos de los agroquímicos en las algas (Debenest et al., 2010). Se han reportado disminuciones de esta variable frente a la exposición de pesticidas (ej: Tang et al., 1997; Carder y Hoagland 1998, Schmitt-Jansen y Altenburger 2005), por lo que en este estudio se esperaba un aumento de este parámetro debido la disminución en los mismos. Sin embargo, en esta experiencia la biomasa, medida a través de la clorofila-a no resultó ser una medida sensible de este aspecto de la calidad de agua.

Los índices de diversidad y la abundancia relativa de los ensambles de diatomeas se usan ampliamente para indicar la presencia y el alcance de contaminantes orgánicos e inorgánicos en los ecosistemas fluviales (Pandey et al., 2017). La exposición a un único pesticida o a una mezcla de éstos, puede alterar de manera selectiva a algunas especies ocasionando así un disturbio en el ensamble. Sin embargo, se ha demostrado que la diversidad puede verse afectada tanto negativamente como positivamente cuando se expone a los ensambles de diatomeas a agrotóxicos (Debenest et al 2010). En la mayoría de los estudios, los índices utilizados habitualmente proporcionan una relación estadísticamente débil entre la diversidad de diatomeas y los contaminantes. Esto coincide con lo reportado en este estudio, dónde ni la riqueza ni la diversidad se mostraron afectados por los diferentes niveles de impacto. No obstante, el índice de diatomeas pampeanas sí reveló cambios frente al cambio en la calidad del agua, disminuyendo su valor en el ensamble translocado y asemejándose al ensamble del sitio de menor impacto. Esto valida lo sugerido por Pandey et al 2017, que plantea la importancia de utilizar índices basados en la composición taxonómica, que consideren las características ecológicas de cada especie, y así puedan proporcionar información estadísticamente más confiable.

En cuanto al análisis de los gremios ecológicos, las diatomeas de bajo perfil fueron más abundantes en el sitio de mayor impacto, y la proporción de este gremio disminuyó en los sustratos translocados, sin embargo siguió siendo mayor que la 
proporción encontrada en los sustratos del sitio con mejor calidad del agua. La mayor abundancia de este gremio en el sitio de mayor impacto agrícola, coincide con trabajos trabajos previos que reportan a las diatomeas de bajo perfil como tolerantes y abundantes en condiciones de exposición a agroquímicos (Rimet y Bouchez, 2011; Roubeix et al. 2012).

Las diatomeas de alto perfil aumentaron su proporción en los sustratos translocados, confirmando así la hipótesis planteada en este estudio. Este gremio, que está compuesto por especies que no están adaptadas a soportar grandes velocidades del flujo del agua, que son vulnerables a la presión por pastoreo y que además tienen la habilidad de incorporar nutrientes disueltos en agua (Passy 2007), resultan más vulnerables frente a la exposición a los tóxicos disueltos (Rimet y Bouchez 2011). Sin embargo, en este estudio el cambio en el porcentaje de este gremio fue liderado por especies muy tolerantes. La especie con mayor representación en el sitio de mayor impacto fue $G$. parvulum, especie catalogada como muy tolerante a la contaminación orgánica y por herbicidas (Debenest et al 2010). En los sustratos translocados se produjo un incremento de la especie $D$. confervacea a partir del día 15. Esta diatomea, también reportada como muy tolerante (Coste 1975; Gómez y Licursi 2001), se caracteriza por formar grandes cadenas y tener una alta tasa de colonización y capacidad de adhesión en sustratos artificiales (Congestri y Albertano, 2011), además fue la especie dominante en el sitio de menor impacto, lo que podría explicar su gran aumento en los sustratos translocados.

La mayoría de los estudios a campo y laboratorio coinciden en que las especies del gremio móvil aumentan frente a la exposición a agrotóxicos (ej: Bayona et al 2014; Morin et al 2009). Sin embargo en este estudio su proporción fue la mayor en los ensambles de todos los tratamientos, y contrariamente a lo esperado fueron significativamente mayores en el sitio de menor impacto. La mayoría de las especies de este gremio, en todos los ensambles son caracterizadas como especies muy tolerantes a la contaminación orgánica y eutrofización (Gómez y Licursi 2001), y particularmente $N$. palea fue reportada como tolerante a la contaminación por herbicidas (Ricart et al., 2010). Asimismo, las formas móviles se caracterizan por ser las dominantes en sitios con baja disponibilidad de luz (Passy 2007), lo que podría explicar su mayor proporción en el sitio de menor impacto agrícola, el cual se caracteriza por tener mayores valores de turbidez y sólidos disueltos en suspensión (Licursi y Gómez 2009).

En este estudio, y en coincidencia con lo reportado por Licursi y Gómez (2013), se encontraron sólo 2 tipos de alteraciones nucleares: la localización anormal y la ruptura de la membrana nuclear. Esta última fue la que mostró diferencias significativas entre los 
tratamientos. Si bien la proporción de diatomeas con ruptura de membrana nuclear fue menor en los sustratos translocados que en el sitio de mayor impacto a partir de transcurridos los 15 días, siguió siendo una proporción mayor que la hallada en el sitio de menor impacto, incluso pasados los 45 días. Se ha demostrado que transcurridas varias semanas de realizada la translocación todavía quedan concentraciones detectables de xenobióticos adsorbidos en la matriz del biofilm (Morin et al 2010), condición que podría estar afectando a las células, causando un retraso en la respuesta causa-efecto del ensamble, producto del fenómeno de histéresis (Licursi 2005).

A pesar de que estudios previos han reportado un alto porcentaje de frústulos anormales en arroyos contamindados por agroquímicos (Debenest et al., 2008, Roubeix et al., 2011), en el estudio desarrollado en este capítulo, el porcentaje de frústulos deformes no mostró diferencias significativas entre los distintos tratamientos. Sin embargo, los valores hallados coinciden con los porcentajes reportados $(0,32-1,5 \%)$ para cuerpos de agua con contaminación orgánica (Morin et al., 2009; Debenest et al., 2008; Roubeix et al., 2011). 


\section{Conclusiones}

En función de las predicciones planteadas para este capítulo se advirtió que las mismas se cumplieron parcialmente. En tal sentido, el estudio del biofilm y su ensamble de diatomeas, desarrollado en sustratos artificiales, translocados de un sitio de mayor a uno de menor impacto agrícola reveló que el ensamble de diatomeas respondió al cambio de la calidad del agua en el tiempo estudiado, modificando su estructura. Sin embargo la concentración de clorofila-a, el índice de diversidad, la riqueza y la proporción de frústulos con deformaciones no resultaron ser variables indicadoras del cambio en la calidad del agua. Contrariamente, la proporción de diatomeas de bajo y alto perfil, la proporción de diatomeas con ruptura de la membrana nuclear y el índice de diatomeas pampeano resultaron sensibles a los impactos ambientales. No obstante en algunos casos, si bien la respuesta fue significativa, los efectos del sitio con mayor nivel de impacto agrícola no se pudieron revertir del todo, como en el caso de las anomalías nucleares y el porcentaje de diatomeas de bajo perfil. Esto sugiere que se necesita de tiempos más prolongados para que el ensamble de diatomeas evidencie la recuperación a través de las variables evaluadas. 

Nitzschia palea frente a la exposición de elutriados del sedimento del arroyo Carnaval

\subsection{Introducción}

Los pesticidas pueden potencialmente ingresar al agua por varias rutas y concentrarse en los sedimentos del fondo de los cuerpos de agua incluso cuando su aplicación se realiza de forma adecuada. La dispersión debido a la pulverización, la escorrentía superficial y el drenaje en el campo son las rutas principales de ingreso a los cuerpos de agua, además de la contaminación por agua subterránea (Katagi 2006). Dentro de estas vías, la escorrentía superficial es una de las principales fuentes de contaminación difusa (Jergentz et al., 2005; Mac Loughlin et al 2017). Este proceso puede movilizar pesticidas en la fase soluble, así como también pesticidas absorbidos en partículas suspendidas del suelo arrastrado por la erosión de las aguas pluviales (Kronvang et al., 2004). Con el tiempo, esas partículas suspendidas se depositan en el fondo de los cuerpos de agua. En consecuencia, los sedimentos del fondo constituyen un sumidero importante para estos compuestos (Burton y Landrum, 2003) y, por lo tanto, pueden usarse como una medida integrada de la entrada de pesticidas en el sistema hidrológico (Friberg et al., 2003).

Los contaminantes asociados a los sedimentos pueden ser resuspendidos de forma natural, por procesos físicos o biológicos (bioturbación), o por la actividad humana, tal como frecuentemente ocurre con el desarrollo de obras hidráulicas (ej: dragado). Estos mecanismos generan la removilización y redistribución de los contaminantes a la columna de agua desde los sedimentos (Parodi et al., 2016).

Dado que los sedimentos del fondo proporcionan nutrientes y hábitat para una amplia variedad de organismos bentónicos, la evaluación de la calidad de los sedimentos se vuelve relevante para la protección de la vida acuática (Paixão et al., 2011). Para evaluar los efectos de sedimentos tóxicos, se pueden utilizar cuatro fases físicas del mismo, cada una de las cuales refleja un tipo diferente de exposición a condiciones tóxicas (Sansiñena et al., 2018): (i) el agua intersticial (poro) del sedimento (Ingersoll et al., 1995), (ii) el elutriado del sedimento (es decir, la fracción extraíble con agua) (Burton et al., 1995), (iii) todo el sedimento y (iv) los extractos orgánicos del sedimento (True y Heyward, 1990). 
Se han encontrado en la literatura pocas pruebas de toxicidad que involucren microalgas directamente expuestas a sedimentos (Adams y Stauber 2004) o al agua intersticial de los poros (Chrishensen et al 2006). La mayoría de los experimentos que involucran pruebas de toxicidad de sedimentos con microalgas se realizaron con elutriados (Munawar y Munawar, 1987; Matthiesen et al., 1998; Wong y Couture, 1986; Cohn and MacGuire 2000; Parodi et al 2016)

En este capítulo se exploraran las respuestas de la diatomea Nitzschia palea frente a la exposición a elutriados procedentes de sedimento de un arroyo con impacto agrícola. Se evaluaron parámetros menos convencionales, como la movilidad y las anomalías nucleares, y variables comúnmente utilizadas en biomonitoreos, como la densidad y el tamaño celular.

\subsection{Objetivos e hipótesis}

El objetivo de este trabajo es analizar las respuestas de descriptores tales como la movilidad, la proporción de anomalías nucleares (localización anormal de núcleo, ruptura de la membrana nuclear), la densidad poblacional y el tamaño celular de Nitzschia palea, a elutriados procedentes de sedimento de un arroyo con impacto agrícola, para proponerlos como posibles biomonitores para la evaluación de toxicidad de sedimentos.

\section{2.a Hipótesis y predicciones}

La hipótesis de esta experiencia es que los descriptores (movilidad, anomalías nucleares, densidad y tamaño celular) de Nitzschia palea responden a la exposición a elutriados provenientes de sedimentos tóxicos.

En las unidades experimentales expuestas a elutriados con concentraciones elevadas de pesticidas y metales pesados, se medirán:

- Disminuciones en la movilidad (velocidad, aceleración, distancia), en la densidad poblacional y en el tamaño celular promedio,

- Aumentos en la proporción de anomalías nucleares. 


\subsection{Materiales y Métodos}

En mayo de 2018 se extrajo $1 \mathrm{~kg}$ de sedimento procedente de los $5 \mathrm{~cm}$ superficiales

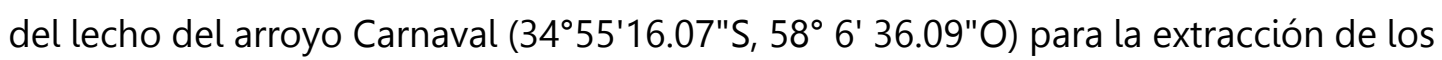
elutriados y medición de pesticidas (organofosforados y organoclorados). Además, se midieron las concentraciones de metales pesados ( $\mathrm{Cu}, \mathrm{Cd}, \mathrm{Cr}$ y $\mathrm{Zn}$ ). Todas las muestras se mantuvieron en la oscuridad y refrigeradas a $4^{\circ} \mathrm{C}$ hasta la realización del bioensayo. Para mayor descripción del sitio, ver sección 2.2.2 de Materiales y Métodos.

\section{3. a Cultivo de N.palea y elutriados}

\section{Cultivo}

Para la realización del ensayo se utilizó un monocultivo de Nitzschia palea (Kützing) W.Smith 1856 aislada del Arroyo Martín (3455'21.27"S 58 5'1.98"O). N. palea es una diatomea bentónica cosmopolita y eurioica (Finlay et al., 2002), para la cual se han descripto diferentes genotipos que podrían ser especies crípticas (Trobajo et al., 2009) La selección de esta especie se fundamentó en su hábito móvil y su amplia representación en la comunidad epipélica de la región pampeana (Gómez y Licursi 2001).

Los especímenes aisaldos se cultivaron hasta alcanzar una densidad de 10.000 células $\mathrm{mL}^{-1}$ (fase exponencial) utilizando medio de cultivo propuesto por Guillard y Lorenzen (1972) diluido con agua destilada (1: 2).

\section{Elutriados}

Se entiende por elutriado a la solución acuosa obtenida tras la adición de agua a una sustancia sólida (p.ej. sedimento) y sometida a posterior agitación (Parodi et al 2016). Los elutriados se obtuvieron siguiendo una versión modificada del protocolo de Pica Granados y Trujillo Domínguez (2008) que garantiza la extracción máxima mediante el uso de un período de decantación corto (Parodi et al. 2018).

Para su preparación, se pesaron 200 gr de sedimento y se colocaron en un Erlenmeyer con $800 \mathrm{ml}$ de medio de cultivo (diluido 1:2) y se colocaron en un agitador (Vicking Shaker Pro ${ }^{\circledR}$ ) a 220 rpm durante 24 hs. Transcurridas las 24 hs, se vertió la solución en embudos de decantación para separar la fase líquida de la sólida. La fase líquida fue pipeteada y colocada en tubos de centrífuga de $50 \mathrm{ml}$, los cuáles se 
centrifugaron durante 15 minutos a $2000 \mathrm{rpm}$. El sobrenadante obtenido se filtró por filtros de fibra de vidrio de 1,2 $\mu \mathrm{m}$ de poro (Whatman GF / C) (Figura 6.1).

Los elutriados así obtenidos se mantuvieron a $4^{\circ} \mathrm{C}$ en la oscuridad hasta su uso en los experimentos (en la misma fecha de extracción).

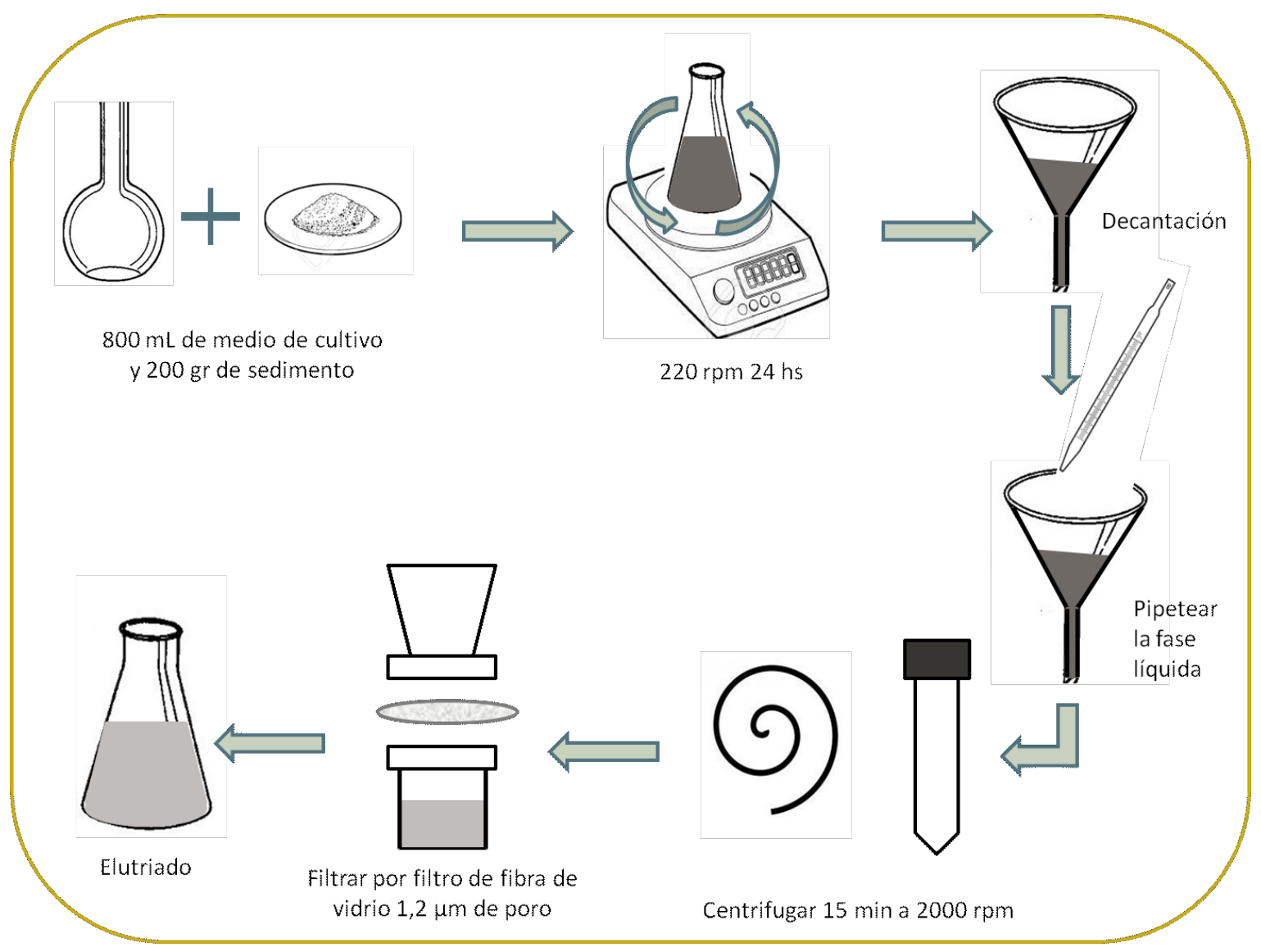

Figura 6.1: esquema del procedimiento para la obtención de los elutriados.

\section{3.b Diseño experimental}

Para llevar a cabo el bioensayo se utilizaron 50 envases de vidrio de $200 \mathrm{ml}$ asignados aleatoriamente a un grupo Control (25 frascos) o Tratamiento (25 frascos), que fueron acondicionados en el laboratorio de bioensayos con temperatura controlada $\left(25^{\circ} \mathrm{C}\right)$ y condiciones de iluminación natural.

A las unidades experimentales del grupo control se les colocaron $90 \mathrm{ml}$ de medio de cultivo estéril y $10 \mathrm{ml}$ del cultivo de diatomeas; en tanto a las unidades experimentales 
del grupo tratamiento se les adicionaron $90 \mathrm{ml}$ de elutriado y $10 \mathrm{ml}$ del cultivo de diatomeas.

Se usaron cinco réplicas para cada una de las fechas de muestreo: al momento de inicio (T0), a las 24 hs (T1), a las 48 hs (T2), a las 72 hs (T3) y a la semana de exposición (T4).

También se usó un control de los elutriados ("Elutriado_Control") con medio de cultivo (sin diatomeas) para medir cualquier posible degradación de los pesticidas en los elutriados debido al medio de cultivo.

\section{3.c Variables medidas}

\section{Parámetros fisicoquímicos y nutrientes}

Durante el bioensayo se midieron temperatura, $\mathrm{pH}$, conductividad, y oxígeno disuelto en las unidades experimentales en todos los tiempos. Los nutrientes se analizaron en los Tratamientos en los tiempos T0, T3 y T4 a partir de tres unidades experimentales, para medir cualquier posible limitación de nutrientes. Los análisis se hicieron según metodología detallada en el capítulo de materiales y métodos (sección 2.1.2).

\section{Medición de pesticidas y metales pesados}

Para el análisis de pesticidas organoclorados se utilizó un Cromatógrafo Gaseoso con un detector de captura electrónica (GC-ECD) siguiendo el protocolo de USEPA \#8081A-ECD. El análisis de los pesticidas organofosforados se realizó con un Cromatógrafo con detector de Espectrometría de Masa (GC-MS) siguiendo el protocolo de USEPA \#8270-GCMS. Las mediciones se realizaron en un laboratorio privado (GEMA).

Las mediciones de metales pesados se realizaron en el laboratorio de química del ILPLA y se utilizaron dos protocolos distintos según el tipo de muestra que se analizó.

Para el caso de los elutriados se colocaron $100 \mathrm{ml}$ de muestra en un vaso de precipitado (tapado casi totalmente con vidrio de reloj) de $250 \mathrm{ml}$ previamente enjuagado con agua bidestilada. Se le agregaron $3 \mathrm{ml}$ de $\mathrm{HNO}_{3} 15,8 \mathrm{M}$ y se colocó en una placa calefactora a $95^{\circ} \mathrm{C}$ hasta reducir el volumen a $25 \mathrm{ml}$. Luego se llevó a un volumen final de $100 \mathrm{ml}$ en un matraz aforado, lavando el vaso de precipitado con agua bidestilada (USEPA \# 3005 A). 
Para el tratamiento de las muestras de sedimento, las mismas se secaron en estufa a $60^{\circ} \mathrm{C}$ y se procesaron con un molinillo. Luego de este procedimiento se digirieron utilizando $1 \mathrm{gr}$ de sedimento procesado con $21 \mathrm{ml}$ de $\mathrm{HCl}$ (c) $12 \mathrm{M}$ y $7 \mathrm{ml}$ de $\mathrm{HNO}_{3}$ 15,8 $\mathrm{M}$ en un matraz de reacción, el cual fue calentado bajo condiciones de reflujo durante $2 \mathrm{hs}$. La solución fue filtrada y diluida a $100 \mathrm{ml}$ con $\mathrm{HNO}_{3}$ 0,5 M (Levei et at, 2010).

Las mediciones de ambas soluciones fueron realizadas en un Espectrofotómetro de Absorción Atómica (EAA) marca Buck 200 utilizando una lámpara de cátodo hueco específica para cada metal medido $(\mathrm{Cu}, \mathrm{Cd}, \mathrm{Zn}$ y $\mathrm{Cr})$.

\section{Variables medidas en Nitzschia palea}

En cada tiempo de muestreo, se tomaron cinco réplicas de las unidades experimentales del Control y del Tratamiento.

Se tomaron submuestras de $5 \mathrm{ml}$ de cada réplica, se separaron en tubos Falcon y se fijaron con formol al 1\% para medir la densidad de la población de N.palea, la longitud celular y el estado de los núcleos. Para la medición de la movilidad se utilizó $1 \mathrm{ml}$ de muestra sin fijar.

La densidad de diatomeas se midió utilizando una cámara de Neubauer, debido a que resulta ser el procedimiento más adecuado si el agua contiene materia suspendida (Moreno Garrido et al 2003).

Para la medición de las alteraciones nucleares, la movilidad y de la longitud celular, se siguieron las metodologías detalladas en el capítulo de materiales y métodos secciones 2.1.5.d, 2.1.5.f y 2.1.5.g, respectivamente.

\section{3.d Análisis estadísticos}

Para analizar las diferencias en las variables medidas en Nitzschia palea entre tratamiento y control y los tiempos se realizó un Análisis de la Varianza 2 vías (Factor 1: tratamiento, Factor 2: tiempo). En todos los casos se analizaron la homogeneidad de varianzas mediante el test de Cochran (Cochran, 1951) y la normalidad mediante el test de Shapiro-Wilk (Shapiro and Wilk, 1965). Para establecer las diferencias entre grupos se utilizó el test a posteriori de Student-Newman-Keuls (o SNK) (Cohen, 2013). Además, se calculó valor Eta-cuadrado $\left(\eta^{2}\right)$, como una medida del tamaño del efecto (Cohen, 2013). 


\subsection{Resultados}

\section{Parámetros fisicoquímicos}

La conductividad varió entre $182 \mu \mathrm{Scm}^{-1}$ y $356 \mu \mathrm{Scm}^{-1}$ en los controles, y entre 222 $\mu \mathrm{Scm}^{-1}$ y $288 \mu \mathrm{Scm}^{-1}$ en los tratamientos; sin embargo, no hubo diferencias significativas entre los tratamientos experimentales en ninguna fecha (tratamiento ANOVA de 2 vías * Fecha $p>0,05$; Tabla 6.1).

La temperatura de las unidades experimentales, durante el experimento se mantuvo entre 21 y $23^{\circ} \mathrm{C}$, y aunque aumentó significativamente de T2 a T3, no hubo diferencias significativas entre los tratamientos experimentales. El oxígeno disuelto varió entre $6,2 \mathrm{mgO}_{2} \mathrm{~L}^{-1}$ y $11,2 \mathrm{mgO}_{2} \mathrm{~L}^{-1}$, sin observarse diferencias significativas entre los tratamientos. El pH fue significativamente mayor en las unidades experimentales control $(8,98 \pm 0,21$, Tabla 6.1) que en las unidades experimentales tratamiento $(8,67$ $\pm 0,11$ ) durante todo el experimento.

En los elutriados, la concentración $\left(\mathrm{mgL}^{-1}\right)$ de nitratos fue de $0,08 \pm 0,03$, de amonio $<0,001$, de nitritos $0,11 \pm 0,04$, y de fosfatos $0,26 \pm 0,03$.

\section{Pesticidas y metales pesados}

Tanto los $\alpha$ como los $\beta$ isómeros de endosulfán $(6,7,8,9,10,10$-hexacloro-1,5, 5a, 6,9, 9a-hexahidro-6,9-metano-2,3,4-benzo (e) dioxathiepin-3-óxido, CAS No. 115-29-7) se encontraron en una proporción de 70:30 en el sedimento y en los elutriados, junto con el endosulfán sulfato. En el sedimento, las concentraciones medias de endosulfán alcanzaron $0,5 \mathrm{mg} \mathrm{kg}^{-1}$ y de endosulfán sulfato $0,1 \mathrm{mg} \mathrm{kg}^{-1}$. En los elutriados, las concentraciones medias de endosulfán alcanzaron $1,6 \mu \mathrm{g} \mathrm{L}^{-1} \mathrm{y}$ de endosulfán sulfato $0,2 \mu \mathrm{g} \mathrm{L}^{-1}$. También en los elutriados se midió una concentración de $0.18 \mu \mathrm{g} \mathrm{L}^{-1}$ de lindano ( $\gamma$-BHC, CAS No. 58-89-9) (Tabla Anexa 6A).

Se detectaron $\mathrm{Zn}$ y $\mathrm{Cu}$ tanto en el sedimento como en los elutriados utilizados para las unidades experimentales de Tratamiento. La concentración media de Zn en los sedimentos fue de $1,87 \mathrm{mg} \mathrm{\textrm {L } ^ { - 1 }}$, diez veces mayor que la concentración de $\mathrm{Zn}$ medida en los elutriados $\left(0,16 \mathrm{mg} \mathrm{L}^{-1}\right)$. La concentración media de $\mathrm{Cu}$ en los sedimentos $\left(0,49 \mathrm{mg} \mathrm{L}^{-1}\right)$ fue 40 veces la medida en los elutriados $\left(0,012 \mathrm{mg} \mathrm{L}^{-1}\right)$. Las concentraciones de $\mathrm{Cr}$ y $\mathrm{Cd}$ estuvieron por debajo del límite de detección tanto en los sedimentos como en los elutriados. 
Tabla 6.1. Media ( \pm desvío estándar) de los principales parámetros fisicoquímicos medidos en las unidades experimentales Control y Tratamiento durante todo el experimento, y resultados ANOVA de 2 vías (Factores Tratamiento y Fecha). Se muestran las diferencias significativas (en negrita) y la medida del tamaño del efecto $\left(\eta^{2}\right.$ Parcial)

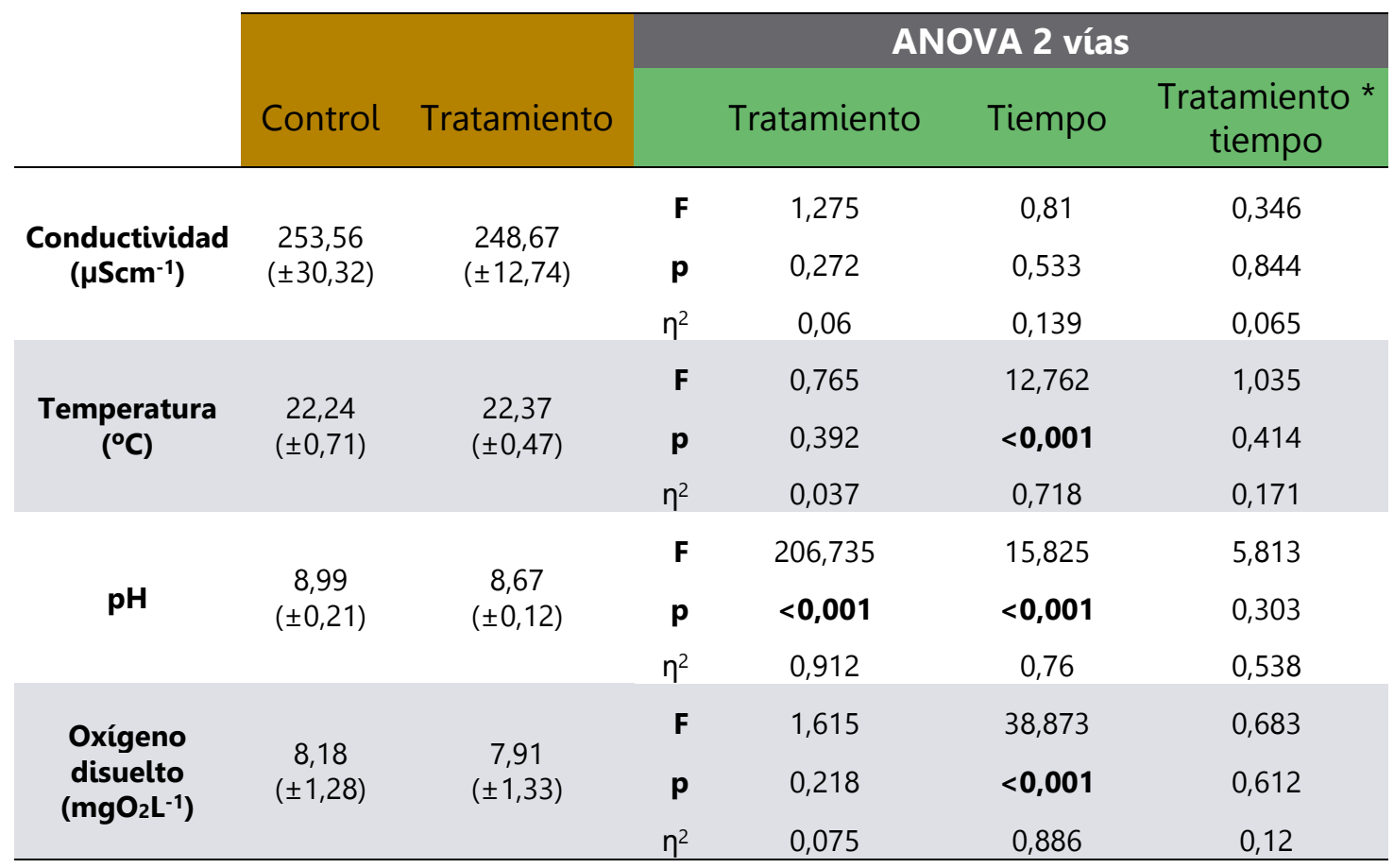

\section{Densidad y longitud celular}

La densidad media aumentó siete veces en los controles desde T0 ( $85 \pm 26$ células $\left.\mathrm{mL}^{-1}\right)$ a T4 $\left(657,6 \pm 272,9\right.$ células $\left.\mathrm{mL}^{-1}\right)$, mientras que en los tratamientos no hubo diferencias significativas de T0 $\left(146,2 \pm 72,7\right.$ células $\left.\mathrm{mL}^{-1}\right)$ a T4 $\left(362,8 \pm 307,1\right.$ células $\mathrm{mL}^{-}$ $\left.{ }^{1}\right)$. Al final del experimento, la densidad celular fue significativamente mayor en los controles que en los tratamientos (Tabla 6.2; Figura 6.2). El tamaño del efecto del tratamiento sobre la densidad celular fue moderado $\left(\eta^{2}=0,20\right)$.

La longitud media de las células se mantuvo similar durante todo el experimento en los Controles (22,4 $\pm 0,37)$, mientras que en los Tratamientos la longitud media disminuyó significativamente en T4 (de 22,6 0,61 en T0-T3 a 20,6 0 0,7 en T4). En ese último tiempo de muestreo, la longitud media de las células fue significativamente menor en los Tratamientos que en los Controles (Tabla 6.2; Figura 6.2). El tamaño del efecto del tratamiento sobre la longitud celular fue moderado $\left(\eta^{2}=0,44\right)$. 


\section{Movilidad}

Todas las medidas de movilidad (velocidad media, aceleración y distancia) fueron significativamente más bajas en los Tratamientos a partir de T2 hasta el final del experimento en comparación con los Controles (Tabla 6.2; Figura 6.2).

La velocidad media de desplazamiento de las células de $N$. palea en los controles aumentó de 1,0 $( \pm 0,2) \mu \mathrm{m} \cdot \mathrm{seg}^{-1}$ a 3,5 $( \pm 0,6) \mu \mathrm{m} \cdot \mathrm{seg}^{-1}$ de T0 a T4; mientras que en los Tratamientos no mostró variación y tomó valores de 1,4 $( \pm 0,29) \mu \mathrm{m} \cdot \mathrm{seg}^{-1}$ (Figura 6.2). La aceleración media siguió un patrón similar que la velocidad en los controles, aumentando de 2,9 $( \pm 0,5) \mu \mathrm{m} \cdot \mathrm{seg}^{-2}$ en T0 a $8,2( \pm 1,4) \mu \mathrm{m} \cdot \mathrm{seg}^{-2}$ en T4. En los tratamientos, la aceleración media permaneció invariable $(3,7 \pm 0,83) \mu \mathrm{m} \cdot \mathrm{seg}^{-2}$.

La distancia en los Controles aumentó de 33,2 $( \pm 7,0) \mu \mathrm{m}$ en T0 a 104,9 $( \pm 9,8) \mu \mathrm{m}$ en T4, mientras que se mantuvo similar durante todo el experimento en los Tratamientos $(49,7 \pm 10,67 \mu \mathrm{m})$.

El tamaño del efecto en las medidas de movilidad fue moderado $\left(0,25>\eta^{2}<0,75\right)$, y el más fuerte se midió en relación con la aceleración $\left(\eta^{2}=0,42\right)$.

Anomalías nucleares

La cantidad de núcleos con ruptura de membrana y mal localizados fue significativamente mayor en los tratamientos desde T1 en adelante (Figura 6.2, Tabla 6.2). No hubo diferencias significativas en los núcleos fragmentados entre los controles y los tratamientos. 
Tabla 6.2. Resultados del ANOVA 2 vías (Tratamiento, Tiempo, Tratamiento*Tiempo) para las variables biológicas. Los valores en negrita indican diferencias significativas.

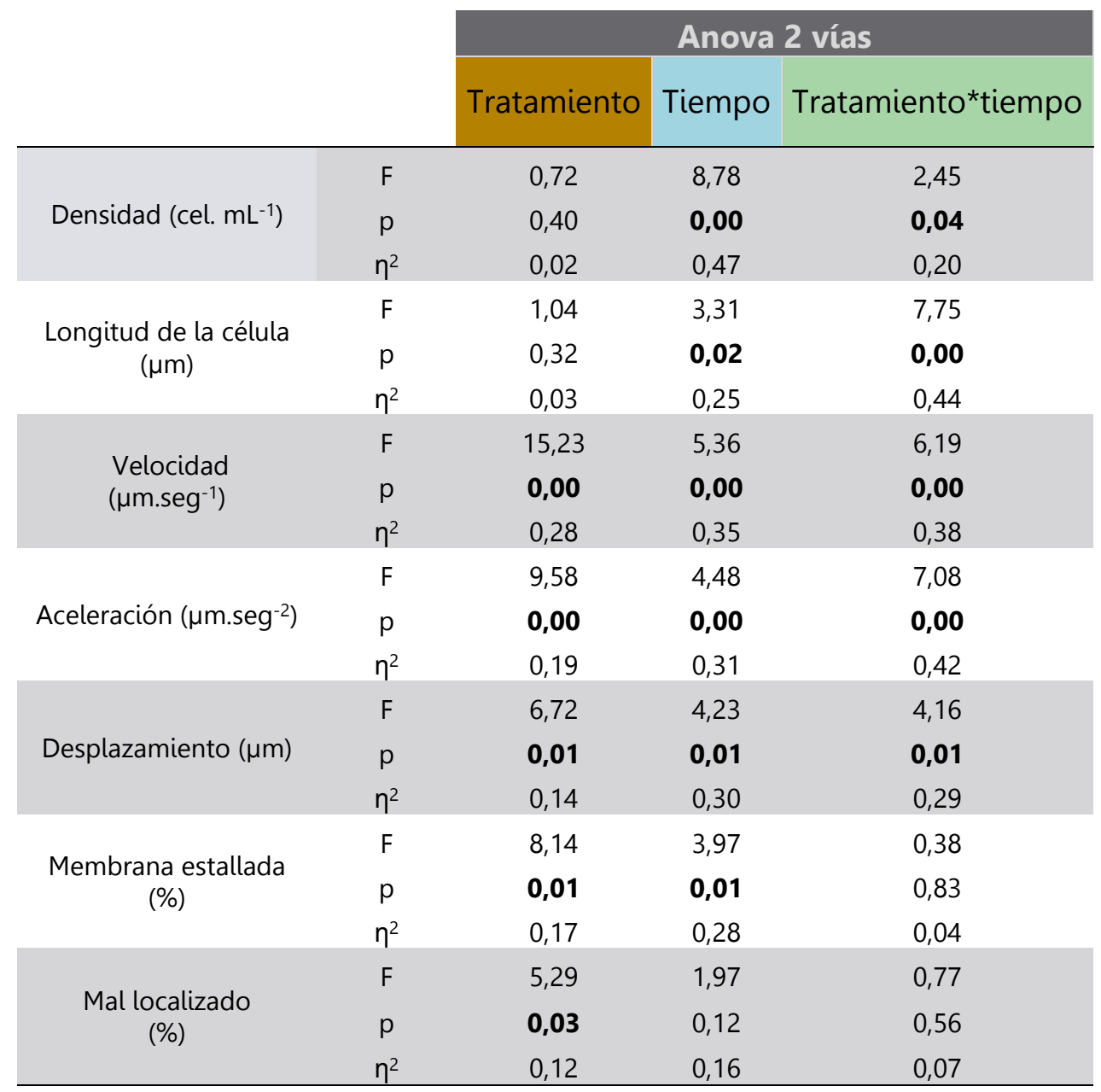




\section{Control}

Densidad

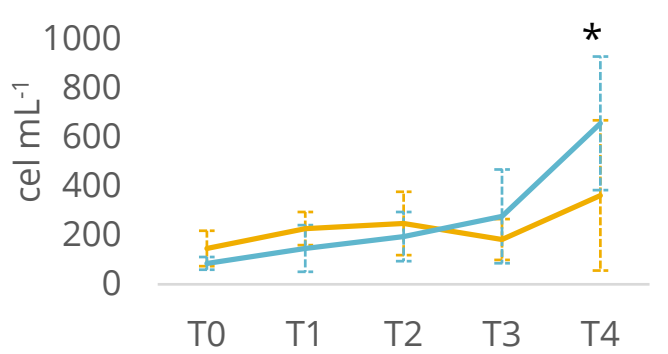

Velocidad

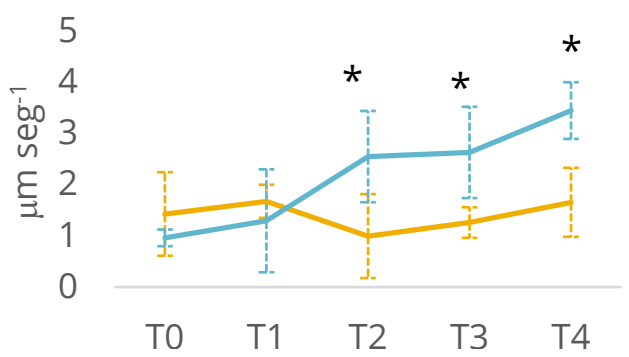

15

Aceleración

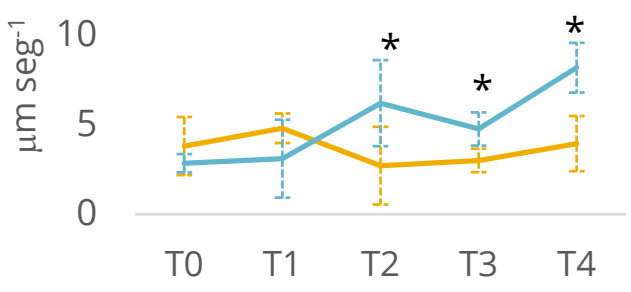

Mal localizado

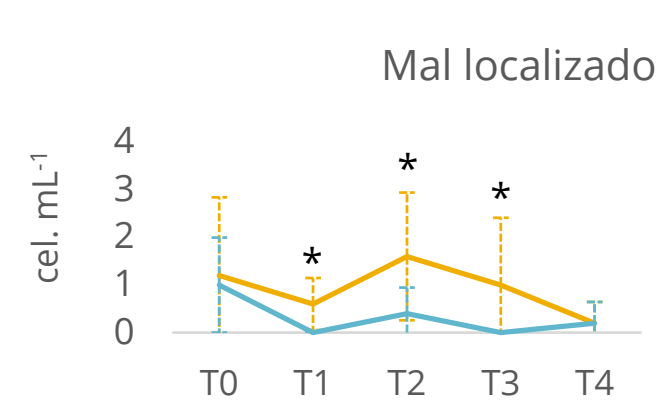

Tratamiento
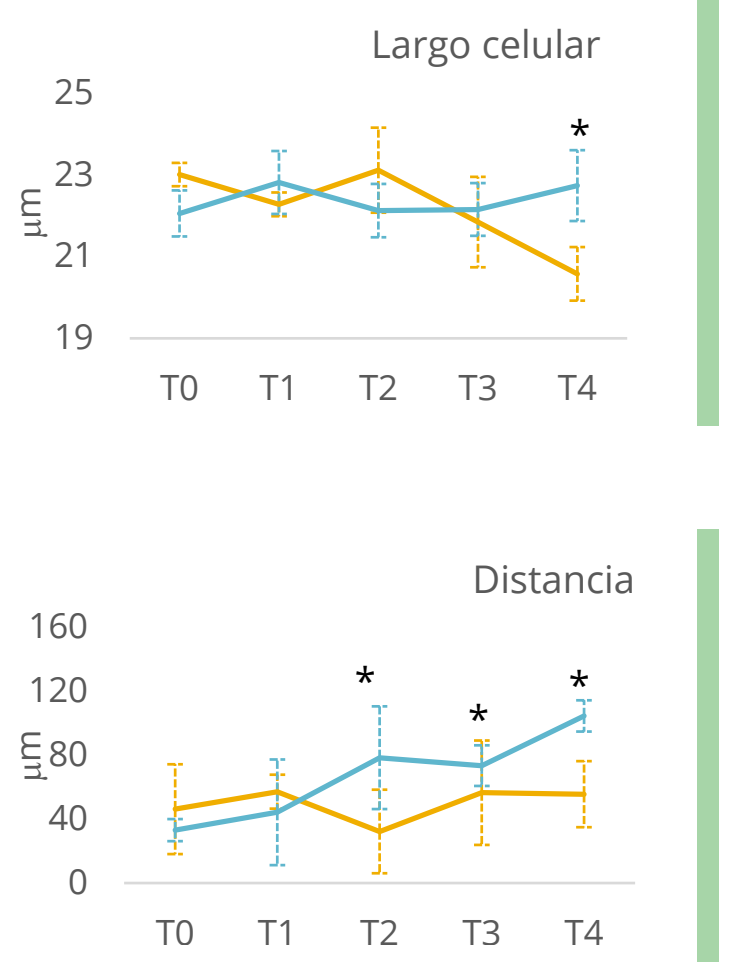

Distancia

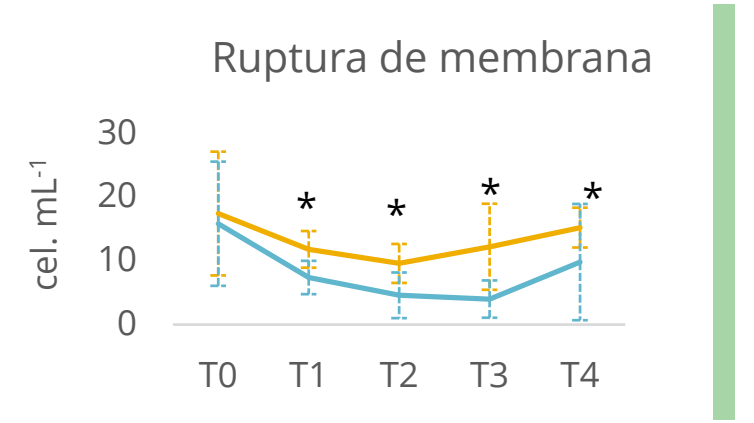

Figura 6.2 Variación de la media $( \pm \mathrm{DE})$ de las variables medidas en Nitzschia palea durante el experimento en las unidades experimentales de Control y Tratamiento. 


\subsection{Discusión y conclusiones}

El bioensayo demostró que las medidas de movilidad en Nitzschia palea y la proporción de anomalías nucleares (ruptura de membrana nuclear y localización anormal) reflejaron rápidamente los efectos de la toxicidad de los sedimentos (con concentraciones detectables de pesticidas y metales pesados) después de sólo 48 horas de exposición, mientras que la densidad y la longitud celular media se vieron afectadas después de una semana de exposición.

Los análisis de metales y pesticidas tanto en los sedimentos como en los elutriados revelaron la presencia de compuestos tóxicos (Endosulfán $\alpha$, Endosulfán $\beta$, Endosulfán sulfato, lindano, $\mathrm{Zn}, \mathrm{Cu}$ ). Las concentraciones de endosulfán y lindano halladas fueron superiores a los niveles guía para la protección de la vida acuática establecidos por la Secretaría de Recursos Hídricos de la Nación ( $\leq 0.007 \mu \mathrm{L} \mathrm{L}^{-1}, \leq 0.02 \mu \mathrm{L} \mathrm{L}^{-1}$ respectivamente). En el caso de los metales pesados, compuestos como en $\mathrm{Zn}$ y el $\mathrm{Cu}$, a concentraciones bajas juegan un papel esencial en el metabolismo de las microalgas (Tadros et al. 1990). Sin embargo, cuando las concentraciones son altas o se produce una mezcla de ellos aún a bajas concentraciones, dan origen a condiciones de contaminación del medio que provocan desbalances metabólicos (Rodríguez y Rivera 1995), llegando a producirse una inhibición del crecimiento y cambios morfológicos, generados como una respuesta fisiológica a la exposición de la mezcla o sustancia problema, que tienen como consecuencia una menor capacidad de respuesta de las poblaciones al nuevo ambiente generado (Sunda y Lewis 1978; Rand y Petrocelli 1985; Visviki y Rachlin 1994; Romero et al. 2001; Gómez y Licursi 2003).

En este ensayo se consideraron dos variables tradicionales como la densidad y el tamaño celular y dos variables del tipo fisiológicas como son la movilidad y el estado del núcleo celular que son menos utilizadas. Las cuatro resultaron afectadas a la exposición de los elutriados tóxicos, pero lo revelaron en diferentes tiempos.

La densidad celular en este estudio resultó afectada a la semana de exposición al elutriado. Se ha reportado que esta variable, puede verse alterada por la presencia de pesticidas (Pérès et al., 1996; Debenest et., 2009; Debenest et al., 2010; Morin et al., 2010) o de metales pesados (Gold et al., 2002; Pandey et al., 2014, Gold et al., 2003a, b; Morin et al., 2008a; Duong et al., 2010; Morin et al., 2010). También se ha encontrado una fuerte inhibición del crecimiento de Nitzschia aff. kuetzingioides en bioensayos con elutriados de sedimento proveniente de lugares con altas concentraciones de metales pesados y compuestos aromáticos (PAHs) (Parodi et al2016). Incluso en ensayos de exposición de 
Gomphonema gracile al agroquímico metacloro, la densidad fue negativamente afectada luego de 7 días de exposición, coincidente con los resultados presentados

Los resultados del ensayo revelaron una disminución significativa en el largo de las células de las diatomeas en el último tiempo de muestreo (a la semana de exposición) en las unidades experimentales expuestas al elutriado. En diatomeas el crecimiento de la población está dominado por la división celular, lo que lleva a una reducción en el tamaño de las células hijas (Round et al., 2007); sólo después de la reproducción sexual se recupera el tamaño original y más grande. Por lo tanto, un cambio en la distribución de tamaños hacia clases celulares más pequeñas reflejaría un predominio de la reproducción asexual, mientras que los tamaños más grandes podrían indicar reproducción sexual. La reducción del tamaño celular, además de estar relacionado con la forma de reproducción asexual que presentan las diatomeas, también ha sido reportada como una respuesta a la exposición a tóxicos, tales como metales pesados y pesticidas (Pandey et al., 2018). Ya que el estrés conduce a una mayor tasa de división celular, en última instancia esta conduce a tamaños reducidos de frústulos (Pandey et al 2017).

Diversas perturbaciones ambientales (Cohn y Disparti, 1994) y antropogénicas (Coquille et al., 2015; Svensson et al., 2014) alteran el patrón y la velocidad de movimiento de las diatomeas. Por ello, el análisis de la movilidad de las diatomeas como marcador fisiológico, permite medir el efecto a corto plazo (minutos a horas) de los estresores en células individuales (Cohn and McGuire 2000). En este ensayo, las medidas de movilidad respondieron negativamente a la exposición al elutriado tóxico, obteniendo resultados significativos a partir de las $48 \mathrm{hs}$. Estos resultados concuerdan con los obtenidos por (Cohn y McGuire 2000) quien reporta menores valores de velocidad frente a la exposición a elutriados tóxicos.

En referencia a los metales pesados, la movilidad ha demostrado ser una buena herramienta para indicar contaminación por Zn y Cu (Pandey and Bergey 2016), aún a concentraciones mucho mayores que las detectadas en este ensayo. Además, se ha visto un efecto inhibidor de varios metales ( $\mathrm{Cu}, \mathrm{Co}, \mathrm{Hg}, \mathrm{Ni}, \mathrm{Zn}$ y $\mathrm{Fe}$ ) y compuestos orgánicos (DDT, captan, 2,4-D) en la tasa de movilidad de dos diatomeas cultivadas en laboratorio, Navicula grimmei y la especie aquí estudiada (Gupta y Agrawal, 2007).

El análisis de las alteraciones nucleares (localización anormal, ruptura de membrana, fragmentación) en este bioensayo arrojó diferencias significativas a partir de T1 (24 hs). Tanto la localización anormal como la ruptura de membrana nuclear se 
hallaron en mayor proporción en las unidades experimentales expuestas al elutriado. Estos resultados coinciden con estudios previos en los que se reportaron mayor proporción de anomalías del núcleo cuándo las diatomeas estuvieron expuestas a herbicidas (Debenest et al. 2008), al cromo hexavalente (Licursi y Gómez, 2013) o a la contaminación por efluentes urbanos (Nicolosi Gelis et al 2020 a). Los estudios de las alteraciones nucleares en diatomeas permiten revelar los efectos de los contaminantes (metales y herbicidas) en estos microproductores que forman el nivel trófico basal de los ecosistemas fluviales, lo que ayuda a comprender los mecanismos de cambio en la composición de los biofilms, especialmente el aumento del dominio de las especies de diatomeas más tolerantes así como factores que podrían conducir a anomalías morfológicas en los frústulos de diatomeas (Debenest et al., 2008; Licursi y Gómez, 2013).

El uso de elutriados para la evaluación de la toxicidad de sedimentos resultó ser una buena técnica, para trabajar con cultivos de diatomeas. Sin embargo, su utilización para la evaluación de la toxicidad de los sedimentos tiene sus limitaciones. Por un lado, la proporción de sedimento en el agua puede ser diferente a la experimentada por las células en su ambiente natural, además, las células en su medio natural están expuestas a la interacción de toxinas tanto soluble como insolubles (con toxinas insolubles que no forman parte del elutriado) (Canter 1985, Rubin et al. 1990, Burton 1991).

Por otro lado, hay que tener en cuenta la persistencia de los compuestos tóxicos durante el tiempo del ensayo. Por ejemplo en el ensayo presentado aquí, las concentraciones de organoclorados al final de la experiencia se encontraron por debajo del límite de detección tanto en los tratamientos (elutriado con diatomeas) como en el control de elutriado (sólo elutriado). Existen varias hipótesis que podrían explicar la reducción de los organoclorados a lo largo del experimento: la bioacumulación en las diatomeas, la degradación de los compuestos naturalmente y/o adsorción en las paredes de las unidades experimentales (Coquillé et al., 2015). 


\subsection{Conclusiones}

Este estudio demostró el efecto de los sedimentos tóxicos (mediante el uso de elutriados) en la población de Nitzschia palea, a través del análisis de diferentes tipos de variables. Los efectos se advirtieron en el último tiempo de muestreo en el caso de las variables como la densidad y el tamaño celular, mientras que los efectos en la movilidad y las alteraciones nucleares, fueron detectables trascurridas $24 / 48$ hs de la exposición.

El uso de las variables de movilidad (distancias, velocidad, aceleración) en este trabajo proporcionó valiosas perspectivas para la evaluación de los sedimentos tóxicos, en este sentido podrían ser incluidas en los protocolos de evaluación de toxicidad de los sedimentos. Si se trabaja con un monocultivo resulta ser una variable fácil, rápida de medir, con bajo costo y que requiere una menor experiencia profesional.

La densidad y el tamaño de las células pueden ser fácilmente medidas en muestras fijadas, mientras que la movilidad, aunque requiere medirse de forma inmediata al muestreo y del equipamiento adecuado, tampoco resulta de gran complejidad. En el caso de las alteraciones nucleares se requiere de más pasos, como la tinción e incubación de las muestras, y de mayor presupuesto debido a que tanto la tinción como las membranas utilizadas son recursos caros. Sin embargo, siguen siendo medidas más rápidas y sencillas que un análisis taxonómico. 
La Región Pampeana se encuentra expuesta a múltiples presiones antrópicas, tales como el uso de las tierras para agricultura, ganadería, así como también a los efectos de la gran expansión demográfica. Todo esto conduce a que los cuerpos de agua de la región se encuentren expuestos a contaminantes provenientes de las actividades agrícolas, industriales y los efluentes urbanos. En tal sentido el estudio de la biota permite integrar la mayoría de los parámetros bióticos y abióticos que influencian su hábitat y proveen un registro continuo de la calidad del ambiente. Dentro de los organismos acuáticos, las diatomeas son usadas comúnmente como indicadores biológicos para evaluar la calidad del agua en ríos y arroyos, debido a que son sensibles a un amplio rango de presiones ambientales. Su uso en las evaluaciones de la calidad del agua se sustenta en las respuestas rápidas tanto a los cambios en las condiciones ambientales debido a un aumento de la contaminación, como al éxito de la restauración del hábitat.

En las últimas décadas ha habido un creciente interés global por explorar nuevas variables del ensamble de diatomeas para estudios de impacto ambiental o ecotoxicológicos. Entre estas variables se encuentran la movilidad, las alteraciones nucleares, las clasificaciones en gremios ecológicos, el análisis del tamaño celular, las cuáles fueron evaluadas en este trabajo de tesis. Estos descriptores cuentan con la ventaja de ser rápidos, más sencillos y en la mayoría de los casos requerir menor experiencia profesional en la identificación de las especies.

Este trabajo de tesis permitió reconocer los efectos sobre la comunidad de la recuperación de la calidad del agua, a través de las respuestas del ensamble de diatomeas mediante el estudio de estos nuevos descriptores. Para ello se exploraron los cambios del ensamble durante las primeras etapas de colonización, y también aquellos observados cuando se trasplantaron a sitios menos contaminados.

De acuerdo a las experiencias realizadas en este trabajo de tesis, fue posible demostrar que el proceso de colonización temprana del biofilm y particularmente del ensamble de diatomeas es afectado por la calidad del agua. Asimismo, se identificaron descriptores de este proceso según el grado y tipo de impacto. 
En las experiencias de colonización, independientemente del impacto estudiado (urbano o agrícola), el desarrollo del biofilm fue menor y más lento en los arroyos con un mayor impacto antrópico. Los principales grupos algales que lideraron el proceso fueron diferentes según el impacto evaluado. Las diatomeas dominaron el biofilm en los arroyos expuestos al impacto urbano; mientras que en los arroyos expuestos a impacto agrícola, las diatomeas estuvieron en igual o mayor medida representadas que las cianofitas y clorofitas. El análisis de descriptores como la riqueza, diversidad e índice de diatomeas pampeanas (IDP) no demostraron cambios significativos durante el proceso de colonización temprana en estos arroyos, ya que no mostraron variaciones en el tiempo, muy probablemente debido a la brevedad de los experimentos. El análisis de los gremios ecológicos reveló que el proceso de colonización temprana se encuentra liderado por las diatomeas del gremio móvil, que además fueron las de mayor representación en el ensamble junto con las diatomeas de alto perfil. A su vez, las diatomeas de tallas intermedias a grandes son las que dominan el proceso de colonización de los sustratos artificiales. En los arroyos expuestos al impacto urbano las clases de tamaños pequeña (Clase 1: 0 a $99 \mu^{3}$; Clase 2: >100-299 $\mu^{3}$ ) reunieron los menores porcentajes del ensamble de diatomeas; mientras que en los arroyos de impacto agrícola, si bien también tuvieron una baja representación, su porcentaje fue más elevado, y resultaron más abundantes en los primeros tiempos de colonización (30 min-24 hs).

El uso de experiencias de translocación, como herramientas de biomonitoreo activo, ha tenido buenos antecedentes en el estudio de la recuperación de las microcomunidades en cuerpos de agua expuestos a distintos impactos antropogénicos, ya sean de origen urbano o agrícola. En las experiencias de translocación realizadas en esta tesis, fue posible reconocer descriptores del ensamble de diatomeas que reflejaron la recuperación en la calidad del agua.

En el ensamble de diatomeas bajo ambos tipos de impacto estudiados (urbano/agrícola) ni la riqueza específica ni el índice de diversidad de Shannon resultaron ser variables indicativas del cambio favorable en la calidad de agua, pero sí lo fue el índice de diatomeas pampeanas (IDP), aún cuando las diferencias en la calidad de agua no fueron tan contrastantes entre los sitios estudiados. Esto demuestra una vez más la importancia de utilizar índices que incorporen las preferencias ecológicas y regionales de las especies.

Las proporciones de los gremios ecológicos (bajo perfil, alto perfil y móvil) demostraron ser variables que reflejan los cambios en la calidad del agua, 
dependiendo del tipo de impacto. En todos los casos de estudio, el gremio móvil fue el de mayor representación en el ensamble (>70\%). Este gremio disminuyó su proporción en los ensambles translocados en arroyos con impacto urbano, pero aumentó en los ensambles translocados en arroyos de impacto agrícola. En cuanto al gremio de bajo perfil, fue un grupo que respondió a las diferencias en la calidad del agua en los arroyos con impacto agrícola, pero no lo hizo en los arroyos con impacto urbano. Sin embargo, en todos los ensambles estudiados fue el gremio de menor representatividad, confirmando así que en ambientes con altos niveles de nutrientes y donde predominan los sustratos blandos son el grupo menos abundante. El gremio de alto perfil respondió en ambos tipos de impacto aumentando su proporción en los ensambles translocados, es decir respondiendo positivamente a la mejora de la calidad del agua.

En cuanto al análisis de las alteraciones nucleares del ensamble de diatomeas, su proporción también fue un descriptor que resultó ser sensible a las diferentes calidades de agua en ambas experiencias. Dentro de las alteraciones, la disminución en la proporción de núcleos con ruptura de membrana fue más sensible a la mejora de la calidad del agua en ambos tipos de impacto; sin embargo, los tiempos de respuesta fueron desiguales. En el caso del impacto urbano, la proporción de núcleos con ruptura de membrana nuclear fue similar a la proporción hallada en los sitios de mejor calidad del agua transcurridos los 45 días. En cambio, en el caso del impacto agrícola, si bien la proporción de esta alteración disminuyó frente al cambio en la calidad del agua, siguió siendo mayor que la hallada en el sitio de menor impacto a los 45 días. Al contrario, la proporción de valvas con deformaciones no resultó ser una variable indicadora de los cambios en la calidad del agua en los arroyos con impacto antrópico. Queda por explorar si en condiciones de una peor calidad del agua (ej: agua contaminada con metales pesados) y un mayor tiempo de exposición inducirán a la manifestación de este tipo de anormalidad.

El análisis de la movilidad de las diatomeas evaluada en arroyos con impacto urbano reveló que las respuestas no fueron significativas frente a los cambios en la calidad del agua. Los resultados sugieren la necesidad de evaluar esta variable a nivel específico, en vez de a nivel de género. Las diferencias entre la movilidad de las distintas especies se reflejan en una alta variabilidad de los parámetros medidos cuando se mide este parámetro a nivel genérico.

La experiencia de laboratorio con elutriados provenientes de sedimentos de un arroyo expuesto al impacto agrícola, permitió advertir que todas las variables analizadas en la población de Nitzschia palea (densidad, tamaño de la valva, alteraciones nucleares, 
movilidad) resultaron afectadas en los tratamientos expuestos a los elutriados de los sedimentos, aún cuando está bien documentado que $N$. palea es una especie muy tolerante tanto a la eutrofización y materia orgánica como a la contaminación tóxica. La movilidad y las alteraciones nucleares evidenciaron los efectos más rápidamente (en 24-48 hs) que la densidad y el tamaño celular (en una semana). Se pudo concluir que las respuestas estudiadas en $N$. palea resultaron eficaces para evaluar la toxicidad del sedimento de los cursos de agua pampeanos.

En síntesis los resultados obtenidos revelaron que las respuestas de las diatomeas tuvieron distinto grado de sensibilidad frente a los cambios en la calidad del agua (Fig. 8.1). En tal sentido la riqueza, diversidad y la proporción de valvas deformadas fueron poco sensibles a la calidad del agua en lapsos de tiempo evaluados. En tanto las proporciones de los gremios ecológicos resultaron más sensibles que las variaciones en las clases de tamaño. Las variables vinculadas a la movilidad de las diatomeas (distancia, velocidad, aceleración) fueron también sensibles cuando se evaluaron a nivel de especie y no de género. En tanto las alteraciones nucleares resultaron ser los mejores indicadores de la calidad del agua, ya que fueron sensibles a todos los impactos evaluados tanto en experiencias in situ como ex situ.

Estas conclusiones permiten remarcar la importancia del estudio de las diatomeas no solamente a través de la estructura y funcionalidad del ensamble (gremios), cómo suelen ser empleadas en los programas de monitoreo, sino también a través de las respuestas a nivel celular y subcelular (ejs.: movilidad, alteraciones nucleares y valvares): Esto enfatiza la necesidad de un abordaje del estudio de la calidad del agua a través de nuevos indicadores basados en el análisis de las diatomeas bentónicas como los mencionados precedentemente, particularmente útiles en el seguimiento temprano de cambios ambientales como pueden ser los involucrados en procesos de restauración o rehabilitación 


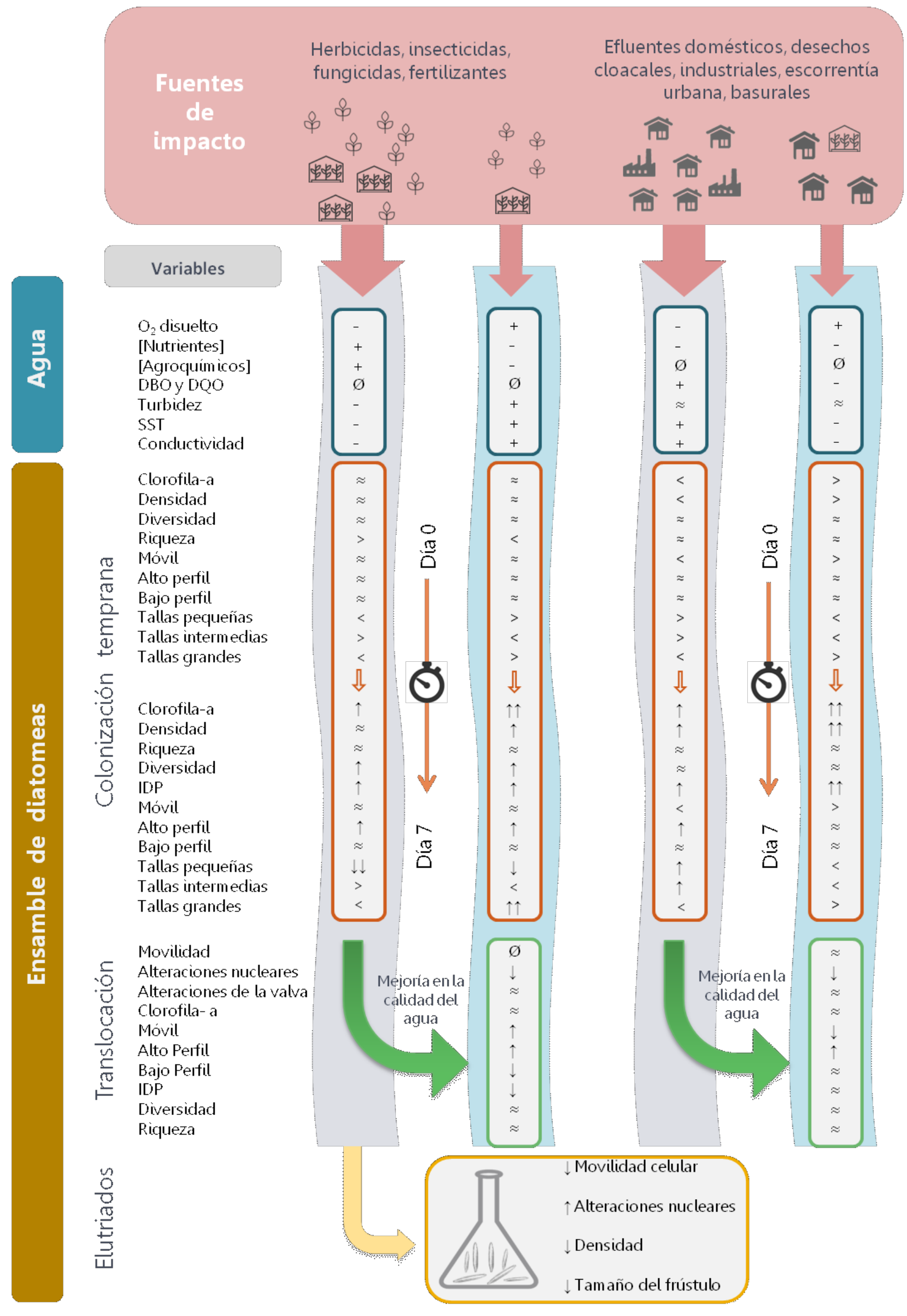


Figura 8.1: Resumen de los principales resultados de las experiencias realizadas en esta tesis. Agua: se indican las diferencias medidas en los parámetros fisicoquímicos medidos en los arroyos (+: mayores valores; -: menores valores; $\approx$ : sin diferencias entre los sitios; $\varnothing$ : variable no medida). Ensamble de diatomeas: se indican las diferencias del ensamble halladas en cada experiencia. Colonización temprana: se muestran las diferencias entre los sitios estudiados $(\approx$ : sin diferencias; <: menores valores; $>$ mayor valores); y en el tiempo ( $\approx$ : sin diferencias; 个aumento de la variable en el tiempo; $\downarrow$ disminución de la variable en el tiempo). Translocación: se muestran las diferencias encontradas en los sustratos translocados al final de la experiencia ( $\downarrow$ : disminución de la variable, $\uparrow$ aumento en la variable; $\approx \sin$ variaciones; $\varnothing$ : variable no medida). Elutriados: se muestras los resultados al final de la experiencia ( $\downarrow$ : disminución de la variable, $\uparrow$ aumento en la variable). 
Ács, E'., Kiss, K. T. (1993). Colonization processes of diatoms on artificial substrates in the River Danube near Budapest (Hungary). En 'Proceedings of the Twelfth International Diatom Symposium', 30 August-5 September 1992, Renesse, Netherlands. (Ed. H. van Dam.) pp. 307-315. (Springer: Dordrecht, Netherlands.) doi:10.1007/978-94-017-3622-0_32

Ács, E'., Kiss, K. T., Szabo'-Taylor, K., y Makk, J. (2000). Short-term colonization sequence of periphyton on glass slides in a large river (River Danube, near Budapest). Acta Botanica Croatica, 100,135-156.

Adams, M.S., Stauber, J.L. (2004). Development of a whole-sediment toxicity test using a benthic marine microalga. Environmental Toxicology Chemistry 2004, 23(8):1957-68.

Agostini, M.G., Kacoliris, F., Demetrio, P., Natale, G.S., Bonetto, C., Ronco, A.E. (2013). Abnormalities in amphibian populations inhabiting agroecosystems in Northeastern Buenos Aires Province, Argentina. Diseases of Aquatic Organisms, 104 (2), 163-171.

Allan, J.D, Castillo, MA. (2007). Stream Ecology: Structure and Function of Running Waters, $2^{\text {nd }}$ ed. Springer, The Netherlands. 400pp.

APHA/AWWA/WEF, 2012. Standard Methods for the Examination of Water and Wastewater. Stand. Methods 4, 541. https://doi.org/ISBN 9780875532356.

Arini, A., Feurtet-Mazel, A., Maury-Brachet, R., Pokrovsky, O.S., Coste, M., Delmas, F. (2012). Recovery potential of periphytic biofilms translocated in artificial streams after industrial contamination (Cd and Zn). Ecotoxicology, 21, 1403-1414. https://doi.org/10.1007/s10646-012-0894-3.

Armendáriz, L. C., Cortese, B., Rodriguez, M., Rodrigues Capítulo, A. (2017). Ecosystem services of runoff arshes in urban lowland basins: Proposals for their management and conservation. Knowledge and Management of Aquatic Ecosystems, 418, 32. https://doi.org/10.1051/kmae/2017022

Barry, M. J., Logan, D. C. (1998). The use of temporary pond microcosms for aquatic toxicity testing: direct and indirect effects of endosulfan on community structure. Aquatic Toxicology, 41(1-2), 101-124.

Bauer, D.E., Donadelli, J., Gómez, N., Licursi, M. (2002a). Ecological status of the Pampean plain streams and rivers (Argentina). Verhandlungen des Internationalen Verein Limnologie, 28, 259-262.

Bauer, D.E., Conde, M.E., Gómez, N. (2002b) Phytoplankton of a Small Lowland Stream Related to Water Quality and Hydraulic Discontinuities. Archiv Für Hydrobiologie, 153(3),421-441.

Bayona, Y., Roucaute, M., Cailleaud, K., Lagadic, L., Bassères, A., \& Caquet, T. (2014). Structural and biological trait responses of diatom assemblages to organic chemicals in outdoor flow-through mesocosms. Environmental Pollution, 192, 186-195. doi:10.1016/j.envpol.2014.05.023

B-Béres, V., Török, P., Kókai, Z., T-Krasznai, E., Tóthmérész, B., Bácsi, I. (2014). Ecological diatom guilds are useful but not sensitive enough as indicators of extremelychanging water regimes. Hydrobiologia, 738, 191204. https://doi.org/10.1007/s10750-014-1929-y.

B-Béres, V., Lukács, Á., Török, P., Kókai, Z., Novák, Z., T-Krasznai, E., Tóthmérész, B., Bácsi, I.(2016). Combined eco-morphological functional groups are reliable indicators of colonisation processes of benthic diatom assemblages in a lowland stream. Ecological Indicators, 64, 31-38. https://doi.org/10.1016/j.ecolind.2015.12.031

B-Béres, V., Török, P., Kókai, Z., Lukács, Á., T-Krasznai, E., Tóthmérész, B., Bácsi, I. (2017). Ecological background of diatom functional groups: Comparability of classification systems. Ecological Indicators, 82, 183-188. https://doi.org/10.1016/j.ecolind.2017.07.007

Berard, A., Benninghoff, C. (2001) Pollution-induced community tolerance (PICT) and seasonal variations in the sensitivity of phytoplankton to atrazine in nanocosms. Chemosphere, 45(4-5),427-437.

Berard, A., Dorigo, U., Humbert, J. F., Bourrain, X., Cauzzi, N., Druart, J.C., Leboulanger, C. (2003) Révélation d'une pollution diffuse par la tolérance induite chez les communautés de microalgues. Application de la 
méthode PICT (Pollution-Induced Community Tolerance) dans une rivière contaminée par des herbicides. 31ème congrès Groupe Français des Pesticides: Transfert des produits phytosanitaires, diagnostic de pollution et solutions correctives, Lyon.

Berthon, V., Bouchez, A., Rimet, F. (2011). Using diatom life-forms and ecological guilds to assess organic pollution and trophic level in rivers: a case study of rivers in South-Eastern France. Hydrobiologia, 673, 259-271. http://dx.doi.org/10.1007/s10750-011-0786-1.

Bertrand, J. (1999). Mouvements des diatomées VI. Les efforts pendant le déplacement apical. Mesures, analyses, relations: longueur, vitesse, force. Cryptogamie Algologie, 20, 43-57. https://doi.org/10.1016/S0181-1568(99)80006-3.

Biggs, B. J. F., Stevenson, R. J., Lowe, R. L. (1998). A habitat matrix conceptual model for stream periphyton. Archiv Für Hydrobiologie, 143, 21-56.

Biggs, B.J. (2000). New Zealand periphyton guideline: Detecting, monitoring and managing enrichment of streams. 1-124.

Biggs, B.J.F., Smith, R.A. (2002). Taxonomic richness of stream benthic algae: effects of flood disturbance and nutrients. Limnology and Oceanografy, 74, 1175-1186.

Blanco, S., Bécares, E. (2010). Are biotic indices sensitive to river toxicants? A comparison of metrics based on diatoms and macro-invertebrates. Chemosphere, 79(1), 1825. doi:10.1016/j.chemosphere.2010.01.059

Blanco, S., Cejudo-Figueiras, C., Tudesque, L., Bécares, E., Hoffmann, L., Ector, L. (2012). Are diatom diversity indices reliable monitoring metrics? Hydrobiologia, 695, 199-206. http://dx.doi.org/10.1007/s10750-012-1113-1.

Blinn, D.W., Fredericksen, A., Korte, V. (1980). Colonization rates and community structure of diatoms on three different rock substrata in a lotic system. British Phycology Journal, 15, 303-310. https://doi.org/10.1080/00071618000650311

Borchardt, M. A. (1996). Nutrients. In Stevenson, R. J., M. L. Bothwell, \& R. L. Lowe (eds), Algal Ecology Freshwater Benthic Ecosystems, Academic Press. San Diego: 183-227, 753.

Bondoc, G,K. (2017) Directed motility of benthic diatoms. Tesis doctoral. Friedich-Schiller Universitat Jena. 146 pp.

Bourrelly, P. (1972). Les algues d'eau douce. Initiation á la systématique. Tome I: Les Algues Vertes. Éditions N. Boubée \& Cie. Paris. 573pp.

Bozzano, H. (2002) "El cinturón verde platense: sistema de objetos, sistemas de acciones". Foro CIVEBA Cinturón Verde Metropolitano Buenos Aires. Jornadas AADER de Argentina y el Mercosur, Facultad de Agronomía, UNLP.

Buma, A.G.J., Hannen, E.J., Roza, L., Veldhuis, M.J.W., Gieskes, W.W.C. (1995).Monitoring ultraviolet-Binduced DNA damage in individual diatom cells by immunofluorescent thymine dimer detection. Journal of Phycology, 31 (2), 314-321. https://doi.org/10.1111/j.0022-3646.1995.00314.x.

Buma, A.G.J., Zemmelink, H.J., Sjollema, K., Gieskes, W.W.C. (1996). UVB radiation modifies protein and photosynthetic pigment content volume and ultrastructure of marine diatoms. Marine Ecolology Progress Series, 142, 47-54. https://doi.org/10.3354/meps142047.

Burton Jr, G. A. (1991). Assessing the toxicity of freshwater sediments. Environmental Toxicology and Chemistry: An International Journal, 10(12), 1585-1627.

Burton Jr, G.A., Denton, D.L., Ho, K., Ireland, D.S. (1995). Sediment toxicity testing issues and methods. En Handbook of Ecotoxicology (pp. 111-150). Boca Raton, Florida.

Burton, G. A.; Landrum, P, F. (2003). Toxicity of sediments. Encyclopedia of sediments and sedimentary rocks, 748-751.

Cabrera, A.L., Willink, A. (1980). Biogeografía de America Latina. Organization of American States, Washington. 122pp. 
Camilión, M.C., Manassero, M.J., Hurtado, M.A., Ronco, A.E., (2003). Copper, lead and zinc distribution in soils and sediments of the south-western coast of the Río de la Plata estuary. Journal of Soils and Sediments, 3 (3), 213-220.

Canter, L. W. (1985). River Water Quality Monitoring., Chelsea, Michigan: Lewis Publishers.

Carder, J.P., Hoagland, K.D. (1998) Combined effects of alachlor and atrazine on benthic algal communities in artificial streams. Environmental Toxicology Chemistry, 17(7),1415-1420.

Casotti, R., Mazza, S., Brunet, C., Vantrepotte, V., lanora, A., Miralto, A. (2005). Growth inhibition and toxicity of the diatom aldehyde 2-trans, 4-trans-decadienal on Thalassiosira weissflogii (Bacillariophyceae). Journal of Phycology, 41, 7-20. https://doi.org/10.1111/j.1529-8817.2005.04052.x.

Christensen, A. M., Nakajima, F., Baun, A. (2006). Toxicity of water and sediment in a small urban river (Store Vejleå, Denmark). Environmental Pollution, 144(2),621-625. doi:10.1016/j.envpol.2006.01.032

Cirelli, A. F., C. Ojeda.(2008). Wastewater management in Greater Buenos Aires, Argentina. Desalination 218(1-3):52-61

Clesceri, L. S., Greenberg, A. E., Y Eaton, A. D. (Eds.) (1998) Standard methods for the examination of water and wastewater. APHA, American Public Health Association, Washington D.C. USA, 20th edition

Cochero, J., Romaní, A. M., Gómez, N. (2013). Delayed response of microbial epipelic biofilm to nutrient addition in a Pampean stream. Aquatic Microbial Ecology, 69(2), 145-155. doi:10.3354/AME01630

Cochero, J., Licursi, M., Gómez, N. (2015). Changes in the epipelic diatom assemblage in nutrient rich streams due to the variations of simultaneous stressors. Limnologica - Ecology and Management of Inland Waters, 51, 15-23. doi:10.1016/j.limno.2014.10.004

Cochero, J., Licursi, M., Gómez, N. (2017). Effects of pulse and press additions of salt on biofilms of nutrientrich streams. Science of Total Environment, 579,1496-1503. https://doi.org/10.1016/j.scitotenv.2016.11.152

Cochero, J., Nicolosi Gelis, M. M., Sathicq, M. B., Gómez, N. (2018).Biofilm early stage development in two nutrient-rich streams with different urban impacts. River Research and Applications, 34(7),755-764. doi:10.1002/RRA.3290

Cochran, W. (1951). Some properties of the (Fo-Fc)-synthesis. Acta Crystallographica, 4(5), 408-411.

Cohen, J., (2013). Statistical power analysis for the behavioral sciences. Routledge. https:// doi.org/10.4324/9780203771587.

Cohn S.A. (2001). Photo-stimulated effects on diatom motility. In: Häder, D.-P., Lebert,M. (Eds.), Photomovement. Elsevier Science B.V., Amsterdam, pp. 375-401. https://doi. org/10.1016/S1568$461 X(01) 80017-X$.

Cohn, S. A., Farrell, J. F., Munro, J. D., Ragland, R. L., Weitzell Jr, R. E., Wibisono, B. L. (2003).The effect of temperature and mixed species composition on diatom motility and adhesion. Diatom Research, 18(2), 225243.

Cohn, S.A., Bahena, M., Davis, J., Ragland, R.L., Rauschenberg, C., Smith, B. (2004). Characterisation of the diatom photophobic response to high irradiance. Diatom Research, 19, 167-179. https://doi.org/10.1080/0269249X.2004.9705869.

Cohn, S.A., Disparti, N.C. (1994). Environmental factors influencing diatom cell motility. Journal of Phycology. 30, 818-828. https://doi.org/10.1111/j.0022-3646.1994.00818.x.

Cohn, S. A. Weitzell, R. E. (1996). Ecological considerations of diatom cell motility. I. Characterization of motility and adhesion in four diatom species. Journal of Phycology, 32(6), 928-939. doi:10.1111/j.00223646.1996.00928.x

Cohn, S.A., McGuire, J.R. (2000). Using diatom motility as an indicator of environmental stress: effects of toxic sediment elutriates. Diatom Research, 15 (1), 19-29. https://doi.org/ 10.1080/0269249X.2000.9705484. 
Congestri, R., Albertano, P. (2011) Benthic Diatoms in Biofilm Culture. In: Seckbach J., Kociolek P. (eds) The Diatom World. Cellular Origin, Life in Extreme Habitats and Astrobiology, vol 19. Springer, Dordrecht. https://doi.org/10.1007/978-94-007-1327-7 10

Coombs, J., Volcani, B.E., (1968). Studies on the biochemistry and fine structure of silica shell formation in diatoms. Planta 80, 264. https://doi.org/10.1007/BF00392396.

Coquillé, N., Jan, G., Moreira, A., Morin, S. (2015). Use of diatom motility features as endpoints of metolachlor toxicity. Aquatic Toxicology, 158, 202-210.http://dx.doi.org/10.1016/j.aquatox.2014.11.021.

Corcoll, N., Bonet, B., Morin, S., Tlili, A., Leira, M., Guasch, H. (2012). The effect of metals on photosynthesis processes and diatom metrics of biofilm from a metal-contaminated river: a translocation experiment. Ecological Indicators, 18, 620-631. https://doi.org/10.1016/j.ecolind.2012.01.026.

Cortelezzi, A., Sierra, M. V., Gómez, N., Marinelli, C., Rodrigues Capítulo, A. (2012). Macrophytes, epipelic biofilm, and invertebrates as biotic indicators of physical habitat degradation of lowland streams Argentina). Environmental Monitoring and Assessment, 185(7), 5801-5815. doi:10.1007/s10661-012-29852

Coste, M. (1975). Sur la prolifération dans la Seine d'une diatomée benthique tropicale: Navicula confervacea (Kütz.) Grunow. Annales de Limnologie, 11(2), 111-123. doi:10.1051/limn/1975007

Dalu, T., Froneman, P., Chari, L., and Richoux, N. (2014). Colonisation and community structure of benthic diatoms on artificial substrates following a major flood event: a case of the Kowie River (Eastern Cape, South Africa). Water S.A. 40(3), 471-480. doi:10.4314/WSA.V40I3.10

Debenest, T., Silvestre, J., Coste, M., Delmas, F., Pinelli, E. (2008). Herbicide effects on freshwater benthic diatoms: induction of nucleus alterations and silica cell wall abnormalities. Aquatic Toxicology, 88 (1), 88 94. https://doi.org/10.1016/j.aquatox.2008.03.011.

Debenest, T., Pinelli, E., Coste, M., Silvestre, J., Mazzella, N., Madigou, C., Delmas, F. (2009). Sensitivity of freshwater periphytic diatoms to agricultural herbicides. Aquatic Toxicology, 93, 11-17. https://doi.org/10.1016/j.aquatox.2009.02.014.

Debenest, T., Silvestre, J., Coste, M.,; Pinelli, E. (2010). Effects of pesticides on freshwater diatoms. En Reviews of environmental contamination and toxicology (pp. 87- 103). Springer, New York, NY. https://doi.org/10.1007/978-1-4419-1352-4_2

Debenest, T., Silvestrea, J., Pinelli, E. (2013). Diatoms in ecotoxicology. En: Férard, J-F.,Blaise, C. (Eds.), Encylopedia of aquatic ecotoxicology. Springer, Netherlands, pp. 295-304.

de Jonge, V. (1979). Quantitative separation of benthic diatoms from sediments using density gradient centrifugation in the colloidal silica Ludox-TM. Marine Biology, 51, 267-278. https://doi.org/10.1007/BF00386807

de Jonge, M., Van de Vijver, B., Blusta, R., Lieven Bervoets, L. (2008). Responses of aquatic organisms to metal pollution in a lowland river in Flanders: A comparison of diatoms and macroinvertebrates. Science of the Total Environment, 407, 615-629. http://dx.doi.org/10.1016/j.scitotenv.2008.07.020

De la-Cruz, J., Pritchard, T., Gordon, G., and Ajani, P. (2006). The use of periphytic diatoms as a means of assessing impacts of point source inorganic nutrient pollution in south-eastern Australia. Freshwater Biology, 51(5), 951-972. doi:10.1111/J.1365-2427.2006.01537.X

De Lorenzo, M.E., Scott, G.I. and Ross, P.E. (2001), Toxicity of pesticides to aquatic microorganisms: A review. Environmental Toxicology and Chemistry, 20, 84-98. doi:10.1002/etc.5620200108

De Nicola, D.M. (1996). Periphyton responses to temperature at different ecological level. En: Stevenson, R.J., Bothwell, M.L., Lowe, R.L. (Eds.), Algal Ecology of Freshwater Benthic Ecosystem, Aquatic Ecology Series. Academic Press, Boston, pp. 149-181.

Descy, J.-P., Coste, M. (1991). A test of methods for assessing water quality based on diatoms. SIL Proceedings, 1922-2010, 24(4), 2112-2116. doi:10.1080/03680770.1989.11899905

Desikachary, T.V. (1959). Cyanophyta. Indian council of agricultural research, New Delhi. 685pp. 
Desrosiers, C., Leflaive, J., Eulin, A., and Ten-Hage, L. (2013). Bioindicators in marine waters: benthic diatoms as a tool to assess water quality from eutrophic to oligotrophic coastal ecosystems. Ecological Indicators, 32, 25-34. doi:10.1016/J.ECOLIND.2013.02.021

Ding, J., Jiang, Y., Liu, Q., Hou, Z., Liao, J., Fu, L., Peng, Q. (2016). Influences of the land use pattern on water quality in low-order streams of the Dongjiang River basin, China: A multi-scale analysis. Science of the Total Environment, 551-552

Dodds, W. K., (2006). Eutrophication and trophic state in rivers and streams. Limnology and Oceanography, $51(1), 671-680$.

Dorigo, U., Leboulanger, C., Bérard, A., Bouchez, A., Humbert, J.F., Montuelle, B., (2007). Lotic biofilm community structure and pesticide tolerance along a contamination gradient in a vineyard area. Aquatic Microbial Ecology, 50, 91-102.

Dorigo, U., Berard, A., Rimet, F., Bouchez, A., Montuelle, B. (2010a). In situ assessment of periphyton recovery in a river contaminated by pesticides. Aquatic Toxicology, 98(4), 396406. doi:10.1016/j.aquatox.2010.03.011

Dorigo, U., Bérard, A., Bouchez, A. (2010b) Transplantation of Microbenthic Algal Assemblages to Assess Structural and Functional Recovery After Diuron Exposure. Archives of Environmental Contamination and Toxicology, 59, 555-563. https://doi.org/10.1007/s00244-010-9511-8

Downing, H.F., Delorenzo, M.E., Fulton, M.H. (2004). Effects of the Agricultural Pesticides Atrazine, Chlorothalonil, and Endosulfan on South Florida Microbial Assemblages. Ecotoxicology, 13, 245-260 https://doi.org/10.1023/B:ECTX.0000023569.46544.9f

DP (Defensor del Pueblo), 2015. Relevamiento de la Utilización de Agroquímicos en la Provincia de Buenos Aires. Mapa de Situación e Incidencia Sobre la Salud. Defensor del Pueblo, Buenos Aires, Argentina, p. 533.

Drum, R.W., Hopkins, J.T., (1966). Diatom locomotion: An explanation. Protoplasma 62, 1. https://doi.org/10.1007/BF01254629.

Duke, E.L., Reimann, B.E.F. (1977) . The Ultrastructure of the diatom cell. En: Werner, D. (Ed. ) The Biology of Diatoms. Blackwell Scientific Publications, Oxford, pp. 13-45.

Duong, T. T., Feurtet-Mazel, A., Coste, M., Dang, D. K., Boudou, A. (2007). Dynamics of diatom colonization process in some rivers influenced by urban pollution (Hanoi, Vietnam). Ecological Indicators, 7(4), 839-851. doi:10.1016/J.ECOLIND.2006.10.003

Duong, T. T., Morin, S., Herlory, O., Feurtet-Mazel, A., Coste, M., Boudou, A. (2008). Seasonal effects of cadmium accumulation in periphytic diatom communities of freshwater biofilms. Aquatic Toxicology, 90(1), 19-28. doi:10.1016/j.aquatox.2008.07.012

Duong, T.T., Morin, S., Coste, M., Olivier Herlory, O., Feurtet-Mazel, A., Boudou, A. (2010). Experimental toxicity and bioaccumulation of cadmium in freshwater periphytic diatoms in relation with biofilm maturity. Science of the Total Environment, 408, 552-562. http://dx.doi.org/10.1016/j.scitotenv.2009.10.015.

Duong, T.T., Coste, M., Feurtet-Mazel, A., Dang, D. K., Ho, C.T., Le, T.P.Q. (2012). Responses and structural recovery of periphytic diatom communities after short term disturbance in some rivers (Hanoi, Vietnam). Journal of Applied Phycology, 24, 1053-1065. http://dx.doi.org/10.1007/s10811-011-9733-9.

Dytham, C. (2011). Choosing and using statistics. A Biologist́s Guide, Third Edit. ed. Wiley-Blackwell, West Sussex, UK.

Ebenezer, V., Ki, J.S. (2014). Quantification of the toxic effects of the organochlorine insecticides endosulfan on marine green algae, diatoms and dinoflagellate. Indian Journal of Geo- Marine Sciences, 43, 393-399.

Edgar, L. A., Pickett-Heaps, J. D. (1984). Valve morphogenesis in the pennate diatom Navicula cuspidata. Journal of Phycology, 20(1), 47-61. https://doi.org/10.1111/j.0022-3646.1984.00047.x

Eulin, A., Le Cohu, R. (1998). Epilithic diatom communities during the colonization of artificial substrates in the River Garonne (France). Comparison with the natural communities. Archiv Für Hydrobiologie, 143(1), 79106. doi:10.1127/ARCHIV-HYDROBIOL/143/1998/79 
Ellis, J.B. (2007). Pharmaceutical and personal care products (PPCPs) in urban receiving waters. Environmental Pollution, 144,184-9

Falasco, E., Bona, F., Badino, G., Hoffmann, L., Ector, L. (2009). Diatom teratological forms and environmental alterations: a review. Hydrobiologia, 623, 1-35 http://dx.doi.org/10.1007/s10750-008-9687$\underline{3}$.

Feijoó, C.S, Giorgi, A., García, M.E., Momo, F. (1999). Temporal and spatial variability in streams of a pampean basin. Hydrobiología, 394(0), 41-52.

Feijoó, C. S., Lombardo, R. J. (2007). Baseline water quality and macrophyte assemblages in Pampean streams: A regional approach. Water Research, 41, 1399-1410. https://doi.org/10.1016/j.watres.2006.08.026

Field, C.B., Behrenfeld, M.J., Randerson, J.T., Falkowski, P. (1998). Primary production of the biosphere: Integrating terrestrial and oceanic components. Science, 281, 237-240,

Fore, L. S., Grafe, C. (2002). Using diatoms to assess the biological condition of large rivers in Idaho (USA). Freshwater Biology, 47, 2015-2037.

Frediani, J.C. (2009). Las nuevas periferias en el proceso de expansión urbana. El caso del partido de La Plata. Geograficando: Revista de Estudios Geográficos, 5(5). ISSN E 2346-898X. http://geograficando.fahce.unlp.edu.ar

Frediani, J.C., Matti, C. (2006). Transformaciones urbanas en el partido de La Plata desde los años '90. ¿Hacia un modelo de ciudad compacta o difusa? Geograficando: Revista de Estudios Geográficos, 2(2). ISSN E 2346-898X.http://geograficando.fahce.unlp.edu.ar

Friberg, N., Lindstrøm, M., Kronvang, B., Larsen, S. E. (2003). Macroinvertebrate/sediment relationships along a pesticide gradient in Danish streams. En The Interactions between Sediments and Water (pp. 103110). Springer, Dordrecht.

Giddings, J.M., Brock, T.C.M., Heger,W., Heimbach, F., Maund, S.J., Norman, S.M., Ratte, H.T., Schäfers, C., Streloke, M., (2002). Community-Level Aquatic System Studies-Interpretation Criteria (CLASSIC). SETAC Press, Pensacola, FL.

Giorgi, A.D.N. (1998). Factores reguladores del fitobentos de arroyos de llanura. Tesis doctoral No 711. UNLP, Argentina. 350pp.

Giorgi, A., Malacalza, L. (2002) .Effect of an industrial discharge on water quality and periphyton structure in pampean stream. Environmental monitoring and assessment, 75,107-109.

Giorgi, A., Feijoó, C., Tell, G. (2005). Primary producers in a Pampean stream: Temporal variation and structuring role. Biodiversity and Conservation, 14(7), 1699-1718. https://doi.org/10.1007/s10531-0040694-z

Gold, C., Feurtet-Mazel, A., Coste, M., Boudou, A. (2002). Field transfer of periphytic diatom communities to assess short-term structural effects of metals $(\mathrm{Cd}, \mathrm{Zn})$ in rivers. Water Research, 36, 3654-3664. http://dx.doi.org/10.1016/S0043-1354(02)00051-9.

Gold, C., Feurtet-Mazel, A., Coste, M., Boudou, A. (2003a). Effects of cadmium stress on periphytic diatom communities in indoor artificial streams. Freshwater Biology, 48(2), 316-328. https://doi.org/10.1046/j.1365-2427.2003.00980.x

Gold, C., Feurtet-Mazel, A., Coste, M., Boudou, A. (2003b). Impacts of Cd and Zn on the development of periphytic diatom communities in artificial streams located along a river pollution gradient. Archives of environmental contamination and toxicology, 44(2), 0189-0197. https://doi.org/10.1007/s00244-002$\underline{2024-3}$

Goldsborough, L.G., Robinson, G.G.C. (1986) Changes in periphytic algal community structure as a consequence of short herbicide exposures. Hydrobiologia, (139),177-192.

Gómez, N. (1998). Use of epipelic diatom for evaluation of water quality in the Matanza- Riachuelo (Argentina), a pampean plain river. Water Research, 32, 2029-2034. 
Gómez, N., (1999). Epipelic diatoms from the Matanza-Riachuelo river (Argentina), a highly polluted basin from the pampean plain: biotic indices and multivariate analysis. Aquatic Ecosystem Health and Management Society 2 (1999), 301-309.

Gómez, N., Licursi, M. (2001). The Pampean Diatom Index (IDP) for assessment of rivers and streams in Argentina. Aquatic Ecology, 35(2), 173-181.

Gómez, N., Licursi, M. (2003). Abnormal forms in Pinnularia gibba (Bacillariophyceae) in a polluted lowland stream from Argentina. Nova Hedwigia, 77,389-398.

Gómez, N., Licursi, M., Hualde, P.R. (2003). Epiphytic algae on the bulrush (Scirpus californicus (Mey) Steud) in the Río de la Plata (Argentina): structure and architecture. Archiv Für Hydrobiologie Suppl Large Rivers, 14 (3-4), 231-247.

Gómez, N., Sierra, M. V., Cortelezzi, A., Rodrigues Capítulo, A. (2008). Effects of discharges from the textile industry on the biotic integrity of benthic assemblages. Ecotoxicology and Environmental Safety, 69(3), 472479. doi:10.1016/j.ecoenv.2007.03.007

Gómez, N., Licursi, M., Cochero, J. (2009). Seasonal and spatial distribution of the microbenthic communities of the Rio de la Plata estuary (Argentina) and possible environmental controls. Marine Pollution Bulletin, 58(6), 878-887. doi:10.1016/j.marpolbul.2009.01.014

Gómez N., Sierra M. V., Cochero J., Licursi M., Bauer D. E. (2010). Epipelic biofilms as indicators of environmental changes in lowland fluvial systems. En: Biofilms: Formation, Development and Properties. Editor: WIlliam C. Bailey Nova Science Publishers, Inc.

Guasch, H., Muñoz, I., Roses, N., Sabater, S. (1997) Changes in atrazine toxicity throughout succession of stream periphyton communities. Journal of Applied Phycology, 9(2),137-146.

Guasch, H., Admiraal, W., Sabater, S. (2003). Contrasting effects of organic and inorganic toxicants on freshwater periphyton. Aquatic Toxicology, 64, 165-175.

Guillard, R. R., Lorenzen, C. J. (1972). Yellow-green algae with chlorophyllide c 1, 2. Journal of Phycology, $8(1), 10-14$.

Gupta, S., Agrawal, S.C. (2007). Survival and motility of diatoms Navicula grimmei and Nitzschia palea affected by some physical and chemical factors. Folia Microbiologica, 52, 127-134. https://doi.org/10.1007/BF02932151.

Gustavson, K., Møhlenberg, F., Schlüter, L. (2003). Effects of Exposure Duration of Herbicides on Natural Stream Periphyton Communities and Recovery. Archives of Environmental Contamination and Toxicology, 45, 0048-0058. https://doi.org/10.1007/s00244-002-0079-9

Hillebrand, H., Sommer, U. (2000). Diversity of benthic microalgae in response to colonization time and eutrophication. Aquatic Botany, 67(3), 221-236. doi:10.1016/s0304-3770(00)00088-7

Hirst, H., Ingrid, J.U., Jüttner, I., Ormerod, S.J. (2002). Comparing the responses of diatoms and macroinvertebrates to metals in upland streams of Wales and Cornwall. Freshwater Biology, 47, 1752-1765. http://dx.doi.org/10.1046/j.1365-2427.2002.00904.x.

Hoagland, K. D., Roemer, S. C., Rosowski, J. R. (1982). Colonization and community structure of two periphyton assemblages, with emphasis on the diatoms (Bacillariophyceae). American Journal of Botany, 69(2), 188-213. doi:10.1002/J.1537-2197.1982.TB13249.X

Hurtado, M.A., Giménez,J.E, Cabral,M.G., da Silva,M.M., Martínez, O.R., Camilión,M.C., Sánchez, C.A., Muntz, D., Gebhard, J.A., Forte, L.M., Boff, L.D., Crincoli, A., Lucesoli, H. (2006) Análisis ambiental del partido de La Plata Aportes al ordenamiento territorial. Ed: Consejo Federal de Inversiones. http://sedici.unlp.edu.ar/handle/10915/27046. 129 pp

INDEC. 2010. Censo Nacional de Población, Hogares y Viviendas. Buenos Aires, Argentina.

Ingersoll, C. G., Brunson, E. L., Dwyer, F. J., Ankley, G. T., Benoit, D. A., Norberg-King, T. J., Winger, P. V. (1995). Toxicity and bioaccumulation of sediment-associated contaminants using freshwater invertebrates: A review of methods and applications. Environmental Toxicology and Chemistry: An International Journal, 14(11), 1885-1894. https://doi.org/10.1002/etc.5620141110 
Ivorra, N., Hettelaar, J., Tubbing, G.M.J., Kraak, M.H.S., Sabater, S., Admiraal, W. (1999). Translocation of microbenthic algal assemblages used for in situ analysis of metal pollution in rivers. Archives of Environmental Contamination and Toxicology, 37, 19-28.

Ivorra, N., Bremer, S., Guasch, H., Kraak, M. H. S., Admiraal, W. (2000). Differences in the sensitivity of benthic microalgae to ZN and CDregarding biofilm development and exposure history. Environmental Toxicology and Chemistry, 19(5), 1332-1339. doi:10.1002/ETC.5620190516

Jergentz, S., Mugni, H., Bonetto, C. y Schulz, R. (2005). Assessment of insecticide contamination in runoff and stream water of small agricultural streams in the main soybean area of Argentina. Chemosphere, 61 , 817-826. doi:10.1016/j.chemosphere.2005.04.036

Johnson, R. E., Tuchman, N. C., and Peterson, C. G. (1997). Changes in the vertical microdistribution of diatoms within a developing periphyton mat. Journal of the North American Benthological Society ,16(3), 503-519. doi:10.2307/1468140

Katagi, T. (2006). Behavior of pesticides in water-sediment systems. En Reviews of Environmental Contamination and Toxicology (pp. 133-251). Springer, New York, NY.

Kelly, M. G. (1998). Use of the trophic diatom index to monitor eutrophication in rivers. Water Research 32(1), 236-242. doi:10.1016/S0043-1354(97)00157-7

Kelly, M.G., (2003). Short term dynamics of diatoms in an upland stream and implications for monitoring eutrophication. Environmetal Pollution, 125 (2), 117-122. https://doi.org/10. 1016/S0269-7491(03)000757.

Kelly, M. G., Whitton, B. A. (1995). The tropic diatom index: a new index for monitoring eutrophication in rivers. Journal of Applied Phycology,7: 433-444.

Kókai, Z., Bácsi, I., Török, P., Buczkó, K., T-Krasznai, E., Balogh, C., Tóthmérész, B., B-Béres, V. (2015). Halophilic diatom taxa are sensitive indicators of even short term changes in lowland lotic systems. Acta Botanica Croatica, 74(2), 287-302.https://doi.org/10.1515/botcro-2015-0025

Komárek, J., Praha, B.F. (1983). Das Phytoplankton des SüBwasswassers, Systematik und Biologie. Schweizerbart, Stuttgart. 1044pp.

Komárek, J., Anagnostidis, K. (1999). SüBwasswasserflora von Mitteleuropa, Cyanoprokaryota 1: Chroococcales. Gustav Fischer Verlag, Jena. 548 pp.

Komárek, J., Anagnostidis, K. (2005). SüBwasswasserflora von Mitteleuropa, Cyanoprokaryota 2: Oscillatoriales. Elsevier GMHB, München. 759 pp

Krammer, K., (1992). Pinnularia: eine Monographie der europäischen Taxa. Bibl. Diatomol 26, 1-353.

Krammer, K. (2000). The genus Pinnularia. In: Lange-Bertalot H (ed) Diatoms of Europe,Vol 1. A.R.G. Gantner Verlag, Ruggell.

Krammer, K., Lange-Bertalot H. (1986). BacillariophyceaeTeil 1: Naviculaceae. In: Ettl H, Gerloff J, Heynig H, Mollenhauer D (eds) Süsswasserflora von Mitteleuropa, Vol 2. Gustav Fischer Verlag, Stuttgart.

Krammer, K., Lange-Bertalot, H. (1988). BacillariophyceaeTeil 2: Bacillariaceae, Epthemiaceae, Surirellaceae. In: Ettl H, Gerloff J, Heynig H, Mollenhauer D (eds) Süsswasserflora von Mitteleuropa, Vol 2. Gustav Fischer Verlag, Stuttgar.

Krammer, K., Lange-Bertalot, H. (1991a). BacillariophyceaeTeil 3: Centrales, Fragilariaceae, Eunotiaceae. In: Ettl H, Gerloff J, Heynig H, Mollenhauer D (eds) SüsswasserfloravonMitteleuropa, Vol 2. Gustav Fischer Verlag, Stuttgart.

Krammer, K., Lange-Bertalot H. (1991b). BacillariophyceaeTeil 4: Achnanthaceae, Literaturverzeichnis. In: Ettl H, Gerloff J, Heynig H, Mollenhauer D (eds) Süsswasserflora von Mitteleuropa, Vol 2. Gustav Fischer Verlag, Stuttgart.

Kronvang, B., Hezlar, J., Boers, P., Jensen, J. P., Behrendt, H., Anderson, T.,Nielsen, C. B. (2004). Nutrient retention handbook. Software Manual for EUROHARP-NUTRET and Scientific review on nutrient retention. EUROHARP report, 9-2004. 
Kruse, E. E., Sarandón, R., Gaspari, F. J. (2014). Impacto del cambio climático en el Gran La Plata. Web oai:naturalis.fcnym.unlp.edu.ar:20180406015117

Lange-Bertalot, H. (2000). Iconographia Diatomologica - Annotated Diatom Micrographs. Vol. 9: Diatoms of the Andes, from Venezuela to Patagonia/Tierra del Fuego. Ganter Verlag, Ruggell.

Lange, K., Liess, A., Piggot, J. J., Townsen, C. R., ; Matthaei, C. D. (2011). Light, nutrients and grazing interact to determine stream diatom community composition and functional group structure. Freshwater Biology, 56(2), 264-278. https://doi.org/10.1111/j.1365-2427.2010.02492.x

Larras, F., Montuelle, B., Bouchez, A. (2013). Assessment of toxicity thresholds in aquatic environments: Does benthic growth of diatoms affect their exposure and sensitivity to herbicides? Science of The Total Environment, 463-464, 469-477. doi:10.1016/j.scitotenv.2013.06.063

Laviale, M., Prygiel, J., Lemoine, Y., Courseaux, A., and Créach, A. (2009). Stream periphyton photoacclimation response in field conditions: effect of community development and seasonal changes. Journal of Phycology 45(5), 1072-1082. doi:10.1111/J.1529-8817.2009.00747.X

Lavoie, I., Campeau, S., Fallu, M., Dillon, P.J., (2006). Diatoms and biomonitoring: should cell size be accounted for? Hydrobiologia, 573, 1-16. http://dx.doi.org/10.1007/s10750-006-0223-z.

Lavoie, I., Lento, J., Morin, A. (2010). Inadequacy of size distributions of stream benthic diatoms for environmental monitoring. Journal of the North American Benthological Society, 29(2), 586-601. https://doi.org/10.1899/09-062.1

Lavoie, I., Hamilton, P. B., Morin, S., Kim Tiam, S., Kahlert, M., Gonçalves, S., Taylor, J. C. (2017). Diatom teratologies as biomarkers of contamination: Are all deformities ecologically meaningful? Ecological Indicators, 82, 539-550. doi:10.1016/j.ecolind.2017.06.048

Leboulanger, C., Rimet, F., de Lacotte, M.H., Berard, A. (2001).Effects of atrazine and nicosulfuron on freshwater microalgae. Environmet International, 26(3),131-135.

Lenoir, A., Coste, M. (1996). Development of a practical diatom index of overall water quality applicable to the French National Water Board Network. p. 29-43. En: Whitton, B. A., \& Rott, E. (Eds.). Institut für Botanik Universität Innsbruck.

Levei, E., Miclen, M., Şenila, M., Cadar, O., Roman, C., Micle, V. (2010). Evaluarea disponibilităţii Pb, Cd, Cu, şi Zn pentru plante în regiunea minieră Baia Mare. Journal of Plant Development, 17, 139-144.

Licursi, M., Gómez, N. (2002). Benthic diatoms and some environmental conditions in three lowland streams. Annales de Limnologie - International Journal of Limnology, 38(2), 109118. doi:10.1051/limn/2002009

Licursi,I M.( 2005). Efectos de las perturbaciones antropogénicas sobre la taxoncenosis de diatomeas bentónicas en sistemas lóticos pampeanos. Tesis doctoral No 859. UNLP, Argentina. 186pp.

Licursi, M., Sierra, M. V., Gómez, N. (2006). Diatom assemblages from a turbid coastal plain estuary: Río de la Plata (South America). Journal of Marine Systems, 62(1-2), 35-45. doi:10.1016/j.jmarsys.2006.03.002

Licursi, M., Gómez, N. (2009). Effects of dredging on benthic diatom assemblages in a lowland stream. Journal of Environmental Management, 90(2), 973-982. doi:10.1016/j.jenvman.2008.03.004

Licursi, M., Gómez, N., Donadelli, J. (2010). Ecological optima and tolerances of coastal benthic diatoms in the freshwater-mixohaline zone of the Río de la Plata estuary. Marine Ecology Progress Series, 418, 105117. doi:10.3354/meps08865

Licursi, M., Gómez, N. (2013). Short-term toxicity of hexavalent-chromium to epipsammic diatoms of a microtidal estuary (Río de la Plata): Responses from the individual cell to the community structure. Aquatic Toxicology, 134-135, 82-91. https://doi.org/10. 1016/j.aquatox.2013.03.007.

Licursi, M., Gómez, N., Sabater, S. (2015). Effects of nutrient enrichment on epipelic diatom assemblages in a nutrient-rich lowland stream, Pampa Region, Argentina. Hydrobiologia, 766(1), 135-150. doi:10.1007/s10750-015-2450-7 
Lobo, E.A., Wetzel, C.E., Ector, L., Katoh, K., Blanco, S., Mayama, S. (2010). Response of epilithic diatom community to environmental gradients in subtropical temperate Brazilian rivers. Limnetica,29 (2), 323-340.

Lobo, E. A., Heinrich, C. D., Schuch, M., Wetzel, C. E., Ector, L. (2016). Diatoms as bioindicators in rivers. p. 245-271. En: Necchi Jr. (Ed.). River Algae. Springer International Publishing

López-Doval, J.C., Ricart, M., Guasch, H. (2010). Does Grazing Pressure Modify Diuron Toxicity in a Biofilm Community? Archives of Environmental Contamination and Toxicology, 58, 955-962. https://doi.org/10.1007/s00244-009-9441-5

López van Oosterom, M. V., Ocon, C., Armendariz, L. C., Rodrigues Capitulo, A. (2015). Structural and functional responses of the oligochaete and aeolosomatid assemblage in lowland streams: A one-way pollution-modelled ecosystem. Journal of Limnology, 74. https://doi.org/10.4081/jlimnol.2015.1142

Lorenzen, C.J. (1967). Determination of chlorophyll and pheopigments: spectrophotometric equations. Limnology and Oceanografy, 12(2), 343-346.

Ludwig, J.A., Reynolds, J.F. (1988) Statistical ecology. John Wiley \& Sons, Nueva York, 337.pp

Lukács,A' ., Kókai, Z., To“ro“k, P., Ba'csi, I., Borics, G., Va'rbı'ro', G., Krasznai, E. T., To'thme're'sz, B., and Be'res, V. B. (2018). Colonisation processes in benthic algal communities are well reflected by functional groups. Hydrobiologia 823(1), 231-245. doi:10.1007/S10750-018-3711-Z

Mac Loughlin, T.M., Peluso, L. Marino, D.J. (2017). Pesticide impact study in the peri-urban horticultural area of Gran La Plata, Argentina. Science of the Total Environment, 598, 572-580. https://doi.org/10.1016/j.scitotenv.2017.04.116

Mac Loughlin, T.M., Peluso, M.L, Aparicio, V.C., Marino, D.J (2020). Contribution of soluble and particulatematter fractions to the total glyphosate and AMPA load in water bodies associated with horticulture. Science of the Total Environmental, 703, 134717. https://doi.org/10.1016/j.scitotenv.2019.134717

Magnusson, M., Heimann, K., Ridd, M., Negri, A.P. (2012) Chronic herbicide esposures affect the sensitivity and community structure of tropical benthic microalgae. Marine Pollution Bulletin, 65 (4-9), 363-372. Doi:10.1016/j.marpolbul.2011.09.029

Maitland, V.C., Robinson, C.V., Porter, T.M., Hajibabaei, M. (2020). Freshwater diatom biomonitoring through benthic kick-net metabarcoding. bioRxiv.

Mann, D.G., Droop, S.J.M.(1996). Biodiversity biogeography and conservation of diatoms. En: Kristiansen, J.(eds) Biogeography of Freshwater Algae. Developments in Hydrobiology, vol 118. Springer, Dordrecht

Margalef, R. (1997). Our Biosphere. En: Kinne, O. (Ed). Excellence in Ecology Series, book. Ecology Institute, Oldendorf. 176 pp.

Martínez De Fabricius, A.L., Maidana, N., Gómez, N., Sabater, N. (2003) Distribution patterns of benthic diatoms in a Pampean river exposed to seasonal floods: the Cuarto River (Argentina). Biodiversity and Conservation, 12, 2443-2454. https://doi.org/10.1023/A:1025857715437

Matthiessen, P., Bifield, S., Jarrett, F., Kirby, M. F., Law, R. J., McMinn, W. R., Whale, G. F. (1998). An assessment of sediment toxicity in the River Tyne Estuary, UK by means of bioassays. Marine Environmental Research, 45(1), 1-15.

Mc Cormick, P. V., Stevenson, R. J. (1991). Mechanisms of benthic algal succession in lotic environments. Ecology, 72:1835-1848.

Medley, C. N., Clements, W. H. (1998). Responses of diatom communities to heavy metals in streams: the influence of longitudinal variation. Ecological Applications, 8(3), 631-644. doi:10.1890/10510761(1998)008[0631:RODCTH]2.0.CO;2

Meijering, E., Dzyubachyk, O., Smal, I., (2012). Methods for cell and particle tracking. Methods Enzymology, 504, 183-200. https://doi.org/10.1016/B978-0-12-391857-4.00009-4.

Metzeltin, D., Lange-Bertalot, H. (1998). Tropical diatoms of South America I. About 700 predominantly rarely known or new taxa representative of the neotropical flora. Lange-Bertalot, $\mathrm{H}$. (Ed.). Iconographia Diatomologica 5, 1-695. 
Metzeltin, D., Lange-Bertalot, H. (2005. Diatoms of Uruguay. Compared with other taxa from South America and elsewhere. In: Lange-Bertalot, H. (Ed.). Iconografia Diatomologica 15:1-736.

Metzeltin D., Lange-Bertalot H. (2007). Tropical Diatoms of South America II. Special remarks on biogeographic disjunction. In: Lange-Bertalot, H. (Ed.). Iconografia Diatomologica 18:1-877.

Morales E.A"Morphological studies in selected fragilarioid diatoms (Bacillariophyceae) from Connecticut waters (U.S.A.)," Proceedings of the Academy of Natural Sciences of Philadelphia 151(1), 105-120, (1 December 2001). https://doi.org/10.1635/0097-3157(2001)151[0105:MSISFD]2.0.CO;2

Moreno-Garrido, I., Hampel, M., Lubián, L. M., Blasco, J. (2003). Sediment toxicity tests using benthic marine microalgae Cylindrotheca closterium (Ehremberg) Lewin and Reimann (Bacillariophyceae). Ecotoxicology and Environmental Safety, 54(3), 290-295. doi:10.1016/s0147-6513(02)00077-5

Morin, S., Costae, M. (2006). Metal-induced shifts in the morphology of diatoms from the Riou Mort and Riou Viou streams (South West France). En: Acs, E., Kiss, K.T., Padiska, J., Szabo, K. (Eds.). Use of algae for monitoring rivers VI. Hungarian Algological Society, God, Hungary, Balatonfured, pp. 91-106.

Morin, S., Vivas-Nogues, M., Duong, T. T., Boudou, A., Coste, M., and Delmas, F. (2007). Dynamics of benthic diatom colonization in a cadmium/zinc-polluted river (Riou-Mort, France). Fundamental and Applied Limnology, 168(2), 179-187. doi:10.1127/1863-9135/2007/0168-0179

Morin, S., Duong, T.T., Dabrin, A., Coynel, A., Herlory, O., Baudrimont, M., Delmas, F.,Durrieu, G., Schäfer, J., Winterton, P., Blanc, G., Coste, M., (2008). Long-term survey of heavy-metal pollution, biofilm contamination and diatom community structure in the Riou Mort watershed, South-West France. Environmental Pollution, 151, 532-542. http://dx.doi.org/10.1016/j.envpol.2007.04.023.

Morin, S., Bottin, M., Mazzella, N., Macary, F., Delmas, F., Winterton, P., Coste, M. (2009). Linking diatom community structure to pesticide input as evaluated through a spatial contamination potential (Phytopixal): A case study in the Neste riversystem (South-West France). Aquatic Toxicology, 94, 28-39. http://dx.doi.org/10.1016/j.aquatox.2009.05.012.

Morin, S., Pesce, S., Tili, A., Coste, M., Montuelle, B. (2010). Recovery potential of periphytic communities in a river impacted by a vineyard watershed. Ecological Indicators, 10, 419-426. http://dx.doi.org/10.1016/j.ecolind.2009.07.008.

Morin, S., Lambert, A.S., Artigas, J., Coquery, M., Pesce, S. (2012). Diatom immigration drives biofilm recovery after chronic copper exposure. Freshwater Biology, 57, 1658-1666. https://doi.org/10.1111/j.13652427.2012.02827.x.

Morin, S., Berta Bonet, B., Corcoll, N., Guasch, H., Bottin, M., Coste, M. (2015). Cumulative stressors trigger increased vulnerability of diatom communities to additional disturbances. Microbial Ecology, 70, 585-595. http://dx.doi.org/10.1007/s00248-015-0602-y.

Morin, S., Gómez, N., Tornés, E., Licursi, M., Rosebery, J. (2016) Benthic diatom monitoring and assessment of freshwater environments: standard methods and future challenges. En: A.M. Romaní, H. Guasch, M.D. Balaguer (Eds.). Aquatic Biofilms: Ecology, Water Quality and Water Treatment. Caister Academic Press, U.K pp. 111- 124, 10.21775/ 9781910190173.06.

Morales, E. A., Edlund, M. B., Spaulding, S. A. (2010). Description and ultrastructure of araphid diatom species (Bacillariophyceae) morphologically similar to Pseudostaurosira elliptica (Schumann) Edlund et al. Phycological Research, 58(2), 97-107. doi:10.1111/j.1440-1835.2010.00567.x

Mugni, H. (2009) Concentración de nutrientes y toxicidad de biocidas en aguas superficiales de cuencas rurales. Tesis doctoral, Universidad de La Plata. 140 pp

Munawar, M. U., Munawar, I. F. (1987). Phytoplankton bioassays for evaluating toxicity of in situ sediment contaminants. En Ecological Effects of In Situ Sediment Contaminants (pp. 87-105). Springer, Dordrecht.

Muñoz, I., Real, M., Guasch, H., Navarro, E., Sabater, S. (2001) Effects of atrazine on periphyton under grazing pressure. Aquatic Toxicology, 55(3-4):239-249. 
Ndiritu, G.G., Gichuki, N.N., Triest, L. (2006). Distribution of Epilithic Diatoms in Response to Environmental Conditions in an Urban Tropical Stream, Central Kenya. Biodiversity and Conservation, 15, 3267-3293. https://doi.org/10.1007/s10531-005-0600-3

Nenadović, T., Šarčević, T., Čižmek, H., Godrijan, J., Pfannkuchen, D. M., Pfannkuchen, M., Ljubešić, Z. (2015). Development of periphytic diatoms on different artificial substrates in the Eastern Adriatic Sea. Acta Botanica Croatica, 74(2), 377-392. doi:10.1515/botcro-2015-0026

Ní Chatháin, B., Harrington, T.J. (2008). Benthic diatoms of the river deel: diversity and community structure. 2008. Biology and Environment: Proceedings of the Royal Irish Academy, 108 (1), pp. 29-42 DOI: $10.2307 / 20694844$

Nicolosi Gelis, M. M., Cochero, J., Donadelli, J., Gómez, N. (2020a). Exploring the use of nuclear alterations, motility and ecological guilds in epipelic diatoms as biomonitoring tools for water quality improvement in urban impacted lowland streams. Ecological Indicators, 110, 105951.https://doi.org/10.1016/j.ecolind.2019.105951

Nicolosi Gelis, M.M, Cochero, J., Sathicq, M.B., Gómez, N. (2020) Effect of pollution on early diatom colonisation on artificial substrata in urban lowland streams. Marine and Freshwater Research (online-early 26 August) https://doi.org/10.1071/MF19293

Öberg, G., Merlinsky, M.G., LaValle, A., Morales, M., Tobias, M.M. (2014). The notion of sewage as waste: A study of infrastructure change and institutional inertia in Bs As, Argentina and Vancouver, Canada. Ecology and Society, 19(2).

Paixão, J. F., de Oliveira, O. M., Dominguez, J. M., dos Santos Almeida, E., Carvalho, G. C., Magalhães, W. F. (2011). Integrated assessment of mangrove sediments in the Camamu Bay (Bahia, Brazil). Ecotoxicology and environmental safety, 74(3), 403-415. https://doi.org/10.1016/j.ecoenv.2010.10.038

Pandey, L.K., Kumar, D., Yadav, A., Rai, J., Gaur, J.P. (2014). Morphological abnormalities in periphytic diatoms as a tool for biomonitoring of heavy metal pollution in a river. Ecological Indicators, 36, 272-279. http://dx.doi.org/10.1016/j.ecolind.2013.08.002.

Pandey, L.K., Han, T., Gaur, J.P. (2015). Response of a phytoplanktonic assemblage to copper and zinc enrichment in microcosm. Ecotoxicology, 24, 573-582. https://doi.org/10.1007/s10646-014-1405-5.

Pandey, L.K., Bergey, E.A. (2016). Exploring the status of motility, lipid bodies, deformities and size reduction in periphytic diatom community from chronically metal $(\mathrm{Cu}, \mathrm{Zn})$ polluted waterbodies as a biomonitoring tool. Science of The Total Environment, 550, 372-381. http://dx.doi.org/10.1016/j.scitotenv.2015.11.151.

Pandey, L.K., Bergey, E.A., Jie, L., Park, J., Choi, S., Lee, H., Depuydt, S., Han, T. (2017). The use of diatoms in ecotoxicology and bioassessment: Insights, advances and challenges, Water Research, doi: 10.1016/j.watres.2017.01.062.

Park, J., Lee, H., Depuydt, S., Han, T., Pandey, L. K. (2020). Assessment of five live-cell characteristics in periphytic diatoms as a measure of copper stress. Journal of Hazardous Materials, 123113. doi:10.1016/j.jhazmat.2020.123113

Parodi, E., Gauna, M.C., Fernández, C., Croce, M.E. (2015). Evaluación de la ecotoxicidad del agua y sedimento en la zona interna del estuario de Bahía Blanca. Informe Técnico CONICET, 176pp.

Passy, S.I. (2007). Diatom ecological guilds display distinct and predictable behavior along nutrient and disturbance gradients in running waters. Aquatic Botany, 86, 171-178. http://dx.doi.org/10.1016/j.aquabot.2006.09.018.

Passy, S.I., Larson, C.A. (2011). Succession in stream biofilms is an environmentally driven gradient of stress tolerance. Microbial Ecology, 62, 414-424

Patrick, R., Reimer, C.W. (1966). The diatoms of the United States, exclusive of Alaska and Hawaii. Monograph Academy of Natural Sciences of Philadelphia 131.

Patrick, R., Reimer, C.W. (1975). The diatoms of the United States, exclusive of Alaska and Hawaii. Monograph Academy of Natural Sciences of Philadelphia 132. 
Paz, L. E., Nicolosi Gelis, M. M., Licursi, M., Gómez, N., Rodrigues Capítulo, A. (2018). Use of native macrophytes for recovery of the habitat structure and complexity of a lowland stream affected by river engineering works: Implications for management. River Research and Applications, 34(6), 575585. doi:10.1002/rra.3280

Peres, F., Florin, D., Grollier, T., Feurtet-Mazel, A., Coste, M., Ribeyre, F., Ricard, M., Boudou, A. (1996). Effects of the phenylurea herbicide isoproturon on periphytic diatom communities in freshwater indoor microcosms. Environmental Pollution, 94(2):141-152. https://doi.org/10.1016/S0269-7491(96)00080-2

Pesce, S., Morin, S., Lissalde, S., Montuelle, B., Mazzella, N. (2011). Combining polar organic chemical integrative samplers (POCIS) with toxicity testing to evaluate pesticide mixture effects on natural phototrophic biofilms. Environmental Pollution, 159(3), 735-741. doi:10.1016/j.envpol.2010.11.034

Pica Granados, Y., Trujillo Domínguez, G. (2007). Procedimiento para la generación de extractos orgánicos y elutriados de suelos y sedimentos para su análisis en ensayos de toxicidad. En: Ensayos toxicológicos para la evaluación de sustancias químicas en agua y suelo La experiencia en México. Compiladoras: Ramírez Romero P, Mendoza Cantú A. Secretaría de Medio Ambiente y Recursos Naturales Instituto Nacional de Ecología. México. 428 pp.

Plenkovic-Moraj, A., Koraljka, K., Gligora, M. (2008). Effect of current velocity ondiatom colonization on glass slides in unpolluted headwater creek. Periodicum Biologorum,110, 291-293.

Pohlon, E., Marxsen, J., Küsel, K. (2010). Pioneering bacterial and algal communities and potential extracellular enzyme activities of stream biofilms. Microbiology Ecology, 71, 364-373. https://doi.org/10.1111/j.1574-6941.2009.00817.x

Potapova, M., Charles, D. F. (2005). Choice of substrate in algae-based water-quality assessment. Journal of the North American Benthological Society, 24(2), 415-427. doi:10.1899/03-111.1

Potapova, M., Charles, D. F.(2007). Diatom metrics for monitoring eutrophication in rivers of the United States. Ecological Indicators, 7: 48-70.

Pringle, C.M., (1990). Nutrient Spatial Heterogeneity: Effects on community structure, physiognomy, and diversity of stream algae. Ecology, 71, 905-920 http://www.jstor.org/stable/1937362

Proia, L., Morin, S., Peipoch, M., Romaní, A.M., Sabater, S. (2011). Resistance and recovery of river biofilms receiving short pulses of Triclosan and Diuron. Science of the Total Environment, 409, 3129-3137. https://doi.org/10.1016/j.scitotenv.2011.05.013.

Rand, G. M., Petrocelli, S. R. (1985). Fundamentals of aquatic toxicology: methods and applications. FMC Corp., Princeton, NJ. 666pp.

Rémy, M., Bouchez, A. Rimet, F. (2013). Influence of herbicide contamination on diversity and ecological guilds of river diatoms. Cryptogamie Algologie, 34(2), 169-183. https://doi.org/10.7872/crya.v34.iss.2.2013.169

Renzi, M., Roselli, L., Giovani, A., Focardi, S.E., Basset, A. (2014). Early warning tools for ecotoxicity assessment based on Phaeodactylum tricornutum. Ecotoxicology, 23, 1055-1072. http://dx.doi.org/10.1007/s10646-014-1249-z

Ricart, M., Guasch, H., Barceló, D., Brix, R., Conceição, M. H., Geiszinger, A., Sabater, S. (2010). Primary and complex stressors in polluted mediterranean rivers: Pesticide effects on biological communities. Journal of Hydrology, 383(1-2), 52-61. doi:10.1016/j.jhydrol.2009.08.014

Rijstenbil, J.W. (2001). Effects of periodic, low UVA radiation on cell characteristics and oxidative stress in the marine planktonic diatom Ditylum brightwellii. European Journal of Phycology, 36 (1), 1-8. https://doi.org/10.1017/S0967026201003043.

Rimet, F., Cauchie, H.M., Hoffmann, L., Ector, L. (2005). Response of diatom indices to simulated water quality improvements in a river. Journal of Applied Phycology, 17, 119-128

Rimet, F., Ector, L., Cauchie, H.M., Hoffmann, L. (2009). Changes in diatom-dominated biofilms during simulated improvements in water quality: implications for diatom based monitoring in rivers. European Journal of Phycology, 44 (4), 567-577. https://doi.org/10.1080/09670260903198521. 
Rimet, F., Bouchez ,A. (2011). Use of diatom life-forms and ecological guilds to assess pesticide contamination in rivers: Lotic mesocosm approaches. Ecological Indicators, 11, 489-499. http://dx.doi.org/10.1016/j.ecolind.2010.07.004.

Rimet, F., Bouchez, A., (2012a). Biomonitoring river diatoms: Implications of taxonomic resolution. Ecological Indicators, 15, 92-99. http://dx.doi.org/10.1016/j.ecolind.2011.09.014.

Rimet, F., Bouchez, A. (2012b). Life-forms, cell-sizes and ecological guilds of diatoms in European rivers. Knowledge and Management of Aquatic Ecosystems, 406, 01. doi:10.1051/KMAE/2012018

Rimoldi, F., Peluso, L., Bulus Rossini, G., Ronco, A. E., Demetrio, P. M. (2018). Multidisciplinary approach to a study of water and bottom sediment quality of streams associated with mixed land uses: Case study Del Gato Stream, La Plata (Argentina). Ecological Indicators, 89, 188-198. doi:10.1016/j.ecolind.2018.01.063

Rodrigues Capítulo, A., Gómez, N., Giorgi, A., Feijoó, C. (2010). Global changes in pampean lowland streams (Argentina), implications for biodiversity and functioning. Hydrobiologia, 657:53-70.

Rodríguez, L., Rivera, D. (1995). Efecto del cobre y cadmio en el crecimiento de Tetraselmis suecica (Kylin) Butcher y Dunaliella salina Teodoresco.[Effects of copper and cadmium on the growth of Tetraselmis suecica (Kylin) Butcher y Dunaliella salina Teodoresco]. Estudios oceanológicos, 14, 61-74.

Rohr, J. R., Crumrine, P. W. (2005). Effects of an herbicide and an insecticide on pond community structure and processes. Ecological Applications, 15(4), 1135-1147. doi:10.1890/03-5353

Romero, Y., Lodeiros, C., Esclapés, M., Marín, N., Guevara, M., Morales, E. (2002). Efecto tóxico del cadmio sobre microalgas aisladas del nororiente de Venezuela. Interciencia, 27(3), 104-109.

Ronco, A., Camilión, C., Manassero, M. (2001). Geochemistry of heavy metals in bottom sediments from streams of the western coast of the Rio de la Plata estuary, Argentina. Environmental Geochemistry and Health, 23, 89-103. https://doi.org/10.1023/A:1010956531415

Ronco, A., Camilión, C., Manassero, M. (2007). Metal occurrence and textural-compositional properties in bottom sediments from right margin tributaries of the lower del Plata basin. Latin American Journal of Sedimentology and Basin Analysis, 14 (1), 43-51.

Rott E. (1991) "Methodological aspects and perspectives in the use of periphyton for monitoring and protecting rivers". En: Whitton, B.A., Rott, E. and Friedrich (eds). Use of Algae for Monitoring Rivers. Innsbruck, Austria: Universität Innsbruck, Rott E. Publisher.

Rotter, S., Sans-Piché, F., Streck, G., Altenburger, R., Schmitt-Jansen, M. (2011). Active bio-monitoring of contamination in aquatic systems-An in situ translocation experiment applying the PICT concept. Aquatic Toxicology, 101(1), 228-236. doi:10.1016/j.aquatox.2010.10.001

Roubeix, V; Mazzella N, Delmas F, Coste M.(2010). In situ evaluation of herbicide effects on the composition of river periphytic diatom communities in a region of intensive agriculture. Atmusephere: The International Online Museum Journal, Atmusephere - The International Association for Museum and Heritage, 60 (2), pp.233-241.

Roubeix,V., Mazzella, N., Schouler, L., Fauvelle, V., Morin, S., Coste, M., Delmas, F., Margoum, C. (2011a). Variations of periphytic diatom sensitivity to the herbicide diuron and relation to species distribution in a contamination gradient: implications for biomonitoring. Journal of Environmental Monitoring, 13, 17681774. http://dx.doi.org/10.1039/c0em00783h.

Roubeix,V., Mazzella, N., Méchin, B., Coste, M., Delmas, F. (2011b). Impact of the herbicide metolachlor on river periphytic diatoms: experimental comparison of descriptors at different biological organization levels. Annales the Limnolgie, 47, 1-11. http://dx.doi.org/10.1051/limn/20110080.

Roubeix,V., Fauvelle, V., Tison-Rosebery, J., Mazzella, N., Coste, M., Delmas, F. (2012). Assessing the impact of chloroacetanilide herbicides and their metabolites on periphyton in the Leyre River (SW France) via short term growth inhibition tests on autochthonous diatoms. Journal of Environmental Monitoring 14, 1655-1663. http://dx.doi.org/10.1039/c2em10887a.

Round, F.E., Crawford, R.M., Mann, D.G. (2007). The Diatoms: Biology \& Morphology of the Genera. Cambridge University Press, Cambridge, UK 
Rubin, H. J., Cosper, E. M., Wurster, C. F. (1990). Influence of light intensity and photoadaptation on the toxicity of PCB to a marine diatom. Environmental Toxicology and Chemistry, 9: 777-784. [Google Scholar]

Rumeau, A; Coste, M. (1988) Introduction into the systematics of freshwater diatoms. For a useful generic diatom index. Bulletin Francais de la Peche et de la Pisciculture, 61: 309. 1-69.

Sabater, S., Guasch, H., Ricart, M. (2007). Monitoring the effect of chemicals on biological communities. The biofilm as an interface. Analytical and Bioanalytical Chemistry, 387, 1425-1434. https://doi.org/10.1007/s00216-006-1051-8

Sabater, S., Artigas, J., Romaní, A.M., Gaudes, A., Muñoz, I., Urrea,G. (2011). Long-term moderate nutrient inputs enhance autotrophy in a forested mediterranean stream. Freshwater Biology, 56, 1266-1280.

Sánchez, M. L., Rodríguez, P., Torremorell, A. M., Izaguirre, I., and Pizarro, H. (2017). Phytoplankton and periphyton primary production in clear and turbid shallow lakes: influence of the light environment on the interactions between these communities. Wetlands, 37(1), 67-77. doi:10. 1007/S13157-016-0840-X

Sansiñena, J. A., Peluso, L., Salgado Costa, C., Demetrio, P. M., Mac Loughlin, T. M., Marino, D. J. G., Natale, G. S. (2018). Evaluation of the toxicity of the sediments from an agroecosystem to two native species, Hyalella curvispina (CRUSTACEA: AMPHIPODA) and Boana pulchella (AMPHIBIA: ANURA), as potential environmental indicators. Ecological Indicators, 93, 100-110. doi:10.1016/j.ecolind.2018.04.061

Schmitt-Jansen, M., Altenburger, R. (2005). Toxic effects of isoproturon on periphyton communities a microcosm study. Estuarine Coastal and Shelf Science, 62(3),539-545.

Seguin, F., Druart, J.C., Le Cohu, R. (2001). Effects of atrazine and nicosulfuron on periphytic diatom communities in freshwater outdoor lentic mesocosms. Annales de Limologie, 37(1), 3-8.

Shannon, C. E., and Weaver, W. (1949). 'The Mathematical Theory of Communication.' (University of Illinios Press: Urbana, IL, USA.)

Shapiro, S. S., Wilk, M. B. (1965). An analysis of variance test for normality (complete samples). Biometrika, 52(3/4), 591-611.

SHRA. (2004). Desarrollos de niveles guías nacionales de calidad de agua ambiente correspondientes a Endosulfan. Secretaría de Recursos Hídricos de Argentina, 18pp.

SHRA. (2005). Desarrollos de niveles guías nacionales de calidad de agua ambiente correspondientes a Lindano. Secretaría de Recursos Hídricos de Argentina, 17pp.

Sierra. M.V, Gómez, N. (2010). Assessing the disturbance caused by an industrial discharge using field transfer of epipelic biofilm. Science of The Total Environment, 408(13), 26962705. doi:10.1016/j.scitotenv.2010.03.020

Sierra, M.V.; Gómez, N., Marano, A.V., Di Siervi, M.A. (2013) Caracterización funcional y estructural del biofilm epipélico en relación al aumento de la urbanización en un arroyo de la Llanura Pampeana (Argentina); Asociación Argentina de Ecología. Ecología Austral, 23 (8), 108-118.

Siver, P.A., Hamilton, P.B. (2011). Diatoms of North America: The freshwater flora of waterbodies on the Atlantic Coastal Plain. Iconographia Diatomologica, 22, 1-916.

Smetacek, V. (1999). Diatoms and the Ocean Carbon Cycle. Protist, 150(1), 25-32. doi:10.1016/s14344610(99)70006-4

Smith, V. H., Schindler, D. W. (2009). Eutrophication science: where do we go from here? Trends in Ecology and Evolution, 24(4), 201-207.

Smucker, N.J., Vis, M.L. (2010). Using diatoms to assess human impacts on streams benefits from multiplehabitat sampling. Hydrobiology, 654, 93-109. https://doi.org/10.1007/s10750-010-0373-x.

Snoeijs, P., Busse, S., Potapova, M. (2002). The importance of diatom cell size in community analysis. Journal of Phycology, 38, 265-272. http://dx.doi.org/10.1046/j.1529-8817.2002.01105.x. 
Solis M.L., 2017. Impacto de agroquímicos en arroyos de cuencas rurales. Tesis Doctoral. Universidad Nacional de La Plata (UNLP). Facultad de Ciencias Naturales y Museo. 131 pp.

Solis, M., Mugni, H., Fanelli, S., Bonetto, C. (2017). Effect of agrochemicals on macroinvertebrate assemblages in Pampasic streams, Buenos Aires, Argentina. Environmental Earth Science, 76, 180. https://doi.org/10.1007/s12665-017-6476-1.

Steinman, A.D. (1996). Effects of grazers on freshwater benthic algae. In: Stevenson, R.J., Bothwell, M.L., Lowe, R.L. (Eds.), Algal Ecology of Freshwater Benthic Ecosystem, Aquatic Ecology Series. Academic Press, Boston, pp. 341-373.

Stenger-Kovács, C., Lengyel, E., Crossetti, L. O., Uveges, V., and Padisák, J. (2013). Diatom ecological guilds as indicators of temporally changing stressors and disturbances in the small Torna-stream, Hungary. Ecological Indicators, 24, 138-147. doi:10.1016/J.ECOLIND.2012.06.003

Stevenson R.J., Peterson C.G. (1989) Variation in benthic diatom (Bacillariophyceae) immigration with habitat characteristics and cell morphology. Journal of Phycology, 25, 120-129.

Stevenson R.J., Peterson C.G. (1991) Emigration and immigration can be important determinants of benthic diatom assemblages in streams. Freshwater Biology, 26, 279- 294.

Stevenson, R. J., Peterson, C. G., Kirschtel, D. B., King, C. C., Tuchman, N. C. (1991). Density-dependent growth, ecological strategies, and effects of nutrients and shading on benthic diatom succession in streams. Journal of Phycology, 27(1), 59-69. doi:10.1111/j.0022-3646.1991.00059.x

Stevenson, J. (1983). Effects of current and conditions simulating autogenically changing microhabitats on benthic diatom immigration. Ecology 64(6), 1514-1524. doi:10.2307/1937506

Stevenson, R. J. (1984). How currents on different sides of substrates in streams affect mechanisms of benthic algal accumulation. International Review der Gesamten Hydrobiology Und Hydrogr., 69, $241-262$. https://doi.org/10.1002/iroh.19840690214

Stevenson, R. J. (1996). An introduction to algal ecology in freshwater benthic habitats. En Stevenson, R. J., M.

L. Bothwell, R. L. Lowe (eds), Algal Ecology Freshwater Benthic Ecosystems, Academic Press. San Diego: 330, 753 .

Stevenson, R.J., Pan, Y. (1999). Assessing environmental conditions in rivers and streams with diatoms. En: Stoermer E.F. \&; Smol J.P. (eds). The diatoms: Applications for the Environmental and Earth Sciences.Cambridge University Press. 469 p.

Stevenson, B. R. J., Bahls, L. L. (1999). Periphyton protocols. En 'EPA Rapid Bioassessment Protocols for Use in Wadeable Streams and Rivers. Periphyton, Benthic Macroinvertebrates and Fish', 2nd edn. (Eds M. T. Barbour, J. Gerritsen, B. D. Snyder, and J. B. Stribling.) pp. 1-23. (US Environmental Protection Agency: Washington, DC, USA.)

Stevenson, R.J., Pan, Y., Vandam, H. (2010). Assessing environmental conditions in rivers and streams with diatoms. In: Smol J.P., and Stoermer E.F., (2nd Eds.), The diatoms: applications for the environmental and earth sciences. Cambridge university press, London, pp. 57-85. https://doi.org/10.1017/CBO9780511763175.005.

Stevenson, J. (2014). Ecological assessments with algae: a review and synthesis. Journal of Phycology, 50, 437-461. https://doi.org/10.1111/jpy.12189.

Strayer, D.L., Dudgeon, D. (2010). Freshwater biodiversity conservation: recent progress and future challenges. Journal of the North American Benthological Society, 29(1), 344-358.

Streble, H., Krauter, D. (1987). Atlas de los Microorganismos de Agua Dulce. La vida en una gota de agua. Ediciones Omega, España. 336pp.

Sunda, W. G., Lewis, J. A. M. (1978). Effect of complexation by natural organic ligands on the toxicity of copper to a unicellular alga, Monochrysis lutheri 1. Limnology andOceanography, 23(5), 870-876. https://doi.org/10.4319/lo.1978.23.5.0870 
Svensson, F., Norberg, J., Snoeijs, P. (2014). Diatom cell size, coloniality and motility: trade-offs between temperature, salinity and nutrient supply with climate change. PLoS ONE 9: e109993. doi:10.1371/journal.pone.0109993

Tadros, M. G., Mbuthia, P., Smith, W. (1990). Differential response of marine diatoms to trace metals. Bulletin of Environmental Contamination and Toxicology, 44(6). doi: 10.1007/BF01702170

Tan, X., Ma, P., Bunn, S. E., \& Zhang, Q. (2015). Development of a benthic diatom index of biotic integrity (BD-IBI) for ecosystem health assessment of human dominant subtropical rivers, China. Journal of Environmental Management, 151, 286-294. doi:10.1016/j.jenvman.2014.12.048

Tang, J.X., Hoagland, K.D., Siegfried, B.D (1997) Differential toxicity of atrazine to selected freshwater algae. Bull Environ Contam Toxicol 59(4):631-637.

Ter Braak, C.J.F., Y Van Tongeren, O.F.R. (1995). Data analysis in community and landscape ecology. Cambridge University Press.

Tlili, A., Dorigo, U., Montuelle, B., Margoum, C., Carluer, N., Gouy, V., Bouchez, A.Berard, A. (2008). Responses of chronically contaminated biofilms to short pulses of diuron. An experimental study simulating flooding events in a small river. Aquatic Toxicology, 87, 252-263.

Tolcach, E. R., Gómez, N. (2002). The effect of translocation of microbenthic communities in a polluted lowland stream. SIL Proceedings, 1922-2010, 28(1), 254-258. doi:10.1080/03680770.2001.11902583

Tornés, E., Mor, J.-R., Mandaric, L., Sabater, S. (2018). Diatom responses to sewage inputs and hydrological alteration in Mediterranean streams. Environmental Pollution, 238, 369378. doi:10.1016/j.envpol.2018.03.037

Trobajo, R., Clavero, E., Chepurnov, V. A., Sabbe, K., Mann, D. G., Ishihara, S., y Cox, E. J. (2009). Morphological, genetic and mating diversity within the widespread bioindicator Nitzschia palea (Bacillariophyceae). Phycologia, 48(6), 443-459.

True, C. J., Heyward, A. A. (1990). Relationships between Microtox test results, extraction methods, and physical and chemical compositions of marine sediment samples. Toxicity assessment, 5(1), 29-45.

USEPA (US Environmental Protection Agency) (2000). Methods for measuring the toxicity and bioaccumulation of sediment-associated contaminants with freshwater invertebrates, second edition. EPA 823-B-99-007, Duluth, MN and Washington, DC.

USEPA (US Environmental Protection Agency) (2012). Pesticide Product Information System (accessed 23.01.12). Vecchia, A.V., Gilliom, R.J., Sullivan, D.J., Lorenz, D.L., Martin, J.D., 2009. Trends in concentrations and use of agricultural herbicides for corn belt rivers, 1996- 2000. Environ. Sci. Technol. 43, 9096-9102.

Valiela, I. (1995). Marine Ecological Processes. Springer, Berlin, Heidelberg, New York, 686 pp.

Van Dam, H., Mertiens, A., Sinkeldam, J. (1994). A coded checklist and ecological indicator values of freshwater diatoms from the Netherlands. Netherlands Journal of Aquatic Ecology, 28, 117-133. https://doi.org/10.1007/BF02334251.

Van Den Hoek C, Mann DG, Jahns, HM. (1995) Algae - An introduction to phycology, Cambridge: Cambridge University Press, p. 623.

Van de Vijver, B., and Beyens, L. (1998). Diatom and water quality in the Klein Nete, a Belgian lowland stream. Limnologica, 28(2), 145-152.

Vera, M.S., Lagomarsino, L., Sylvester, M. Pérez, G.L., Rodríguez, P., Mugni, H., Sinistro, R., Ferraro, M., Bonetto, C., Zagarese, H., Pizarro H. (2010). New evidences of Roundup ${ }^{\circledR}$ (glyphosate formulation) impact on the periphyton community and the water quality of freshwater ecosystems. Ecotoxicology 19, 710-721. https://doi.org/10.1007/s10646-009-0446-7

Verb, R.G., Vis, M.L. (2005). Periphyton Assemblages as Bioindicators of Mine-Drainage in Unglaciated Western Allegheny Plateau Lotic Systems. Water Air \& Soil Pollution, 161, 227-265. https://doi.org/10.1007/s11270-005-4285-8 
Vilches, C., Giorgi, A., Mastrángelo, M., Ferrari, L. (2011). Non-point contamination homogenizes the water quality of pampean streams. Bulletin of Environmental Contamination and Toxicology, 87(2):147151.

Vis, C., Hudon, C., Cattaneo, A., Pinel-Alloul, B. (1998). Periphyton as an indicator of water quality in the St Lawrence River (Que'bec, Canada). Environmental Pollution, 101(1), 13-24. doi:10.1016/S02697491(98)00042-6

Visviki, I., Rachlin, J. W. (1994). Acute and chronic exposure of Dunaliella salina and Chlamydomonas bullosa to copper and cadmium: effects on ultrastructure. Archives of Environmental Contamination and Toxicology, 26(2), 154-162. https://doi.org/10.1007/BF00224799

Walsh, C. J., Roy, A. H., Feminella, J. W., Cottingham, P. D., Groffman, P. M., Morgan, R. P. (2005) The urban stream syndrome: current knowledge and the search for a cure. Journal of the North American Benthological Society, 24:706-723.

Wetzel RG. Limnology. 3rd ed. San Diego: Academic Press; 2001. 1006 pp.

Winder, M., Reuter, J.E., Schladow, S.G. (2009). Lake warming favours small-sized planktonic diatom species. Proceedings of Royal Society B: Biological Sciences, 276, 427-435. http://dx.doi.org/10.1098/rspb.2008.1200.

Wong, P. T. S., Couture, P. (1986). Toxicity screening using phytoplankton. Toxicity testing using microorganisms, 2, 79-100.

Wood, R. J., Mitrovic, S. M., Kefford, B. J. (2014). Determining the relative sensitivity of benthic diatoms to atrazine using rapid toxicity testing: A novel method. Science of The Total Environment, 485-486, 421427. doi:10.1016/j.scitotenv.2014.03.115

Wood, R. J., Mitrovic, S. M., Lim, R. P., Kefford, B. J. (2017). Chronic effects of atrazine exposure and recovery in freshwater benthic diatoms from two communities with different pollution histories. Aquatic Toxicology, 189, 200-208. doi:10.1016/j.aquatox.2017.06.013

Wyatt, K. H., Stevenson, R. J., Turestky, M. R. (2010). The importance of nutrient co-limitation in regulating algal community composition, productivity and algal-derived DOC in an oligotrophic marsh in interior Alaska. Freshwater Biology, 55: 1845-1860. 
Tabla Anexa 2A: especies de diatomeas: halladas en el presente trabajo de tesis. Se indica con "•" las especies encontradas en los sitios BIU(bajo impacto urbano) y AlU (alto impacto urbano) en la experiencia de colonización; con "o" las especies encontradas en los sitios BIA(bajo impacto agrícola) y AIA (alto impacto agrícola) en la experiencia de colonización; con " $\bullet$ " las especies encontradas en los sitios BIU, AIU y TU (ensamble translocado del impacto urbano) y con "ם"las especies encontradas en los sitios BIA, AIA y TA (ensamble translocado del impacto agrícola)

\begin{tabular}{|c|c|c|c|c|c|c|c|c|c|c|}
\hline \multirow{2}{*}{ Especies } & \multicolumn{4}{|c|}{ Colonización temprana } & \multicolumn{6}{|c|}{ Translocación } \\
\hline & BIU & AIU & $\mathrm{BIA}$ & AIA & BIU & TU & AIU & $\mathrm{BIA}$ & TA & AIA \\
\hline Achnanthes inflata (Kützing) Grunow & & & $\circ$ & & & & & & $\square$ & $\square$ \\
\hline Achnanthidium exiguum (Grunow) Czarnecki & $\bullet$ & $\bullet$ & $\circ$ & ○ & - & & - & 口 & & \\
\hline Achnanthidium minutissimum (Kützing) Czarnecki & $\bullet$ & $\bullet$ & & ○ & $\cdot$ & - & - & & & \\
\hline Amphora coffeaeformis (Agardh) Kützing & $\bullet$ & $\bullet$ & $\circ$ & ○ & & & & & & \\
\hline Amphora libyca Ehrenberg & $\bullet$ & $\bullet$ & $\circ$ & $\circ$ & - & - & - & & & \\
\hline Amphora ovalis (Kützing) Kützing var.ovalis & & & & & & & & $\square$ & & \\
\hline Amphora pediculus (Kützing) Grunow & & & & ○ & & & & & $\square$ & \\
\hline Anomoeoneis sphaerophora (Ehrenberg) Pfitzer & & $\bullet$ & & o & $\cdot$ & $\cdot$ & • & & & \\
\hline Bacillaria paradoxa Gmelin in Linneaeus & & & $\circ$ & ○ & & & & & & $\square$ \\
\hline Biremis circumtexta (Meister ex Hust.) Lange-Bertalot \& Witkowski & & & & $\circ$ & & & & $\square$ & & \\
\hline Caloneis bacillum (Grunow) Cleve & - & $\bullet$ & ○ & $\circ$ & - & - & $\cdot$ & $\square$ & $\square$ & \\
\hline Caloneis columbiensis Cleve & & & $\circ$ & $\circ$ & & & & $\square$ & & \\
\hline Caloneis molaris (Grunow) Krammer & & & & & - & & & & & \\
\hline Caloneis silicula (Ehrenberg)Cleve & & & & & & & & $\square$ & & $\square$ \\
\hline Caloneis silicula (Ehrenberg)Cleve var. elliptica Frenguelli & & & & & & & & & $\square$ & \\
\hline cf Gomphonema gracile Ehrenberg & & $\bullet$ & & $\circ$ & - & - & - & & & \\
\hline Cocconeis placentula Ehrenberg var. placentula & $\bullet$ & & ○ & $\circ$ & - & - & $\cdot$ & $\square$ & & $\square$ \\
\hline Cocconeis placentula Ehrenberg var.euglypta (Ehrenberg) Grunow & & $\bullet$ & & $\circ$ & & & - & & & \\
\hline Craticula accomoda (Hustedt) Mann & $\bullet$ & $\bullet$ & $\circ$ & $\circ$ & $\cdot$ & ' & " & $\square$ & $\square$ & $\square$ \\
\hline Craticula ambigua (Ehrenberg) Mann & - & - & $\circ$ & 0 & - & - & - & $\square$ & $\square$ & 口 \\
\hline
\end{tabular}




\begin{tabular}{|c|c|c|c|c|c|c|c|c|c|c|}
\hline \multirow{2}{*}{ Especies } & \multicolumn{4}{|c|}{ Colonización temprana } & \multicolumn{6}{|c|}{ Translocación } \\
\hline & BIU & AIU & BIA & AIA & $\mathrm{BIU}$ & TU & AIU & BIA & TA & AIA \\
\hline Craticula citrus (Krasske) Reichardt & & & o & ○ & & & & $\square$ & $\square$ & \\
\hline Craticula cuspidata (Kützing) Mann & & & & ○ & & & $\cdot$ & & & $\square$ \\
\hline Craticula halophila (Grunow ex Van Heurck) Mann & & & ○ & ○ & - & - & - & $\square$ & $\square$ & $\square$ \\
\hline Craticula molestiformis (Hustedt) Lange-Bertalot & $\bullet$ & $\bullet$ & ○ & ○ & - & - & - & $\square$ & $\square$ & $\square$ \\
\hline Cyclotella meneghiniana Kützing & & & & & - & - & - & & & \\
\hline Denticula kuetzingii Grunow var. kuetzingii & & & & & & & - & & & \\
\hline Denticula subtilis Grunow & & & & o & - & - & - & $\square$ & $\square$ & \\
\hline Diadesmis confervacea Kützing var. confervacea & $\bullet$ & $\bullet$ & ○ & ○ & - & - & - & $\square$ & $\square$ & $\square$ \\
\hline Diadesmis contenta (Grunow ex V. Heurck) Mann & $\bullet$ & & o & o & - & - & $\cdot$ & $\square$ & $\square$ & $\square$ \\
\hline Diploneis elliptica (Kützing) Cleve & & & & & - & - & & & $\square$ & \\
\hline Diploneis ovalis (Hilse) Cleve & & & o & & - & & & $\square$ & $\square$ & \\
\hline Diploneis puella (Schumann) Cleve & & & ○ & o & & & $\cdot$ & $\square$ & $\square$ & $\square$ \\
\hline Encyonema minutum (Hilse in Rabh.) D.G. Mann & $\bullet$ & $\bullet$ & ○ & o & - & - & - & $\square$ & $\square$ & $\square$ \\
\hline Encyonema silesiacum (Bleisch in Rabh.) D.G. Mann & & & ○ & ○ & - & - & - & $\square$ & $\square$ & \\
\hline Eolimna minima(Grunow) Lange-Bertalot & $\bullet$ & $\bullet$ & ○ & o & - & - & - & $\square$ & $\square$ & $\square$ \\
\hline Eolimna subminuscula (Manguin) Moser Lange-Bertalot \& Metzeltin & $\bullet$ & $\bullet$ & ○ & $\circ$ & - & - & - & $\square$ & $\square$ & $\square$ \\
\hline Eunotia bilunaris (Ehrenberg) Mills var. bilunaris & & & ○ & o & - & - & & $\square$ & $\square$ & $\square$ \\
\hline Eunotia camelus Ehrenberg & & & & & & & & $\square$ & & \\
\hline Eunotia diodon Ehrenberg & & & ○ & ○ & & & & & & \\
\hline Eunotia maior (W.Sm.) Rabenhorst & & & & & & & & & $\square$ & \\
\hline Eunotia monodon Ehrenberg var. monodon & & & O & & & & & & & $\square$ \\
\hline Eunotia pectinalis(Kützing)Rabenhorst var.minor (Kützing) Rabenhorst & & & ○ & & & - & & & & \\
\hline Eunotia pectinalis(Kützing)Rabenhorst var.undulata (Ralfs) Rabenhorst & & & & & - & & & & & \\
\hline Eunotia tecta Krasske & & & ○ & $\circ$ & - & & & $\square$ & $\square$ & \\
\hline
\end{tabular}




\begin{tabular}{|c|c|c|c|c|c|c|c|c|c|c|}
\hline \multirow{2}{*}{ Especies } & \multicolumn{4}{|c|}{ Colonización temprana } & \multicolumn{6}{|c|}{ Translocación } \\
\hline & BIU & AIU & $\mathrm{BIA}$ & AIA & BIU & TU & AIU & BIA & TA & AlA \\
\hline Fallacia clepsidroides Witkowski & & & & & $\cdot$ & $\cdot$ & $\cdot$ & & & \\
\hline Fallacia insociabilis (Krasske) D.G. Mann & & & & & & - & & & & \\
\hline Fallacia omissa (Hustedt) D.G. Mann in Round Crawford \& Mann & $\bullet$ & $\bullet$ & o & ○ & - & - & $\cdot$ & $\square$ & $\square$ & $\square$ \\
\hline Fallacia pygmaea (Kützing) Stickle \& Mann & $\bullet$ & $\bullet$ & ○ & ○ & - & - & $\cdot$ & $\square$ & $\square$ & $\square$ \\
\hline Fallacia tenera (Hustedt) Mann in Round & & & ○ & ○ & - & - & $\cdot$ & & $\square$ & $\square$ \\
\hline Fragilaria capucina Desmazieres var.capucina & & & ○ & $\circ$ & - & $\cdot$ & $\cdot$ & & $\square$ & \\
\hline Fragilaria capucina Desmazieres var.vaucheriae (Kützing) Lange-Bertalot & & & & - & - & & & & & \\
\hline Fragilaria pinnata Ehrenberg var. pinnata & & & ○ & & & & & & & \\
\hline Frustulia pumilio Lange-Bertalot \& Rumrich & $\bullet$ & & & & $\cdot$ & - & $\cdot$ & & & \\
\hline Frustulia rhomboides(Ehrenberg)De Toni var.rostrata Manguin & & & & $\cdot$ & & & & & & \\
\hline Frustulia vulgaris (Thwaites) De Toni & • & & ○ & & $\cdot$ & - & $\cdot$ & & & \\
\hline Geissleria decussis(Ostrup) Lange-Bertalot \& Metzeltin & $\bullet$ & & & & & & & & & \\
\hline Gomphonema affine Kützing & $\bullet$ & & ० & ○ & - & - & $\cdot$ & $\square$ & $\square$ & $\square$ \\
\hline Gomphonema angustatum (Kützing) Rabenhorst & & $\bullet$ & ○ & ○ & $\cdot$ & - & $\cdot$ & $\square$ & $\square$ & $\square$ \\
\hline Gomphonema angustum Agardh & & & & & - & & & & & \\
\hline Gomphonema augur Ehrenberg & & & ○ & & & & & & $\square$ & \\
\hline Gomphonema batei Metzeltin Lange-Bertalot \& Garcia-Rodriguez & • & & & & & & & & & \\
\hline Gomphonema clavatum Ehrenberg & $\bullet$ & $\bullet$ & ○ & ○ & $\cdot$ & - & $\cdot$ & $\square$ & $\square$ & $\square$ \\
\hline Gomphonema lagenula Kützing & & & o & ○ & & & & $\square$ & $\square$ & $\square$ \\
\hline Gomphonema minutum Agardh & & & ○ & & & & $\cdot$ & $\square$ & $\square$ & $\square$ \\
\hline Gomphonema olivaceum (Hornemann) Brébisson & & & & & & & & $\square$ & & \\
\hline Gomphonema parvulum (Kützing) Kützing & $\bullet$ & $\bullet$ & ० & ० & $\cdot$ & $\cdot$ & $\cdot$ & $\square$ & $\square$ & $\square$ \\
\hline Gomphonema pseudoaugur Lange-Bertalot & & & & & & $\cdot$ & & & & \\
\hline Gomphonema truncatum Ehrenberg & & & ○ & & - & - & & & $\square$ & $\square$ \\
\hline
\end{tabular}




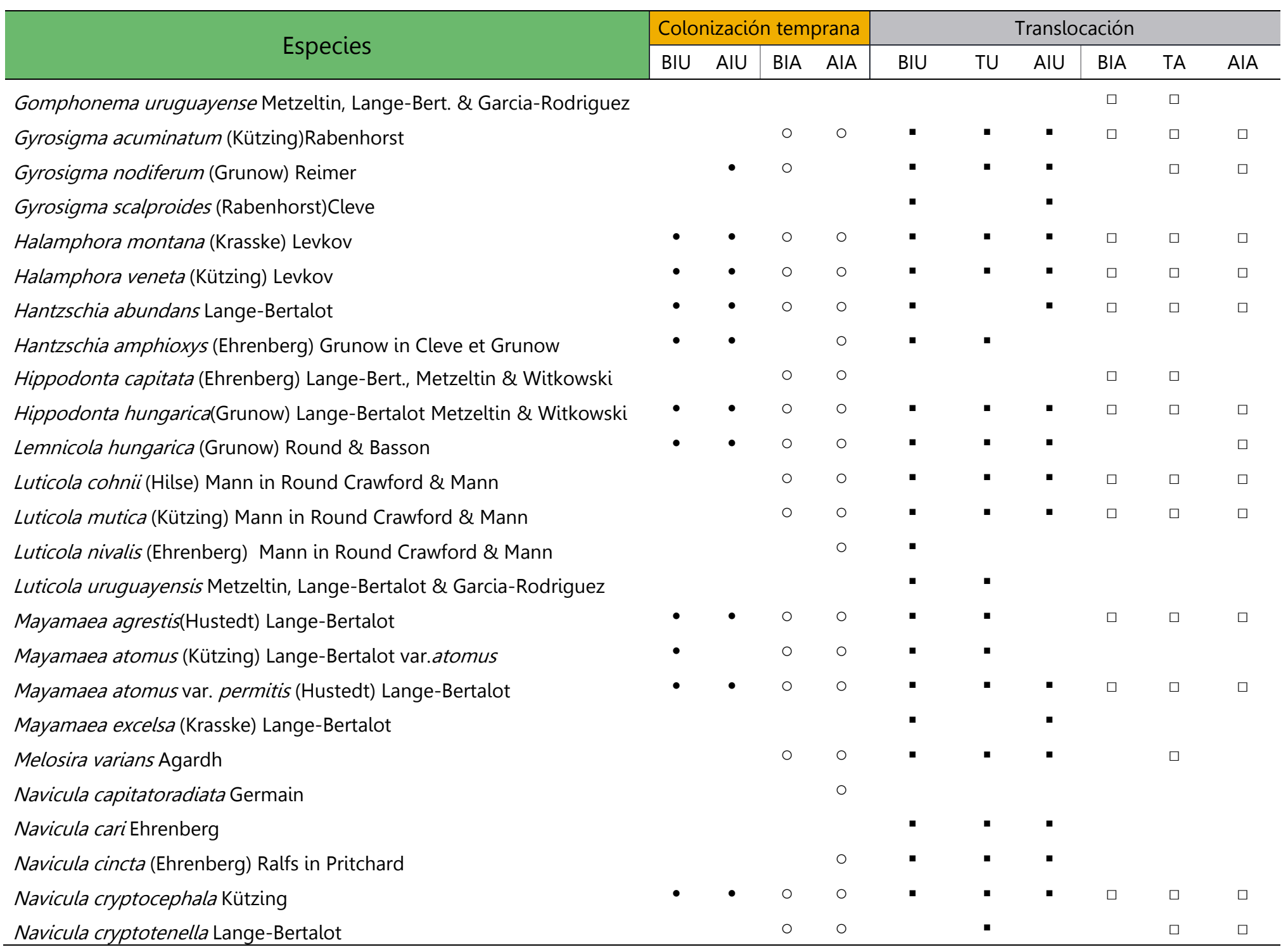




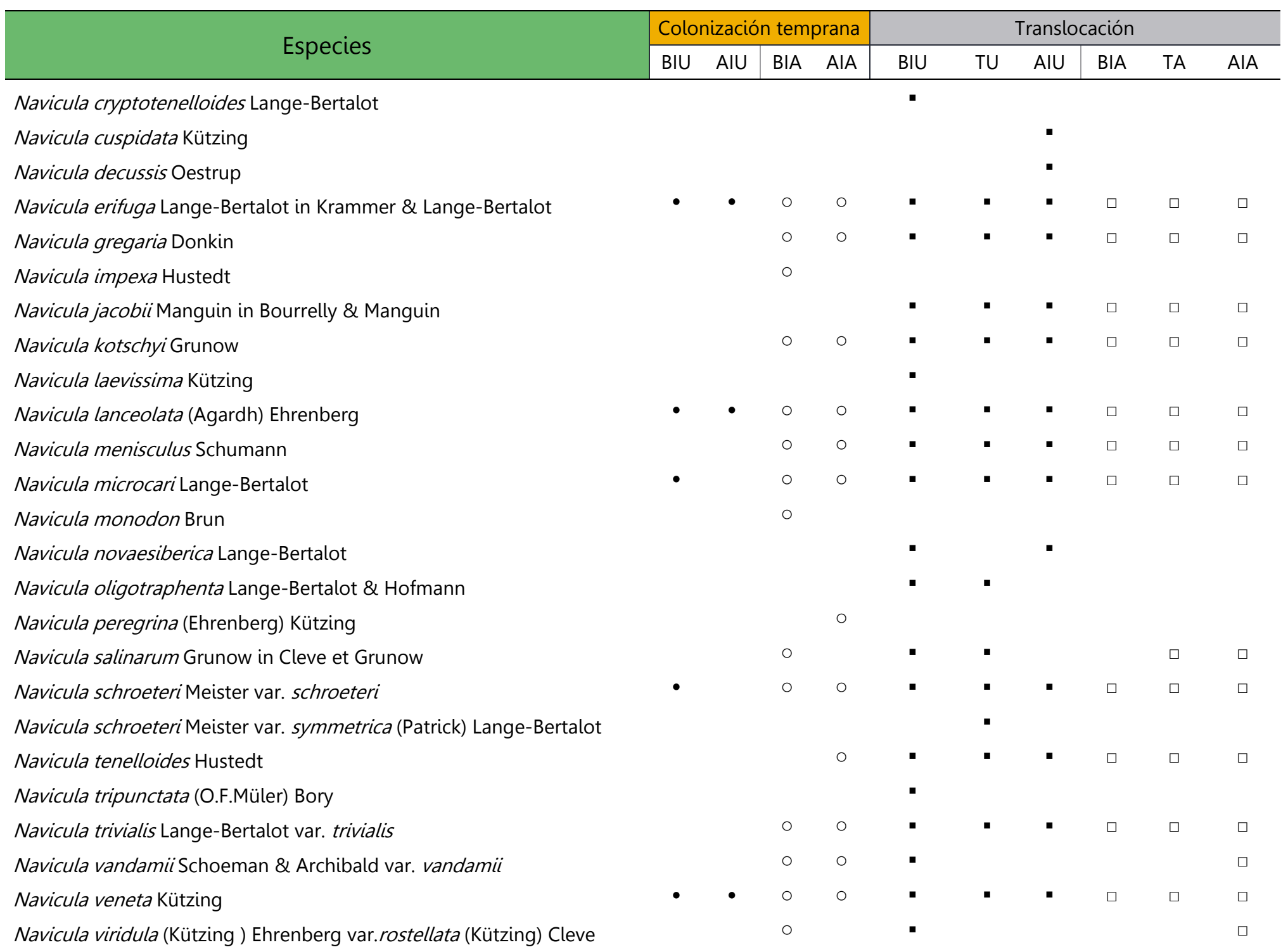




\begin{tabular}{|c|c|c|c|c|c|c|c|c|c|c|}
\hline \multirow{2}{*}{ Especies } & \multicolumn{4}{|c|}{ Colonización temprana } & \multicolumn{6}{|c|}{ Translocación } \\
\hline & BIU & AIU & $\mathrm{BIA}$ & AIA & BIU & TU & AIU & $\mathrm{BIA}$ & TA & AIA \\
\hline
\end{tabular}

Navicula viridula (Kützing) Ehrenberg

Navicula viridula var.germainii (Wallace) Lange-Bertalot

Neidium ampliatum (Ehrenberg) Krammer

Neidium dubium(Ehrenberg)Cleve

Neidium siveri Metzeltin \& Lange-Bertalot

Nitzschia acicularis(Kützing) W.M.Smith

Nitzschia amphibia Grunow

Nitzschia amphibioides Hustedt

Nitzschia angustatula Lange-Bertalot

Nitzschia aurariae Cholnoky

Nitzschia bergii Cleve-Euler

Nitzschia brevissima Grunow in Van Heurck

Nitzschia calida Grunow in Cleve \& Grunow

Nitzschia capitellata Hustedt in A.Schmidt \& al.

Nitzschia clausii Hantzsch

Nitzschia communis Rabenhorst

Nitzschia constricta (Kützing) Ralfs in Pritchard

Nitzschia desertorum Hustedt

Nitzschia dissipata(Kützing)Grunow

Nitzschia dubia W.M.Smith

Nitzschia fasciculata (Grunow) Grunow in V.Heurck

Nitzschia filiformis (W.M.Smith) Van Heurck var. filiformis

Nitzschia filiformis var. conferta (Richter) Lange-Bertalot

Nitzschia fonticola Grunow

Nitzschia frustulum(Kützing)Grunow

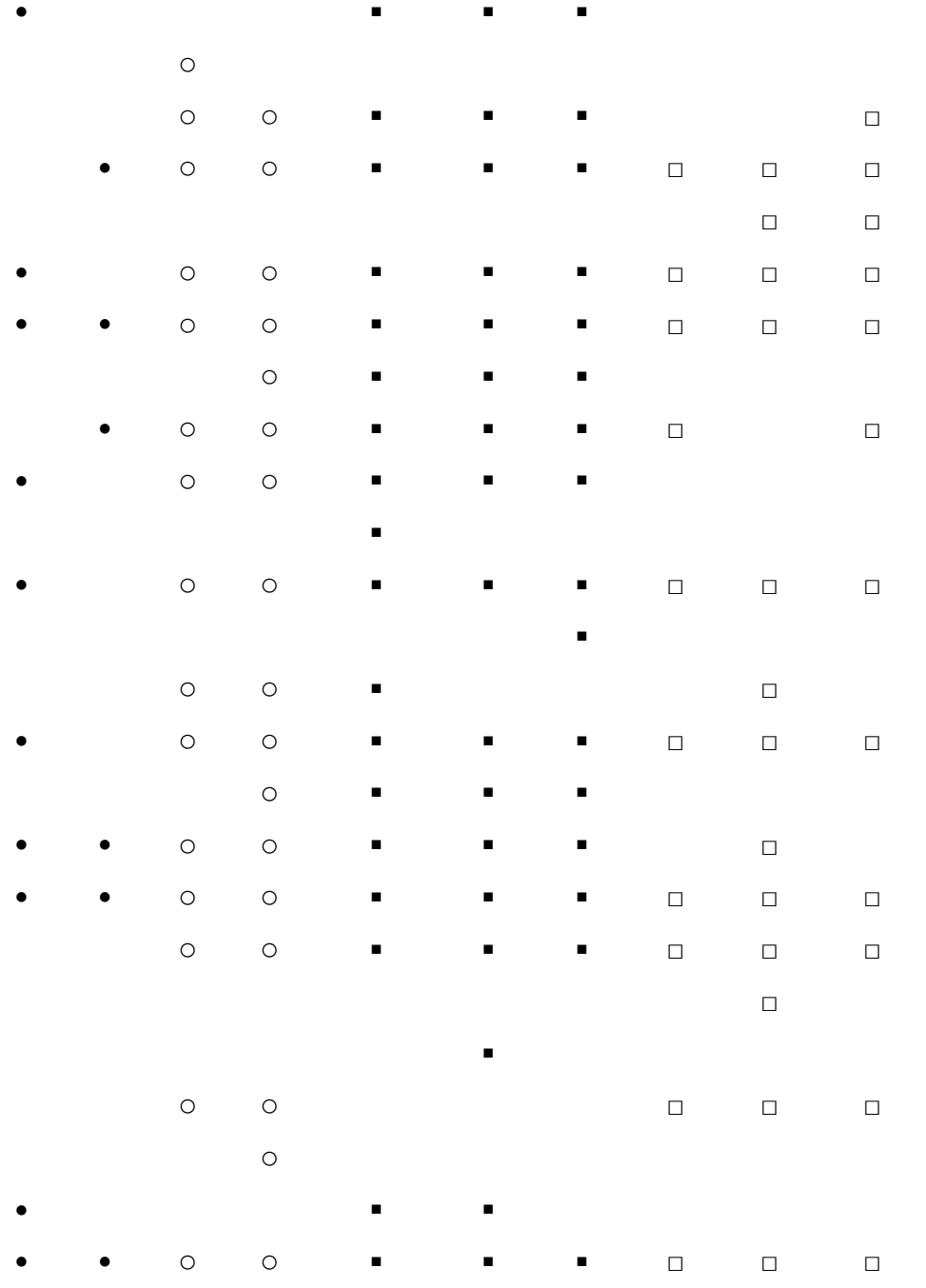




\begin{tabular}{|c|c|c|c|c|c|c|c|c|c|c|}
\hline \multirow{2}{*}{ Especies } & \multicolumn{4}{|c|}{ Colonización temprana } & \multicolumn{6}{|c|}{ Translocación } \\
\hline & BIU & AIU & $\mathrm{BIA}$ & AlA & BIU & TU & AIU & BIA & TA & AIA \\
\hline Nitzschia gracilis Hantzsch & • & & o & o & - & - & - & $\square$ & $\square$ & $\square$ \\
\hline Nitzschia hungarica Grunow & $\bullet$ & & o & ० & $\cdot$ & - & - & $\square$ & $\square$ & \\
\hline Nitzschia inconspicua Grunow & • & • & ○ & o & - & - & $\cdot$ & $\square$ & & \\
\hline Nitzschia intermedia Hantzsch ex Cleve \& Grunow & $\bullet$ & & ○ & ○ & - & - & - & $\square$ & $\square$ & $\square$ \\
\hline Nitzschia levidensis (W.Smith) Grunow in Van Heurck & & & o & ○ & & & - & $\square$ & $\square$ & $\square$ \\
\hline Nitzschia linearis(Agardh) W.M.Smith var.linearis & $\bullet$ & & ○ & ○ & - & - & - & & & $\square$ \\
\hline Nitzschia linearis(Agardh) W.M.Smith var.subtilis(Grunow) Hustedt & & & & o & & & & & & \\
\hline Nitzschia linearis(Agardh) W.M.Smith var.tenuis (W.Smith) Grunow & & & ○ & & & & & & & \\
\hline Nitzschia microcephala Grunow in Cleve \& Moller & & & ○ & ○ & & & - & $\square$ & & $\square$ \\
\hline Nitzschia nana Grunow in Van Heurck & & & & & & $\cdot$ & - & & & \\
\hline Nitzschia palea (Kützing) W.Smith var. palea & $\bullet$ & • & o & o & $\cdot$ & $\cdot$ & - & $\square$ & $\square$ & $\square$ \\
\hline Nitzschia paleacea (Grunow) Grunow in van Heurck & $\bullet$ & $\bullet$ & ○ & o & $\cdot$ & - & $\cdot$ & & & \\
\hline Nitzschia perminuta (Grunow) M.Peragallo & - & • & ○ & o & & - & - & & & \\
\hline Nitzschia perspicua Cholnoky & & & ○ & & & & & & & \\
\hline Nitzschia pumila Hustedt & & $\bullet$ & & & & & - & & & \\
\hline Nitzschia punae Frenguelli var.major Frenguelli & & & & & & & & & $\square$ & \\
\hline Nitzschia pusilla (Kützing) Grunow emend Lange-Bertalot & $\bullet$ & & ○ & ○ & & & & & & \\
\hline Nitzschia scalpelliformis (Grunow) Grunow in Cleve \& Grunow & & & & ○ & & & & & & \\
\hline Nitzschia sigma (Kützing) W.M.Smith & $\bullet$ & $\bullet$ & ० & o & $\cdot$ & - & - & $\square$ & $\square$ & $\square$ \\
\hline Nitzschia sinuata (Thwaites) Grunow & & & & & $\cdot$ & & & & & \\
\hline Nitzschia supralitorea Lange-Bertalot & & & & ○ & & & & & & \\
\hline Nitzschia umbonata(Ehrenberg)Lange-Bertalot & $\bullet$ & $\bullet$ & ○ & ○ & · & - & $\cdot$ & $\square$ & $\square$ & $\square$ \\
\hline Nitzschia valdecostata Lange-Bertalot et Simonsen & & & o & ○ & $\cdot$ & $\cdot$ & • & & $\square$ & \\
\hline Nitzschia valdestriata Aleem \& Hustedt & & & & ○ & & & & & & \\
\hline Nitzschia vermicularis (Kützing) Hantzsch in Rabenhorst & & & & & & & ' & & & \\
\hline
\end{tabular}




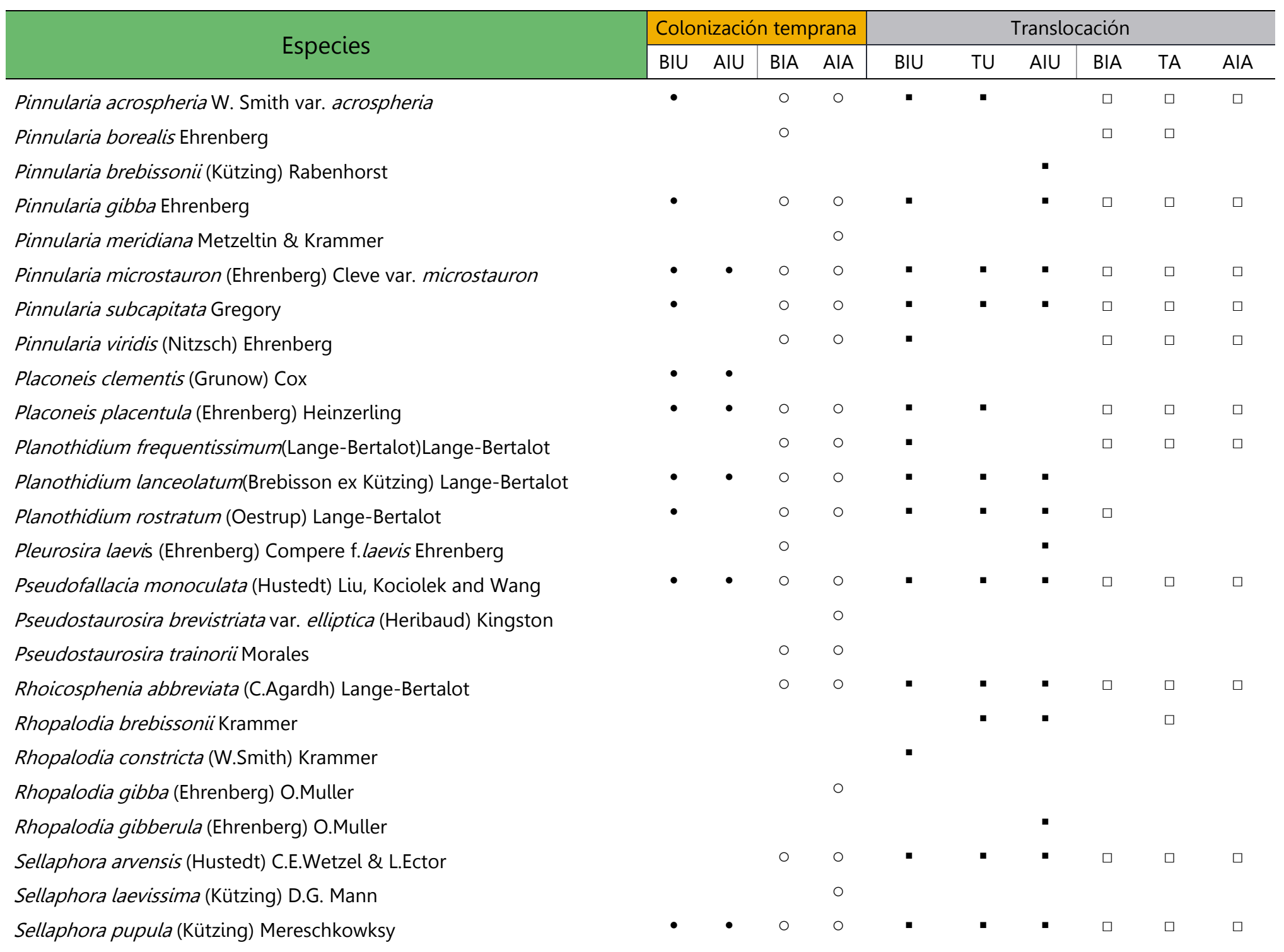




\begin{tabular}{|c|c|c|c|c|c|c|c|c|c|c|}
\hline \multirow{2}{*}{ Especies } & \multicolumn{4}{|c|}{ Colonización temprana } & \multicolumn{6}{|c|}{ Translocación } \\
\hline & BIU & AIU & BIA & AIA & BIU & TU & AIU & BIA & TA & AlA \\
\hline Sellaphora seminulum (Grunow) D.G. Mann & $\bullet$ & $\bullet$ & o & O & - & - & - & $\square$ & $\square$ & $\square$ \\
\hline Stauroneis anceps Ehrenberg & & & & & & & & $\square$ & & $\square$ \\
\hline Stauroneis brasiliensis (Zimmerman) Compere & & & o & & & & $\cdot$ & & & \\
\hline Stauroneis phoenicenteron (Nitzsch) Ehrenberg & & & & ○ & & & & & & \\
\hline Surirella angusta Kützing & $\bullet$ & & ○ & ○ & - & - & - & $\square$ & $\square$ & \\
\hline Surirella brebissonii Krammer \& Lange-Bertalot & & & o & & - & - & $\cdot$ & & & \\
\hline Surirella ovalis Brebisson & & & ○ & ○ & $\cdot$ & - & & & & \\
\hline Surirella splendida (Ehrenberg) Kützing & & & & & $\cdot$ & & & & & \\
\hline
\end{tabular}


Tabla Anexa 3A. Especies más representadas de cada gremio en cada uno de los sitios expuestos a Impacto Urbano.

\begin{tabular}{|c|c|c|c|}
\hline Gremio & Especie & BIU & AIU \\
\hline \multirow{3}{*}{ BP } & Lemnicola hungarica (Grunow) Round \& Basson & * & * \\
\hline & Halamphora veneta (Kützing) Levkov & * & * \\
\hline & Planothidium lanceolatum (Brebisson ex Kützing) Lange-Bertalot & * & * \\
\hline \multirow{3}{*}{ AP } & Diadesmis confervacea Kützing & * & * \\
\hline & Gomphonema parvulum (Kützing) Kützing & * & * \\
\hline & Encyonema minutum (Hilse in Rabh.) D.G. Mann & * & * \\
\hline \multirow{4}{*}{ M } & Nitzschia palea (Kützing) W.Smith & * & * \\
\hline & Nitzschia umbonata (Ehrenberg) Lange-Bertalot & * & \\
\hline & Nitzschia amphibia Grunow & * & * \\
\hline & $\begin{array}{l}\text { Eolimna subminuscula (Manguin) Moser Lange-Bertalot \& } \\
\text { Metzeltin }\end{array}$ & & * \\
\hline
\end{tabular}

Tabla Anexa 3B. Especies más representadas de cada clase de tamaño en cada uno de los sitios expuestos a Impacto Urbano.

\begin{tabular}{|c|c|c|c|}
\hline $\begin{array}{l}\text { Clase de } \\
\text { tamaño }\end{array}$ & Especie & BIU & AIU \\
\hline 1 & Eolimna minima (Grunow) Lange-Bertalot & * & * \\
\hline \multirow{5}{*}{2} & Nitzschia frustulum (Kützing)Grunow & * & * \\
\hline & Nitzschia perminuta (Grunow) M.Peragallo & * & \\
\hline & Nitzschia paleacea (Grunow) Grunow & * & \\
\hline & Eolimna subminuscula (Manguin) Moser Lange-Bertalot \& Metzeltin & & * \\
\hline & Encyonema minutum (Hilse in Rabh.) D.G. Mann & & * \\
\hline \multirow{3}{*}{3} & Nitzschia palea (Kützing) W.Smith & * & * \\
\hline & Gomphonema parvulum (Kützing) Kützing & * & * \\
\hline & Nitzschia amphibia Grunow & * & * \\
\hline \multirow{4}{*}{4} & Placoneis placentula (Ehrenberg) Heinzerling & * & * \\
\hline & Gomphonema clavatum Ehrenberg & * & * \\
\hline & Navicula lanceolata (Agardh) Ehrenberg & * & \\
\hline & Sellaphora pupula (Kützing) Mereschkowksy & & * \\
\hline 5 & Nitzschia umbonata (Ehrenberg) Lange-Bertalot & * & * \\
\hline
\end{tabular}


Tabla Anexa 3C. Especies más representadas de cada gremio en cada uno de los sitios expuestos a Impacto Agrícola.

\begin{tabular}{|c|c|c|c|}
\hline Gremio & Especie & BIA & AIA \\
\hline \multirow{5}{*}{ BP } & Planothidium frequentissimum (Lange-Bertalot) Lange-Bertalot & * & \\
\hline & Halamphora veneta (Kützing) Levkov & * & * \\
\hline & Achnanthidium exiguum (Grunow) Czarnecki & * & \\
\hline & Planothidium rostratum (Oestrup) Lange-Bertalot & & * \\
\hline & Planothidium lanceolatum (Brebisson ex Kützing) Lange-Bertalot & & * \\
\hline \multirow{5}{*}{ AP } & Diadesmis confervacea Kützing & * & \\
\hline & Gomphonema parvulum (Kützing) Kützing & * & * \\
\hline & Pseudostaurosira trainorii Morales & * & \\
\hline & Gomphonema clavatum Ehrenberg & & * \\
\hline & Eunotia bilunaris (Ehrenberg) Mills & & * \\
\hline \multirow{4}{*}{ M } & Nitzschia palea (Kützing) W.Smith & * & * \\
\hline & Nitzschia filiformis (W.Smith) Van Heurck & * & \\
\hline & Nitzschia amphibia Grunow & * & * \\
\hline & Pseudofallacia monoculata (Hustedt) Liu, Kociolek \& Wang & & * \\
\hline
\end{tabular}


Tabla Anexa 3D. Especies más representadas de cada clase de tamaño en cada uno de los sitios expuestos a Impacto Agrícola.

\begin{tabular}{|c|c|c|c|}
\hline $\begin{array}{l}\text { Clases de } \\
\text { tamaño }\end{array}$ & Especie & BIA & AIA \\
\hline \multirow{4}{*}{1} & Pseudostaurosira trainorii Morales & * & \\
\hline & Mayamaea atomus var. permitis (Hustedt) Lange-Bertalot & * & * \\
\hline & Navicula agrestis Hustedt in A.W.F.Schmidt & * & * \\
\hline & Sellaphora seminulum (Grunow) D.G.Mann & & * \\
\hline \multirow{6}{*}{2} & Nitzschia frustulum (Kützing) Grunow in Cleve \& Grunow & * & \\
\hline & Hippodonta hungarica (Grunow) Lange-Bertalot, Metzeltin \& Witkowski & * & \\
\hline & Nitzschia clausii Hantzsch & * & \\
\hline & Pseudofallacia monoculata (Hustedt) Liu, Kociolek \& Wang & & * \\
\hline & Planothidium rostratum (Østrup) Lange-Bertalot & & * \\
\hline & Eolimna subminuscula (Manguin) Gerd Moser, Lange-Bertalot \& Metzeltin & & * \\
\hline \multirow{4}{*}{3} & Nitzschia palea (Kützing) W.Smith & * & * \\
\hline & Nitzschia amphibia Grunow & * & * \\
\hline & Diadesmis confervacea Kützing & * & * \\
\hline & Gomphonema parvulum (Kützing) Kützing & * & * \\
\hline \multirow{4}{*}{4} & Nitzschia filiformis (W.Smith) Van Heurck & * & * \\
\hline & Sellaphora pupula (Kützing) Mereschkovsky & * & * \\
\hline & Navicula schroeteri Meister & * & \\
\hline & Gomphonema clavatum Ehrenberg & & * \\
\hline \multirow{3}{*}{5} & Nitzschia umbonata (Ehrenberg) Lange-Bertalot & * & * \\
\hline & Ulnaria ulna (Kützing) Compère & * & * \\
\hline & Halamphora veneta (Kützing) Levkov & * & * \\
\hline
\end{tabular}


Tabla Anexa 4A. Especies más representadas en cada gremio los tratamientos en las translocaciones de sitios con impacto urbano.

\begin{tabular}{|c|c|c|c|c|}
\hline Gremio & Especie & CBIU & CAIU & TU \\
\hline \multirow{5}{*}{ BP } & Halamphora montana (Krasske) Levkov & & * & * \\
\hline & Lemnicola hungarica (Grunow) Round \& Basson & & * & * \\
\hline & Planothidium rostratoholarcticum Lange-Bertalot \& Bak & * & & \\
\hline & Achnanthidium minutissimum (Kützing) Czarnecki & * & * & * \\
\hline & Planothidium lanceolatum (Brebisson ex Kützing) Lange-Bertalot & * & & \\
\hline \multirow{2}{*}{ AP } & Melosira varians Agardh & * & * & * \\
\hline & Gomphonema parvulum (Kützing) Kützing & * & * & * \\
\hline \multirow{5}{*}{ M } & Nitzschia palea (Kützing) W.Smith & * & * & * \\
\hline & Pseudofallacia monoculata (Hustedt) Liu, Kociolek \& Wang & * & * & * \\
\hline & Navicula veneta Kützing & * & & \\
\hline & Sellaphora pupula (Kützing) Mereschkovsky & & & * \\
\hline & Nitzschia umbonata (Ehrenberg) Lange-Bertalot & & * & \\
\hline
\end{tabular}

Tabla Anexa 5A. Especies más representadas en cada gremio los tratamientos en las translocaciones de sitios con impacto agrícola.

\begin{tabular}{clrcc} 
Gremio & \multicolumn{1}{c}{ Especie } & CBIA CAIA TA \\
BP & Planothidium frequentissimum (Lange-Bertalot) Lange-Bertalot & $*$ & $*$ & $*$ \\
\hline \multirow{2}{*}{ AP } & Diadesmis confervacea Kützing & $*$ & $*$ & $*$ \\
& Gomphonema lagenula Kützing & $*$ & $*$ & $*$ \\
\hline \multirow{2}{*}{ M } & Nitzschia palea (Kützing) W.Smith & $*$ & $*$ & $*$ \\
& Nitzschia amphibia Grunow & $*$ & $*$ & $*$ \\
\hline
\end{tabular}


Tabla Anexa 6A: Agroquímico medidos en los elutriados al inicio y final, en el "Elutriado_Control" y en el sedimento, durante la experiencia.

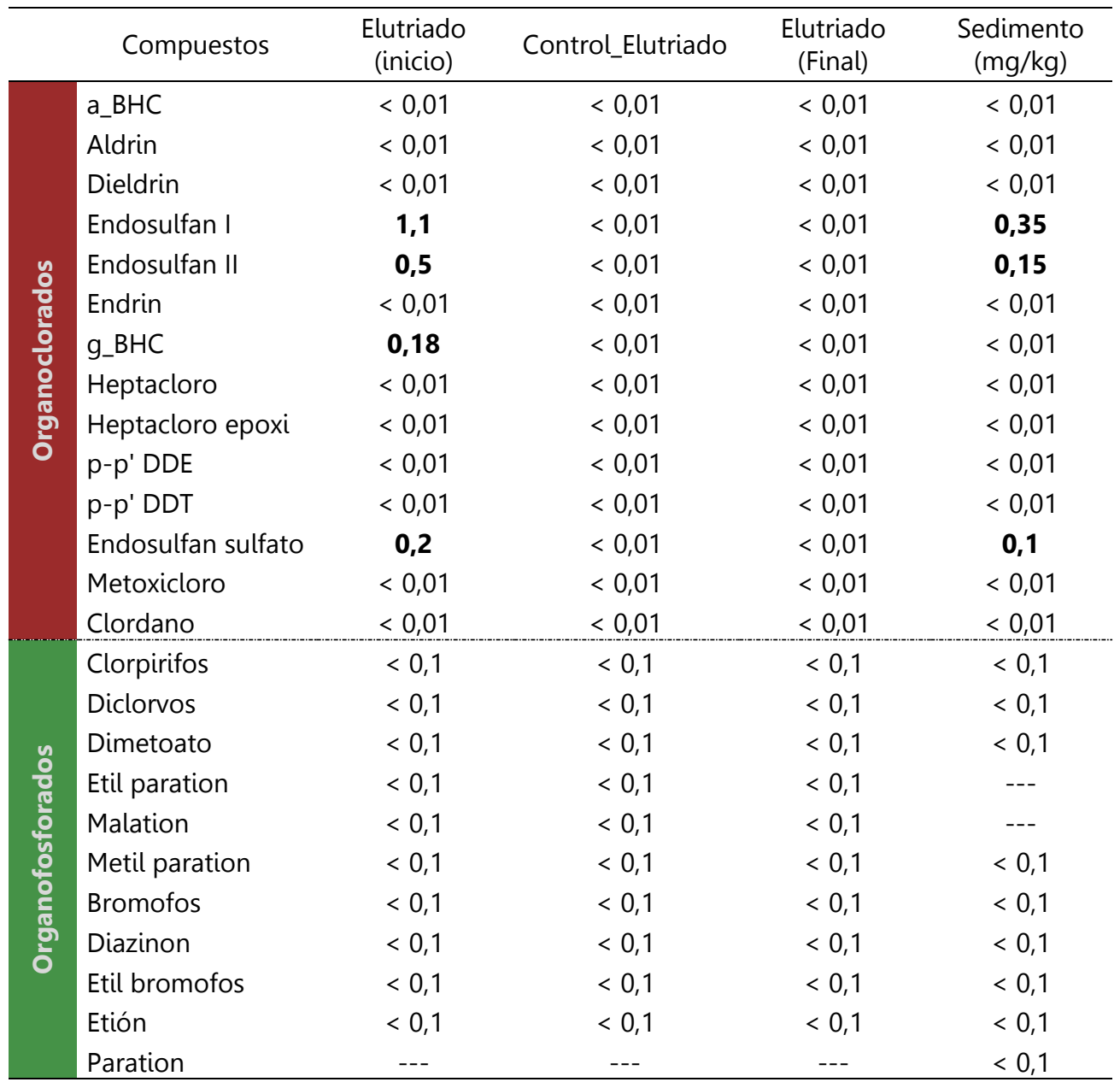

